\title{
"WE HAD TO COPE WITH WHAT WE HAD": AGENCY PERSPECTIVES ON DOMESTIC VIOLENCE AND DISASTERS IN NEW ZEALAND
}

\author{
By
}

Rosalind Margaret Elise Houghton

\author{
A thesis \\ submitted to the Victoria University of Wellington \\ in fulfilment of the requirements for the degree of \\ Doctor of Philosophy \\ in Social Policy
}

Victoria University of Wellington

2010 



\section{Abstract}

Under an over-arching feminist framework, this thesis utilises disaster sociology and domestic violence theory to examine the complex and multi-faceted relationship between domestic violence and disasters. The applicability of previously published theories was tested through a postal survey of communities affected by 17 Civil Defence emergencies in New Zealand and in 5 detailed case studies (taken from the 17 surveyed communities) relating to the impact of Civil Defence emergencies on domestic violence and disaster response agencies in New Zealand. The case studies involved the collection of reporting statistics from Women's Refuge, interviews with representatives of agencies working in domestic violence response and disaster management, and analyses of case file summaries from the Women's Refuge national database across the five affected geographic areas. These methods provided both quantitative and qualitative data on domestic violence reporting during disasters in New Zealand.

In almost all of the communities studied there was an increase in reporting of domestic violence following the Civil Defence emergencies. Pre-existing theory and interviews within the case studies were used to examine significant factors and demographics that were common across the women seeking assistance during the disasters in order to provide coherent generalisations that may be applied in other contexts. The research concluded that domestic violence reporting did increase during disasters. Whilst it was not possible to determine whether it was only domestic violence reporting or domestic violence itself that had increased, interviews with key agency representatives revealed some of the possible causes of their increased workload. Confirming the findings of international studies, agency representatives stated that prior abuse and financial strain were some of the main factors behind the reported increases in domestic violence.

Agency representatives reported a range of issues concerning the official responses to increased domestic violence reporting during disasters, many of which were structural issues regarding procedures set out in current Civil Defence policies. These procedural problems are examined in line with the feminist goals guiding this work and a case is made for policy changes that should lead to improved handling of increased domestic violence reporting during disasters and lead to the development of a more co-ordinated approach to the social impacts of disasters. In order to address the needs of domestic violence victims, the degree of gender mainstreaming within Civil Defence and Emergency Management policy and practice should also be reviewed.

New Zealand is subject to both national and international obligations to address the impact that gender norms have on the outcomes of those experiencing disasters. It is currently not meeting these obligations. These lacunae in policy and planning are placing already vulnerable women and children at heightened risk during disasters. As a country that prides itself on progressive social policy, New Zealand can do better. 

This thesis is dedicated to Raewyn Good (1952 - 2008) 



\section{Acknowledgements}

My parents and sister for their unflinching support

The interviewees for their time and wisdom

Sandra Grey and Jan Jordan

The SPEaR Linkages Programme

Ministry of Civil Defence and Emergency Management

Alison Chetwin

Christine and Jimmy Cole

Ann Dostine

Elaine Enarson

Maureen Fordham

Marg and Don Gilling

Raewyn Good

Heather Henare

Noeline Holt

David Johnston

Lori Peek

Charles Sedgwick

Christina Smits

Kanye West

Sara Williams

Tom Wilson 



\section{Table of Contents}

$\begin{array}{lll}\text { Chapter One: } & \text { Introduction }\end{array}$

$\begin{array}{ll}\text { Chapter Two: } & 11\end{array}$

$\begin{array}{lll}\text { Chapter Three: } \quad \text { Methodology } & 55\end{array}$

$\begin{array}{lll}\text { Chapter Four: } & \text { Descriptions and Definitions }\end{array}$

$\begin{array}{lll}\text { Chapter Five: } & \text { The Increase } & 125\end{array}$

$\begin{array}{lll}\text { Chapter Six: } & \text { Factors and Demographics } & 161\end{array}$

$\begin{array}{lll}\text { Chapter Seven: } & \text { Planning and Response Issues } & 199\end{array}$

$\begin{array}{lll}\text { Chapter Eight: } & \text { Policy Implications } & 229\end{array}$

$\begin{array}{lll}\text { Chapter Nine: } & \text { Conclusions } & 265\end{array}$

$\begin{array}{lr}\text { Appendices } & 275\end{array}$

$\begin{array}{lr}\text { References } & 293\end{array}$ 



\section{List of Figures}

Figure One: $\quad$ Total Number of Reported Disasters Globally

(1900 to 2008)

Figure Two: $\quad$ Estimated Decadal Cost of Reported Disasters

Figure Three: Map of Case Study Locations

Figure Four: $\quad$ Map of the Wellington Region

Figure Five: $\quad$ Map of the Masterton District

Figure Six: Map of the Manawatu-Wanganui Region

Figure Seven: Map of the Manawatu District

Figure Eight: $\quad$ Map of the Lower Hutt City District

Figure Nine: $\quad$ Map of the Bay of Plenty Region

Figure Ten: $\quad$ Map of the Whakatane District

Figure Eleven: Map of the Canterbury Region

Figure Twelve: Map of the Timaru District 



\section{List of Tables}

Table One:

Table Two:

Table Three:

Table Four:

Table Five:
Natural Hazard Events in the Last Ten Years where

Civil Defence Emergencies were Declared

Numbers of Returned Surveys for Each Event (during 2006)

Agency Representative Interviews Conducted in Case

Studies (completed between $2005 \& 2008$ )

Comparative Demographics of Case Study Locations from Statistics New Zealand

Changes to Domestic Violence Reporting found in Survey by Civil Defence Emergency (1996-2006)
77

66

69

117 



\section{Appendices}

Appendix A:

Appendix B:

Appendix C:

Appendix D:

Appendix E:
Survey to Agencies

275

Information Sheet for Interviewees

287

Consent Form for Interviewees

288

Newspaper Article in Whakatane Beacon

289

Ethics Approval from Victoria University of Wellington 

Chapter One: Introduction 

To be a survivor - first you must bleed. You bleed all that was inside of you: the pain, the memories, the fear, the wounds fusing together, the ties to what was, in all its forms. You bleed not once but several times. And when you are empty, you either fade into a shadow or find the strength, and courage to live. When you stand up again, you are for a time, hollow-empty, like a bottle of beer lying on the street, cracked and reeking of its bitter contents. Then you fill yourself up with the new, you recreate yourself - you reform. You don't have the same heart or mind. The way you see the world is forever changed.

(Lynn Mari, 2009)

Domestic violence is an issue that confronts one in three New Zealand women in their lifetime (Fanslow \& Robinson, 2004). It is thus likely that all New Zealanders know or will know someone who has experienced domestic violence. As a child of the 1980's, I had always, somewhat naively, believed that it was not my generation perpetrating this abuse. I held the belief that domestic violence was somehow removed from my life and only relevant through research and work. However, one day while catching up with an old friend, I learnt that she had recently escaped an abusive relationship. I knew the man she had been in a relationship with. The relationship had existed for many years. It had escalated to the point where he controlled her diet, her clothes and aspects of her physical appearance, such as her hair, before she left. She did not report this to any agency and had no intention of doing so. As I listened, I was shocked and it struck me that I had accepted inadvertently the societal stereotyping of domestic violence victims. I had been exposed as believing that victims and perpetrators of domestic violence were poor, less educated and at least ten years older than we were. At that time, in my early20's, middle class, and with a post-graduate educated lifestyle, I had assumed it would never happen in my world. We have undoubtedly all been guilty at some point of thinking domestic violence is someone else's problem; that the women 
who suffer abuse belong to a different world than ours. However, domestic violence is not just a problem of the poor or the uneducated. With such an incidence in New Zealander society, it is everyone's problem. This thesis considers one aspect of domestic violence - the impact of disasters on the incidence and reporting of domestic violence. In this regard, I believe it is critical to understand the complex relationships between domestic violence and disasters so that these women, women we all know, are assured of the help they need and deserve during disasters.

The conclusions made in this thesis are derived from five case studies and a postal survey of agencies that work in the domestic violence field in New Zealand. Where increases in reporting were observed, I examined the policy and planning in place to meet the needs of those reporting domestic violence to determine whether this policy and planning is, and has been, effective. Where shortfalls in policy and planning were established, recommendations have been made to address these.

Throughout the course of this research, many of the individuals involved commented to me that it seemed "commonsense" or "logical" that domestic violence would increase during a natural disaster. These comments were often supported by analogies to events such as factory closures or the loss of significant sports games. These seemingly analogous events may produce similar results - such as a rise in domestic violence reporting, however, they do not possess the same complexity that a natural disaster presents. Natural disasters can result in loss of key lifelines (roads, electrical power, telephones), isolation, and immediate destruction of both homes and possessions. These complications are not present, on this scale, in the aftermath of factory closures or losses at sporting events. The added layer of complexity makes natural 


\section{Chapter 1}

disasters a particularly important context in which to examine domestic violence reporting. The findings of this research can be transposed loosely to events not categorised as natural disasters, which also result in significant stress or life-shocks to a population. However, the dynamics at play will differ, thus research specific to these life-shocks will undoubtedly yield more relevant results.

The next three chapters of this thesis focus on the context of the data by discussing the theoretical and methodological frameworks used in the research, and describing the events, areas, and agencies involved in the studies. In these chapters, previous studies in this area are introduced and the parallels with this research explained.

This thesis sits juxtaposed between a number of broad research fields dealing with theoretical and methodological issues. In order to study the interaction between domestic violence reporting and disasters, a clear understanding of the sociology of disasters, gender and disasters, domestic violence, and the theories and literature relevant to gendered policy, is required.

Chapter Two outlines theories and models used in this research to explain why domestic violence might increase during a disaster, specifically disaster sociology and the Pressure and Release model. It also places the research in the current body of knowledge, discussing the existing empirical literature linking domestic violence and disasters and demonstrating how this study corroborates and builds on this pre-existing body of work.

The third chapter examines feminist methodology and explains how this research embodies the theoretical base underpinning feminist studies. Key 
elements of feminist research are it is reflexive, focuses on gender inequality, gives voice to women and marginalised groups, rejects traditional power dynamics between researcher and subjects and has a goal of bringing about social change (Renzetti, 1997: 133; Skinner, Hester \& Malos, 2005: 10; Landman, 2006: 431). Chapter 3 also presents the methods utilised in data collection and the analysis phase of this research, before concluding with a review of the limitations of the work and how future research would build on this thesis. The methodologies used were selected based on previous empirical studies and comprised a mixed-method approach to gain a broad perspective on the relationship between domestic violence reporting incidence and disasters. There were two phases to this research: a survey of 17 Civil Defence emergencies in New Zealand between 1996 and 2006 and, five in-depth case studies selected from the 17 emergencies surveyed. The case studies involved a collection of statistics from a non-government domestic violence agency, aggregation of case file summaries from the previously mentioned domestic violence organisation and, interviews with agency representatives from domestic violence response and disaster management organisations.

The fourth chapter is contextual and provides the reader with information about the events included in this research and the communities that took part in the case studies. It also provides a description of the agencies that took part in the case studies, for readers not familiar with the domestic violence and Civil Defence fields in New Zealand. In discussing the demographic characteristics of the communities, the chapter includes a generalised perspective, to render the findings and recommendations of this study applicable to other communities, both within New Zealand and internationally. 


\section{Chapter 1}

The second set of three chapters presents the data collected in this study and examines the increases observed across the five case studies and the postal survey. It considers the factors reported as relevant by the agencies and any demographic groupings that are over-represented in the data and may explain any shifts in domestic violence reporting independent of the disaster. These chapters conclude with a consideration of the planning and response issues stemming from an increase in domestic violence reporting, that arose during the disasters. These data are compared with previous studies and put into context with theories that may explain issues not cognisable by reference to the data in isolation.

Chapter Five is the first chapter to present the findings of the research. It documents the increases reported by participants in the survey phase and the case studies phase. These increases are considered community-by-community to provide the reader with a comprehensive image of each community including which agencies, if any, reported an increase. The final section of the chapter reviews the increases by agency, with the aim of providing an organisation-wide perspective on any potential increases. Increases were found to have varied in scale and scope across the agencies that participated in the interviews, with non-government agencies reporting larger and more sustained increases than government agencies. These differential impacts are examined to decipher the grounds for such variation. This establishes the basis for the policy recommendations presented in Chapter Eight.

Chapter Six focuses on the factors that agency representatives, past empirical studies and theory suggest are related to or causative of the increases in domestic violence reporting presented in Chapter Five. The Pressure and Release model introduced in Chapter Two, is evaluated to assess its ability to 
explain potential increases in the nature and incidence of domestic violence in the aftermath of disasters. This chapter presents and analyses the extensive body of literature relevant to a woman's decision to stay in or leave an abusive relationship and how this decision may be impacted upon by disasters.

Chapter Seven introduces the issues that agencies reported in dealing with increased domestic violence reporting during their respective disasters. The chapter highlights the variations and also the commonalities observed between agencies. The chapter is structured by agency to reflect the reality that future policy suggestions are necessarily agency-specific, rather than communityspecific. Many of the issues stem from a lack of planning. The implications of this for policy are discussed further in Chapter Eight.

Chapter Eight examines the policy implications of this research and presents suggestions for policy change. The chapter commences with a picture of current local and international policies that are relevant to this research. The issue of gender-mainstreaming in policy is then discussed, coupled with an exposition of why the incorporation of gender analysis in policy formulation is essential in fulfilling policy requirements for all policies in New Zealand, including those of Civil Defence and Emergency Management. The second half of the chapter focuses on policy suggestions for the individual agencies involved in Civil Defence and Emergency Management response and recovery and domestic violence agencies who will need to continue providing services during a disaster.

The final chapter presents the conclusions from my research and the preexisting body of work. Suggestions are also made for future research, which 


\section{Chapter 1}

may play a critical role in ensuring that victims of domestic violence in New Zealand are not left at greater risk than others during disasters in the future.

This research is the first of its kind in New Zealand. It aims to provide a benchmark for future evaluation of how agencies respond to increased domestic violence reporting during natural hazard events. The final policy chapter offers New-Zealand-specific recommendations for policy change directed at the central organisations involved in the research. However, the lessons learned by agencies in New Zealand should be capable of transposition to organisations in other countries. Finally, this work substantiates lessons elucidated by earlier researchers, such as Wilson, Phillips \& Neal (1998), Enarson (1999), Fothergill (1999) and Jenkins \& Phillips (2008), and confirms a need for policy change that these researchers have advocated for over the last decade. 

Chapter Two: Literature Review Disasters \& Domestic Violence 

The study of domestic violence and disasters is a small field, yet it bridges a number of broad bodies of literature dealing with theoretical and methodological issues. To study domestic violence rates after disasters, a clear understanding of the sociology of disasters, gender and disasters, domestic violence, and the theories and literature relevant to gendered policy is needed. This chapter will focus on the sociology of disasters and the literature related to domestic violence, and will show how they are theoretically and empirically linked. A discussion of gender and disasters, and gendered policy will begin the chapter on policy implications.

The first half of this chapter is dedicated to discussing the terminology and philosophy of research into natural hazards and disasters, and describing the current approach, which emphasises disasters as social phenomena (see Mileti, 1999; Pelling, 2001; Posner, 2004; Tierney, 2006). It will cover the debate concerning the definition and conceptualisation of the term 'disaster', before reviewing the different models used in Emergency Management. The first section will finish with a review of the Pressure and Release model from disaster sociology literature, which underpins this research. The Pressure and Release model suggests that domestic violence places its victims at greater risk than other women in the community during disasters.

The second half of the chapter begins by examining the limited existing literature on domestic violence and disasters, which indicates a reciprocal relationship between domestic violence and disasters, that domestic violence places its victims at greater risk during disasters, and that disasters increase the level of domestic violence recorded in a community. The definition of, and conceptual issues surrounding, domestic violence are discussed, including an analysis of the three dominant underlying theoretical perspectives for 


\section{Chapter 2}

examining domestic violence - feminist, individual-based, and societal. This thesis applies a feminist approach to domestic violence and, this section concludes with a discussion of the gendered nature of domestic violence and the rationale for looking solely at female victims of domestic violence.

\section{Disasters}

Today, it is widely accepted that disasters are fundamentally social events; a natural hazard event without any interaction with a human is rarely called a disaster (Alexander, 1997: 289; Mileti, 1999; Quarantelli, 2001; Stallings, 2005; Rodriquez \& Russell, 2006: 193; Perry, 2007). To disaster researchers, physical events are simply triggers of disasters, the underlying root causes are social, political and economic factors (Blaikie et al., 1994). Recent events like the Indian Ocean tsunami in 2004 (Amarasiri de Silva, 2008) and Hurricane Katrina in 2005 (Daniels et al., 2006) show the magnitude and course of disasters are shaped by inequalities in society, and the capability of local and national institutions to respond to the hazard event. Tierney (2006) singles out gender as a key dimension of inequality, linked to power, privilege, and social expectations. Below I present the case for treating disasters as social phenomena that have led to increased support for people-focused approaches to hazard mitigation and the recognition of a need for social policy responses (Pelling, 2001).

Natural hazards are generally defined as processes in the physical environment harmful to human life or property, caused by forces extraneous to society (e.g. Pelling, 2001; Keller and Blodgett, 2008; Hyndman and Hyndman, 2009). Disaster is a term used for both (1) any event that causes significant damage and loss of life and (2) the emergency situation that is the consequence of such an event. For a disaster to be entered into the International Emergency 
Disasters Database maintained by the Centre for Research on the Epidemiology of Disasters (CRED) at the Universite Catholique de Louvain, the source of the comparative data used below, it must fulfil at least one of the following criteria:

- Ten (10) or more people reported killed.

- Hundred (100) people reported affected.

- Declaration of a state of emergency.

- Call for international assistance.

(http://www.emdat.be/ExplanatoryNotes/explanotes.html)

\section{Natural disasters?}

The case that disasters cannot be viewed solely from the narrow perspective of the triggering physical events lies in statistical databases for disaster impacts (For example, Rodriquez et al., 2009). These show that there has been a steady increase in the number of declared disasters since 1900, (Figure 1), coupled with a significant increase in their cost (see Figure 2, a 15-fold increase for 1990-1999 with respect to 1950-1959) despite no significant change in the frequency of large hazard events. 
Figure 1: Total Number of Reported Disasters Globally (1900 to 2008)

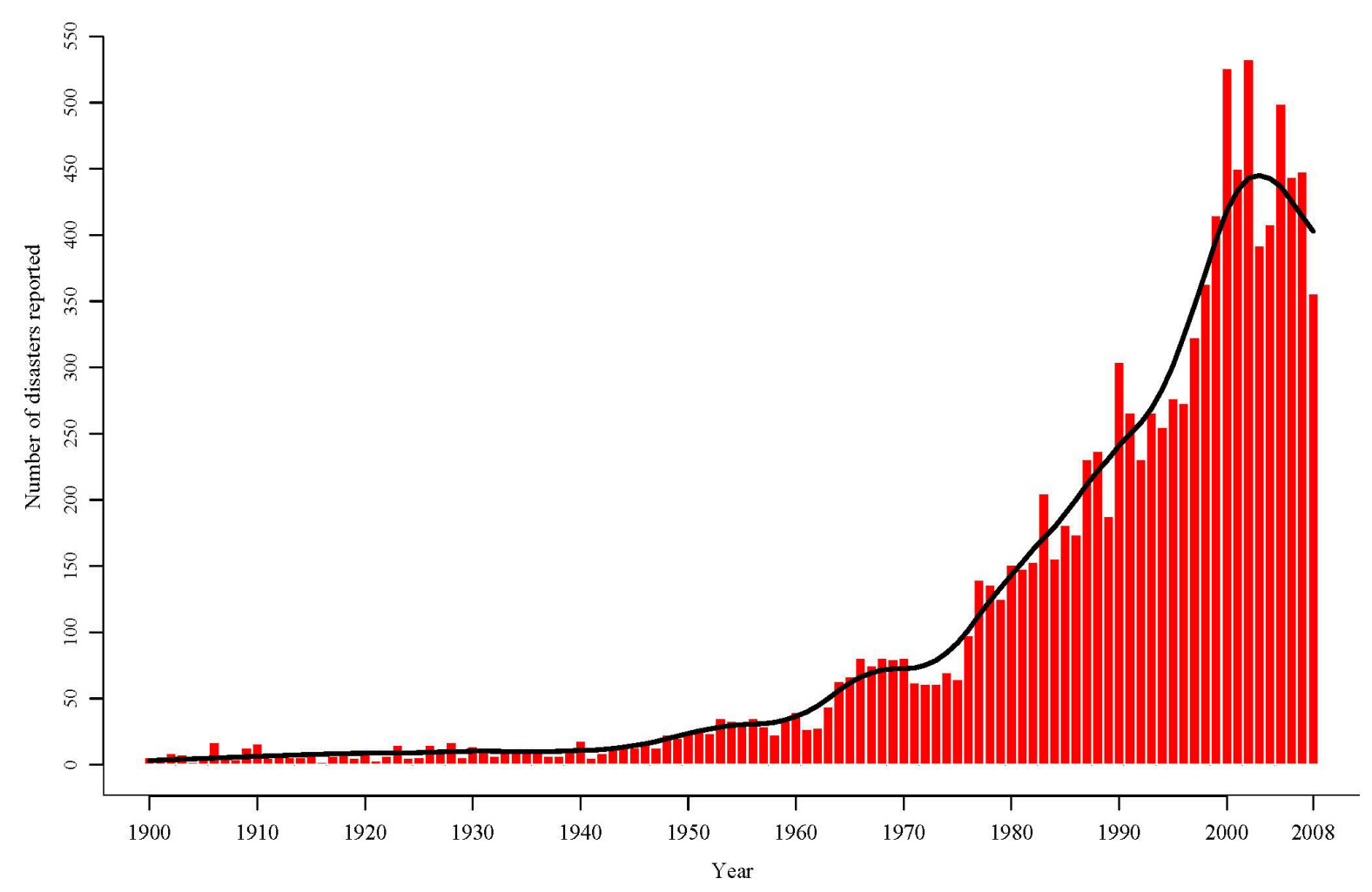

Source: http://www.emdat.be/Database/Trends/trends.html

The increased number of disasters reflects dominantly societal factors, such as population growth, particularly in vulnerable coast and flat-lying regions, and also more accurate tracking and reporting of disasters (World Bank, 2006: 3-4). 
Figure 2: Estimated Decadal Cost of Reported Disasters 1950- 1959 to 1990- 1999

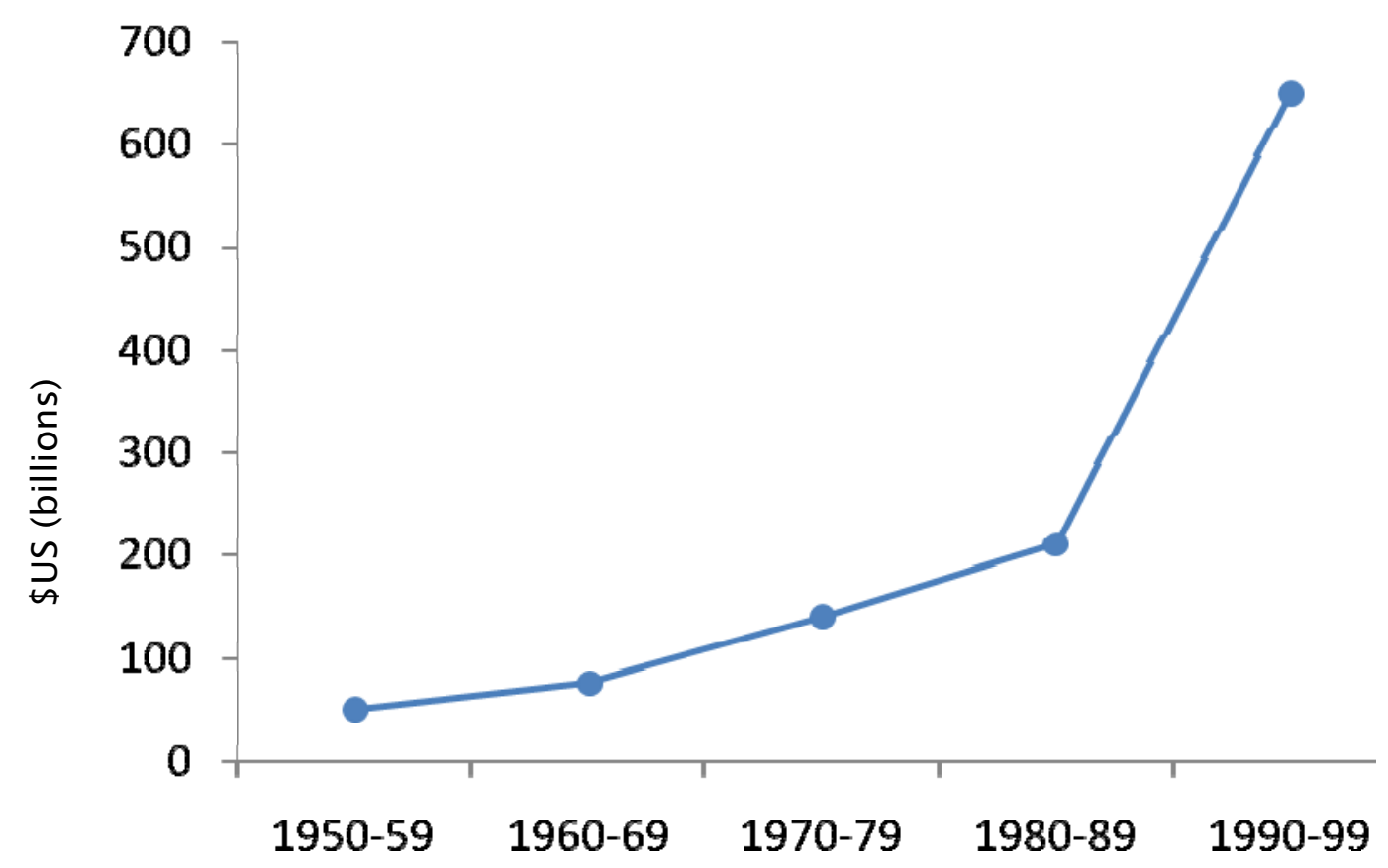

Source: http://www.emdat.be/Database/Trends/trends.html

The increased dollar cost also reflects human factors like population growth but also a heightened vulnerability of infrastructure in increasingly complex societies (Mileti, 1999: 67).

The recognition of disasters as intrinsically social phenomena has led to suggestions that hazard mitigation must move beyond technological solutions that address accurate and rapid identification of hazard but do not address society's reaction to hazards, warning messages, or the differential impacts that pre-existing social structures create for different groups within the society affected (White and Hass, 1975; Mileti 1999; Wisner et al., 2004). 


\section{Disciplines and approaches in disaster research}

The field of disaster research began along a path parallel to other physical sciences (Alexander, 1991: 293; Tierney 2006). In these initial stages, the primary focus of researchers was the quantification and interpretation of the physical processes occurring (Alexander, 1997: 293; Quarantelli, 1978; Perry, 2007: 4). This involved modelling a disaster as a cycle of events that moved from dormancy to a warning stage to crisis, moving eventually, via recovery, back to dormancy (Alexander, 1997: 289; Perry, 2007: 4).

There are now a number of disciplines that study disasters. Each discipline has a different approach to the research and understanding of disasters. In order to isolate those theories which provide the greatest utility for understanding the issue of increased domestic violence reporting during disasters, each discipline, its seminal researchers and key theories were examined. Alexander (1991) lists these as:

- Technical (see Press, 1975; Alexander, 1991; Coburn and Spence, 1992; Wright and Pearson, 1992; Bernard, 2005; Roberts et al., 2006)

- Geographical (see Barrows, 1923; White, 1945; White \& Hass, 1975; Hewitt, 1994)

- Anthropology (see Torry, 1979; Clay, 1988; Cernea, 1990; Oliver-Smith, 1999; Hofmann \& Oliver-Smith, 2002)

- Development studies (see Davis 1978; Cuny, 1983 \& 1994; Rivers, 1982; McAllister, 1993; Berke et al., 1993)

- Medical (see Beinin, 1985; Manni \& Magalini, 1985; Briggs \& Brinsfield, 2003; Ciottone, 2006; Hogan \& Burstein, 2007)

- Sociology and Psychology (see Marks \& Fritz, 1954; Quarantelli, 1954; Spiegel, 1957; Weisman, 1958; Enarson, 1998; Johnston et al., 2005; Paton, 2008)

Within his list of disciplines that are used to understand the effects of natural hazards, Alexander has grouped sociology and psychology together. However, I submit that these fields are logically distinct and that psychology should be 
viewed as a separate school of thought. Psychology and sociology may be more closely allied than, for example, sociology and the technical approaches, in that they shift the focus away from purely the recovery phase of disasters. However, the schools of thought differ in both methodological approach and focus. Many of the current psychology-based studies focus on the planning and mitigation techniques of individuals or individual households, and how to communicate risk to groups of individuals living in certain areas Johnston, et al., 2005; Paton, 2008). Sociological studies focus on how the structures within a society contribute to unsafe conditions, building on the geographical approach of White and Hass (1975). Although authors may use individual case studies to illustrate how the structures interact with a hazard event to create inequality, the focus is very much on the structures and the need for change at the societal level, rather than on the individual (Enarson, 1999; Wisner et al., 2004).

The geographical, development studies, anthropological, technical, psychological and medical approaches, though valid for other studies, are not the most useful in this research as domestic violence is a primarily social issue. These approaches fail to answer the question of whether domestic violence increases during disasters and, if yes, why. This field of research belongs within the school of sociology and disaster, and, within this, the specific area of gender and disasters.

\section{Evolution of sociological study of disasters}

Although sociology and disaster work began in the 1920's (Prince, 1920), the next surge in the growth and formalisation of the field did not occur until the 1950’s (Marks \& Fritz, 1954; Quarantelli, 1954; Spiegel, 1957; Weisman, 1958) with much significant work taking place between the late 1960's and early 1970's (Barton, 1969; Quarantelli \& Dynes, 1977; Picou, Marshall \& Gill, 2004: 


\section{Chapter 2}

1495). The early focus was on disaster-related behaviours, such as helping actions, social cohesion, and the setting-aside of community conflict. Later emphasis switched to diversity and stratification in society, and the influence of wealth, ethnicity, gender, age (Tierney, 2006). During this period, sociologists were able to shift the focus of disaster researchers from understanding the physical processes of disasters to the consequent social disruption and change brought about by those processes (Quarantelli, 1978; 1998; Mileti, 1991; Rosenthal, 1998).

The move to include social impacts did not lead to a consensus concerning the broader definition of a disaster, rather it served as the catalyst for heightened debate and disagreement, both conceptually and quantitatively (Dombrowsky, 1995: 241; Hewitt, 1995; Quarantelli, 1995: 221). However, during the 1970's and 1980's, there was a degree of agreement regarding how to define the spatial and temporal boundaries of disasters (Dombrowsky, 1995: 245; Alexander, 1997). The social impacts were considered to be relatively simple and equal in their effects across the physically affected population. For example, in the case of a flooding event, all those who were affected by floodwaters entering their house were considered to have the same needs in terms of the response action (Rosenthal, 1998: 150). The social impacts were also limited to those which occurred in the immediate response phase of the event and little attention was given to long-term impacts. There were a smaller number of researchers, such as Barton (1970), Merton (1970) and Quarantelli (1977), who made reference to differential vulnerability and, examined the disproportionate impact that disasters had on groups in society made more vulnerable by the social structures in place, such as the aged, poor, and ethnic minorities. However, these perspectives were not readily included in policy or 
procedural documents and mainstream disaster research (Bolin et al., 1998: 27).

It was during the 1970 s that researchers began to focus on quantifying the social impacts of disasters (Quarantelli \& Dynes, 1977: 26). Aid agencies, insurance companies and government agencies sought to calculate the financial costs of a disaster, incorporating the direct and some indirect costs of the natural hazard event. Examples of the costs included were the more obvious physical damage to housing, roads and other infrastructure, the cost of emergency supplies such as food, blankets, water, and emergency housing, and the cost to insurance companies of compensating victims. This might be extended to include less direct costs such as loss of earnings, or the sum total of insurance excesses and items not covered by insurance that individuals had to bear (Foster, 1976; Burton, et al., 1978; Quarantelli, 2001).

A second figure often used to measure the scale of the event was the mortality rate, augmented, in certain instances, by the injury rate. However, issues arose as the counting procedures varied from event to event and even across agencies in the same event (Quarantelli, 2001). Quarantelli highlighted a particular issue in developed countries with large ethnic minority populations. It was found in the 1901 San Francisco earthquake and the 1953 typhoon in Australia that both countries had large minority populations of Chinese, and Aboriginal Australians (respectively) that were not included in the mortality rates (2001: 326). The result of this was underestimates in the overall death rates for the events and a total lack of analysis of the impact the event had on these minority groups. Researchers argued that quantitative measures were not sufficient to provide an accurate picture of the social impacts of disasters, and began to develop alternative qualitative measures utilizing surveys with open-ended questions 


\section{Chapter 2}

and interviews (Drabek, 1989; Blaikie et al., 1994; Alexander, 1997; Quarantelli, 2001).

As the measurement scales for disasters changed, so too did the understanding of what constituted a disaster. Current sociological research has evolved into theories of complex social structures that have more gradational boundaries in terms of when the disaster starts (Morrow \& Enarson, 1996; Stehlik et al., 2000; Enarson, 2001; Fothergill, 2003; Bradshaw, 2004). Included in this increased complexity, are layers linked to vulnerability or disadvantage that pre-dated the natural hazard event and the term disaster was then separated from the hazard event and defined in terms of the social impacts of the event (Dynes, 1970; Ploughman, 1997: 120; Morrow, 1999; Hutton \& Haque, 2004; Rodriguez \& Russell, 2006: 196). Disasters were then considered in a framework of the interactions of the destructive physical events, with people and vulnerable environments (Mileti, 2001; Tierney, 2006), that is the juxtaposition of physical, social and infrastructural systems in the nomenclature of White and Hass (1975). Quarantelli (1998), Enarson (1999) and Wisner et al. (2004) highlight the intricate social, political, legal and economic structures that all intersect with the natural hazard event and lead to a disaster. These structures produce different outcomes based on an individual's position within the structures; as a result, not all individuals within the disaster zone experience disasters equally. This acknowledgement of social phenomena has impacted on definitions of the term disaster.

\section{Defining disaster}

Consensus on a definition of disaster has yet to be reached; different agencies continue to use different definitions depending on the context (Dombrowsky, 1995: 241; Hewitt, 1995: Quarantelli, 1995: 221). Quarantelli (1977 (with 
Dynes); 1978; 1994; 1998; 2001) suggests that there is no need for a common definition of disaster across practitioners, researchers, policy makers, and aid agencies as each has a different use for the term. For example, aid agencies, policy makers and practitioners require a term with spatial and temporal limitations, as they are concerned with resourcing the response, which involves defining how much response and for how long. Researchers do not require such a focused definition as, more often than not, their work is simply limited by such a definition, not improved (Quarantelli, 2001).

The definition of disaster used here is in line with those put forward by Wisner et al. (2004), and Quarantelli (2001):

A disaster occurs when a significant number of vulnerable people experience a hazard and suffer severe damage and/or disruption of their livelihood system in such a way that recovery is unlikely without external aid

(Wisner et al., 2004: 50).

and

...those crisis occasions generated by the threat of or the actual impact of relatively sudden natural and technological agents (such as earthquakes, floods, hurricanes, volcanic eruptions, tornadoes, and tsunamis as well as toxic chemical spills, radiation fallouts, large-scale explosions and fires, structural failures, massive transportation wrecks and crashes, etc.) that have significant negative social consequences. Basically we include only those instances where everyday community life is disrupted and where local resources cannot handle the demands of the situation.

(Quarantelli, 2001: 332-333)

The above definitions match formal definitions used in the context of declared Civil Defence emergencies in New Zealand. Once a Civil Defence emergency is declared formally in a region, external support becomes available from outside the region (i.e., Central Government). The Ministry of Civil Defence and Emergency Management's definition of an emergency, taken from the CDEM Act 2002 is: 
"emergency" means a situation that -

"(a) is the result of any happening, whether natural or otherwise, including, without limitation, any explosion, earthquake, eruption, tsunami, land movement, flood, storm, tornado, cyclone, serious fire, leakage or spillage of any dangerous gas or substance, technological failure, infestation, plague, epidemic, failure of or disruption to an emergency service or a lifeline utility, or actual or imminent attack or warlike act; and

(b) causes or may cause loss of life or injury or illness or distress or in any way endangers the safety of the public or property in New Zealand or any part of New Zealand; and

(c) cannot be dealt with by emergency services, or otherwise requires a significant and co-ordinated response under this Act"

(CDEM Act, 2002)

Events studied were selected on the criteria of (a) a declaration of a Civil

Defence Emergency; and (b) a significant impact on the community (for example, there must be more than localised surface flooding in the case of floods or limited closure of roads). The events selected produced impacts which disrupted everyday life to an extent that provided an insight into community life not available prior to the event.

The five case studies in this research are all rapid-onset or 'catastrophic' disasters. One of the key distinctions drawn by Wisner et al. (2004) is between rapid-onset disasters and slow-onset (chronic) disasters. Rapid-onset disasters involve natural hazard events that have a sharp initiation (and ending). These are events such as floods, earthquakes, tsunamis or hurricanes (Wisner et al., 2004: 10). These can be distinguished from events, such as droughts and environmental degradation, which move very slowly but can have longer and more devastating effects on the affected population than rapid-onset disasters.

More research has been conducted in the context of rapid-onset disasters. A plausible explanation for this is that the clear boundaries of the actual event create a well-delineated structure for the research. Wisner et al. (2004) are in 
favour of including prolonged events, such as droughts and epidemics, in their interpretation of disaster. However, Quarantelli states that these should be treated separately as "social problems involving chronic stress" rather than crisis situations (2001: 333). This emphasises Quarantelli's perception of the need for the hazard event causing the disaster to have distinct limits. Wisner et al. do not recognise the necessity for these criteria. Despite their divergence of opinion as to what constitutes a disaster, Quantarelli and Wisner agree that disasters are entirely social phenomena.

\section{Models of Disasters}

In this research, I use the Pressure and Release model (Blaikie et al., 1994; Wisner et al., 2004) as a tool for considering how domestic violence and disasters interact. This model focuses on vulnerability, highlighting the multiple layers and structures in place in society prior to the disaster, as well as the nature of the hazard event itself, in placing different individuals at varying levels of risk.

\section{Background}

The model used in the context of disasters during the late 1970's was the Comprehensive Emergency Management model (McEntire et al., 2002: 268). The Comprehensive Emergency Management model focussed primarily on the hazard phenomena and not the social, political and economic variables that create a disaster. It has been criticised as overly simplistic (Neal, 1997; McEntire, 2002: 268). Notwithstanding, this model laid much of the groundwork for subsequent models. A lack of focus on social, poltical, cultural and economic variables indicates that this model would not be the most appropriate for an examination of domestic violence reporting rates during disasters. 
The Disaster Resistant Community model is another alternative. Geis describes the model as:

...a means to assist the communities in minimising their vulnerability to natural hazards by maximising the application of the principles and techniques of mitigation to their development and/or redevelopment decision-making process

(2000: 152)

The model ignores the social, political and economic structures existing in society that lead to increased or reduced vulnerability, which makes it unsuitable for this study which looks at the intersection of social and natural disasters. Another shortcoming is its focus on mitigation and not post-disaster issues. This limits the utility of the model to planners and engineers, and not those participants in the disaster process dealing with the social impacts, such as counsellors (McEntire, 2002: 269).

The Disaster-Resilient Community model is a third means of conceptualising disasters. However, the inclusion of the term 'resilience' has meant that this model lends itself to wide variations in interpretation (Mileti, 1999: 33; Buckle, Mars \& Smale, 2000: 8-9). Little consensus has been reached as to what creates resiliency. However, the model does focus more on the social side of disasters and is thus more applicable across disciplines in the field. It is perhaps this farreaching applicability that has resulted in such a wide interpretation of its meaning. The model does identify that disaster mitigation practises alone will not be 100 percent effective and a focus solely on post-disaster efforts will leave societies at risk. This model may prove more applicable to a study looking at ways to mitigate increases in domestic violence during disasters, however, it does not provide the appropriate tools necessary for establishing if 
increased domestic violence reporting is an issue that needs addressing and so is not the best model for this research.

Sustainability models have also been used to examine disasters. Mileti has been a major proponent of sustainable hazards mitigation, defining sustainability as existing if "a locality can tolerate - and overcome - damage, diminished productivity, and reduced quality of life from an extreme event without significant outside assistance" (1999: 4). Again, this model focuses on mitigation rather than examining social issues that arise during disasters. As such, it is not the most suitable model for an examination of domestic violence reporting and disasters.

Finally, vulnerability models focus on the ways in which pre-existing social structures put populations at risk during disasters. These models examine the juxtaposition of natural hazard events with multi-layered social inequalities to create concepts of being "at risk" to disasters. More recently, two models in particular have gained recognition in the field of social impacts of disasters. The term vulnerability is used in a specific manner in this research. The definition of vulnerability in this thesis is:

...the characteristics of a person or group and their situation that influence their capacity to anticipate, cope with, resist and recover from the impact of a natural hazard...

(Wisner et. al., 2004: 11).

This definition focuses on the pre-existing social, cultural, political, economic and legal structures that designate differing levels of vulnerability and consequently risk to groups in a society during a disaster. It purports that groups who are adversely affected by pre-existing structures, such as patriarchy or capitalism, are more vulnerable during disasters and will face a greater risk 
to their livelihood, leading to a slower and harder recovery (Wisner et al., 2004: 11). This will be discussed more specifically in the models discussed below.

Differential vulnerability is recognised in the Access model. The Access model is a more complex model that focuses on the micro-scale, in contrast with the Pressure and Release model in which the focus is the macro-level. The Access model is restricted to the level of individual households or individuals, and, therefore, cannot represent society-wide problems such as domestic violence. As a consequence of this individualised focus, it offers less utility here for an examination of domestic violence rates after a disaster. The model of disasters used in this research is the Pressure and Release model which offers a framework to analyse the intersection of disasters and domestic violence.

\section{The Pressure and Release model}

Without the context of vulnerability issues, the perception of natural hazard events is that all people in an affected community will be impacted in the same ways and to the same extent (particularly, those living in the same residence). However, disasters intersect with the pre-existing structures and inequalities in society - political, cultural, legal and social (Morrow, 2004; Fothergill \& Peek, 2004: 89; Rodriguez \& Russell, 2006: 193). These structures stratify society and limit the access of some groups to the resources required to protect themselves from the physical impacts and to facilitate their recovery from disasters.

Wisner et al. (2004) developed the Pressure and Release model, based on the interaction of the natural hazard event and the societal structures that put members of the affected society "at risk" and renders them consequently vulnerable to a significant negative impact from the event. This model falls 
within the vulnerability approach to disaster research. The Pressure and Release model states that prior to the event, individuals already experience pressure to varying degrees from structures in society, such as capitalism or patriarchy. When the hazard event occurs this pressure is released and the impact this release has on individuals is related to the degree of pressure they were under prior to the event (Wisner et al., 2004: 51). As a simple illustration, a low-waged individual who has little or no savings or insurance is more adversely affected by a tsunami than a person with savings and insurance. Lowwage jobs stem from a capitalist structure; the vulnerability stems not from the event itself, but from the structures pre-dating the event. Vulnerability is dependent on the structure of society and is not purely a function of the natural hazard. The Pressure and Release model discusses three "layers" of vulnerability (Wisner, 2004: 49):

(a) Root causes, such as political or legal systems;

(b) Dynamic pressures, such as lack of appropriate skills and macro-forces, such as rapid population growth; and

(c) Unsafe conditions, including lack of local institutions and low-income levels.

Root causes in the Pressure and Release model are those furthest removed from the risk. Root causes include political structures, and other social, cultural and legal factors, which structure a society (Wisner, 2004: 53). Root causes are often ignored in disaster analysis and presumed to be an entrenched, immovable part of society's structure. These forces impact on society by myriad means, through the way the law is enforced and upon whom; via military force and power; by marginalising those without power or interest to those with power; through the relationship between the State and the public; and the relative sense of empowerment of members within society. Root causes are the most difficult issues to address and yet yield the most effective results if challenged and amended. 


\section{Chapter 2}

Dynamic pressures are "processes and activities that translate the effects of root causes both temporally and spatially into unsafe conditions" (Wisner et al., 2004: 53). Dynamic pressures are more readily visible than root causes but not as palpable as unsafe conditions. Moreover, dynamic pressures operate on large spatial scales. Wisner et al. cite the examples of foreign debt, rapid urbanisation of a population, and war (2004: 54). Ending a war or repaying foreign debt are processes that can endure for decades. These pressures create and sustain unsafe conditions that stratify different groups and expose these groups to different levels of risk. The pressures can overlap further increasing the risk applicable to certain groups. Gender and disaster literature often highlights the higher levels of risk faced by women than their male counterparts, due to gender inequalities (Scanlon, 1996; Kottegoda, 1997; Enarson, 1998a; Major, 1999; Enarson \& Morrow, 1999; Fothergill, 1996; Enarson, 2001a; Enarson, 2001b; Cannon, 2002; Fothergill, 2003; Enarson et al., 2003; Ahmed, 2004; Abeysekera, 2006; Burnad \& SRED team, 2006; Prasertcharoensuk \& Sirisook, 2006; Sayeed, 2006). For example, Ariyabandu discusses the situation in Bangladesh in which widowed women can have their land and home taken from them by evocation of Shariah law (2000: 4). In this example, a social and religious norm has placed this group of women at greater risk than widower men, or non-widowed women in the wake of a disaster. While the hazard event itself has not targeted women, it has a higher cost for women who lose their husbands than men who lose their wives and may have the permanent effect of moving widowed women from a life of comparative stability, in terms of a steady income and housing, to a life of poverty and homelessness.

The final layer, unsafe conditions, are routinely witnessed everyday by community agencies working with marginalised groups and common examples 
include unstable incomes, heavy reliance on the State for provision of basic necessities (if available), unsafe buildings and at-risk neighbourhoods (e.g. the hillside shanty towns in Brazil (Wisner et al., 2004: 55)); and specifically related to disasters, translates to a lack of preparedness for a hazard event. These factors are the most frequently targeted by policy as they are the most apparent and, in some cases, urgent symptoms of vulnerability. However, without addressing the root causes of these symptoms, this is analogous to putting a bandage over an infected wound.

\section{Gender and the Pressure Release model}

Applying the Pressure and Release model to this research: domestic violence is one of the many dynamic pressures that can create unsafe conditions for groups of women. The root cause is a society stratified by gender and, specifically, one that has underlying patriarchy. Patriarchy has two key elements. The first is a structure in which "men have more power and privilege than women" (Smith, 1990: 257). The second is an ideology which legitimises this structure (Smith, 1990: 258). Patriarchy is largely invisible in everyday life and yet it is one of the most pervasive structures in societies (MacKinnon, 1983: 638). This invisibility often makes it hard to pinpoint the structure and how it manifests itself in the society. Nevertheless, the downstream effects of a patriarchal society are apparent in every census or time-use survey, and are detected by domestic violence research. The effects include wage-gaps, women being more likely to take parental-leave, women being more likely to be in a caring role for parents or children (Statistics New Zealand, 2001; Statistics New Zealand, 2006a), and women forming the overwhelming majority of those seeking protection orders against partners (Bartlett, 2006: 36) or help from domestic violence agencies (National Collective of Independent Women's Refuges, 2005). 
Gender stratification is one of the social structures that are brought to light following disasters (Fordham \& Ketteridge, 1998; Fothergill, 1998; Wilson, Phillips \& Neal, 1998; Enarson, 1999). Gender stratification is a root cause in the Pressure and Release model. It creates different impacts in different societies and can vary in its rigidity. In societies where gender roles and norms are strongly ascribed to, and where stratification is commonplace, disasters can have significant and often fatal consequences for women. An example can be found in the Boxing Day 2004 tsunami in Sri Lanka during which 91 percent of adults killed were women (Abeysekera, 2006: 5). This was created through social norms that put the onus on women to save any children in the family (sometimes at the cost of their own lives) (Abeysekera, 2006: 5). Women were also less likely to leave the house without their husbands who may not have returned to the home during the tsunami as this is a cultural norm in Sri Lanka (Abeysekera, 2006: 5).

Furthermore, ethnic, age and class stratifications intersect with gender and can compound inequalities (Fordham, 1999; Fothergill, 2003; Bolin, 2007). Stratification is evident in the degree of access to resources, such as education, health, food, and shelter. Lack of access to resources is further compounded during an event and consequently groups that are disadvantaged in everyday life are relatively more vulnerable after a disaster (Fordham, 1998).

\section{Summary}

Disasters expose latent social situations and problems that can be obscured during times of environmental normalcy (Merton, 1970; Fothergill, 1998: 11). Vulnerability, social stratification and the consequent inequalities are elements of this. It is too simplistic to conclude that all women are more vulnerable than 
all men are. This would be to ignore other existing stratifications in class, ethnicity, religion, ability and age, inter alia, which intersect with gender stratification and create multiple vulnerabilities with individualised levels of risk. (Ariyabandu, 2000; Enarson et al., 2003; Fothergill, 2003; Phillips \& Morrow, 2008). As a feminist researcher, I am concerned predominantly with the issues arising from gender stratification. In societies, or in subsections of societies, where the impact of gender stratification is not obvious, the difference in impacts may not be marked. However, this does not negate the fact that specific groups of women within these societies will be more adversely affected than their male counterparts. Domestic violence victims are such a group; this group is comprised of individuals from a range of backgrounds in terms of class, ethnicity, ability and age.

\section{Domestic violence and disasters}

The everyday situation of domestic violence victims is typically one that is characterised by a lack of social networks; isolation that creates a lack of access to social services, money and other resources, and decision-making power within the domestic relationship; low self-esteem; and frequently a high incidence of fatalism (Stets, 1991; Hague \& Wilson, 2000; Jewkes, 2002; Logan et al., 2003; Levendosky et al., 2004; Michalski, 2004; Bogat, Levendosky, \& von Eye 2005). These characteristics are exploited as tools by the perpetrators of domestic violence to attain and maintain control over the women. The characteristics can also augment complications in situations of disaster response and recovery. For example, if a woman is unable to make the decision to evacuate for fear of reprisal, this exacerbates the high level of risk inherent to the hazard event itself and may result in the loss of life or the need for external agencies to step in and enforce evacuation (Enarson, 1998b: 1-2). The emergency management literature assumes that a woman has access to 
mandatory evacuation orders. However, if a woman is entirely isolated from the outside world, such an order can go unnoticed creating the same result as if the order was wilfully ignored. These are two more examples, of which there are many more that demonstrate the need to be aware of domestic violence within disaster response, and recovery plans and policies. Moreover, the relationship between the incidence of domestic violence and disaster impacts appears to be reciprocal, with studies overseas showing that disasters affect domestic violence reporting.

A limited amount of overseas research over the last 18 years has shown that an increase in the rate of reported and non-reported domestic violence in affected areas is one social consequence of disasters (both natural and non-) (Palinkas et al., 1993; Dobson, 1994; Honeycombe, 1994; Enarson \& Morrow, 1996; Wilson, Phillips \& Neal, 1998; Davis \& Ender, 1999; Enarson, 1999; Fothergill, 1999; Rashid, 2000; Fisher, 2005; Jenkins \& Phillips, 2008). Only four of these studies have focused specifically on domestic violence and the observed changes in reporting levels during disasters: Enarson (1999); Fothergill (1999); Jenkins and Phillips (2008); and Wilson, Phillips and Neal (1998).

Elaine Enarson investigated the impact that natural hazard events had on domestic violence shelters in Canada and the United States. Enarson's work is the most comparable to the current study as Enarson focuses on the agency level of domestic violence reporting during disasters, rather than the individual. Initially a postal survey was sent out to domestic violence agencies across the United States and Canada. The returned surveys provided the organisations that would participate in the second phase of the research, which consisted of telephone and face-to-face interviews. The second phase involved interviewing representatives from 77 different shelters across the two countries. Enarson 
observed that in those areas affected by a severe natural hazard event, the caseloads of surveyed shelters had increased between 15 and 59 percent (1999: 756-757). Enarson also showed that little or no planning was in place within shelters for disaster events due to a lack of time and money within the shelters. As a result the shelters' limited resources were placed under extreme pressure with less staff available to cope with the increased workloads (Enarson, 1999: 757).

In fact, shelter workload did not simply increase, the work itself had become more complex due to the necessity for new interactions with other agencies that were similarly unprepared for the needs of the shelters. Enarson cites an example observed on Kauai, Hawaii during Hurricane Iniki during which the Police failed to enforce pre-existing protection orders during the disaster (Enarson, 1999: 758). This situation was attributed to the over-stretching of police resources, and a lack of power, phones and water. A consequence was an increase in the workload and complexity of cases that the women's shelters were dealing with (Enarson, 1999: 758). Heightened need for interactions with State agencies further increased the work of the women's shelters. Moreover, there was a fundamental lack of recognition on the part of officials of the special needs of an evacuated women's shelter (Enarson, 1999: 760). Shelters reported that officials did not understand that the general evacuation site was not appropriate for the women's shelter (Enarson, 1999: 760). Finally, a range of financial burdens were placed on the agencies responding to increased domestic violence reporting. Women's shelter representatives perceived that the "sympathy" of the community lasted for approximately six months following the commencement of a disaster and then financial donations became scarce. Often pre-existing fundraising events were delayed due to the disasters and, finally, federal and State funders' resources were diverted to general disaster 


\section{Chapter 2}

programmes leaving women's shelters with less resources to meet a much higher demand (Enarson, 1999: 760).

Enarson's work laid the foundation for research into increased domestic violence reporting during disasters. Enarson's methods and considerations were replicated and expanded on in the current study. This will be discussed further in the methodology chapter.

Wilson et al. (1998) examined domestic violence following three events in the United States, from the perspective of agency-level impacts. The three case studies were Santa Cruz County, California following the 1989 Loma Prieta earthquake; Lancaster, Texas following the 1994 tornado; and Dade County, Florida following Hurricane Andrew in 1992. Data were collected through semistructured interviews with agency representatives, statistics and information materials from agencies, and analysis of contemporaneous documents and media items.

The aim was to establish whether existing agencies coped with the levels of reported domestic violence in the aftermath of these disasters, and if not, whether there was a gap necessitating the formation of new agencies designed to meet the shorter-term needs of the community. The most significant finding was that pre-disaster attitudes towards domestic violence "strongly influence the perception and handling of domestic violence after a disaster" (Wilson, Phillips \& Neal, 1998: 120). The authors submit that if agencies were aware of a domestic violence problem in their community, then they were able to handle any increases in domestic violence reporting and, therefore, no significant gaps exist (Wilson, Phillips \& Neal, 1998). Conversely, if agencies in a community 
refused to acknowledge that there was a problem prior to the event, agencies consequently did not recognise an increase had occurred after an event.

This finding highlights the significant impact that agency representatives' awareness and opinions have on research examining domestic violence reporting during disasters. The reliance on secondary source opinion and information is a potentially significant limitation on this research. Information provided by agencies that work in the field, rather than women experiencing domestic violence, is necessarily filtered (even if unintentional) which can result in distortion, this issue is discussed in detail in the methodology chapter. However, there are countervailing benefits to interviews with agency representatives that outweigh any potential distortion. These will also be discussed in the methodology chapter.

Fothergill (1999) investigated increases in the incidence of domestic violence following the Red River flooding in 1997 in North Dakota and Minnesota in the United States. Fothergill recorded shelter work volumes following the flood and compared them to the statistics for the year prior to the event. Fothergill (1999) noted significant increases in the number of cases presenting, coupled with decreases in the number of staff available to work in the shelter. Whilst agency impacts were included, Fothergill's focus was at the individual level. Fothergill's work centred around two cases of women she spoke to who reported incidents of domestic violence during the flood itself. These case studies illustrate both the situation for the two women following the flooding and their understanding of the dynamics involved.

The first case study concerned a relationship that had involved domestic violence prior to the flood. A physical assault had taken place 20 years prior to 
the flood, followed by a period without physical assault up until the flooding occurred. However, the relationship was characterised by controlling behaviour exerted over the woman by her partner over the 20-year duration of the relationship (Fothergill, 1999: 88). Post-flooding, the violence returned (Fothergill, 1999: 87). The victim of the violence left the relationship in the period following the flood and remained separated from the abuser. The woman in this case was a middle-class, employed, able-bodied, white woman, who was able to draw on her extended family resources as well as the knowledge that she had a secure income stream to leave the relationship (Fothergill, 1999). This case was contrasted with the second case.

The second case involved a woman from a working-class background, who had been disabled in a car accident leaving her unable to walk on her own. She had grown up in an abusive family and had been in abusive relationships since her teenage years (Fothergill, 1999: 90). Prior to the flooding, the relationship was violent. The woman had become dependent on her perpetrator for physical and financial assistance (Fothergill, 1999: 90). However, during the flooding event, the perpetrator was absent from their home in an alcohol and drug treatment centre. The woman had faced the flood and its destruction on her own (Fothergill, 1999: 91-92). In doing this, the woman's level of self-efficacy improved, and consequently, she felt that if she could survive the flood, she could survive on her own. The second woman also left the abusive relationship. The woman's disability had compounded her increasing isolation and, therefore, the support she received from a domestic violence agency in the months following the flooding were recognised as invaluable for her continued independence and sense of empowerment (Fothergill, 1999). 
Fothergill's work has given insight into the impact experiencing and surviving a disaster has on a woman's decision to stay or leave an abusive relationship. In both of the case studies, the women themselves said that the flooding had acted as a catalyst for them to seek help from domestic violence agencies. It was the first study that realistically voiced individual women's perspectives of the dynamics involved in domestic violence reporting during disasters. The first case study noted that the abuse in the relationship had intensified in the aftermath of the flooding. This increase in abuse coupled with the other effects of the flooding compelled the woman to leave the relationship and seek help from domestic violence agencies. The second case study highlighted the positive effect that the victim's own ability to cope with the event had on the victim's self-esteem and self-efficacy. This in turn led to her accessing help from domestic violence agencies. The coalescence of the two stories suggests that a disaster can affect both the perpetrator and the victim. Moreover, it is apparent that both domestic violence and domestic violence reporting may increase during disasters. However, this work was based on two stories only and a study that includes a greater number of women will greatly improve the understanding in this area.

These two cases studied by Fothergill also highlight the different effects of one disaster on different women. The impact of the flood on both of the women was shown to be influenced by the intersection with pre-existing social strata (particularly economic strata) and their specific needs pursuant to leaving the abusive relationship. One of the women had greater financial resources to draw from post-flooding and did not require as much agency intervention as the women with lesser financial resources. The work demonstrates that there is no single, universal domestic violence victim. This is significant in policy formulation (which will become relevant at the end of this thesis) and needs to 


\section{Chapter 2}

be understood by those working with abused women during disasters and, also, more generally in times of non-disaster.

During the final months of this thesis, Jenkins and Phillips (2008) published a study of the impact of Hurricane Katrina on both domestic violence victims and domestic violence shelters. Data was collected through four methods: focus groups with survivors of domestic violence, interviews with domestic violence advocates, statistics of domestic violence incidence and observations at community meetings (Jenkins \& Phillips, 2008: 55). There were five focus groups with women survivors that focused on the impact Hurricane Katrina had on their decision to leave abusive relationships. Interviews with domestic violence advocates focused on the impact the storm had on their services and the difference in service provision after the hurricane. The community meetings were specifically related to domestic violence. These were held between legal and social service providers in New Orleans and occurred monthly between November 2005 and November 2007 Jenkins \& Phillips, 2008: 55).

The research found two significant issues for domestic violence victims. The first was child custody (Jenkins \& Phillips, 2008: 56). An example given was that of a woman whose husband was late returning her daughter from his visit with her prior to the storm. Worried about the impending storm and needing to evacuate, the woman faced a barrage of threats and abuse in trying to regain custody of her daughter to evacuate (Jenkins \& Phillips, 2008: 56). Eventually, she had to remove her daughter from the house by covert means in order to evacuate in time. Issues were also raised in the context of women whose children were evacuated with the non-custodial parent. Custodial parents were not necessarily evacuated to the same location as their children. Examples 
were given of legal battles of more than two years duration to regain custody of their children (Jenkins \& Phillips, 2008: 57).

The second issue was housing. A lack of alternative housing was a significant barrier for domestic violence victims wanting to leave their abusive partners after Hurricane Katrina. In some cases, a flawed housing policy resulted in abusers sharing residence with their victims in FEMA-supplied housing Jenkins \& Phillips, 2008: 57). In those examples, the fact that the victim was still married to the abuser (although legally separated) coupled with a one trailer per family policy, meant that the abuser was able to claim he was entitled to stay in the FEMA housing (Jenkins \& Phillips, 2008: 56). However, the cost and availability of housing, more generally, produced a significant barrier to women who wanted to leave abusive relationships (Jenkins \& Phillips, 2008: 59). With less housing available, the standards of available housing declined while prices escalated. These two housing policy issues emphasise the complexity of domestic violence victims' needs during disasters (Jenkins \& Phillips, 2008).

Jenkins \& Phillips found that Hurricane Katrina had a dual role as a marginalising event and an impetus for change. In some cases, policy shortcomings during the disaster proved a barrier for domestic violence victims to leave abusive relationships, particularly those that ignored women's financial situations, and this is a potential pitfall that will need to be avoided in future policy formulation. However, for some women the event itself proved a motivator for change (Jenkins \& Phillips, 2008: 61). For some women, the incidence and severity of the domestic violence had increased, which motivated them to leave the relationship or the event had catalysed a rise in their selfesteem and self-efficacy, which then encouraged change Jenkins \& Phillips, 2008: 61). These conclusions echo those of Enarson (1999) and Fothergill 
(1999). This suggests that while both the scale and nature of domestic violence may change during a disaster, the level of reporting may also increase. Either of these effects produces an increased workload for domestic violence agencies during disasters. The Jenkins \& Phillips study concluded that the disaster had an effect on the behaviour of both the victim and perpetrator (refer also to Fothergill (1999) who reached a similar conclusion).

The review of research on gender and disasters shows all studies unequivocally found that domestic violence reporting had increased in the months following a significant natural hazard event. These studies, combined with the existing theory on disaster vulnerability, provide the foundation for an investigation into whether domestic violence reporting increases during disasters in New Zealand.

The subsidiary question of whether it is reporting alone or the level of domestic violence that increases has yet to be answered, although two of the previous studies suggest both occur. To examine this, a clear understanding is needed of what domestic violence is and what factors are involved. A discussion of the definition of domestic violence used in this research and the three central approaches to conceptualising domestic violence follow.

\section{Domestic Violence}

Definitions and the terminology of domestic violence, like disasters, have been the subjects of extensive debate (Gelles, 1985: 352; Hegarty, Sheehan, \& Schonfeld, 1999; Brownridge, \& Halli, 1999; Rhatigan et al., 2005; Hegarty \& Roberts, 2008). Domestic violence researchers have not yet settled on a universal definition. However, New Zealand's most widely used definition of domestic violence comes from the Te Rito strategy, which is cited by both researchers and practitioners. This definition has been adopted in this 
research. In Te Rito, domestic violence is defined as "a broad range of controlling behaviours, commonly of a physical, sexual, and/or psychological nature which typically involve fear, intimidation and emotional deprivation" (Ministry of Social Development, 2002: 8).

The Te Rito definition highlights that domestic violence is not simply physical violence but rather it is fundamentally about the control of another individual. In fact, research indicates that physical violence is not necessarily the most common type of domestic violence experienced (Hornung, McCullough, \& Sugimoto, 1981: 690). Domestic violence can also take the form of verbal cruelty, emotional abuse, or sexual abuse (Ritchie \& Ritchie, 1993). The incidence of abuse spans the entirety of the demographic spectrum; crossing boundaries of age, ethnicity, gender, income and geography. A 2001 study observed no correlation between any demographic data set and the rate of abuse in New Zealand (Semple, 2001).

There are three main approaches to examining the causes of domestic violence - individual-based, societal, and critical/feminist Jasinski, 2001; Buzawa \& Buzawa, 1996). Each offers factors that are present in the lives of those that perpetrate violence against their spouses.

\section{Individual-Based Perspectives}

Individual-based factors are the personality and psychological characteristics of the perpetrators and any external forces acting on those individuals. Inherent characteristics include low self-esteem, traditional and stereotypical beliefs, low self-efficacy, fatalism, denial, stress and stress-related disorders (sometimes linked to more serious psychological conditions such as schizophrenia and depression) (Hotaling \& Sugarman, 1986; Margolin, 1993; Holtzworth-Monroe 
et al., 1997; Emery \& Laumann-Billings, 1998; Halpern et al., 2001; Vest et al., 2002). These factors found to be present in the perpetrators of domestic violence also impact on their response to, and recovery from, disasters. If this person is also in control of a household, as abusers are, this will create problems for Civil Defence staff trying to evacuate the entire household, which is subject to the sole will of one individual. Though not currently acknowledged by Civil Defence in New Zealand, this is a very real issue that could present to first responders in an emergency, making it a Civil Defence issue.

External factors such as a violent family background, substance abuse, lack of employment, and isolation also increase the likelihood of domestic violence (Margolin, 1993; Buzawa \& Buzawa, 1996: 14-16; Holtzworth-Monroe et al., 1997; Emery \& Laumann-Billings, 1998; Jackson \& Oates, 1998: 126-128; Kantor \& Jansinski, 1998: 13; Campbell et al., 2003; Ehrensaft, 2003; Bogat, Levendosky, \& von Eye, 2005). Isolation, either geographical or enforced, presents problems for Civil Defence in communicating information to isolated parties. Without access to radios, televisions or computers, some domestic violence victims will be unaware of the seriousness of the situation until it is too late for them to act (and anyone else in their house).

Domestic violence can affect the way in which both perpetrators and victims respond to disasters, however, the relationship between disasters and domestic violence is reciprocal. A disaster can impact on domestic violence and domestic violence reporting and has been seen to do this in previous studies on domestic violence and disasters (Enarson, 1999; Fothergill, 1999; Jenkins \& Phillips, 2008). Disasters can create a feeling of a lack of control in individuals experiencing them. As mentioned earlier, control is crucial in understanding domestic violence (Goode, 1971: 624; Williams, 1992; Margolin, 1993; Felson \& 
Messner, 2000: 86). Umberson et al. discuss the role of personal control (also called self-efficacy or mastery) in the lives of both perpetrators and victims of domestic violence. The authors argue that for victims of domestic violence, their perceived level of personal control is eroded over time by their abuser, to a level where they feel they have little or no control over their own lives or their environment. The opposite is true for the perpetrator; the perpetrator is able to control more and more of the home environment, which may compensate for a lack of control in other aspects of the perpetrator's life, such as their working environment or place in wider society (1998: 442-444).

Further to this, Umberson et al. discuss the impact that the loss of control can have on the intensity of domestic violence (1998: 444). The authors argue that when abusers feel loss of control over their wider environment, they will tighten the level of control at home (Umberson et al., 1998: 444). The examples cited by Umberson et al. include the loss of a job or the end of the relationship. However, this analysis can be readily transposed to the circumstances following a disaster. Disasters can destroy homes or render them uninhabitable, can impact on the work of both abuser and victim through business and road closures, and can throw the whole daily routine of a family into upheaval. During disasters, families often become heavily reliant on external support agencies for even the most basic resources, which can foster a sense of hopelessness and embarrassment. If a person who seeks a high level of personal control, such as an abuser, is put into this dependent situation it follows, from the argument that Umberson et al. have presented, that domestic violence will intensify as abusers seek to regain the feeling of control they had prior to the disaster. This could mean domestic violence transmutes from psychological and economic abuse to physical assaults or that the violence becomes more frequent. This change in the pattern of violence was 


\section{Chapter 2}

demonstrated by Fothergill in her first case study, where the violence changed from being controlling emotionally to physical violence (1999).

These individual-based theories have gained widespread public acceptance as they offer a so-called 'commonsense' explanation. Society is more comfortable with the idea that an individual is able to control his/her behaviour, and thus perceives abusers as deviant and not part of normal society (Buzawa \& Buzawa, 1996: 14). Conversely, these approaches have been criticised, as they have been unable to produce a typology that covers all men who abuse their partners and, therefore, cannot in isolation, give an effective understanding of domestic violence (Buzawa \& Buzawa, 1996: 14).

\section{$\underline{\text { Societal Perspectives }}$}

The second set of non-feminist perspectives are societal perspectives that fill in some gaps that exist in the individual-based perspectives. Societal perspectives look at the correlation between social phenomena and structures, such as race/ethnicity, class, religion, access to education, employment status and age, and domestic violence incidence (Straus, Gelles, \& Steinmetz, 1980: 132-150). Straus et al. (1980) found a correlation between age, income employment and, to a lesser extent, religion and the presence of domestic violence in a relationship (1980: 151).

Societal perspectives have argued that a man's class can impact on his capacity to release tension in a socially acceptable form, such as sport, therefore, the home becomes an outlet (Margolin, 1993: 675). Another pressure point may be an inability to vent their frustration or air grievances in the workplace; the problems become internalised, and can escalate until the perpetrator gets home to a place where he can exert power (Margolin, 1993). However, this argument 
contradicts the well-established fact that domestic violence occurs across the demographic spectrum, in both very poor families and very wealthy families (Semple, 2001). Moreover, it ignores the control aspect of domestic violence as it limits domestic violence to physical assaults and not the psychological, emotional, sexual and financial abuse that can also be a part of domestic violence and thus has limited application in explaining domestic violence.

\section{Feminist Perspectives}

At their core, feminist perspectives seek to highlight the role of gender. However, the way this manifests and is addressed varies greatly across the feminist school of thought (hooks 1984).

The origins of domestic violence show how fundamentally gendered it is. In the Middle Ages, women were burned alive for a wide variety of behaviour from talking back to a husband, scolding and nagging, and miscarriage of an unborn child (Davis, 1971). In 1768, the "rule of thumb" was codified into law in London, which allowed a husband to discipline an ill-tempered or poorlybehaved wife as long as the stick used was no thicker than his thumb (Moore, 1979; Bograd, 1988; Straus \& Gelles, 1986: 466; Jukes 1999). In this structured society, husband or society had the right to discipline a woman through the use of violence if she did not conform with their requirements.

Since this time, much legal headway has been made internationally and in New Zealand with the eventual passing of the Domestic Violence Act in 1995. However, incidents of domestic violence persist in the present day, for at least one in three women in New Zealand (Fanslow \& Robinson, 2004: 1). Socially and legally, domestic violence was historically a private matter, and not a matter for public intervention. However, thinking in this area has shifted (Mears 


\section{Chapter 2}

\& Visher, 2005: 205), assisted in large part by feminist researchers and activists (Schecter, 1982; Morrow, 1994).

Feminist perspectives argue that society is gendered (Yllo, 1983). Gender roles and norms are ascribed to individuals and we are socialised into, and constantly striving to achieve these through our interactions with others (Butler, 1997). Many feminists consider gender to be the central organising principle in social relations and that gender roles and norms are influenced by an underlying patriarchy within the society (Cranny-Francis et al., 2003). As stated previously, patriarchy has two key elements. The first is a structure in which "men have more power and privilege than women" (Smith, 1990: 257). The second is an ideology, which legitimises this structure (Smith, 1990: 258).

Patriarchy creates an inequality of power between men and women and this creates further inequalities, such as work and wage differences, and fosters domestic violence. There is typically inequality between spouses and the spouse with the greater power or control over resources and decision-making (typically the male) will dominate the other (Bograd, 1988; Margolin, 1993). In this context, the need for control and dominance are again viewed as the central motivations of domestic violence perpetrators. Violence is one of the means of achieving control and dominance (Yllo, 1983: 279; Margolin, 1993; Fothergill, 1996; Enarson, 1999; Michalski, 2004). Moreover, masculinity is inherently associated with dominance and the use of violence to show dominance. Against this background, domestic violence can be viewed as the mechanism through which some men attempt to demonstrate their masculinity (Moore, 1979: 11; Margolin, 1993; Dobash \& Dobash, 1998: 164). In a disaster situation, if abusive men start to lose control of their assets and resources and consequently feel that their masculinity is being diminished, an assertion of 
dominance over the only people with less power than them (i.e., their wives and children) may be used to bolster or re-establish the perpetrator's masculine identity (Anderson, 1997: 658).

Other feminist perspectives focus on the ways in which a patriarchal society contributes to high levels of acceptance of domestic violence as an outlet for men's anger (Yllo, 1983: 279; Anderson, 1997; Hanmer, 2000). Giles, Curreen \& Adamson show that when a society's formal sanctions against domestic violence are not consistently enforced, this can result in an informal endorsement of domestic violence, sending a message to perpetrators that assault against an intimate partner is not as serious as assault against a stranger (2005). The sanctioning of such conduct indicates that there is a subculture of violence in the relevant society which accepts men's violence against women (Buzawa \& Buzawa, 1996: 20; Anderson, 1997; Giles, Curreen \& Adamson, 2005). An example of this is inconsistent enforcement of protection orders by Police officers or failure to prosecute domestic perpetrators to the fullest extent of the law (Giles, Curreen \& Adamson, 2005: 107), which reinforces the belief that domestic violence does not have the same gravitas as assault on a stranger.

To render policy effective, researchers need to understand why some men become perpetrators and others do not. It is almost certainly an intersection of the factors identified in each of the three perspectives that leads to a relationship becoming abusive (Mears \& Visher, 2005: 209).

\section{The current perspective}

Literature suggests that different social structures, such as ethnicity/race, class, gender and sexual orientation, cannot be considered in isolation and 
researchers need to include considerations of all of the factors (Sokoloff \& Dupont, 2005). In this research, all of these factors will be considered. However, this study is rooted in a feminist perspective and stresses patriarchy as the most significant social structure and indicator of the prevalence of domestic violence, as it is patent that domestic violence is a gendered issue.

One study recently released in New Zealand on the role gender plays in domestic violence has suggested that it is not significant and that both men and women are equally violent in relationships (Fergusson, Horwood, \& Ridder, 2005: 1113). The authors utilised the Conflict Tactics Scale (CTS) to measure the number of violent outbursts by each individual in an intimate relationship. The use of the CTS has been strongly criticised for its simplicity and lack of contextualisation - by merely counting the number of violent acts committed during a conflict situation, it does not establish the presence of control, nor the reasoning or impact of said violent acts (Dobash \& Dobash, 1988: 59; Saunders, 1988: 91; Yllo, 1988: 41; Vivian \& Langhinrichsen-Rohling, 1996: 25). Similar early works by Straus (1980) and Gelles (1974) have merited the same conclusions. By contrast, there are many New Zealand statistics that reinforce the gendered nature of domestic violence:

- $\quad$ Of applications made for protection orders in New Zealand in 2004, 91 percent were female applicants (Bartlett, 2006: 36).

- Domestic violence has been found to affect 1 in 3 New Zealand women in their lifetime (Fanslow \& Robinson, 2004: 28).

- $\quad$ Fifty percent of female murders were related to family violence (Ministry of Justice, 2005).

- Women's Refuge constantly reports increasing numbers of women coming to them for help, and in the 2005/06 financial year reported over 20,000 new cases across their 50 refuges (National Collective of Independent Women's Refuges, 2006). 
Johnson suggests that domestic violence researchers should consider the proposition that there are two types of violence against women: one that is referred to as "patriarchal terrorism" and the other as "common couple violence" (1995: 283). Johnson submits that "patriarchal terrorism" is the domestic violence that feminist researchers, Women's Refuges, and others working in the field encounter (1995: 284). Patriarchal terrorism involves violence used systematically to gain control over a woman in an intimate relationship.

Johnson submits that the second type of violence, "common couple violence" is not gendered and is not used as a means of control but rather as an outlet for frustration. This is the type of violence that is reported to researchers using the CTS scale (Johnson, 1995: 285). Thus, the two sides of the debate are looking at different problems, one of common couple violence and one of domestic violence, and thus see very different results. This theory has received some recognition (Rhatigan, Moore \& Street, 2005: 84) and explains the vast differences in figures cited by the two sides of the debate. In effect, it invalidates the CTS as a measurement of domestic violence and supports the use of information derived from shelters and practitioners in the field.

Domestic violence is not only an issue in heterosexual relationships, and research has been conducted that shows non-heterosexual relationships can also be abusive (Brand \& Kidd, 1986; Gardner, 1989; Island \& Letellier, 1991; Lockhart et al., 2004). Domestic violence in non-heterosexual relationships is not examined in this thesis, however, this issue would be a worthwhile topic for future research.

As stated above, all the data received from those working in the field of response to domestic violence and service provision in New Zealand illustrate 
that domestic violence is highly gendered. For this reason and because of the feminist approach taken in this research, the focus of this work is on domestic violence against women during disasters in New Zealand and not violence against men. However, the study remained open to the factors listed in both the individual-based and societal-based perspectives as clear lacunae exist in all three perspectives, all of which fail to explain domestic violence in its entirety.

\section{Positive impacts of natural disasters}

As well as using a feminist perspective to look at how patriarchal divisions have an impact on domestic violence, previous studies have acknowledged one possible positive outcome that can come from experiencing a disaster. Overseas research has observed that domestic violence victims can feel empowered by the circumstance of being able to recover from a disaster and, consequently take steps to leave an abusive relationship (Enarson, 1999; Fothergill, 1999). This will be discussed in more detail in Chapter Seven in which I will analyse New Zealand evidence. This coincides with Umberson et al.'s perspective on personal control and domestic violence, in which, the disaster may empower the victim and this new found sense of control over their future may persuade the victim that they are no longer willing to accept violence (1998). Disasters thus present opportunities for domestic violence agencies to intervene, where asked, and it is crucial that they are both functional during disasters and operating at a high level of efficiency and effectiveness. Victims of domestic violence must feel able to leave and remain out of abusive relationships whilst also recovering from the direct effects of the disaster. Thus, promotion of domestic violence services during disasters so women who choose to leave the relationship or seek help for continuing the relationship safely are aware of how to access these is an important change to current practice if lessons from overseas are to be learnt in New Zealand. 


\section{Conclusions}

Both domestic violence and disasters are social issues. The impact of the two social phenomena intersecting allows for an examination of each and their relationship. Domestic violence and disasters have a complex and multi-layered relationship. Domestic violence can and does affect the way in which both victims and perpetrators of abuse respond to and recover from domestic violence. Many factors linked to domestic violence increase a person's vulnerability to a natural disaster by creating unsafe conditions (isolation, lack of economic resources, lack of social resources) because the victim of domestic violence has, in all likelihood, already been stripped of access to basic social networks. Heightened levels of vulnerability are a major issue and victims of domestic violence are seriously at risk during a disaster. For emergency management policy to be relevant to domestic violence victims, emergency management planners and emergency responders need to be aware of what domestic violence is, the impact it has on a victim's ability to respond to disasters, and any complicating issues that arise from the needs of a woman in a disaster who has left an abusive relationship.

The Pressure and Release model demonstrates the way in which an underlying patriarchy can lead to unsafe conditions that put women at greater risk than men during disasters. In particular, this study focuses on the way in which domestic violence acts as a "dynamic force" within the model to put domestic violence victims at a high level of risk during disasters. It is not an exaggeration to say that this risk can mean the difference between life and death. The root causes of domestic violence are social stratification, predominantly gender, but juxtaposed with other structures in the society, including political, economic, legal and other social structures. These strata are implicit in wage-gap figures (Statistics New Zealand, 2006), and, related to this 
research, domestic violence figures (National Collective of Independent Refuges, 2006). Patriarchy permits men to use domestic violence (whether physical, psychological or economic) to dominate their female partner. In turn, domestic violence creates unsafe conditions, such as isolation (Stets, 1991: 670) and a lack of access to resources and decision-making (Hague \& Wilson, 2000: 164) that mean victims of domestic violence are at a higher risk than some other groups within society when disaster strikes.

Domestic violence has been shown to impact clearly on disasters. However, domestic violence is also affected by disasters. The loss of control felt by abusers during a disaster, or perhaps the removal of existing outlets for their frustration and anger, may cause an increase in domestic violence (not merely reporting) during a disaster. Fothergill's work (1999) with women who experienced a coincidence of a disaster and domestic violence highlighted the change in the nature and intensity of abuse in the relationships during the observed disasters. The disaster may also empower women and influence decisions to stay or leave the abusive relationships (Fothergill, 1999).

The relationship between domestic violence and disasters is clearly multifaceted. Policy needs to acknowledge this complexity in order to address the differences in risk level created by the intersection of these two social issues, and to be effective and relevant to all those it covers. Emergency Management policy seeks to enable a community to recover from an event and, therefore, should be inclusive of all members of that community. Therefore, if domestic violence does increase following a disaster, policy must adapt to reflect this and respond to the special needs that women in or leaving abusive relationships may require. Against the background of the theoretical and empirical basis described above, this research will examine whether domestic 
Chapter 2

violence reporting in New Zealand increases during disasters. Prior to discussing the results of the research in the following chapters, Chapter Three will focus on the appropriate methodology and methods to undertake such research. 

Chapter Three: Methodology 

A theoretical and empirical case has been presented in the previous chapter that reported levels of domestic violence may increase in the aftermath of disasters. In the next phase of this research, I identified the appropriate methodology and methods to test out the impact of Civil Defence emergencies on domestic violence in New Zealand. This chapter will outline the methodology and methods used in the following research. The approach of this research is feminist and, therefore, the chapter begins with a discussion of the basic principles of a feminist methodology and how they were applied to this study. Next, the chapter covers the three previous studies (which linked the incidence of domestic violence and natural hazards in Canada and the United States) that provide the foundation for developing methods for this research. The last section of the chapter addresses the research design, including the methods used in this work, the ethical obligations of researching domestic violence, and a description of the acknowledged limitations of the research.

In establishing which methods to adopt and in what fashion, the aims of the research must be well-understood or results could be flawed by the omission of critical questions germane to the study. This line of research should begin by establishing whether the incidence and nature of domestic violence increases after disasters in New Zealand. If an increase is observed, the research can then move to understand the determinant factors that are at play, and if there are structural and policy factors that can either reduce the incidence of domestic violence or ensure that frontline agencies are better equipped to deal with this consequence of natural disasters.

\section{Methodology}

The term methodology has been used interchangeably to describe different aspects of research, from the finite elements of research design to the broad 
approach taken to the research as a whole (Landman, 2006: 429-430). In this thesis, the term methodology is used to describe the approach to the research and the way in which the methods used in the research relate to the underpinning theoretical framework. The theoretical and methodological orientation of this research is feminist, and specifically sits in the field of gender and disaster. Gender and Disasters is a field that aims to underscore the role that gender plays in all aspects of natural disasters: planning, response and recovery (Honeycombe, 1994; Fordham, 1998; Wilson, Phillips \& Neal, 1998; Enarson, 1999; Enarson \& Scanlon, 1999; Fothergill, 2004). Whilst this research focuses on gendered vulnerability, gender and disaster researchers also target gendered strengths. Through examination of a specific vulnerability, domestic violence, some of the gender-based strengths also became apparent (Enarson, 1999).

\section{Feminist methodology}

This research is feminist research in the same vein as Enarson (1999), Fothergill (1999) and Fisher (2005). As previously noted in Chapter One, I am primarily concerned with domestic violence against women, and whether this will bias the impact of a disaster to disproportionately and adversely affect women.

Feminist methodology is a broad term, and, over time, the definition of what is or is not feminist methodology has changed considerably (e.g., Millman \& Kanter, 1975; Smith, 1979; Cook \& Fonow, 1986; Cancian, 1992; Griffiths \& Hanmer, 2005; Skinner, Hester \& Malos, 2005). The literature indicates a general consensus that there is no single, unified feminist methodology, which is coupled with the absence of a single, unified feminist theory (hooks, 1984; Ramazanoglu, 1992; DeVault, 1996; Eichler, 1997; Renzetti, 1997; Fonow \& Cook, 2005). However, five key characteristics of feminist methodology have 


\section{Chapter 3}

been commonly agreed upon (Renzetti, 1997: 133; Skinner, Hester \& Malos, 2005: 10; Landman, 2006: 431). I will discuss each of these and highlight how they are reflected in the methods of this research.

The first principle is that feminist research is concerned with gender and gender inequality (Ramazanoglu, 1992; DeVault, 1996; Eichler, 1997; Renzetti, 1997: 133; Fonow \& Cook, 2005; Skinner, Hester \& Malos, 2005: 10; Landman, 2006: 431). It is important to recognise the distinction between a person's sex and his or her gender. A person's sex refers to the biological dichotomy used to describe their genitalia - either man or woman (West \& Zimmerman, 1987: 127; Ridgeway \& Smith-Lovin, 1999: 192). A person's gender refers to the socially ascribed and created category people are placed into - masculine or feminine (Ridgeway \& Smith-Lovin, 1999: 192; Ridgeway \& Correll, 2004: 510). This definition of gender focuses on a performative state that individuals are socialised into believing can be achieved by following roles and norms in interactions with other people (West \& Zimmerman, 1987: 126; Stets \& Burke, 1996; Litton Fox \& McBride Murry, 2000: 1163; Risman, 2004: 430). Individuals typically strive to gain approval by acting in gender-appropriate ways (West \& Zimmerman, 1987: 139; Ridgeway \& Smith-Lovin, 1999: 192; Messerschmidt, 2009: 86).

Gender inequality refers to the unequal outcomes that stem from these gender roles and norms (Wood \& Eagly, 2002). Most commonly, gender inequality refers to a situation where masculinity is privileged and, as a consequence, most women experience lesser opportunities and, in some instances discrimination (Stets \& Burke, 1996; Ridgeway \& Smith-Lovin, 1999; Wood \& Eagly, 2002). Gender stratification is another term used to describe a situation in which the structure of gender in society creates inequalities. This is typically 
reflected in income disparities, childcare arrangements, violence, and the division of labour (Collins et al., 1993; Ridgeway \& Smith-Lovin, 1999).

Domestic violence is an area where gender inequality is clearly evident. As previously noted, women accounted for $91 \%$ of the applicants for protection orders in New Zealand in 2004 (Bartlett, 2006: 36) and every year Women's Refuge reports working with tens of thousands of women (National Collective of Independent Women's Refuges, 2008). One of the key goals of this research is to examine this gendered inequality in the context of the additional stress posed by natural disasters and the role that an underlying gender stratification within New Zealand plays in the aftermath of natural hazard events.

The second principle is that feminist research has the goal of giving voice to the experiences of women and other marginalised groups (Eichler, 1997; Renzetti, 1997: 133; Fonow \& Cook, 2005; Skinner, Hester \& Malos, 2005: 12; Landman, 2006: 431). Domestic violence victims are a group of marginalised women. Whilst in an abusive relationship, women are often isolated from society, friends and family, and denied access to other resources such as family finances and assets. This limits or entirely negates the power these women possess both within the home and in wider society. This research strives to vocalise the experiences of these women that are currently not included in any meaningful way in New Zealand Civil Defence practice and policy. However, the stories of women's experiences are conveyed through agency representatives in this research and thus, are subject to interpretation, which must be acknowledged.

This research presents the experiences of both domestic violence victims, and the women (and men) working to help them, through the narratives of domestic violence agencies. Insofar as it has been possible, I have quoted sources 
directly, rather than paraphrasing into my interpretation of what the sources can impart. Initially I had hoped to speak to the victims of domestic violence directly. However, this was not possible, and therefore, the stories have been told through the agency workers and, in particular, through Women's Refuge workers (a voice that can be marginalised) who had the most insight into the women's needs and experiences. Currently, the experience of New Zealand women subjected to domestic violence during disasters is not known. This thesis aims to shed some light on this. Future research may be able to obtain these stories directly from the women and build on what is presented in this research.

The third principle of feminist research is a commitment to using the research to bring about social change and the understanding that as a consequence there is, a priori, an aspect of political activism to the work (Ramazanoglu, 1992; Thompson, 1992; Eichler, 1997; Renzetti, 1997: 133; Fonow \& Cook, 2005; Skinner, Hester \& Malos, 2005: 14; Landman, 2006: 431). As Ramazanoglu (1992) states, domestic violence research can never be apolitical, domestic violence is a highly politicised issue and one in which gender inequalities are highly evident. Moreover, any research that evaluates policy and highlights shortfalls in current practice will involve a degree of political activism. This research primarily evaluates Emergency Management policy to establish whether the policy makers and planners have contingency structures in place to ensure that local agencies have the resources to cope with potential influxes in domestic violence cases. It also looks at agency protocols to examine whether agencies themselves are adequately prepared for a disaster. However, I hope that this research will not conclude with making recommendations. In accord with the third principle, once the study is completed, if increases are observed that are not adequately dealt with, I will 
work to ensure the results reach those in a position to action the necessary changes.

In this regard, during the interviewing process there was a significant raising of awareness for both myself and for the interviewees. In discussing the impacts that could have occurred following the recent Civil Defence emergencies and the gaps in current planning, many interviewees clearly began to see a need for planning in the future. For policy and planning changes to be effective they must be accepted at all levels from the national level to the operational, local level. This cannot be achieved by simply sending a new policy document out to local agencies. To attain a level of investment from local agencies, I have asked for and integrated their views as to what is feasible and necessary in a revised policy or plan. This will be discussed further in Chapter Eight.

The fourth principle central to feminist work is that the research has reflexivity (Eichler, 1997; Renzetti, 1997: 133; Litton Fox \& McBride Murry, 2000; Fonow \& Cook, 2005; Skinner, Hester \& Malos, 2005: 15; Landman, 2006: 431). Reflexivity requires that the researcher stand back from and examine the impact that the actions of the researcher have on the research. Feminists believe that research cannot be completely objective, and that a researcher's values, judgements and beliefs influence the final product of the research. In recognising and acknowledging my own background and potential biases from the beginning of the research, I am acknowledging that this research is not completely value-free and, as with all research, is not entirely objective but rather it is subject to my and others' values and assumptions. However, this subjectivity does not reduce the validity of the research. In fact in acknowledging this level of subjectivity, which is present in all research (Landman, 2006: 431), I am increasing the robustness of the study. 
As a feminist researcher with a background in Sociology and Economics, my focus in this research has been on domestic violence committed by men against women in heterosexual relationships. One of my first jobs as a teenager was working for my father, a physical volcanologist, conducting experiments to gauge the density of rocks. It was repetitious work that involved 100 rocks per sample and was solely quantitative. However, as I progressed through my studies at University, I came to appreciate the value that qualitative data brought a richer picture of what an event was like to experience or the relationships involved in a situation, among other things. This background has meant I value both quantitative and qualitative methods in research. Whilst feminist research has historically rejected quantitative research, more recently feminists have argued that the use of quantitative methods with qualitative methods is still in line with feminist methodology (Smith, 1990; Mattingly \& Falconer-al-Hindi, 1995; McLafferty, 1995; Oakley, 1998). My interpretation of the data examined in this thesis is also affected by this background, and as such the results of the research are also affected.

Finally, feminist research rejects the traditional dynamics of balance of power between researcher and the subjects of the research, and instead chooses an approach that empowers the subjects by giving them a greater degree of influence in research design and reporting (Thompson, 1992; Eichler, 1997; Renzetti, 1997: 133; Litton Fox \& McBride Murry, 2000; Fonow \& Cook, 2005; Skinner, Hester \& Malos, 2005: 11). This can be contentious if the researcher and the subject disagree over interpretations and can create a conflict of interest for the researcher who desires preserving rapport and goodwill with their research subject but also wishes to express their opinion (Skinner, Hester \& Malos, 2005: 11). Reinharz (1992) argues that the use of open-ended 
questions is a way to mitigate some of the power-differential in an interviewing relationship as it allows for the interviewees to direct the discussion, rather than the interviewer doing this. This method was incorporated into this research; all interviews involve open-ended questions as a way of challenging the traditional power dynamics between myself and the interviewees.

The process of incorporating the needs, knowledge and interests of the agencies involved in my study began during the first stages of the research. I approached the national bodies of all participating agencies and asked them what they would want from this research. This information was collated and incorporated into the research design. As well as incorporating the perspectives of participants in the design phase of the research, the instrument used was semi-structured interviews that allowed participants some flexibility to discuss the key issues they observed, whilst ensuring I covered the basic topic areas that came out of the design phase. Semi-structured interviews are particularly valuable when research is aimed at developing an issue rather than attaining a yes/no answer (May, 1998). Throughout the interviews, I was careful to maintain the position of an interested student (which I am), rather than an "expert", a measure that reduced the potential power differential between interviewer and interviewee.

A tension that has existed throughout this research is how to incorporate the feminist methodology that I employ effectively whilst still maintaining research that is accessible to policy makers and analysts. This tension is not rare, feminist scholars have noted the competing needs that occur between feminist research and other methodologies (McRobbie, 1982, 46; Maynard, 1994: 24; Devault, 1996). This factor has influenced both the research design and the way in which the results are presented. However, in making this thesis 
accessible to policy makers and analysts, I am meeting the third principle of feminist methodology discussed above, that the research has the goal of bringing about social change. The next section will discuss the methods used to meet these competing needs.

\section{Research Methods/ Design}

This research is designed to establish whether the current emergency management policy and planning is appropriate for the actual impact of natural hazard events on incidences of domestic violence. Very little research has been conducted on what is potentially a very serious consequence of natural hazards for many women in New Zealand. In undertaking this research, it was hoped that if increases are identified, suggestions for amendments to emergency management policy and planning can be formulated, making both more realistic and relevant for New Zealand society. If the recommendations are accepted, this should create a more well-rounded approach to emergency management policy and planning. The aim is to foster and encourage policy and planning that will allow government and non-government agencies access to the resources to better prepare for and to mitigate the effects of such an event. There are two main objectives:

- To determine whether there is evidence of an increase in the incidence of domestic violence following natural hazards in New Zealand, through a national postal survey and statistics collation, case studies of five affected communities, and interviews with representatives of response agencies within those communities.

- To ascertain whether there is adequate provision in New Zealand emergency management policy and planning to assess and respond to potential increases in the incidence of domestic violence and, if not, to formulate suggestions for amendments to emergency management policy and planning.

In deciding on the methods used to investigate increased domestic violence reporting after disaster in New Zealand, previous studies undertaken on the 
topic were examined for insight into which methods were successful. As noted in Chapter Two, there had been four studies conducted prior to this research specifically on domestic violence and disasters (Wilson, Phillips \& Neal, 1998; Enarson, 1999; Fothergill, 1999; Jenkins \& Phillips, 2008). This thesis uses methods from all four studies to gain a comprehensive picture of the situation in New Zealand with regard to domestic violence reporting in disasters. It does this in two phases. The first is a survey of social service agencies in areas affected by Civil Defence emergencies in New Zealand in the last ten years. This method was utilised by Enarson in her study of domestic violence reporting in the United States and Canada (1999). The survey was completed first and provided input for the selection of the case studies, a method also employed by Enarson (1999). The second is five detailed case studies of communities affected by a Civil Defence emergency in the last five years. This involves interviews with agency representatives from both domestic violence agencies and Civil Defence welfare organisations, and the collection of statistics from domestic violence agencies in the areas under consideration. Agency interviews were undertaken in Enarson's work (1999), Wilson, Phillips \& Neal's study (1998) of agency response to domestic violence in three communities in the United States, and in Jenkins \& Phillips' study (2008) of domestic violence after Hurricane Katrina. The collection of agency statistics was included in all four previous studies (Wilson, Phillips \& Neal, 1998; Enarson, 1999; Fothergill, 1999; Jenkins \& Phillips, 2008).

Overall, the thesis involves a mixed-method approach. Part of this research involves analysis of quantitative data - the use of descriptive statistics from the Women's Refuge database to evaluate the scale of any increases found in caseloads after data analysis, and a postal survey with both open and closed ended questions. Quantitative data has been viewed by some feminist 


\section{Chapter 3}

researchers as positivistic and full of false claims of objectivity, having little to offer the field of social science (Smith, 1990; Mattingly \& Falconer-al-Hindi, 1995; McLafferty, 1995; Oakley, 1998). This is due, in large part, to its ties to early social science research that did not include women or capture their experiences of social phenomena (Oakley, 1998). However, feminist research has evolved from involving only qualitative data, through the utilisation of descriptive statistics, to finally incorporating quantitative data (Smith, 1990; DeVault, 1996: 35; Griffiths \& Hanmer, 2005: Sharp, 2005: 305). This inclusion has not been welcomed by all feminist researchers (Thompson, 1992; Mattingly \& Falconer-al-Hindi, 1995; McLafferty, 1995; Oakley, 1998). However, quantitative data has been used in domestic violence and policy research, both relevant areas to this thesis (Straus et al., 1980; Straus \& Gelles, 1986; Smith, 1990). Quantitative data is critical in the area of policy evaluation and research, especially in a time where evidence-based reporting is increasingly popular (Packwood, 2002; Taylor, 2005). Reported changes (in this case in reported levels of domestic violence) must include a level of quantification if analysts and government agencies are to seriously consider the issue (Packwood, 2002; Taylor, 2005).

C. Wright Mills argues that whilst quantitative data can be numerically and statistically accurate, it may not reflect the reality of a situation (1959). As a result, the policy derived from this information alone will prove ineffective. Qualitative research may offer a more complete and salient perspective for a particular situation, especially in domestic violence where the quality and scope of record-keeping are varied (Bouma, 1996; Oakley, 1999). In this research, qualitative methods were used to record the experiences of agencies and individuals post-event and their impressions of what they believe could enable them to cope better with future events. Qualitative research was particularly 
suited to this phase of the research as there had been no prior work undertaken on this subject in New Zealand. Statistics in isolation give limited insight into the lived experience of a Civil Defence emergency.

\section{Phase 1: Survey}

The first approach was a postal survey of agencies that provide social services in all areas that have been affected by a Civil Defence emergency in the last ten years. In communities that have been affected by multiple events, only the most recent event was chosen. This left 17 events, which are listed below:

Table 1: Natural Hazard Events in the last ten years where Civil Defence Emergencies were declared

\begin{tabular}{|l|r|}
\hline Ruapehu Eruption & June 1996 \\
\hline Northland \& Pukekohe Floods & 22 January 1999 \\
\hline Dargaville Floods & 18 April 1999 \\
\hline Clutha District Flooding & 17 November 1999 \\
\hline Central Otago Flooding & 17 November 1999 \\
\hline Queenstown Lakes District Floods & 1 December 1999 \\
\hline Thames/South Waikato Weatherbomb & 21 June 2002 \\
\hline South Taranaki Storm & 17 February 2004 \\
\hline Marlborough Storm & 17 February 2004 \\
\hline Hawke's Bay Flooding & 18 October 2004 \\
\hline Lower North Island Storm & 15 \& 16 February 2004 \\
\hline Eastern Bay of Plenty Floods & 17 \& 19 July 2004 \\
\hline Dunedin Rain Storm & 7 February 2005 \\
\hline Greymouth Tornado & 10 March 2005 \\
\hline BOP Tauranga / Matata Flooding & 18 May 2005 \\
\hline Gisborne/East Cape Flooding & 23 October 2005 \\
\hline Oamaru/Timaru Snowstorm & 12 June 2006 \\
\hline
\end{tabular}

The surveys served two purposes; first, they captured more communities than interviewing would allow and secondly they acted as a filter for the selection of communities for the case studies. The surveys also satisfied a need in that decision-makers want research representative of a range of people and communities to ensure that policy will apply to a majority of the people affected by it (Baehler, 2003). 


\section{Chapter 3}

Agency selection for the survey phase was done by focussing on the epicentre of the emergency, then widening the area to gauge whether impacts were localised or if there was "ripple" effect extending into other communities. Many sources were used to identify those agencies in each area that dealt with the victims and perpetrators of domestic violence following the respective events. A number of online directories were searched in the selected communities (Families \& Communities, 2006; NZ Yellow Pages, 2006). A check made of the websites of government agencies such as Work and Income NZ, Child, Youth and Family, and the New Zealand Police, as well as non-government agencies such as Women's Refuge, Relationship Services, the Open Home Foundation, Plunket, and National Network of Stopping Violence Services, ensured that no agencies were overlooked. Across the 17 communities affected by Civil Defence emergencies, 601 government and non-government agencies were identified as relevant to the research.

Postal surveys consistently have a low rate of return. In this research, this was dealt with by despatching a second repeat survey to those that did not respond by the deadline, together with a second reminder letter. This is in keeping with Fowler's suggestions of approaches to increase the response rate (2002). This was successful in creating a second wave of surveys after the reminder letter was received. The second wave was smaller than the first (for the total response rate, see page 62). However, it was clear the letter had made a difference in at least a proportion of the second wave as some survey respondents noted the letter or returned it with the survey.

A further strategy to improve response rates was to gain national-level support in agencies such as Work and Income New Zealand, New Zealand Police, and Women's Refuge. Covering letters of support from Chief Executives were 
attached to letters to members of the National Network of Stopping Violence Services and the National Collective of Independent Women's Refuges. These were sought on the assumption that if a national office gave backing to the research, local agencies might be more willing to participate than if they were simply contacted by an unknown researcher from outside the community. Contact with the New Zealand Police and Work and Income were made through a representative at each national office who assisted in sourcing the appropriate interviewee and initiated contact.

The time window of selecting areas affected by disasters during the previous ten years was selected as the surveys depend on current members of staff being present during the emergency, and also on the accuracy of their memories of events. It was assumed that events that occurred over ten years ago would be too far back to be remembered without any sort of documentation and it was already known that record-keeping in domestic violence agencies was not formalised until after this time. This was established in previous discussions with national-level representatives of the agencies in the initial stages of the research formulation (as mentioned on page 64).

The survey involved 30 questions and combined the use of quantitative questions and qualitative questions as to the impact any change had on the agency. The questions included both closed- and open-ended examples; the latter allowed respondents to give wider perspectives on issues such as preparedness and the size and duration of any changes, as well as articulate their understanding of these changes (see Appendix A).

Another section of questions asked about the preparedness of agencies for the primary impacts of the hazard events and their preparedness for an increase in 
domestic violence following a disaster. Finally, the survey asked participants to list other agencies they had worked with in this field. This gave a picture of the extent of networks at the local level and highlighted any lacunae that need to be filled to ensure the agency response is broad enough to catch as many women as possible at any stage (i.e., before, during, and after violence occurs).

In total, there were 601 surveys sent and 122 replies, a response rate of $20 \%$. This was a good result given that the questionnaires were relatively detailed and that many NGO agencies are under-resourced. Survey responses were coded into SPSS for analysis. The SPSS analysis was confined to frequency calculation and simple comparisons, as this research is predominantly qualitative and the primary purposes of the survey were to provide an overview of as many events as possible in New Zealand and aid in the selection of case study sites.

Table 2: Numbers of Returned Surveys for Each Event (during 2006)

\begin{tabular}{|l|r|r|r|}
\hline Event & $\begin{array}{l}\text { Non- } \\
\text { government } \\
\text { agency }\end{array}$ & $\begin{array}{l}\text { Government } \\
\text { agency }\end{array}$ & \multicolumn{2}{l|}{ TOTAL } \\
\hline Ruapehu Eruption & 4 & 1 & $\mathbf{5}$ \\
\hline Northland \& Pukekohe Floods & 4 & 0 & $\mathbf{4}$ \\
\hline Dargaville Floods & 3 & 0 & $\mathbf{3}$ \\
\hline Clutha District Flooding & 1 & 1 & $\mathbf{2}$ \\
\hline Central Otago Flooding & 3 & 1 & $\mathbf{4}$ \\
\hline Queenstown Lakes District Floods & 1 & 0 & $\mathbf{1}$ \\
\hline Thames/South Waikato Weatherbomb & 13 & 2 & $\mathbf{1 5}$ \\
\hline South Taranaki Storm & 7 & 1 & $\mathbf{8}$ \\
\hline Marlborough Storm & 13 & 2 & $\mathbf{1 5}$ \\
\hline Hawke's Bay Flooding & 2 & 2 & $\mathbf{4}$ \\
\hline Lower North Island Storm* & 32 & 5 & $\mathbf{4}$ \\
\hline Eastern Bay of Plenty Floods* & 4 & 0 & $\mathbf{4}$ \\
\hline Dunedin Rain Storm & 4 & 0 & $\mathbf{3}$ \\
\hline Greymouth Tornado & 2 & 1 & $\mathbf{3}$ \\
\hline BOP Tauranga / Matata Flooding & 0 & 3 & $\mathbf{9}$ \\
\hline Gisborne/East Cape Flooding & 1 & 1 & $\mathbf{1 2 2}$ \\
\hline Oamaru/Timaru Snowstorm* & 8 & $\mathbf{2 0}$ & $\mathbf{1 0 2}$ \\
\hline TOTAL & $\mathbf{1 3}$ & & \\
\hline
\end{tabular}

*Areas chosen for the case study phase of the research 
Responses were received from a variety of agencies, both governmental and non-governmental (see Table 2). Within the non-governmental group there were domestic violence agencies, faith-based welfare organisations, and agencies working specifically with Maori (New Zealand's indigenous people).

This research suggested that because the surveys rely on the memories of individuals, research must follow shortly after the event. Comments on many survey responses showed that record keeping has been limited as had been noted by head offices. It would seem that past events are likely to yield poor and incomplete results as staff move and people forget. This was observed in the survey phase. Therefore in the case studies, a limit of five years prior was put in place. The time window of five years allowed me to capture enough data to draw conclusions confidently about what happened at the time of the disaster.

\section{Phase 2: Case Studies}

Once the survey provided an overview, I utilised five case studies to examine the issue of increased domestic violence reporting during disasters more thoroughly. The five case studies are examined in detail in Chapter Four. A case study is "an empirical inquiry that investigates a contemporary phenomenon within its real-life context, especially when the boundaries between phenomenon and context are not clearly evident" (Yin, 2003:13). Case studies have been shown to be particularly useful in looking at issues that have been neglected in earlier research (Yin, 2003). There are only four published studies with a specific focus on domestic violence during and after disasters and none of these studies are particular to New Zealand. For this reason, multiple cases studies, is an ideal method for this research. Use of multiple 
case studies achieves a greater level of consensus and generalisation than available from any one case study (Gerring, 2004).

Case studies need to have clear boundaries defining what is being examined (Yin, 2003; Gerring, 2004). This ensures that the focus is not lost when utilizing a holistic approach, examining every aspect of the case from as many angles as possible and using multiple types of data (Yin, 2003). The case studies in this thesis utilised a mixed-method process that combines quantitative and qualitative data to establish whether reported cases of domestic violence increase after natural disasters in New Zealand, and understand what both agencies and individuals went through after the hazard event. Understanding these issues and the relationships involved is central in creating policy that is both relevant and realistic. Berg (1998) argues that a triangulation of methods gives three complimentary perspectives that is more likely to represent the situation correctly. This research uses four different methods, two quantitative and two qualitative, to gain insight into domestic violence increases after disasters.

\section{Statistics}

The first data set within the five case studies is the collection of statistics from Women's Refuge at a local and nationwide level. Women's Refuge is a nongovernment organisation in New Zealand that provides both crisis response and prevention services for women and children affected by domestic violence (Buckley, 2008). Women's Refuge has a database that all clients are entered into at a local level. Each individual Refuge can then produce summaries of the number of clients during a particular period, delineated by a specified set of criteria including ethnicity, service type and age. Each local database is then transmitted to the national office for collation, which allows a national picture 
to be built. This established whether any local increases in domestic violence reporting found in the months following each disaster were part of a national trend, or if they were isolated events and thus may correlate with the impact of the associated disaster. This quantified the increases, if any, and established the duration of any effects.

Attempts were also made to attain statistics from the New Zealand Police. However, following discussions, it was decided not to present these within the results of the study. New Zealand Police statistics are not suitable for simple time-series analysis due to ongoing changes in categorising and recording methods, and random shifts related to the training of new officers. There have not been a sufficient number of Civil Defence emergencies in the period since the New Zealand Police's database's creation and, therefore, this was not a feasible task to complete.

As already noted, the type of quantitative data gathered from Women's Refuge appeals to policy-makers and planners that are concerned with funding agencies in the aftermath of disasters, as well as those with a preference for having tangible statistics to incorporate in policy debates. The value of qualitative and anecdotal data is not as strongly recognised, or as appealing politically (Baehler, 2003: 30).

Women's Refuge statistics were collated into Microsoft Excel spreadsheets and simplified to the number of cases each month for the period two years before and two years after the events. This was then graphed to illustrate any peaks or drops in the number of reported cases of domestic violence in communities. The qualitative data permits the identification and elimination of those increases due to other exogenous factors such as an increased awareness of 


\section{Chapter 3}

the agency, a high-profile case in the media or a new media campaign. The quantitative data alone gives little insight into what is happening in the community. It is the interviews in the final stage of the research that add substance to the quantitative figures taken from the Women's Refuge database.

\section{Interviews}

Interviews provide the largest amount of data of the four methods used. There were three types of interviews - one at the national organisation level, one at the community agency level and, finally, a small number of interviews with women living in rural areas in two of the case studies. Interviews were used in all four previous studies on domestic violence and disasters (Wilson, Phillips \& Neal, 1998; Enarson, 1999; Fothergill, 1999; Jenkins \& Phillips, 2008) and provided the benefit of allowing readers to hear the voices of those affected by disasters, rather than relying on the researchers' interpretations. In deciding which methods to use, this was considered one of the most useful and advantageous as feminist research aims to give voice to marginalised groups as part of its fundamental values.

The first set of interviews to take place (see Table 3) was with representatives of frontline agencies for domestic violence crisis response and other agencies who deal with domestic violence in a secondary role, such as through education programmes or by providing one-on-one counselling. The agencies were used to identify commonalities between cases, such as demographics, extent of loss, levels of insurance, and of family and outside support, that explain rises in reporting of domestic violence. These issues were all potential factors explored by the interviews. 
Of the five case studies, four of the interview sets took place between 2007 and 2008 in Palmerston North/Feilding, Lower Hutt, Masterton and Timaru. The other set of interviews in Whakatane took place in 2005 as part of an Honours dissertation. The data gathered in the Whakatane interviews has been included in this thesis and expanded upon with other forms of information such as the case files summaries, which are described below.

All interviewees were given an information sheet on the research and asked to sign a consent form (see Appendices B \& C). Interviews were semi-structured but flexible enough to allow any extra input the individuals had to contribute and most lasted approximately an hour. These were transcribed by myself for a thematic analysis.

The use of interviews in evaluating historical events is one form of an oral history (Geiger, 1986: 336). It is a method that has been both advocated for and contested by researchers (Berger Gluck \& Patal, 1991; Thomson, 1998; Kirby, 2008: 23). Early feminist researchers found the use of oral history a necessary method as much of the early written material did not include the perspectives of women, issues that affect women, or their stories (Berger Gluck \& Patal, 1991: 9; Anderson \& Jack, 1991: 11; Bornat \& Diamond, 2007: 21). Interviewing is a technique that is informed by culture, which dictates forms of both oral and other communication (Thomson, 1998: 582), which means that in conducting interviews, researchers must at all times be aware that an interview method that may work perfectly with one individual will not necessarily engender the same response from another (Minister, 1991: 31; Thomson, 1998: 583). 


\section{Chapter 3}

A consideration discussed by researchers who utilise oral history or interviewing in their research is that of memory and its subjectivity (Geiger, 1986; Thomson, 1998; Kirby, 2008). In the 1970's interviews with individuals on historical events were criticised in three areas:

1. Physical deterioration and nostalgia;

2. Personal bias of both the interviewer and interviewee;

3. And the influence of collective and retrospective versions of the past.

(Thomson, 1998: 584; Kirby, 2008: 24-27)

Physical deterioration and nostalgia refer to either the forgetting of or the romanticising of details that can occur in individuals that can create a distorted view of the event being discussed (Polishuk, 2005; Kirby, 2008). Personal bias of both the interview and interviewee refers to the agendas of each side of the interview (Polishuk, 2005). These agendas are suggested to reduce the reliability of the data being given and presented as either or both of the parties involved may be using the interview to get across a particular message which may not be accurate (Polishuk, 2005; Thomson, 2006: 61; Kirby, 2008: 25-26). The influence of collective and retrospective versions of the past refers to an individual's memory being informed by subsequent information they have collected since the event itself, which in turn changes their memory of the event being discussed (Thomson, 1998: 585). Thus, rather than relating the event in an objective manner, the data gained from an interview is subjective (Kirby, 2008: 27).

Initially, work began on how these criticisms could be mediated and what methods could alleviate these criticisms of the method (Thomson, 2006: 54). However, in the late 1970's, these suggested shortfalls of the method were challenged and argued to be strengths (Sangster, 1994: 6; Thomson, 1998: 
584; Bornat \& Diamond, 2007; Thomson, 2006: 54) and the benefits of gaining access to information that is not usually recorded arguably outweigh issues with the method.

Frequently, oral histories are used in conjunction with other data sources in establishing the events that occurred at a particular time and the implications of these events on individuals involved (Geiger, 1986: 337; Thomson, 1998: 585). This was seen in some of the interviews in this research, where interviewees required documentation (mostly monthly statistics from their respective databases, but also minutes from meetings) to remind them of the events, issues and solutions arising during the disaster in their area. Added to this, in this research, a triangulation of data is used to compare the data from the interviews with other sources. The data from statistics and case files summaries are used to provide a quantitative base. The interviews are used to provide context and an understanding of what it was like on the ground after Civil Defence emergencies for agency representatives. 
Chapter 3

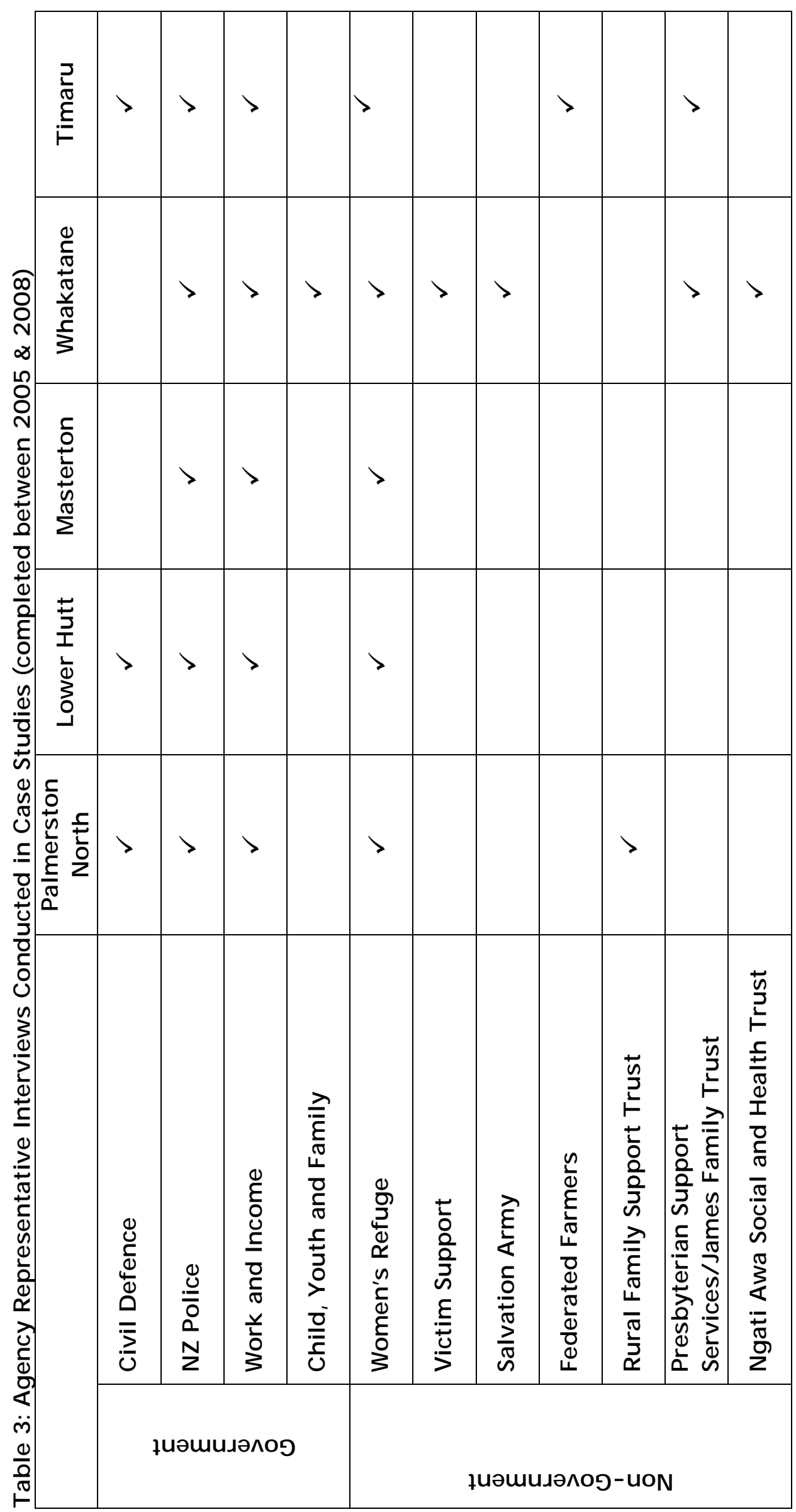


The nature of domestic violence and the associated social stigma means that it is hard to quantify the level of violence. One of the few ways to do this is through levels of reported cases, although this is an under-representation of true levels of violence, as the majority of domestic violence cases are largely unreported (Mayhew \& Reilly, 2007: 35). However, often data gathered from those working in the field has been treated with contempt and there has been a reluctance to trust this perspective as it is considered to be influenced by the aims of the interviewee (Yllo, 1988: 43). Researchers have historically been reluctant to utilise the analyses of field workers as their perspectives have been criticised as unscientific and politically motivated. Yllo advocates for the dismissal of such prejudice in feminist research (1988: 44). These workers are in the unique position of seeing multiple cases daily, which gives them a rare and highly valuable insight into any commonalities between cases that cannot be seen from a more distanced position.

As with the survey phase, agencies were also asked about their relationships with other agencies in the context of both referrals and joint projects. The aim was to build an accurate picture of the complexity within each community and establish the way in which inter-agency relationships are built and managed. Inter-agency relationships are vital to successful response to domestic violence, as no agency has yet managed to end or even curtail violence in a community on its own. The focus of domestic violence response has now moved to intersectoral approaches that aim to catch at-risk families through a variety of avenues: education, health, justice, and governmental and non-governmental institutions. This approach holds the most promise, although it has yet to be fully realised in any community (Kelly, 2004; Robinson, 2006; Hague \& Bridge, 2008). 
As the research progressed, the need for interviews with national level policy makers and planners became apparent. The resulting policy recommendations are aimed at being multi-level including national and community. To gain perspective on what was feasible and what is currently known at a national level about the rates of domestic violence after Civil Defence emergencies, it was decided to include a second tier of interviews with national level representatives.

Through the interviews and survey, a clear picture of the key agencies that are involved in responding to increased domestic violence cases was formed. This guided the choices for the national level interviews. There were three significant organisations involved that were interviewed in this study:

- New Zealand Police

- Ministry of Civil Defence and Emergency Management

- Women's Refuge

Interviews were again semi-structured and involved questions about the national-level role in response and recovery from Civil Defence emergencies, and levels and perceptions of increased domestic violence. For Women's Refuge and the New Zealand Police, a portion of the time was spent discussing their specific continuity planning to enable them to continue providing services during medium- and large-scale Civil Defence emergencies. The interview with the Ministry of Civil Defence and Emergency Management focussed on the institutional understanding of domestic violence and on the role that they see Civil Defence playing in dealing with increased domestic violence after emergencies. The different focuses were designed to gauge what each organisation knew about the other's work in order to create a base level for future discussions to begin from. 
The interviews were also an opportunity to allow input from these agencies into the final policy recommendations in keeping with the feminist approach, whilst at the same time raising awareness of the issues at hand in the hope of planting a seed to initiate social change. Gaining recognition from governmental and non-governmental agencies that domestic violence is a significant issue and one that is worth the effort of policy reform is a vital first step in using this research to make changes to bridge the gap between current policy and the actual reality of what is occurring on the ground during disasters.

All interviews were transcribed and sent to participants to check for factual accuracy and final review before being analysed. Analysis of the interviews took the form of establishing whether there had been a change in the agency workloads and then collation of common themes. Interviews were placed in context by looking across communities at commonalities between agencies within the same organisation, and by looking across agencies in one community.

As noted earlier, an initial goal of this research was to speak to women who had reported domestic violence to a Women's Refuge in the areas being studied in the months after the respective event. This is something that had not been undertaken before in any previous domestic violence and disasters study. The closest example was Alice Fothergill's interviews of 90 women in her study of the Grand Forks Valley flooding in the United States (Fothergill, 1999). However, these women did not seek help from an agency at the time of the event and interviews were not specific to domestic violence victims. 


\section{Chapter 3}

To maintain the privacy of the women, contact was to be made through the local Women's Refuges. This meant that if women did not want to participate, they could decline and their confidentiality with Women's Refuge would be maintained. Much time and planning went into this part of the research to ensure that any potential harm to the women was minimised and that interviews would be carried out in a respectful and safe manner.

Initially, Women's Refuge representatives were receptive to the idea of facilitating these interviews. However, due to the nature of their work, it soon became evident that this was not a viable option. Repeated requests were made for help in gaining access to women clients of Women's Refuge. However, these were met with a realisation that the heavy workloads of the local Women's Refuges were prohibitive.

In one case study, a local newspaper that had previously reported on the research was approached for a follow-up story. It included a note that I was going to be in the community the following month and would like to interview any women who experienced abuse in their relationship, reported or not, about their experience of the event. The story ran on the front page of the local paper with a photo of me and an email and phone contact for me (see Appendix D). Unfortunately, this also proved unfruitful and no women came forward to take part in the research.

At this stage, I decided to admit defeat. Although much effort was expended on trying to gain access to the victims of domestic violence during disasters, it proved much harder than imagined. Given the secretive nature of domestic violence and confidentiality involved in prevention work, this is not a surprising result, though disappointing. However, interviews with agency representatives 
provided a wealth of knowledge and numerous issues were extracted during the research. Agency representatives and, in particular, Women's Refuges representatives, were able to discuss what women had been reporting to them. Interviews with victims of domestic violence during disasters is a potential future research project that would build on the findings of this work in understanding why domestic violence reporting is increased during disasters.

Once all the interviews were completed, a thematic analysis was undertaken on the contents of each interview. Themes included the factors suggested for why an increase in reporting occurred and problems the agency faced in their work, such as a staffing shortage or lack of communication. Issues included whether agency representatives stated there was an increase, decrease or no change in their workload. If an agency representative made reference to one of the above, their name was written on a post-it note and stuck on the relevant piece of paper. Post-it notes were colour-coded by community and placed on the paper in columns by agency to allow for both community and organisation comparisons. This eventually provided a map of themes and issues that will be discussed in the following chapters. Data from other studies (Enarson, 1999; Fothergill, 1999; Wilson, Phillips \& Neale, 1998) were then compared with the results of this research to find commonalities and differences. The results of this analysis provide the bulk of the data in this thesis, supported by other empirical studies and relevant theory that may explain questions raised by the results.

This research was approved by the Victoria University of Wellington Human Ethics Committee (see Appendix E). A second ethics approval process was followed to gain approval to work with the New Zealand Police. Ethical practice in domestic violence research is essential to ensure participants are not harmed 


\section{Chapter 3}

by the process, and also in ensuring that the researcher is not at risk (Ellsberg \& Heise, 2001: 1; Sullivan \& Cain, 2004: 603).

\section{Case File Summaries}

When it became clear that interviewing women who accessed Women's Refuges' services was not straight forward, I began to look at other ways of capturing information about any commonalities between women seeking assistance from agencies during the disasters studied. Questions had been raised during the research process about whether there were any demographic commonalities, the length of time needed to be spent with each woman, whether this was their first time using Women's Refuges' services and anything else that might prove useful in formulating effective policy. Having the knowledge that Women's Refuge keeps a database of clients, both locally and nationally, that may have captured all this information, I sought permission from the national office to examine the database and pull out information that would be aggregated so as to make any identification of individual women impossible. This involved aggregating the case studies from women using Refuges in the areas selected in the first three months after a Civil Defence emergency. The limit of three months was chosen as the time period given by Women's Refuge representatives during the interviews as the duration of increases in reporting. These ranged from three months in Lower Hutt (Williams, 2008) to 12 months in Whakatane (Te Are, 2005).

The Women's Refuge national database already has in place a measure that strips out the name of both clients and their perpetrators and any addresses given. To ensure that the women could not be identified by the number of children they have or a birth date, this information will only be presented in 
aggregate and birth dates were not recorded, only ages. These types of measures were paramount in my mind at all times when working with the data as maintaining the privacy of these women is a priority for Women's Refuge and access to the database is highly restricted.

One of the key priorities when doing research on victims of domestic violence is to keep their safety paramount and always consider potential adverse effects of decisions made or actions taken. This has been at the forefront of my thinking in all aspects of the research, from interviews to collation of the case file summaries. The safety of the women included in the research could be compromised if they can be identified by their perpetrator or a member of the community. Therefore, ensuring their anonymity is fundamental (Sullivan \& Cain, 2004). This limits how much detail can be used in discussions and necessitates constant checking of how recognisable any person is. For the case file summaries this means that the data will only be presented in aggregate form. For the interviews, this means that some details about the woman may need to be omitted or changed if it does not affect the context.

The data gathered from the case file summaries were all coded and input into SPSS for analysis. The Women's Refuge database holds information on two types of clients, those who accessed Women's Refuge services and those who were brought to Women's Refuge's attention through POL400's (reports used by the NZ Police when responding to a domestic violence callout).

Once input into SPSS, simple frequency tables were run and any common factors extracted. This permitted evaluation of current models and theories on why domestic violence may increase after disasters. Much of the previous work has highlighted that vulnerability is a concept that is strongly linked to negative 


\section{Chapter 3}

outcomes of natural hazard events. Vulnerability can occur through a variety of factors including low-income, institutionalised racism, a lack of access to social networks or social support. A prior history of domestic violence (which was measured through prior contact with a Women's Refuge and duration of abuse collected by some Women's Refuges) can be seen to link to a lack of access to social networks or social support. Data collected also includes what the employment status and ethnicity of clients are, which were also analysed for any trends.

Being able to look at the case notes of individuals also provided the opportunity to note if the Civil Defence emergency was mentioned at any point during the work the Refuge was doing with the woman. This type of note may be the only direct link that can be made between the emergency and the reporting of domestic violence, and, therefore, is a very useful parameter.

\section{Limitations of the research}

The study of increased domestic violence after Civil Defence emergencies is a relatively new field and with only four other published studies with a specific focus on domestic violence (Wilson, Phillips \& Neal, 1998; Enarson, 1999; Fothergill, 1999; Jenkins \& Phillips, 2008), a case study approach was selected as the most effective way to examine the issue. Much of the methodology used in the other studies was emulated in this research. However, the number of data types has been extended. The use of five different case studies that utilise diverse communities and events means this research is, to date, the largest systematic study of the topic. The next largest studies are the three case studies in the study from Wilson, Phillips and Neal (1998) and the other two focussing on one event (Enarson, 1999; Fothergill, 1999). 
However, as with all research, this study has limitations. In particular, finding the scale of the increase that is directly linked to the Civil Defence emergency is something that currently could only be obtained by interviewing each woman that accessed services in the months after the event. This has not been done and so the research can only discuss whether an increase has occurred and if those working in the field, who are in the best position to discuss, believe it was related to the emergency. In the future, research could be improved by advocating to the agencies working with domestic violence victims to note down specifically if the clients they are working with mention the emergency has impacted on the violence. Of course, because this is a new field, this sort of observation has not been integrated into agency systems.

Secondly, this study utilised interviews and statistics from community and government agencies as the primary data for understanding the situation for domestic violence victims during disasters. Whilst this is a good start to research into this area, future research could build on this study by interviewing the actual victims. This does not invalidate the opinions of these agency representatives and I submit that these opinions are educated opinions and do supply an accurate impression of what was happening. However, it must be acknowledged that second-hand information may come from sources with their own agendas (Miller \& Glassner, 1998). Awareness of this has meant the personal biases can be minimised but may not be entirely eliminated. 


\section{Conclusions}

In summary, this research has employed a variety of methods to examine the issue of domestic violence increases after Civil Defence emergencies or disasters in New Zealand communities. It is rooted in feminist scholarship. As in previous studies on the same topic, gender stratification is seen to lead to a situation where domestic violence victims are both at more risk from the disaster than non-victims, but also face increased levels of domestic violence following the disaster.

A feminist framework has provided five governing principles for the study: to be concerned with gender and gender inequality; to give voice to marginalised groups; to use the research as a tool for political change; to have reflexivity; and to reject the traditional power dynamics between researcher and researched. These principles have been practiced in this research and have influenced the research methods and design.

The chapter also discussed the aims and objectives of the research before discussing the methods and research design in this study, and the limitations of this study. This allows for future research to build upon the work and address some of the areas that were not covered in this study. The next chapter discusses the three events and five areas examined in this research, as well as giving descriptions of the agencies involved in the research. This is the last chapter of the three setting the context of the data that will be presented from Chapters Five to Seven. 

Chapter Four: Descriptions and Definitions

The Events and Agencies 

There are three natural hazard events examined in this research; the first discussed is the February 2004 flooding of the lower North Island, the second is the July 2004 flooding of the Eastern Bay of Plenty and, finally, the June 2006 snowstorm in South Canterbury (see Figure 3). As can be seen in Figure 3, the events are spread across the length of the country. In the first of these events, the February 2004 flooding of the lower North Island, three communities were studied. The scale of the event meant many communities were affected. This gave the opportunity to compare areas with different demographic compositions after experiencing the same event.

Once the limit of five years was placed on events to be studied, communities were chosen that varied in demographic makeup. This was done to capture as many of New Zealand's different communities and groups as possible in the research, which is hoped would increase applicability of the findings and also help tease out why the increase occurred. There are a number of distinctive markers for each community. Whakatane is a community with a higher than average population of Maori people (New Zealand's indigenous people). The South Canterbury snowstorm case study includes Timaru in New Zealand's South Island, as well as a high representation of rural communities. Lower Hutt was chosen for its highly diverse population, which includes many different refugee and migrant groups as well as New Zealand Maori and New Zealand European. As will be seen in this chapter, the communities at the heart of the five case studies also vary in size and in socio-economic conditions. Census data from 2006 produced by Statistics New Zealand are the most current data available on all five areas and, therefore, have been used for the demographic information presented on each area. (These statistics are collated in Table 4, found on page 119). 
Figure 3: Locations of Case Studies

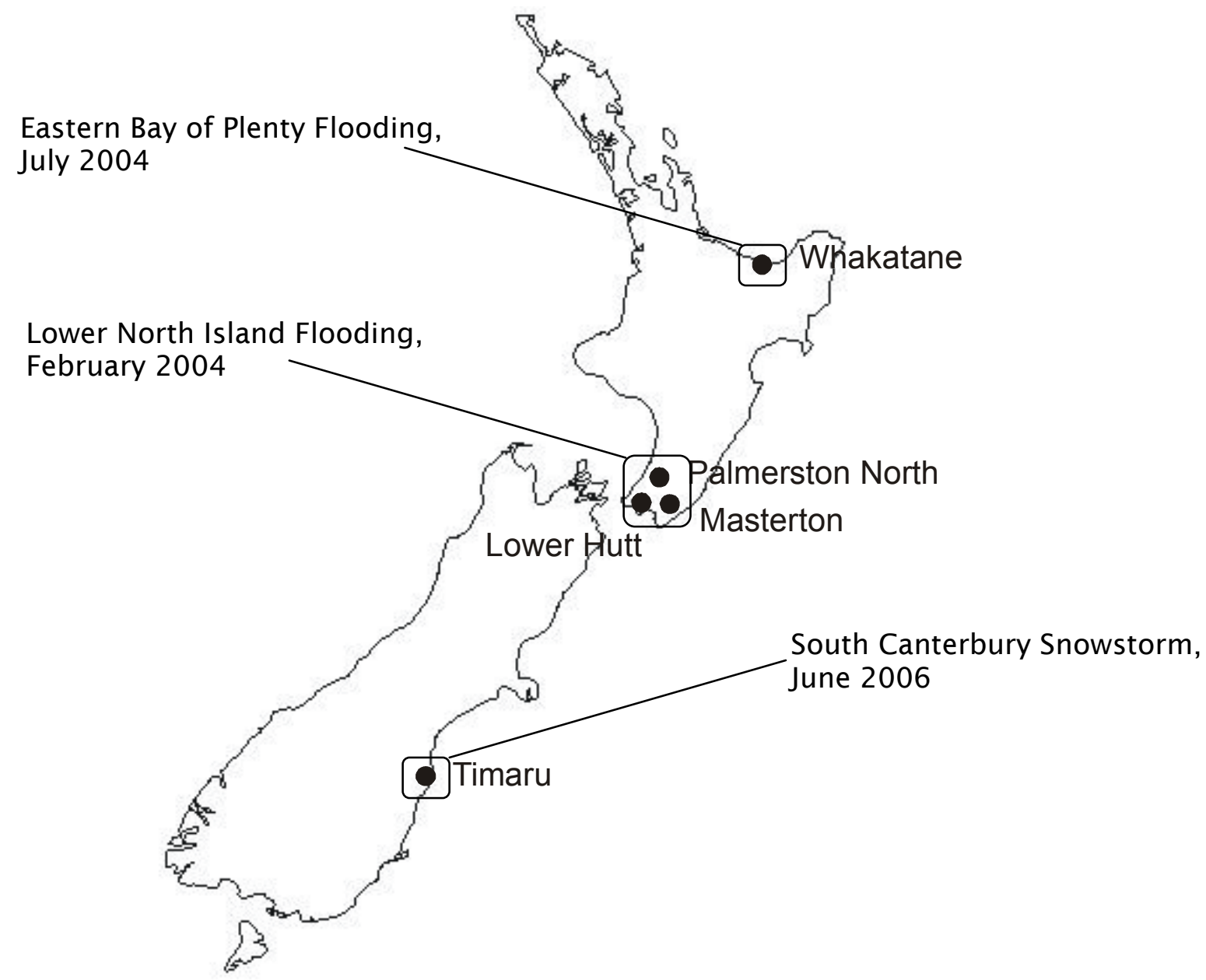

As well as being demographically diverse, each community had a different combination of agencies and organisations that are involved in the welfare response to disasters. In each community, many agencies/organisations were approached and asked to participate. Not all agencies agreed to participate in each community and, each case study consists of a different combination of organisations. However, there were two consistent agencies who provided interviews: the New Zealand Police and Women's Refuge. These two agencies are the primary agencies responding on the frontline to domestic violence in New Zealand and, therefore, participation from these agencies was viewed as vital for this research. 
Explaining the roles of agencies and describing the events and communities is necessary in order to provide background information that puts this study into context. Understanding which organisations are frontline agencies for domestic violence response will show why certain organisations take a predominant role in this research. The communities chosen were diverse to demonstrate that increases in domestic violence reporting are universal. The data also provides a snapshot of each community for comparison with other communities in future studies on domestic violence reporting during disasters.

\section{The Lower North Island Flooding July 2004}

The Lower North Island flooding in July 2004 was a sizeable event in terms of the number of areas affected. Three of the case studies in this research were subject to the flooding - Masterton, Palmerston North/Feilding and Lower Hutt. These were not the only areas affected by the flooding, but were diverse enough in demographics to reflect the broader New Zealand population.

The Lower North Island Flooding represented one of the largest Civil Defence emergencies in recent years in New Zealand, and the largest event in this research. In all affected communities, the flooding began with heavy rain on 14 February 2004 and continued for several days. Many communities reported rainfall of five or six times the usual monthly average for February; Feilding reported $334 \mathrm{~mm}$ compared to $57 \mathrm{~mm}$, Palmerston North reported $299 \mathrm{~mm}$ compared to $60 \mathrm{~mm}$, and Lower Hutt reported $482 \mathrm{~mm}$ compared to $68 \mathrm{~mm}$ (Reid et al., 2004: 9)

The levels of two rivers were at their highest (Manawatu River) or third highest (Rangitikei River) levels in over 100 years (Reid et al., 2004: 10; Vision 
Manawatu et al., 2004: 3). Four rivers burst their stopbanks during this period (Horizons District Council, 2004). As occurred in the Bay of Plenty flooding later in the same year, this was described as a 100-year flood, meaning a flood as large as this one has the likelihood of occurring once every 100 years (Horizons District Council, 2004). There were major roading disruptions from the flooding with four bridges destroyed and 21 others seriously damaged (Reid et al., 2004: 10). Major highways were reported blocked, including the Manawatu Gorge, which was closed for 75 days until the end of April 2004 (Horizons District Council, 2004; Reid et al., 2004: 10). Power and telecommunication outages also occurred, with 15,500 households without power during the flooding (Horizons District Council, 2004). The number of evacuated people was estimated at a minimum of 2,500 people across the whole region (Reid et al., 2004: 10) with 1,200 of those in the Palmerston North/Feilding district (Rounthwaite, 2008). As with the other two events, schools were closed in response to this event (Reid et al., 2004: 10). Schools were closed in Feilding and Lower Hutt but not in Masterton (Buckley, 2008; Harrison, 2008; Rodgers, 2008)

This event had significant impacts on rural communities. Communities, such as Scott's Ferry (a village roughly $20 \mathrm{~km}$ out of Bulls), were entirely flooded and required a complete evacuation of the village at short notice (Horizons District Council, 2004). There were 10,000 dairy cows relocated in the Manawatu region and the estimated cost of sheep stock losses was placed at $\$ 2.5$ million (Horizons District Council, 2004). The cost to the insurance industry from claims was \$124.58 million adjusted to 2007 dollars (Insurance Council of New Zealand, 2008), the largest insurance bill of all three events being researched. 
Masterton

Figure 4: Map of the Wellington Region

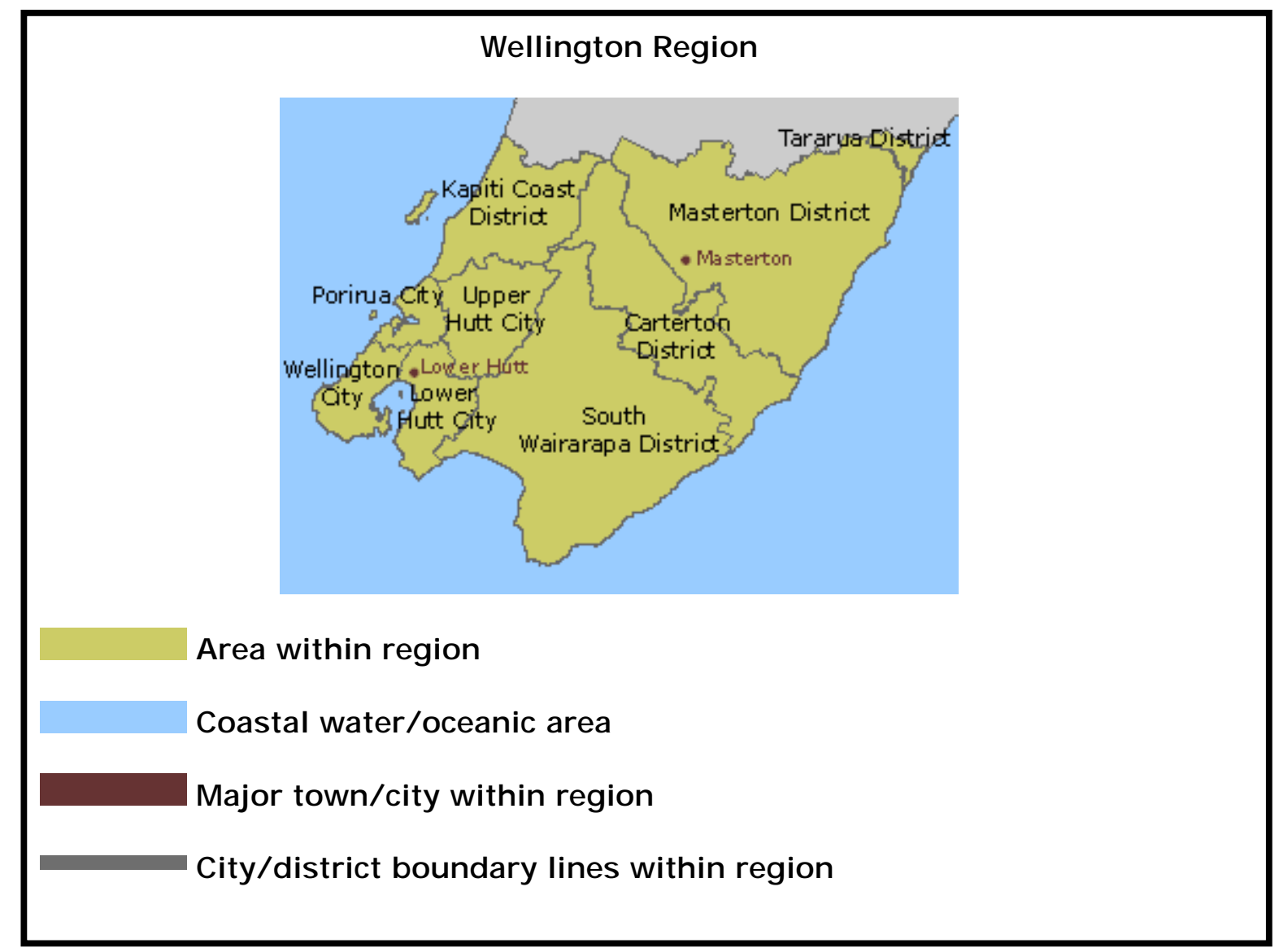

(Image Source: Statistics New Zealand)

The Wellington region is $8,124 \mathrm{~km}^{2}$ (Statistics New Zealand, 2009) and is located at the southern end of the North Island in New Zealand. It covers both the western and eastern sides of the island with nine districts in total. It includes both urban and rural areas, including New Zealand's capital city, Wellington. The Masterton district is located on the eastern side of the island and covers both coastal and inland areas. Much of this district is rural, with an urban centre (Masterton) located at the southern end of the region. 
Figure 5: Map of the Masterton District

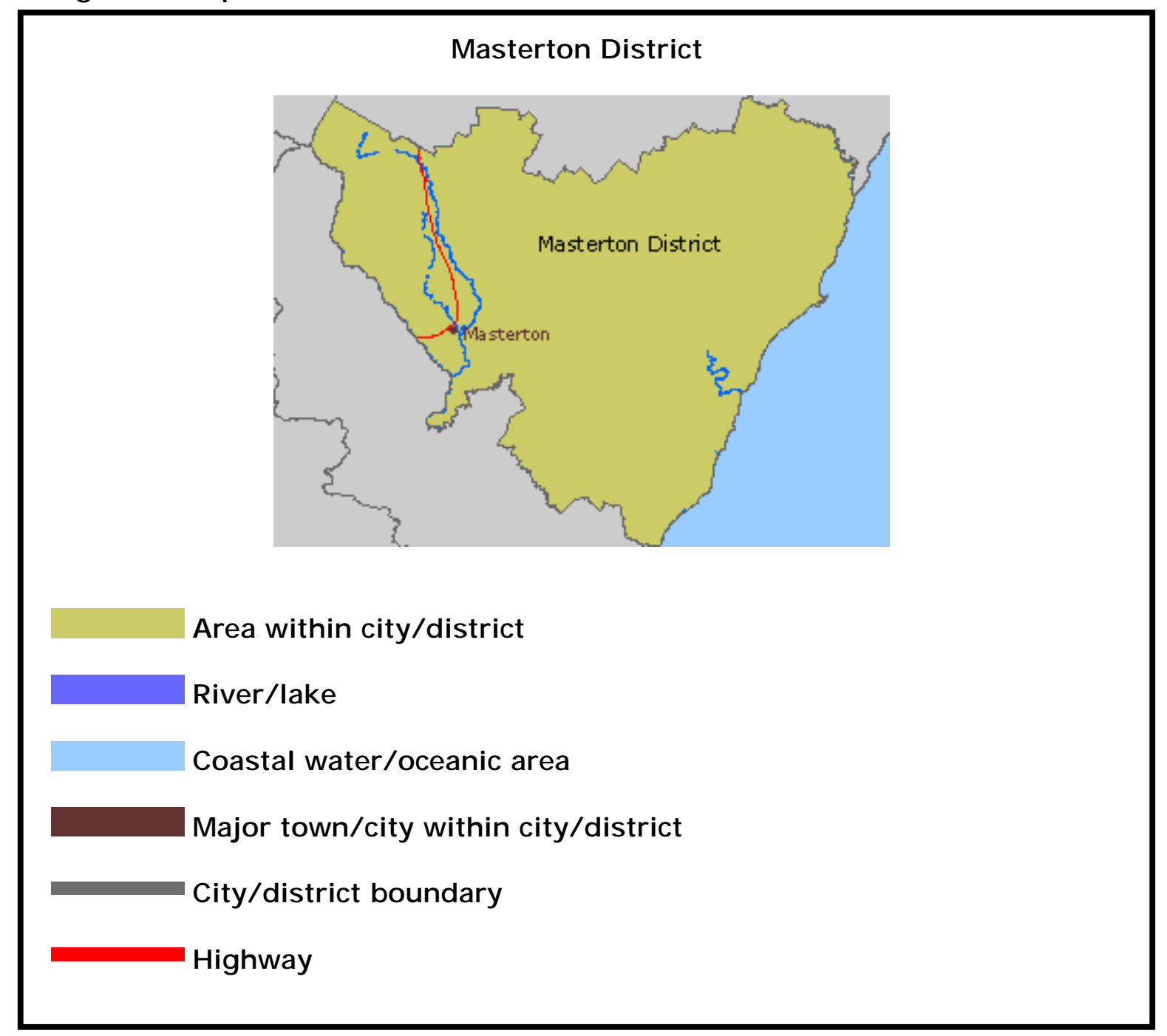

(Image Source: Statistics New Zealand)

The geographic area of the Masterton district is $2,298 \mathrm{~km}^{2}$ (Statistics New Zealand, 2009). In the 2006 Census, the Masterton district was found to have a total population of 22,623 people living in 9,033 dwellings (Statistics New Zealand, 2008c). Of this, $16.9 \%$ identified as belonging to the Maori ethnic group, slightly higher than that of the New Zealand population size of $14.6 \%$ (Statistics New Zealand, 2008c). The predominant ethnic group in the community is European, in line with the New Zealand population. However, this is at the higher level of $76.7 \%$ compared with $67.6 \%$ in the New Zealand 
population (Statistics New Zealand, 2008c). The next largest group after this is Pacific Peoples at just under 3\% (Statistics New Zealand, 2008c).

Masterton district has a median income level of $\$ 21,700$, which is lower than the median income in New Zealand of $\$ 24,400$ (Statistics New Zealand, 2008c). This is the same median income as the Whakatane district, making them comparable in terms of income levels in the district. However, the two communities have a very different ethnic make-up. The Masterton district has a higher population on an annual income of $\$ 20,000$ or less than New Zealand as a whole. Masterton district reported $46.7 \%$ of the population making $\$ 20,000$ or less annually compared with New Zealand's 43.2\% (Statistics New Zealand, 2008c).

The Census in New Zealand also records other markers of socio-economic status, such as access to communications and education level. In particular, access to a phone (or lack of it) is used in other measures of community wellbeing, such as the Economic Living Standards Index (Jensen et al., 2006). A lack of access to telephone communications is a marker on the deprivation scale used in the Economic Living Standards Index (Jensen et al., 2006: 53). Therefore, understanding what proportion of the community lacks access is an additional measure of socio-economic status for those wanting more than income levels. Masterton district is also characterised by less access to internet, phones (both land and cell) and fax machines than New Zealand as a whole. Measures of access to technology are used as part of the indicia of socio-economic status in an area. $51.9 \%$ of Masterton district households reported access to the internet compared with $60.5 \%$ in New Zealand as a whole (Statistics New Zealand, 2008c). Cellphone access was reported to be $69.6 \%$ compared to New Zealand's $74.2 \%$, and landline phone access was reported at 
90.2\% compared with $91.6 \%$ in New Zealand overall (Statistics New Zealand, 2008c). Finally, in terms of education, residents of Masterton district are less likely than New Zealand as a whole to have any formal qualification. $32.8 \%$ of Masterton district residents reported having no formal qualification compared with 25.0\% across New Zealand (Statistics New Zealand, 2008c).

Masterton has 59 social service agencies available to the community (Families and Community Services, 2009). This is an average of 2.6 agencies per 1,000 people in the community, the second highest figure across the five case studies. Agencies include adoption support groups, ante-natal classes and Age Concern. The success rate for gaining interviews with social service agencies in Masterton was lower than in the other four case studies. The agencies interviewed in Masterton were:

- New Zealand Police

- Women's Refuge

- Work and Income

The second case study profiled was also affected by the Lower North Island flooding. The impact of the flooding on the Manawatu-Wanganui region, and in this study, the Palmerston North/Feilding area was greater than that experienced in the Masterton and Lower Hutt areas. 
Manawatu

Figure 6: Map of the Manawatu- Wanganui Region

Manawatu- Wanganui Region

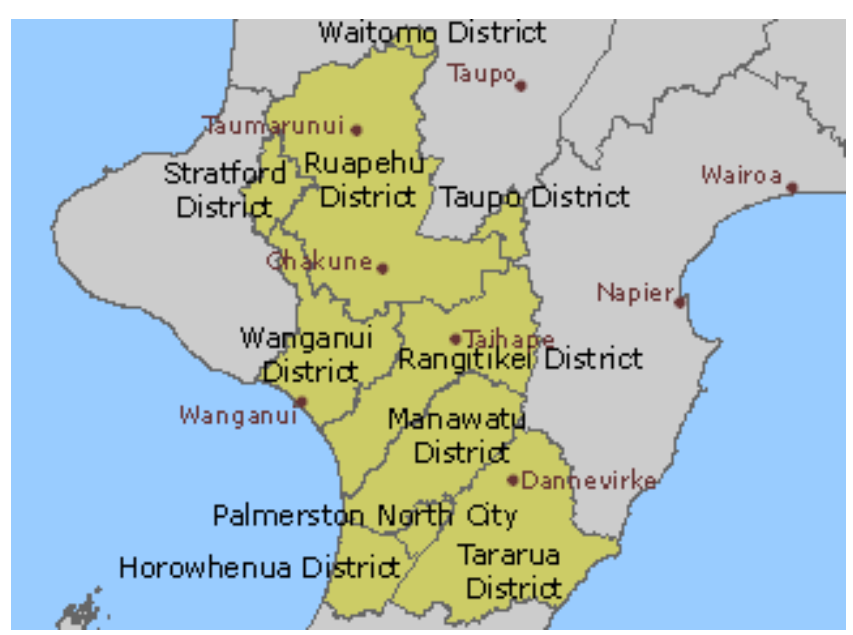

\section{Area within region}

Coastal water/ oceanic area

Major town/ city within region

City/ district boundary lines within region

(Image Source: Statistics New Zealand)

The Manawatu-Wanganui region is $22,215 \mathrm{~km}^{2}$ (Statistics New Zealand, 2009) and is located in the lower half of the North Island of New Zealand, above the Wellington region. Geographically it is a large region, covering much of the North Island's lower half. There are ten districts within the region, some of which are coastal, where others are located on inland plateaus. The Manawatu district is in the centre of the region, and includes large plains and many rural communities within its boundaries. 
Figure 7: Map of the Manawatu District

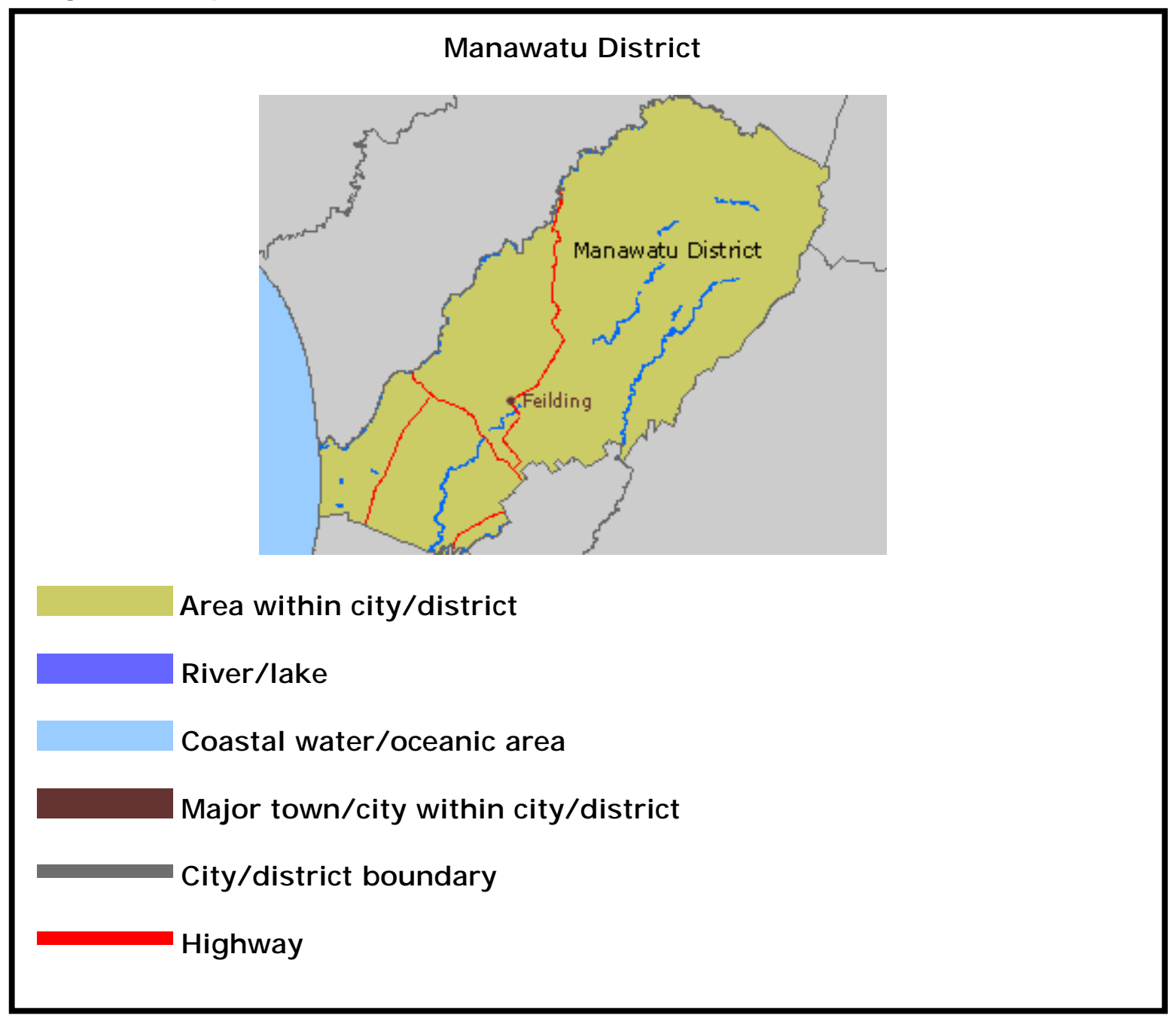

(Image Source: Statistics New Zealand)

Within the Manawatu-Wanganui region, the case study centres on the Manawatu district. The Manawatu district is $2,628 \mathrm{~km}^{2}$ (Statistics New Zealand, 2009). In the 2006 Census, the Manawatu district was found to have a total population of 28,254 people living in 10,515 dwellings (Statistics New Zealand, 2008d). Of this, $14.0 \%$ identified as belonging to the Maori ethnic group (Statistics New Zealand, 2008d). The majority ethnic group in the community is European, in line with the New Zealand population. However, this is at a higher level of 77.9\% compared with $67.6 \%$ in the New Zealand population (Statistics New Zealand, 2008d). 
The median income in the Manawatu district is slightly lower than that of New Zealand's median income. The Manawatu district has a median income level of $\$ 24,200$ compared with New Zealand's $\$ 24,400$ (Statistics New Zealand, 2008d). The Manawatu district reported $43.2 \%$ of the population making $\$ 20,000$ or less annually, which correlates with the New Zealand overall percentage of 43.2\% (Statistics New Zealand, 2008d).

People in the Manawatu district, have less access to internet than New Zealanders generally, but higher levels of access to phones (both land and cell) and fax machines than New Zealand generally. $58.7 \%$ of Manawatu district households reported access to the internet compared with $60.5 \%$ in New Zealand generally (Statistics New Zealand, 2008d). Cellphone access was reported to be $74.9 \%$ compared to New Zealand's $74.2 \%$, and landline phone access was reported at $92.9 \%$ compared with $91.6 \%$ in New Zealand overall (Statistics New Zealand, 2008d). Phone access is only slightly higher than the general statistics for New Zealand's, suggesting that in combination with income levels and ethnicity demographics, overall the Manawatu district mirrors wider New Zealand quite closely.

Regarding education levels, residents of Manawatu district are less likely than New Zealanders generally to have acquired a formal qualification. $31.4 \%$ of Manawatu district residents reported having no formal qualification compared with 25.0\% across New Zealand (Statistics New Zealand, 2008d).

Palmerston North City is within the Manawatu district and is the major city/service centre of the district. Palmerston North has 110 social service agencies available to the community according to Families and Community Services (2009). The Manawatu district had the highest ratio of agencies to 
population with 3.9 agencies for every 1,000 people in the area. This is by far the highest and almost four times that of Timaru, the final case study examined in this chapter. These agencies are as diverse as Amputee support, housing advocacy and multiple sclerosis support agencies. This is the second-largest group of agencies of all the five case studies, second to Lower Hutt city. The agencies interviewed in Palmerston North were:

- Civil Defence

- New Zealand Police

- Rural Family Support Trust

- Women's Refuge

- Work and Income

The final community examined that was significantly affected by the 2004 Lower North Island flooding is Lower Hutt. Lower Hutt experienced less of an impact than Palmerston North/Feilding, but more than the Masterton district.

\section{Lower Hutt}

As previously stated, the Wellington region (see Figure 4) is on the southern tip of the North Island and is $8,124 \mathrm{~km}^{2}$ in size (Statistics New Zealand, 2009). The Lower Hutt City district is located at the southern end of the region and is mostly an urban district. Sitting within $15 \mathrm{~km}$ of the Nation's capital city, Wellington, Lower Hutt city has a diverse population. It is the most ethnically diverse of all five case studies in this research, although this did not appear to render the ethnic breakdown of domestic violence reporters after the flooding significantly different from that of the other four case studies. 
Figure 8: Map of the Lower Hutt City District

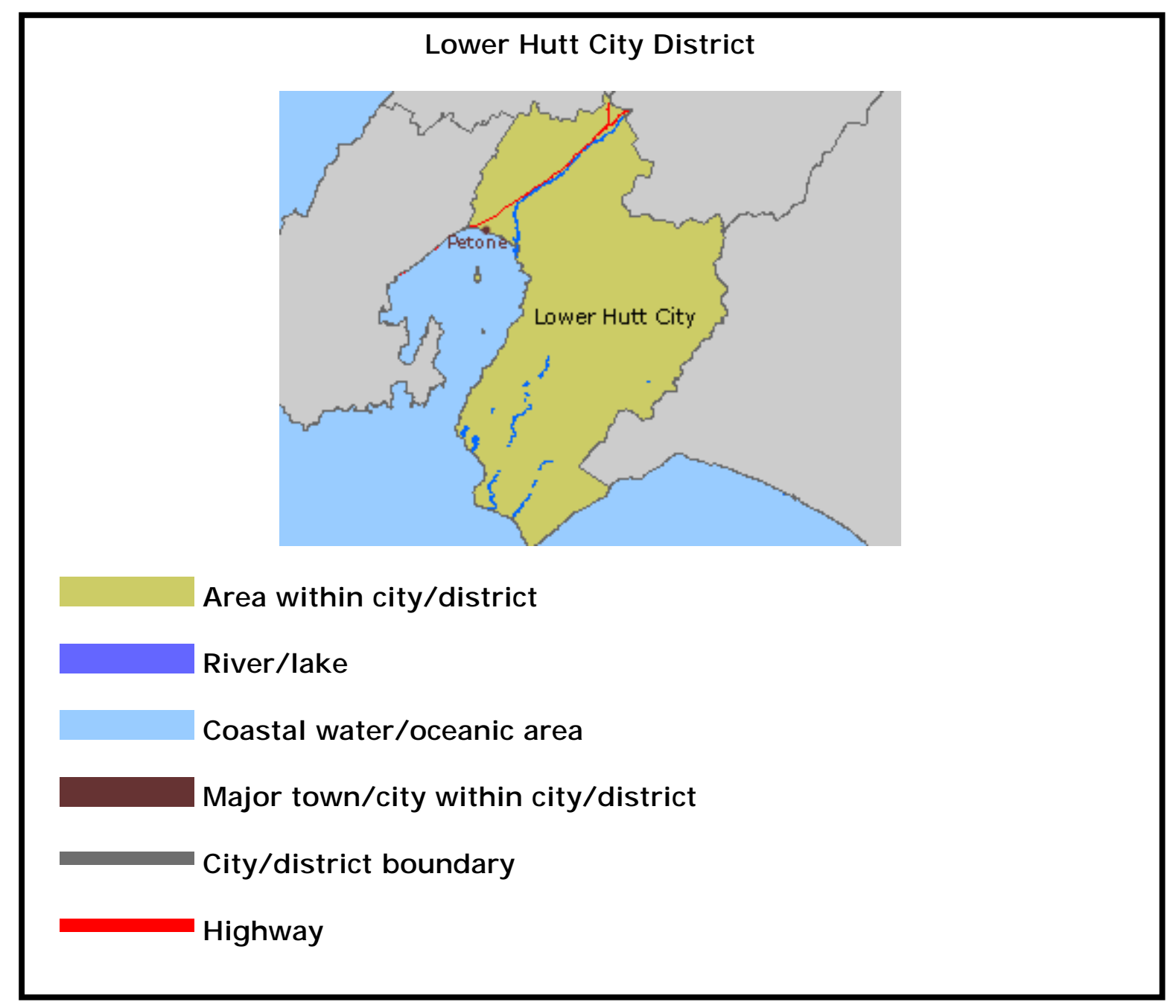

(Image Source: Statistics New Zealand)

Lower Hutt City has a geographic area of $377 \mathrm{~km} 2$ (Statistics New Zealand, 2009), the smallest land area of all the five case studies. The 2006 Census data showed that the Lower Hutt City district had a total population of 97,701 people living in 35,724 dwellings (Statistics New Zealand, 2008e). Of this, $17.1 \%$ identified as belonging to the Maori ethnic group. This is higher than that of the New Zealand population size of $14.6 \%$ (Statistics New Zealand, 2008e). The majority ethnic group in the community is European, in line with the New Zealand population. However, this is at a lower level of $64.9 \%$ compared with $67.6 \%$ in the New Zealand population (Statistics New Zealand, 


\section{Chapter 4}

2008e). The next largest group is Pacific Peoples at just over 10\%, followed closely by ‘Asian' at just over 8\% (Statistics New Zealand, 2008e).

The median income in Lower Hutt City district is higher than that in New Zealand generally. Lower Hutt City district has a median income level of $\$ 27,300$ compared with New Zealand's $\$ 24,400$ (Statistics New Zealand, 2008e). This can in part be explained by the large population of government employees in the wider Wellington region. Lower Hutt City district reported $39.0 \%$ of the population making $\$ 20,000$ or less annually compared with New Zealand's 43.2\% (Statistics New Zealand, 2008e).

Lower Hutt City district is also characterised by greater access to internet, cellphones, and landline phones than New Zealand generally. However, the figures for Lower Hutt City district and New Zealand as a whole are all within 1\% of each other, which is not a great difference. $61.2 \%$ of Lower Hutt City district households reported access to the internet compared with $60.5 \%$ in New Zealand generally (Statistics New Zealand, 2008e). Cellphone access was reported to be $75.2 \%$ compared to New Zealand's $74.2 \%$, and landline phone access was reported at $92.3 \%$ compared with $91.6 \%$ in New Zealand overall (Statistics New Zealand, 2008e).

Finally, with regard to education levels, residents of Lower Hutt City district are roughly equally as likely as New Zealander generally to hold no formal qualification. $24.8 \%$ of Lower Hutt City residents reported having no formal qualification compared with $25.0 \%$ across New Zealand (Statistics New Zealand, 2008e). 
Lower Hutt City has 124 social service agencies available to the community (Families and Community Services, 2009). The services provided range from Addiction services, Aspergers syndrome support, and domestic violence prevention and intervention agencies. Lower Hutt City has the largest number of social service agencies of all five case studies, with almost three times that in Timaru and Whakatane. However, due to its larger population than other areas, the ratio of agencies to people is the second lowest at 1.3 agencies per 1,000 people living in the area. Agencies involved in the Lower Hutt case study were:

- Civil Defence

- New Zealand Police

- Women's Refuge

- Work and Income

\section{The July 2004 Bay of Plenty Flooding}

The second Civil Defence emergency studied was the July 2004 flooding of the Bay of Plenty region. This event, centred on Whakatane, was chosen in part because news reports suggested there was already a level of awareness among social service agencies that domestic violence reporting had increased in their community in the months after the flooding (NZPA, 2004: Online). However, Whakatane also has a unique ethnic makeup, with a significantly higher than average population of New Zealand's indigenous people, Maori, with respect to other towns and cities. This will be discussed further in the demographics below. The use of this community as a case study gives the opportunity to examine whether domestic violence reporting increases for Maori populations as well as non-Maori populations because the size of the sample is greater than in other communities.

On 16 July 2004, the Bay of Plenty region and, in particular, the Whakatane 
district, was struck by heavy rain (MetService, 2009). This rain, coupled with a swarm of 30 earthquakes, caused many slippages around the district (MetService, 2009; AP, 2004). Around 17,000 hectares of the Rangitaiki Plains and most of the coastal land were flooded, in part due to stopbank breaches as well as the swollen rivers (Environment Bay of Plenty, 2004a; Eastern Bay of Plenty Recovery, 2005). The flooding also led to the temporary closure of Fonterra's Edgecumbe factory, a major dairy factory that employs much of the Edgecumbe population (Eastern Bay of Plenty Recovery, 2005). The cost of this event to the Insurance industry was $\$ 19.37$ million in dollars adjusted to 2007 dollars (Insurance Council of New Zealand, 2008). This flood was considered a 100-year flood and was the third major flood in the region in the previous 15 years (Environment Bay of Plenty, 2004a).

Whakatane and Opotiki were among the towns most severely affected with flood waters up to a metre deep in the town centres (AP, 2004; MetService, 2009). Within Whakatane, the area most seriously affected was Awatapu, which is surrounded in part by a lagoon that flooded (Peterson, 2005). These houses were evacuated and many have remained uninhabitable since. The figure put on the number of evacuees from the flooding and slippages was 1,500 people in Whakatane town (AP, 2004). The flooding closed off all access roads to Whakatane for two days and a state of emergency was declared until 30 July 2004 (Eastern Bay of Plenty Recovery, 2005; Peterson, 2005). Although the state of emergency ended after a matter of weeks, the recovery period lasted much longer than this. In particular the physical recovery continued into 2005 (Environment Bay of Plenty, 2004b; 2004c)

The Whakatane Council assessed 371 homes after the event and 228 of those were deemed unable to be reoccupied until repair. In nine instances it was 
unclear whether the homes could ever be repaired and three homes were condemned (Eastern Bay of Plenty Recovery, 2005; Peterson, 2005). Many found themselves in the evacuation centre, the Whakatane War Memorial Hall, but others moved in with extended family. Some elderly residents moved into the Salvation Army Hall, which was considered a little warmer and more comfortable (Anderson, 2005). Anecdotally, it was reported up to two years later that some residents were still not back in their homes following the floods (Turner, 2006).

The following data covers the Whakatane district as a whole. Statistics New Zealand includes Ohope, Taneatua, Edgecumbe, Matata, and Murupara in this district. The use of the entire district rather than Whakatane town is warranted as the July 2004 flooding affected all of the Eastern Bay of Plenty, which includes the entire Whakatane district. Furthermore, the Whanau Awhina Women's Refuge, which features in this case study, covers all these areas in its service provision so the two lots of data on demographics (census data and Women's Refuge client data) are of comparable areas. 
Whakatane

Figure 9: Map of the Bay of Plenty Region

The Bay of Plenty Region

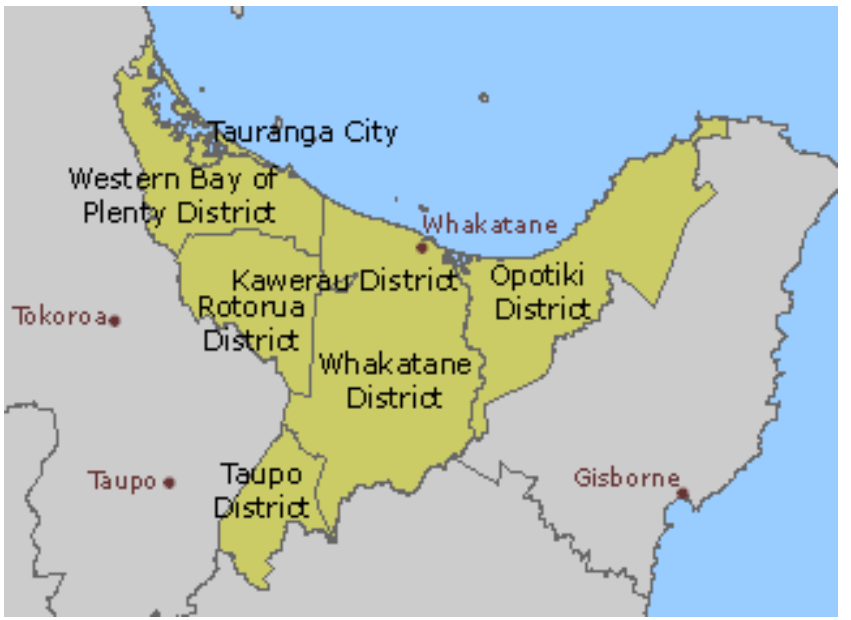

Area within region

Coastal water/ oceanic area

Major town/ city within region

City/ district boundary lines within region

(Image Source: Statistic New Zealand)

The Bay of Plenty region is $12,247 \mathrm{~km}^{2}$ in size (Statistics New Zealand, 2009) and close to the centre of New Zealand's North Island on the Eastern coast. The flooding mostly affected the Eastern Bay of Plenty, which consists of the Whakatane District and the Opotiki District (Environment Bay of Plenty, 2004a). 
Figure 10: Map of the Whakatane District

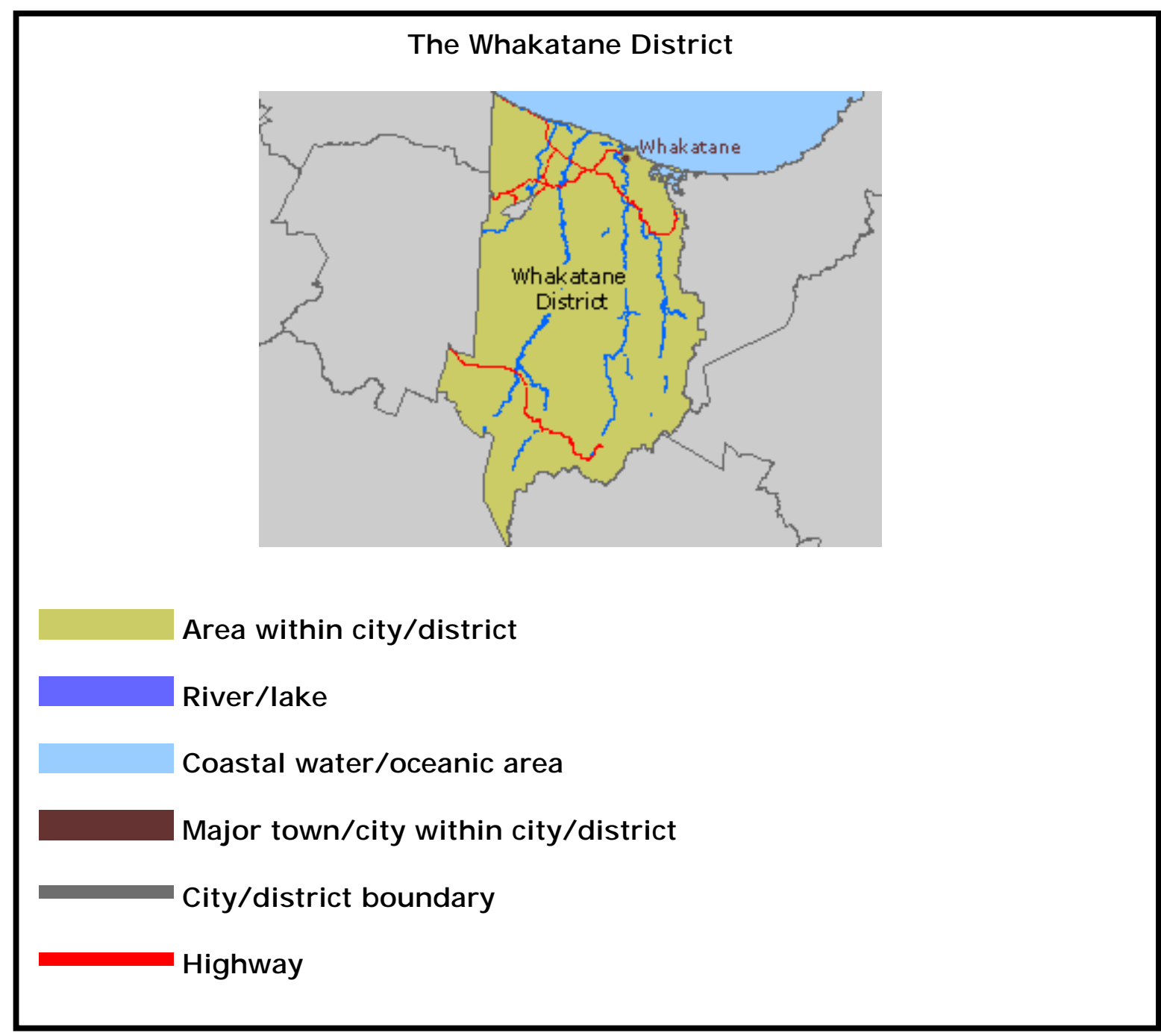

(Image Source: Statistic New Zealand)

Within the Bay of Plenty region, The Whakatane district is $4,441 \mathrm{~km}^{2}$ in size (Statistics New Zealand, 2009). In the 2006 Census, the Whakatane district was found to have a total population of 33,297 people living in 11,931 dwellings (Statistics New Zealand, 2008a). Of this, $42.2 \%$ identified as being Maori. This is almost three times that of the New Zealand population size of $14.6 \%$ (Statistics New Zealand, 2008a). Put another way, whilst Whakatane district only has $0.8 \%$ of New Zealand's entire population, it has $2.3 \%$ of New Zealand's Maori population (Statistics New Zealand, 2008a). The majority ethnic group in the area is still New Zealand European, in line with the New Zealand population. However, this is at a reduced level of $58.4 \%$ compared with $67.6 \%$ in the New 
Zealand population (Statistics New Zealand, 2008a). The next largest group after Maori and New Zealand European is Pacific Peoples at just over 2\% (Statistics New Zealand, 2008a).

The median income in Whakatane district is lower than that of New Zealand's median income. Whakatane district has a median income level of $\$ 21,700$ compared with New Zealand's $\$ 24,400$ (Statistics New Zealand, 2008a). Whakatane district reported $47.1 \%$ of the population making $\$ 20,000$ or less annually compared with New Zealand's 43.2\% (Statistics New Zealand, 2008a).

Whakatane district is also characterised by less access to internet, telephones (both land and cell) and fax machines than New Zealand generally. 53.6\% of Whakatane district households reported access to the internet compared with 60.5\% in New Zealand generally (Statistics New Zealand, 2008a). Cellphone access was reported to be $68.5 \%$ compared to New Zealand's $74.2 \%$, and landline phone access was reported at $87 \%$ compared with New Zealand's $91.6 \%$ (Statistics New Zealand, 2008a).

Finally, in terms of education, residents of Whakatane district are less likely than New Zealanders generally to have a formal qualification. $32.1 \%$ of Whakatane district residents reported having no formal qualification compared with 25.0\% across New Zealand (Statistics New Zealand, 2008a).

Whakatane town is listed as having 48 social service agencies available in their community (Families and Community Services, 2009). These range from budgeting service agencies to domestic violence agencies to literacy support agencies. Of the five communities involved in the case studies, this is the second lowest, with only Timaru having fewer at 44 . However, in terms of the 
ratio of agencies per head of population it is the median figure with 1.4 agencies for every 1,000 residents, only slightly more than Lower Hutt City.

Whakatane was the most successful case study in terms of getting participation from social service agencies. In total, there were eight interviews from this area, representing both non-government and government agencies. Representatives from the following agencies were interviewed:

- Child, Youth and Family

- James Family Trust (Presbyterian Support Services)

- New Zealand Police

- Ngati Awa Social and Health Trust

- Salvation Army

- Victim Support

- Women's Refuge

- Work and Income

\section{The June 2006 Canterbury Snowstorm}

While four case studies focus on flooding events, the final event to be studied was a significant snowstorm in New Zealand's South Island. The Canterbury snowstorm event began on 12 June 2006 when, after a night of heavy snow, Civil Defence emergencies were declared throughout the Canterbury region (see Figure 11). The snow was reported to have fallen from as far north as Amberley and covered (in differing depths) areas down to Oamaru from the east coast through to as far west as Mt Cook Village (Hendrikx, 2006: 13). The snow levels varied from less than $10 \mathrm{~cm}$ near the coastline to over a metre in the inland areas (Hendrikx, 2006: 13). This meant the scale of the event was not the same for all areas in Canterbury. Hendrikx attempted to compare the size of the snowfall in this storm (using snow depths recorded) with past storms and 
concluded that for some communities this was the largest storm in 30 years, while for others it was the biggest in 60 years (2006: 15). The greatest impacts were reported in the Timaru, Ashburton, MacKenzie, and Waimate districts (Wilson et al., 2008). The cost to the Insurance industry from claims was $\$ 43.91$ million adjusted to 2007 dollars (Insurance Council of New Zealand, 2008).

Wilson et al. (2008) examined the social and agency impacts of the snowstorm. This research pointed to the rural nature of this event by highlighting some of the key impacts. These impacts included stock welfare issues, building collapses, damage to farm buildings, fences and trees, and loss of power to electric fences (Wilson et al., 2008). However, there were also impacts across Canterbury including loss of power for up to six weeks in some areas, road closures, loss of telecommunications, loss of water, closure of schools, financial hardship for those unable to get to work, and financial pressure through the impacts on employers (Wilson et al., 2008). The research concluded that the isolation felt by families through the road closures and disruption to services was a major issue. This was perhaps felt most strongly by rural families who were characterised by having the slowest physical recovery in terms of infrastructure repairs, some were left without electricity for up to six weeks after the initial snow fall (Bang, 2008; Wilson et al., 2008). 
$\underline{\text { Timaru }}$

Figure 11: Map of the Canterbury Region

\section{Canterbury Region}

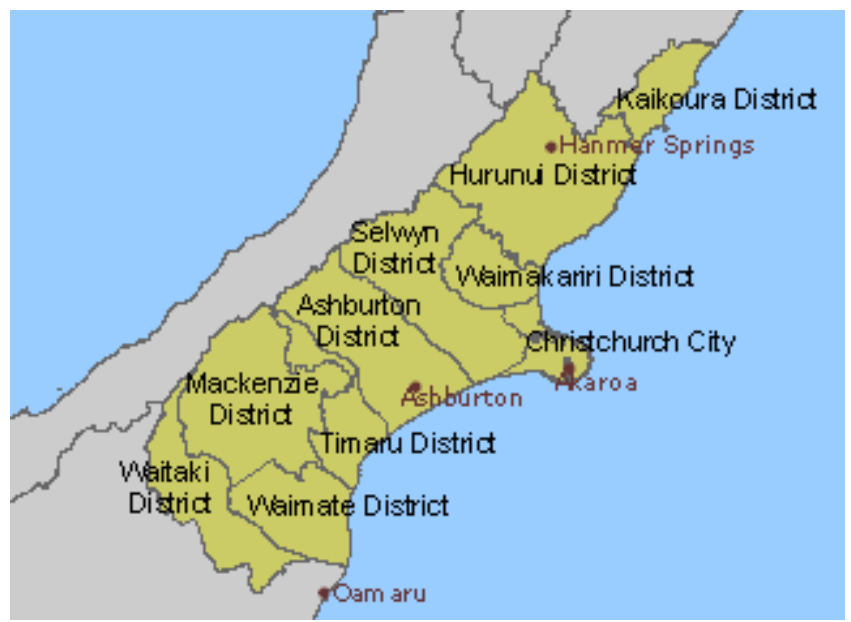

\section{Area within region}

Coastal water/ oceanic area

Major town/ city within region

City/ district boundary lines within region

(Image Source: Statistics New Zealand)

The Canterbury region is located on the eastern coast of New Zealand's South Island and is $45,326 \mathrm{~km}^{2}$ (Statistics New Zealand, 2009). It covers a large geographic area and consists of ten districts, many of which have large rural populations. The district studied in this research is the Timaru district (see Figure 12), which includes a coastal area as well as inland foothills, a large majority of which is rural. 


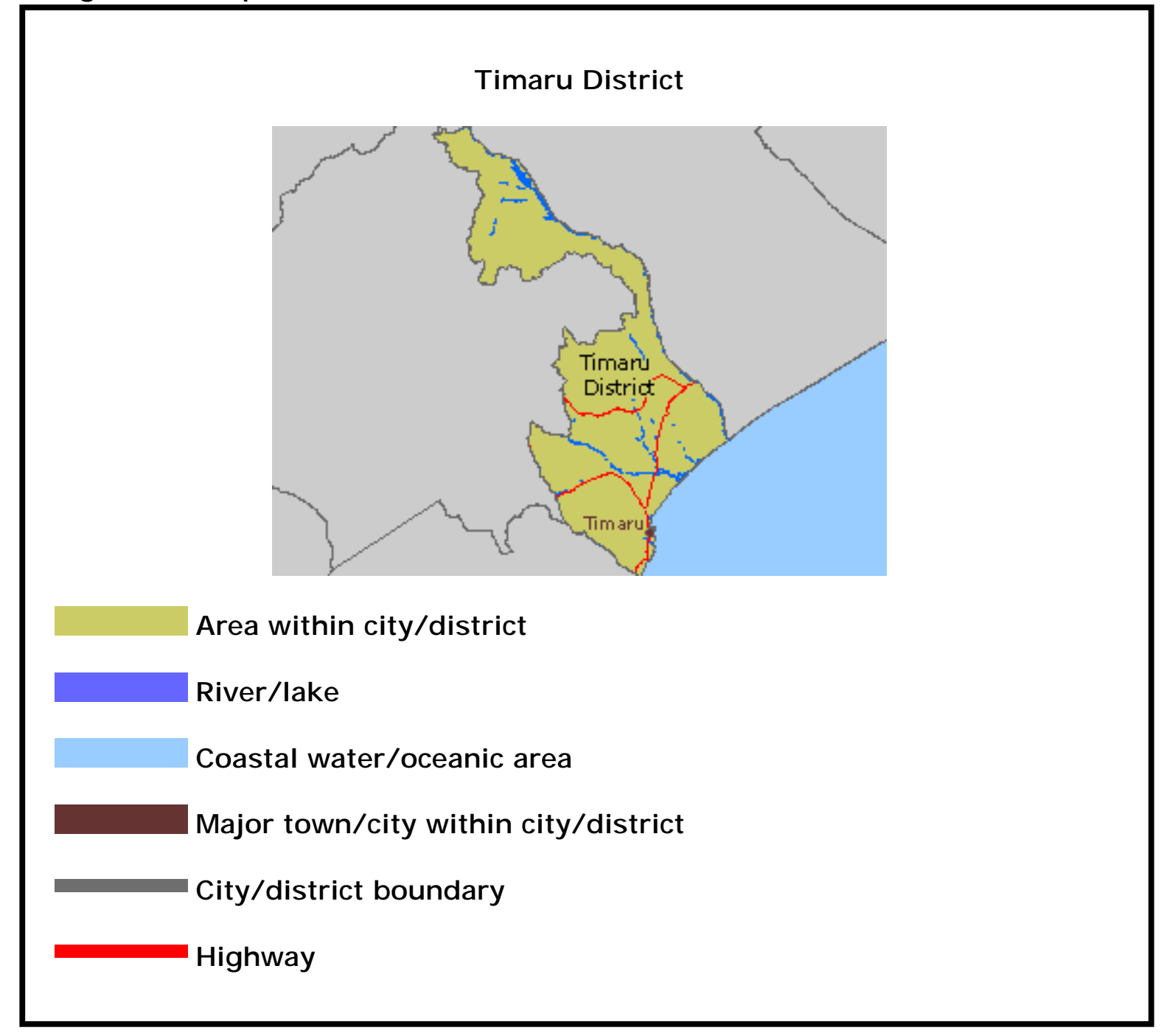

(Image Source: Statistics New Zealand)

The Timaru district is the second largest studied in terms of land area at $2,726 \mathrm{~km}^{2}$ (Statistics New Zealand, 2009). The 2006 Census data show the Timaru district had a total population of 42,870 people living in 17,688 dwellings (Statistics New Zealand, 2008b). As with many South Island districts, there was a very low level of Maori population in the Timaru district. Only $6.2 \%$ identified as belonging to the Maori ethnic group, which is less than half the figure for the New Zealand population size generally of $14.6 \%$ (Statistics New Zealand, 2008b). Stated another way, whilst Timaru district has $1.1 \%$ of New Zealand's entire population, it only has $0.5 \%$ of New Zealand's Maori population 
(Statistics New Zealand, 2008b). The majority ethnic group, European, is at the higher level of $81.2 \%$ compared with $67.6 \%$ in the New Zealand population (Statistics New Zealand, 2008b). The next largest group after this is 'Asian' at 1.5\% (Statistics New Zealand, 2008b).

In terms of income, the median income in Timaru district is lower than that of New Zealand's median income. Timaru district has a median income level of $\$ 21,200$ compared with New Zealand's $\$ 24,400$ (Statistics New Zealand, $2008 b$ ). Timaru district reported $47.9 \%$ of the population earning $\$ 20,000$ or less annually compared with New Zealand's 43.2\% (Statistics New Zealand, 2008b).

With regard to access to communication technology, Timaru district also has less access to internet, cellphones and fax machines than New Zealand generally. $54.0 \%$ of Timaru district households reported access to the internet compared with 60.5\% in New Zealand generally (Statistics New Zealand, 2008b). Cellphone access was reported to be $71.5 \%$ compared to New Zealand's $74.2 \%$, and fax machine access was reported at $22.3 \%$ compared with New Zealand's 26.0\% (Statistics New Zealand, 2008b). However, in contrast to this, Timaru district residents reported a higher level of access to landline phones than New Zealand generally with $93.5 \%$ of residents having access compared with $91.6 \%$ of New Zealanders generally.

Finally, in terms of education, residents of Timaru district are less likely than New Zealander generally to hold any formal qualification. 34.0\% of Timaru district residents reported having no formal qualification compared with $25.0 \%$ across New Zealand (Statistics New Zealand, 2008b). 
Timaru has 44 social service agencies available to the community (Families and Community Services, 2009). These range from Alzheimer's support agencies, to asthma support agencies, to a YMCA. Timaru is the area with the least social support agencies of all five case studies. It is also the community with the least number of agencies per resident, with only 1.0 agency per 1,000 people in the community. A wide range of agencies were interviewed in Timaru:

- Civil Defence

- Federated Farmers/MAF

- New Zealand Police

- Presbyterian Support Services

- Women's Refuge

- Work and Income 


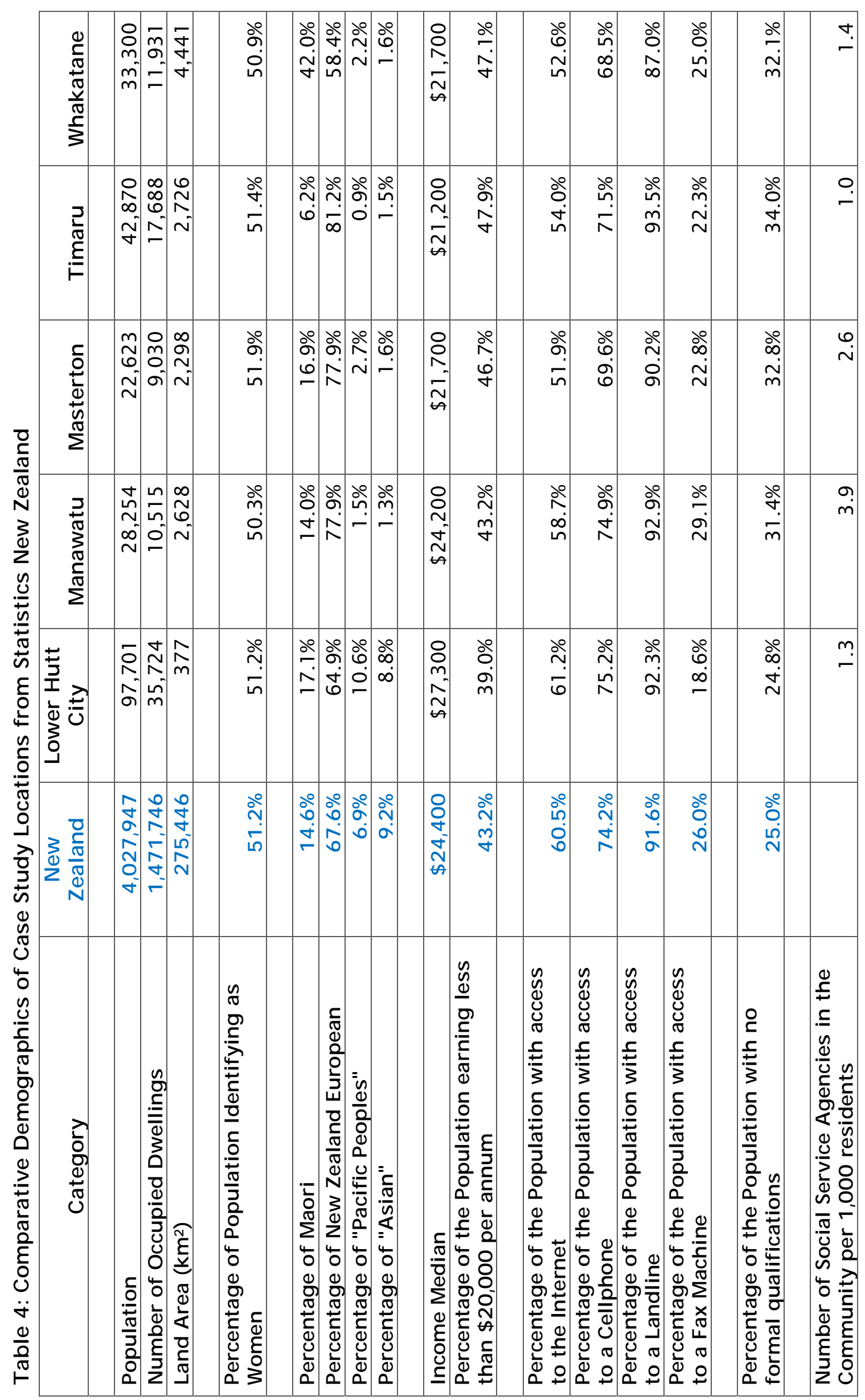


As has been noted, each community offered a different combination of agencies willing to take part in the research. To understand the role the different organisations play in both Civil Defence and domestic violence response, each will be discussed below beginning with government agencies who have mandated roles in Civil Defence emergencies, or domestic violence, or both.

\section{Agencies}

\section{Civil Defence and Emergency Management}

New Zealand's Civil Defence and Emergency Management involves three layers of policy and planning - national, regional and local. The Ministry of Civil Defence and Emergency Management is New Zealand's national-level government-mandated organisation to prepare for and respond to disasters in New Zealand. Within regional and local councils, there are positions responsible for Civil Defence that will run and co-ordinate the response to local and regional emergencies (Bang, 2008; Harrison, 2008; Rodgers, 2008). Whilst other government agencies also have responsibilities during a disaster, Civil Defence and Emergency Management has the primary responsibility to coordinate all these organisations and agencies, and ensure the response and subsequent recovery phases are conducted effectively (Mamula-Seadon, 2009).

\section{New Zealand Police}

The New Zealand Police is New Zealand's only law enforcement organisation and is the lead agency responsible for reducing crime and enhancing community safety. The New Zealand Police have a statutory obligation to respond during a Civil Defence emergency. In most cases, this includes carrying out evacuations but may extend to other tasks where suitable when asked by Civil Defence. 
The Police list their work as:

- Empowering communities to deal with issues of community safety and creating more effective community partnerships.

- Reducing the fear of crime by reducing actual crime.

- Helping to support and rehabilitate victims.

- Maintaining order and keeping the peace.

- Keeping people free from intimidation, civil disturbance and unreasonable annoyance.

- Helping to keep traffic flowing easily.

- Increasing people's personal safety.

- Reducing the risk of property theft, loss or damage.

(NZ Police, 2009)

\section{Work and Income New Zealand}

Work and Income is an agency of the Ministry of Social Development and is the government agency that provides financial support to New Zealand residents and citizens. This is available to residents and citizens who are not in employment or in some cases in special needs situations, such as disasters and women leaving abusive relationships:

Work and Income provides financial assistance and employment services throughout New Zealand. We offer a single point of contact for New Zealanders needing job search support, financial assistance and in-work support. Work and Income helps people into work and pays income support on behalf of the Government. This includes New Zealand Superannuation and Veteran's Pension payments along with the administration of residential care and support subsidies. They work with other government agencies, employers, business and community groups to design and run projects that generate work opportunities. These projects assist people throughout New Zealand to improve their and their family's lives through paid employment.

(Work and Income, 2009)

During a Civil Defence emergency, Work and Income have a statutory duty to respond and be available to provide their services, and other tasks where suitable when asked by Civil Defence.

\section{Child, Youth and Family}

Child, Youth and Family is the second agency of the Ministry of Social Development, which has been dealing with family violence. It is the statutory 
agency that is responsible for the safety and welfare of those in New Zealand under the age of 18 years:

Child, Youth and Family is the government agency that has legal powers to intervene to protect and help children who are being abused or neglected or who have problem behaviour. We work with the Police and the Courts in dealing with young offenders under the youth justice system.

(Child, Youth and Family, 2009)

Alongside state agencies, non-government agencies provide help and support for domestic violence victims and those affected by Civil Defence emergencies.

\section{Women's Refuge}

One of the primary non-government agencies involved in domestic violence response is Women's Refuge. Women's Refuge is a national, women-run organisation that provides services for women and children who are victim to domestic violence. The first Women's Refuge opened in Christchurch in 1973 (Women's Refuge, 2009: Online). The services provided range from crisis response, to early intervention and prevention. These services include crisis accommodation, advocacy and support when working with other agencies including the New Zealand Police and Work and Income, and national lobbying (Te Are, 2005). The National Collective of Independent Women's Refuges was established in 1981; each Women's Refuge in the National Collective is independently run, however, they are part of a national body with a national office in Wellington (Women's Refuge, 2009). The national office provides support, advice, quality assurance, policy, and fundraising services to the National Collective.

\section{Victim Support}

Whilst Women's Refuge is the only domestic violence-focussed non-government agency, there was a second non-government agency involved in helping victims 
of crime, including domestic violence that was interviewed in this research. "Victim Support provides 24 hour emotional support, personal advocacy and information to all people affected by crime and trauma throughout New Zealand" (Victim Support, 2009). These services can be offered at the scene of a crime, or after the fact. Victim Support works closely with the New Zealand Police and is provided with administrative support by the Police. However, it is an independent non-government agency (Thomas, 2005).

Alongside the major national agencies, there were a number of other nongovernment agencies interviewed.

\section{James Family Trust and Presbyterian Support Services}

The James Family Trust has since renamed itself Family Works Northern. Family Works is a Presbyterian Support initiative (Family Works, 2009). Family Works Northern is the child and family services division of Presbyterian Support Northern (Presbyterian Support, 2009). Presbyterian Support Services is a nationwide faith-based agency that provides social services for New Zealand. This includes domestic violence work including women's education programmes and one-on-one counselling and support (Oomen, 2005).

\section{Ngati Awa Social and Health Trust}

New Zealand has a number of indigenous run non-government agencies - one was found to be relevant in this research. Ngati Awa Social and Health Trust in Whakatane "is constituted and mandated to provide all social, health and employment services to Ngati Awa and the wider community within the Ngati Awa tribe" (NASH, 2009). Ngati Awa Social and Health Services Trust is a nongovernmental agency that provides a myriad of social and health services to 
Whakatane residents, particularly Maori who are affiliated to the Ngati Awa iwi.

After the flooding event, they provided:

Everything from Social Work services right though to Health, like they were doing checks because we've got three registered nurses here, and they were going down to Marae looking after families with young children, making sure - because we didn't want people getting Meningococcal so there were education rounds, don't share drink bottles. It was quite warm so they did education programmes around that, wellchecks for babies and young children.

(Hetet, 2005)

\section{Conclusions}

There are a broad range of communities and agencies in this research. This broad range captures a wide range of avenues through which domestic violence victims seek help during disasters - through primary domestic violence nongovernment agencies, the justice system, religious organisations and indigenous agencies. This wide scope aids in meeting the aim of this research, to draw generalisations that will aid in understanding the intersection between natural hazard events and domestic violence in New Zealand broadly.

This chapter was a descriptive chapter focussing on setting the context of the research areas in the case studies and the agencies involved for those unfamiliar with either. The next chapter will discuss any increases observed in the postal survey and the case studies. 
Chapter Five: The Increase 

Chapter Four demonstrated that the communities in the case studies are diverse in terms of their demographic makeup. The three events they experienced are two of the most common Civil Defence emergencies in New Zealand, flooding and snowstorms. Each case study offered different findings for the research, the first of which was the scale of any changes in domestic violence reporting observed. There were also differences in the duration of any increased reporting, in the level of agency response to this, and the amount of inter-agency communication during the event. This chapter will focus on any increased reporting and on the level of awareness across domestic violence and Civil Defence agencies in each community.

This chapter will discuss those increases in domestic violence reporting after Civil Defence emergencies that were identified in both the postal survey and the five case studies. The postal survey was conducted in 2006 and, as has been noted, provided some of the input for the selection of case study sites. The case studies took place over 2007 and 2008 with the exception of the Whakatane interview set, which was conducted in 2005 . Typically, the statistics were collected first and the interviews with agency representatives conducted afterwards. The first section of this chapter will focus on the postal survey and the information gained about the increases in domestic violence from a wide group of social service agencies from 17 different hazard events in New Zealand from 1997 onward. Results of the five case studies will follow. Incorporated into this section will be a summary of what each agency in the case studies experienced. This is described to show where the increase has been felt most intensely in the past and, therefore, where it will most likely impact in the future. 


\section{Chapter 5}

\section{Survey}

As noted in Chapter Three, the survey had 30 closed- and open-ended questions (see Appendix A). The survey base was kept very broad at the outset to cover all possibilities where increases could have been felt and to avoid the limitation of assumptions as to who should have experienced an increase in workload due to an expected intersection between domestic violence and natural hazards. This meant that a broad range of social service agencies were included in the mail out, many of which do not work primarily with domestic violence but do encounter cases in their work. This breadth risked the dilution of any significant changes in domestic violence reporting. However, this proved not to be a substantial issue and defined clearly those agencies that would play a significant role in this research. Agencies who did not feel the survey was relevant to their work may not have responded, or in some cases sent an email or letter stating it was not relevant.

One of the initial questions asked was whether the number of active domestic violence cases had changed after the respective event in their area. Domestic violence was reported to have increased after 11 of the 17 events (see Table Five). 
Table Five: Changes to Domestic Violence Reporting found in Survey by Civil Defence Emergency (1996- 2006)

\begin{tabular}{|l|c|c|}
\hline \multicolumn{1}{|c|}{ Event } & Year & Change? \\
\hline Ruapehu Eruption & 1996 & No \\
\hline The Northland Floods & 1999 & Increase \\
\hline Dargaville Floods & 1999 & No \\
\hline Clutha District Flooding & 1999 & No \\
\hline Central Otago Floods & 1999 & Increase \\
\hline Queenstown Lakes District Floods & 1999 & No \\
\hline Thames/South Waikato Weatherbomb & 1999 & No \\
\hline South Taranaki Storm & 2004 & No \\
\hline Marlborough Storm & 2004 & Increase \\
\hline Hawkes Bay Floods & 2004 & Increase \\
\hline Lower North Island Floods & 2004 & Increase \\
\hline Eastern Bay of Plenty Floods & 2004 & Increase \\
\hline Dunedin Rainstorm & 2005 & Increase \\
\hline Greymouth Tornado & 2005 & Increase \\
\hline BOP/Matata Floods & 2005 & Increase \\
\hline Gisborne/East Cape Floods & 2005 & Increase \\
\hline Canterbury Snowstorm & 2006 & Increase \\
\hline
\end{tabular}

Most of the communities that did not report an increase were linked to events that occurred five or more years ago and comments were made by some participants that they could not remember that far back to the event:

The flood was seven years ago and in those days we didn't retain the incidents of domestic violence, therefore unable to provide you with any data. I do remember we had to lift all carpets \& get new ones \& empty the storeroom/filing room.

(Survey Response 1)

As Table Five shows, all but one event from 2004 on that were surveyed reported an increase in domestic violence in the months after their respective event. This further demonstrates that time is a significant factor in the lack of increased reporting noted by agencies in previous events. However, this is not a concrete indicator as a growing awareness and recognition of domestic violence more generally in New Zealand is likely to be part of the dynamics affecting the prevalence of increases reported. 


\section{Chapter 5}

As previously noted, this highlighted some of the limitations of this type of research. Because it is qualitative in nature and based on the memories of individuals working in the organisations at the time of the event, it seems research should not take place too long after an event and a triangulation of data collection will provide more reliable results than interviewing alone. Moreover, in this area of domestic violence response, record keeping has traditionally been limited, and staff are mobile, both of these factors mean there is little institutional knowledge. Based on this discovery, events that occurred earlier than five years prior were excluded from the second phase of the study.

Further, whilst reports of domestic violence did not increase in every case, they did not decrease either. This means that all agencies, regardless of an increase or not, will need to plan to keep their services running in an event, despite the possibility of direct impact on their facilities and operations of the hazard event. This finding is in keeping with what Enarson (1999) concluded in her work examining domestic violence shelters' responses to disasters across the United States and Canada. The quality of agency response impacts on whether a woman will stay separated from the abusive partner or not (Berk \& Newton, 1985; Berk, Newton, \& Berk, 1986; Holiman \& Schilit, 1991; Sullivan, 1991; Davis et al., 1994; Barnett et al., 1996; Sullivan \& Bybee, 1999; Allen et al., 2004; McDermott \& Garofalo, 2004). Therefore, maintaining a high standard of service is vital.

Three time periods were used to establish when any changes were occurring. The first time period was in the first two weeks from the onset of the event; the second period was between two weeks and six months after the event; the final 


\section{Chapter 5}

period was six months and over. Increases were reported by survey participants in all three time periods used.

The length of increased workloads also varied greatly across agencies. Some agencies only reported workload increases in the first two-week period, whilst others reported workload increases consistently across all three periods. Increases in the number of women seeking assistance with regard to domestic violence were reported to last up to 24 months after the onset of the event in one survey. This highlights that these increases will need to be planned for from the outset of a natural hazard event, and planning will need to consider the impact lasting at least as long as two years:

Probably the long term effects on victims - two years on say often those people have had to totally relocate and start again the financial burden of this, the effect on their relationships etc.

(Survey Response 2)

The reported increases in domestic violence reporting ranged from $5 \%$ to $50 \%$ in each of the three time periods mentioned above. These percentages were not exact; participants were asked to provide their best estimate of any percentage change in their workloads (see Appendix A).

After establishing an increased, decreased or consistent workload, participants were asked about the demographics of their clients. The respondents reported that $88 \%$ of their clients were female. The $12 \%$ of male clients recorded were from agencies that work with both victims and perpetrators, therefore, it is not clear whether these men were victims or perpetrators. With such a clear majority of women affected, the issue is not gender-neutral and this suggests that any policy created to address increased reports of domestic violence cannot be gender-neutral either. This finding is consistent with much of the 


\section{Chapter 5}

domestic violence literature (Yllo, 1983; Buzawa \& Buzawa, 1996: Fanslow \& Robinson, 2004) and with the figures practitioners in the domestic violence field report (Bartlett, 2004; National Collective of Independent Women's Refuges, 2006).

In terms of the other demographic characteristics of the people presenting to agencies following all of the events, the clients were reported to be across all ethnic groups but with the two majority ethnic groups comprising of NZ European/Pakeha and Maori. These two groups were essentially equal in numbers of clients ( $35.3 \%$ and $36.8 \%$ respectively). However, this constitutes an over-representation of Maori as the Maori population of New Zealand currently sits at $14.6 \%$ (Statistics New Zealand, 2008c). This over-respresentation is not uncommon, Women's Refuge consistently reports an over-representation of Maori clients accessing their services (National Collective of Independent Women's Refuges, 2005; 2006; 2007; 2008; 2009). Age representation was also across the spectrum with all age groups reported to be accessing services in the months after the event. However, the two main age groups were 25-34 and children 17 years and under.

A further question asked participants about whether the clients they were assisting after their respective Civil Defence emergencies were first-time clients or repeat clients (see Appendix A). Of the respondents, $68.0 \%$ said their clients were first-time reporters (of domestic violence). This has significant implications for researchers, policy and planning, and organisations. If firsttime reporters do not receive a high quality of service on their first attempt, this could significantly hinder or prohibit any future attempts to leave (Berk \& Newton, 1985; Berk, Newton, \& Berk, 1986; Holiman \& Schilit, 1991; Sullivan, 
1991; Davis et al., 1994; Barnett et al., 1996; Sullivan \& Bybee, 1999; Allen et al., 2004; McDermott \& Garofalo, 2004).

The survey also asked participants how able they were to continue on their services in the months after the Civil Defence emergency. Positively, $88.4 \%$ of the respondents reported that they were able to keep their normal services running during the disaster in their area. This does not guarantee quality was maintained but does speak well of the agencies' ability to adapt to such a situation.

Whilst 11 of the 17 events surveyed reported an increase in domestic violence reporting, the events impacted on agencies differently. A small number of agencies felt the event had little effect on their work and caseloads. Others felt that there had been a significant impact from the event on both the resources of the organisation and the amount of work:

It's true to say the magnitude of this event caught all agencies, both government and non, by surprise. Had it not been for defence forces' availability (helicopters and machinery) there would no doubt have been loss of life. Much has been learnt through the exercise and debriefing sessions have been valuable in establishing new policies.

(Survey Response 3)

What we experienced was that as a community agency we considered closing down our whole agency because: huge impact on staff; personal loss as staff; workload too heavy; no extra staff; loss of experienced staff due to above; compliances from extra government money; compliances to government contracts; financial strain on agencies; gatekeeper from local groups; long-term financial/resource strain.

(Survey Response 4)

Flooding was isolated to a few same farm blocks, didn't have any major effects. Martinborough was only isolated for a day so no long effects.

(Survey Response 5) 


\section{Chapter 5}

The survey provided a valuable base set of data for this thesis. The data conclusively demonstrated that domestic violence reporting had increased in a majority (11 of 17) of the events surveyed. It also showed the diversity of impacts that could result from very little disruption to everyday work to an agency considering closing down due to the extra pressure on resources created by the increased reporting. The results of the survey provided guidance as to which communities to base the case studies on by giving initial data on any increases. The case studies were designed to expand on this data and to piece together some of the reasons for increased reporting of domestic violence during disasters in New Zealand.

\section{Case Studies}

The second phase of the research was the five case studies. The case studies gave the opportunity to obtain more in-depth data and perform analysis of the impacts of Civil Defence emergencies and re-examination of questions that arose from the surveys. The next section will focus on these case studies and will give voice to the experiences of agency representatives working in the aftermath of significant Civil Defence emergencies in their community.

The five case studies were selected because survey data showed an increase in domestic violence reporting to varying degrees and each offered different demographics for comparison. The increases found through the survey data were substantiated either quantitatively (through Women's Refuge statistics), qualitatively (through interviews) or both. The differences in awareness and in other response characteristics, and the issues that stem from these, will be examined in the next chapter. 
In all five case studies, an increase in domestic violence reporting was found most commonly in the month of, or the month directly after, their respective hazard events. However, as in the survey, the onset and timing of the increases varied from event to event, and from agency to agency. The pattern of increase by agency was in congruence with the agency's place in the domestic violence field. Agencies such as the New Zealand Police, Victim Support, and Women's Refuge who offer crisis assistance as part of their core workload were the agencies that experienced immediate increases. Agencies such as the James Family Trust that offer women's education programmes and counselling experienced a delayed increased workload, with the impact coming months after the natural hazard event itself.

As explained in the methodology chapter, during the course of the research, it became clear that two agencies are central in terms of providing response to domestic violence and as a result provide crucial data for this research Women's Refuge and the New Zealand Police. Women's Refuge provided monthly statistics in each area involved in the case studies as well as participating in the interviews in each community. Women's Refuge also allowed access to their case file summaries. Case file summaries are the records kept at the national office of the National Collective of Independent Women's Refuges of client data, such as the demographics and characteristics of the cases, (e.g. whether the client needed housing, was a rural or urban client) and any other notes pertinent to each case. These will be addressed later in this chapter in order to demonstrate any common characteristics of the clients seeking help from Women's Refuge in the months after each event. The purpose of this is to glean as much information as possible about the specific nature of any increased reporting and to examine the Pressure and Release model's applicability to the situation of domestic violence and disasters. The 


\section{Chapter 5}

New Zealand Police participated in the interviewing in each community. However, as explained previously, statistics were not used from the New Zealand Police due to changes in their recording systems and a lack of sufficient numbers of Civil Defence emergencies to carry out significant statistical analysis on.

\section{Whakatane and the July 2004 Flooding}

The Whakatane case study indicated the greatest awareness in terms of the level of increase. The factors involved in this case study will be discussed first. Whanau Awhina Women's Refuge in Whakatane was very aware of the increase in domestic violence reporting and of all the five case studies demonstrated the greatest level of awareness of the effect the flooding event had on their work, both at the time it was happening and at the time of interviewing. When asked about the scale of the increase immediately following the flooding, Whanau Awhina Women's Refuge workers reported that their caseloads had tripled (Te Are, 2005). This level remained high but progressively decreased in the subsequent months until the point where other social agencies pulled out of the flood-affected area. When the other agencies removed their services from Whakatane, Women's Refuge experienced a second surge in the number of women coming to them:

Wini: What we're finding...is that the services that were present at the beginning of the flood dissipated rapidly, within about two months from the July floods, by September/October those services had gone, had retracted back into wherever they went. The council went into a committee, which didn't provide services. So community agencies were left with very little support and hence I think the numbers grew as well.

(Te Are, 2005)

This case study was complicated by a second flooding in May 2005 that impacted heavily on the community of Matata, which falls under the Whakatane umbrella for services. At the time of interviewing, Women's Refuge was in the 
middle of another wave of increased service demand, following the Matata flooding. However, the Women's Refuge representative also stated that they were still dealing with the repercussions of the first event, a year on from the flooding, as families were still not back in their homes and the earlier event continued to a be a real issue for families on an everyday basis.

Awareness of the issues of escalating domestic violence in the wake of disasters has consistently been highlighted throughout this research as a key factor in the extent to which agencies perceive an increase in the incidence of domestic violence (Wilson, Phillips \& Neal, 1998). If an agency was aware of a link between the domestic violence they were seeing and the Civil Defence emergency, at the time that the Civil Defence emergency was impacting on families, its representatives were more likely to discuss this with their client base and an increased proportion of their caseloads was seen to be related to the emergency. In the Whakatane district, the level of awareness of the first flood's impact on domestic violence reporting meant that this Refuge, in particular, was conscious of whether enquiries were specifically disastertriggered during the 2004 floods.

Whakatane Police was the only Police station of the five involved that was aware of increased domestic violence callouts both during the event and at the time of interviewing. This station had a Family Violence co-ordinator in place at the time of the flooding, meaning there was an individual in a position to identify change in the caseload. Whakatane Police reported an immediate doubling in their domestic violence callouts in the weeks after the floods, from 14 in June before the flooding to 29 callouts in the month of July 2004 . The Whakatane Police representatives felt that this increased workload was maintained for six months after the event. The participant noted that the first three months were 


\section{Chapter 5}

the most intense, before a gradual reduction to a level similar to that experienced prior to the flooding:

Neil: $\quad$...the first two or three months after it was quite a marked one, but we were probably stretched for six months after. Looking at our weekly, normally we have 5 family violence cases a week, we went up to 10 and that probably lasted for six months. I think there's still impact out there - people are still recovering from last year's one.

(Peterson, 2005)

It was not only front-line agencies that experienced the effects of a rise in domestic violence reporting in Whakatane following the flooding. The James Family Trust in Whakatane, a faith-based agency that is part of Presbyterian Support Services nationally, experienced such a significant increase in demand for their women's education programme that they needed to create a waiting list. This was a first time for them and has not been repeated since, suggesting the increase in work was directly linked to the flooding in Whakatane:

Diana: I don't know that our family workers who went out and did work with the families came back and reported an increase but I do know that after the floods we had a waiting list which we don't normally have. However, because of the size of our rooms and the number of people wanting to attend, we created it and we've never had that before and that is a direct result of the floods.

(Oomen, 2005)

Whakatane's Work and Income New Zealand representative also reported a tripling in their domestic violence caseload following the flooding in their community. They were in the fortunate position of having a domestic violence co-ordinator at the time of the flooding, which meant the increased workload was evident to both the co-ordinator and the manager of the centre. The coordinator went from working between five and fifteen hours per week to fulltime employment on domestic violence cases in the months after the flooding:

Ros: $\quad$ Did you notice an increase in domestic violence any time after the floods, related to the floods?

Roberta: Yes, very much so. To the point where I took responsibility for bringing the key agencies together to look for alternative, sorry 
additional housing because our own Women's Refuge was bursting at the seams.

Ros: $\quad$...Did you get the impression that there was domestic violence, did they tell you, I mean to say how does WINZ recognise domestic violence?

Roberta: Oh okay, what happens is I have a Women's Refuge coordinator in place. That person's responsibility is to be available at very short notice for Refuge - when they get a woman into the refuge they ring up my key person because they need to be seen right there and then. So, they are booked out on a daily basis for a half hour everyday. Sometimes it's never used, over this particular period there weren't enough hours in the day to cope with the influx of people that were arriving at the refuge. And I'm only talking from a Refuge perspective here.

Ros: $\quad$ So can you give an estimate of how much of an increase there was? Was it $50 \%$ more, did it double, triple?

Roberta: So in comparison to what we usually have? Oh, it tripled, tripled.

(Ripaki, 2005)

Victim Support in Whakatane reported a doubling in caseload in parallel with the trend observed by the New Zealand Police during this time. For Victim Support, the first three months were the most intense. However, the number of cases remained high for six months before subsiding back to a more typical level:

Jenny: I would say also that it would be found that the initial three months was an intense increase, you know, a heightened number of notifications of family violence, but it would be six months before the situation went back to be something of more familiar numbers...

(Thomas, 2005)

Other social service agencies (both NGO and government) such as the Salvation Army and Child, Youth and Family, stated that although they did not experience an increase in their own work with incidents of domestic violence, they were aware of the increased domestic violence work in the community in the months after the event: 
Ros: Did you have any, because I don't want any specifics or individual cases, but with any of the people you were dealing with, did you ever have to deal with domestic violence?

Glen: Not in a way of where physical violence was involved, no, but I know there were some instances of that from Neil's [the New Zealand Police Family Violence coordinator] point of view - he would have filled you in - there was an increase.

(Anderson, 2005)

Pania: There were significant amounts of domestic violence reported to the forum - we have a forum here in Whakatane called Family Violence Forum which in encompasses across the Eastern Bay and it's all those agencies that are associated with working with people who are subjected to domestic violence and we meet monthly there. And significantly with Women's Refuge and those types of organisations. So we go to the meetings and clearly there was an increase in domestic violence, but they didn't necessarily come back to Child Youth and Family for investigation.

(Hetet, 2005)

Overall, Whakatane displayed a sector-wide awareness of the increase and was the only community of the five to do this. Participants in the other four case studies displayed different levels of awareness and understanding of the situation. The community with the second highest level of awareness was Timaru though the patterns of reporting and assistance are different from Whakatane.

\section{Timaru and the June 2006 Snow Storm}

South Canterbury Refuge in Timaru experienced a decrease in the number of women coming to them during June 2006 when the snowstorm hit the region with the number of women seeking help falling to just four women. However, in July 2006 the numbers jumped to 25 women seeking crisis support. The size of this increase is clear from the two-year long cycle of data surrounding the flood. Women's Refuge statistics show the July 2006 figure was almost double the average value of 14 new women a month who seek the NGOs help. While there were other peaks, none reached the level of July 2006. 


\section{Chapter 5}

South Canterbury Women's Refuge stated that they were only aware of the increase in caseload as a consequence of the request for participation in this research. When I approached the Refuge to ask for an interview, they went back to look at caseloads and held discussions amongst the staff, to find there was a very noticeable increase that was felt by caseworkers at the time of the event. After discussions within the collective, it was remembered that one of the head caseworkers was significantly over-committed in the months following the snowstorm.

Dawn: Well, from talking to the caseworker, she said, I remember at that point, she said she was absolutely snowed in, if you don't mind the pun, with caseloads coming out her ears.

(Rangi-Smith, 2008)

However, without this study, it is unlikely this increase would have been recognised by staff. This was a common feature of many of the agencies interviewed across numerous events, and provides some explanation of why increased domestic violence reporting has not been brought to the attention of Civil Defence in the past. This example illustrates the active role of feminist research, when participation in the research itself serves as a catalyst for change (Ramazanoglu, 1992; Thompson, 1992; Eichler, 1997; Renzetti, 1997: 133; Fonow \& Cook, 2005; Skinner, Hester \& Malos, 2005: 14; Landman, 2006: 431). Creating increased awareness at the level of community-based agencies is required to ensure that any policy changes suggested by this research and instituted at a national level are also implemented at the local level.

The South Canterbury snowstorm provided an interesting case study for comparison with the other communities, as many of those affected by the snowfall were living in rural communities. Refuge workers noted that the 


\section{Chapter 5}

women were mostly from lifestyle-block and share-milking families. The representative stated that whilst there were some women coming to them from the urban (Timaru) population, the majority were from rural areas (Rangi-Smith, 2008). Rural Timaru was affected for the longest duration by the snowfall, both in terms of the length of time it took to clear snow from the roads and also in terms of the time it took for the power supply to be restored to households (up to six weeks in some areas) (Bang, 2008). Much like the Whakatane case study, those living in areas significantly affected by the natural hazard event formed the majority of those seeking help for domestic violence. Whilst this does not establish a causal relationship between the events and the increased domestic violence reporting, it does show a relationship between the degree of impact the event has and the level of domestic violence reporting.

Timaru Police also reported a decrease in domestic violence reporting during the month of June 2006, which is consistent with Women's Refuges' reports. However, rather than an increased level of reporting, Timaru Police felt that the numbers reverted to a more common level during July 2006, which was maintained in subsequent months.

Stephen: ...in fact during the snow period - sort of the week or two after, we actually had a decrease in reported incidents.

(Wills, 2008)

The decrease in reporting was attributed by the Police representative to a lack of access to phones and Police stations due to the snowfall, rather than a decrease in the incidence of domestic violence itself.

Stephen: We actually found there was a lower increase in reporting than normal sort of day-to-day because basically people weren't able to get out and about so people hunkered in houses and that sort of thing...

(Wills, 2008) 


\section{Chapter 5}

Other agencies in the community did not report any noticeable change in domestic violence cases in the months after the snow event. Most agencies stated that there was no formal way of recording domestic violence cases specifically in their reporting and that, therefore, they could not say, with any certainty, whether there was a change. At this stage it appears the increased domestic violence reporting did not extend past the crisis agencies in the community, as seen in this quote from the Federated Farmers representative. Federated Farmers employed co-ordinators in the months after the snowstorm who visited farmers in the area to assess their needs for recovery.

Ros: Did you hear, of any increase, in family tension or family violence?

Rob: No, certainly not in terms of family violence, no. I know of several cases where it's been commented that dad was grumpy. Well, probably mum was grumpy too. I wasn't aware of any violence at all actually - not saying that violence didn't occur, but I wasn't aware of any.

(Phiske, 2008)

\section{Palmerston North/Feilding and the February 2004 Flooding}

Palmerston North has two Refuges; one is a Refuge solely for Maori clients, and it works with a kaupapa Maori focus and one is a general Refuge, which takes clients of all ethnicities including Maori. When looking at the number of cases reported in the national database, Te Roopu Whakaruruhau Women's Refuge went from three women clients in January 2004 to 13 clients in February (the month of the event). This figure stayed at this level for three months before dropping back slightly. Palmerston North Women's Refuge (the general Refuge in Palmerston North) went from 16 clients in January to 25 women in February, over three times their two-year average of eight new women per month. 


\section{Chapter 5}

Palmerston North Women's Refuge staff were unable to participate in the interviewing phase. However, both Refuges co-operate closely with daily contact and discussion about work so the representative from Te Roopu Whakaruruhau Women's Refuge had knowledge of the impact on Palmerston North Women's Refuge also (Tukariri, 2008). The response of Te Roopu Whakaruruhau Women's Refuge was similar to that of the South Canterbury Women's Refuge and staff stated that they were aware of an increased work level by the time of interviewing, but not during the event. Although conscious of the impacts of the event and the limitations it placed on their ability to respond to rural calls, the increase in work went unnoticed - as for of all the studied Refuges with the exception of Whakatane.

Te Roopu Whakaruruhau Refuge have a second recording system which had not been detected at the time of collation of the base line statistics, which they refer to as the "crisis call statistics". Every time a crisis call is received by a Refuge, it is logged into a crisis calls' log and later entered into the national database. The staff found the flooding itself had been in part responsible for some of the women to call:

Julie: We had an unbelievable log of crisis calls of women, they had some concerns. Funnily enough it was the natural disaster that caused them to double-think around their environment. They already were prisoners, and that's what we found.

(Tukariri, 2008)

The calls include women that sought help from a Women's Refuge but may not have accessed the service formally, for a variety of reasons. One of these reasons women may not have accessed these services, particular to the flooding in Palmerston North and Feilding, was that the Refuge was geographically isolated from women. The Refuge is based in Palmerston North but services a far-reaching area that includes Feilding, Dannevirke and other rural areas in the Manawatu. During the flooding, many of these areas were cut off from 
Palmerston North by road and the Refuge was unable to work with women via any medium except the telephone.

Julie: It was terrible. We didn't have any contingency plans. We were blocked North, South, East and West. We had one road to Dannevirke, but that was it... a lot of them rang us up, and we tried to place them till the flood subsided...in the Foxton area. Most of them were talking about the fear of no one knowing what was happening to them. It was like, "I better let Refuge know that I'm going through this, because I don't know if something's going to happen to me." They felt totally isolated, just isolated from everything.

(Tukariri, 2008)

One specific case discussed with the representative of Te Roopu Whakaruruhau, centred on a woman involved in a long-term violent relationship whose partner was unable to get home due to the flooding. During this time the woman wanted to leave the abusive relationship and felt that she had enough lead-time to pack up her and her children's possessions and escape. However, the Refuge workers could not reach the woman because of the flooding. An offer was made by the Police to come and collect the family but this was not a suitable option for the woman as her partner's past criminal background and current gang involvement meant that the Police were not welcome in her neighbourhood. She was in fear of the repercussions if it became known that she was co-operating with the Police (Tukariri, 2008). This case highlights how the complex needs of domestic violence victims can mean an ad hoc arrangement is not always a feasible solution for domestic violence agencies. This case was unresolved; the woman stayed in the relationship and, to the knowledge of the Women's Refuge workers, had not left at the time of interviewing.

The Palmerston North Civil Defence representative noted that domestic violence had been discussed at "a couple of meetings" during the recovery phase of the 


\section{Chapter 5}

event. However, Women's Refuge was not present at the meeting and he was unsure of the context of this discussion.

Mark: In respect to domestic violence, there were no major reports about increases, even though tensions were probably running high, but as I say a lot of it probably was external. It was, "the council was at fault," that sort of stuff.

(Harrison, 2008)

No action was taken by the local Civil Defence to follow up on the discussions of domestic violence. More will be discussed in Chapter Seven on this issue.

The representatives of the New Zealand Police in Palmerston North and Feilding did not recall any significant change in domestic violence callouts in the months after the event. At the time of the event, there was not a specific Family Violence Co-ordinator to interview.

Zane: You won't find a significant peak I don't think [in the number of domestic violence callouts], and even if you did, you could only loosely tie it back to the event I suppose because the files won't have enough detail in them to know.

(Kearns, 2008)

Palmerston North Work and Income were also unaware of changes in levels of domestic violence, at the time of the flooding:

Penny: We have very good connections with the local Refuges at each of our offices, but I wasn't made aware of any increases directly as a result of the flooding and the event.

(Rounthwaite, 2008)

However, this was constrained by the fact that Work and Income Palmerston North did not have any system for recording cases of domestic violence at that time (Rounthwaite, 2008). Finally, domestic violence cases were assigned to whoever was available, rather than one specific individual, so lack of communication between staff meant that any evaluation of increases or decreases was difficult and not straightforward. Work and Income co-ordinated 


\section{Chapter 5}

a one-stop, welfare shop on behalf of the New Zealand government (Rounthwaite, 2008). Women's Refuge was not a part of this co-ordinated effort meaning the potential opportunity for capturing any increased need for domestic violence services through this medium was lost.

Other social service agencies, such as the Rural Family Support Trust and Rural Women New Zealand networks, were not aware of any increased violence at this time.

\section{Lower Hutt and the February 2004 Flooding}

Lower Hutt City has two Women's Refuges, a Maori Women's Refuge and a general Refuge. Kokiri Marae Women's Refuge is the Maori Women's Refuge in Lower Hutt. Kokiri Marae Refuge went from working with 14 women in January 2004 to 21 in February and remained at an elevated level for three months, before dropping back slightly. Hutt City Women's Refuge is the general Women's Refuge in Lower Hutt. This Refuge experienced an increase from 71 women clients in February 2004 to 80 in March 2004. This figure dropped back slightly for the following three months before increasing up to 87 in June 2004 .

Hutt City Women's Refuge displayed a significant level of awareness of the effect the flooding had on their work. This was seen in the context of the effect that remote traumatic events both nationally and internationally had on their work. When asked to further speculate why this increase had occurred, the representative of the Refuge stated that for many of the women they work with, watching other women and families go through such a trauma motivated them to face traumas happening in their lives and seek help to deal with this.

Lorraine: I can't say off the top of my head, I can't recall any statistics for you, but I can recall that, you're talking about the floods here, but any traumatic event over the years, we've found, has increased the number of women contacting us. And I think 
what it does is trigger their own stuff. Like after September $11^{\text {th }}$, our stats went up dramatically and when people are watching traumatic things, it's like they have a parallel to their own stuff. It's not necessarily because it's happened to them, but it's because it's trauma and we do have a hell of a lot more people contact us - that was with the tsunami, after September $11^{\text {th }}$ and other incidents that have happened around the world. We've found that there's been a pattern with that and the floods.

(Williams, 2008)

Clearly shown in the above quote is the impact that traumatic events have on victims of domestic violence. This expands upon, and confirms the hypothesis, that the event impacts not just on the abuser and the level of abuse in the relationship, but also on the victim of the abuse and their level of acceptance (Fothergill, 1999). The Hutt City Women's Refuge offers a long-term one-onone counselling service as well as other, more standardized, Refuge services. It is during these sessions that staff members are able to discuss with women their reasons for seeking help and, therefore, they are in a sound position to comment on similarities in women's stories.

The Lower Hutt Police did not have a Family Violence Co-ordinator at the time of the flooding. Therefore, no specific individual was assigned to the recording and monitoring of domestic violence callouts. The Lower Hutt Police stated that there had not been a noticeable change in domestic violence callouts in their area after the flooding (Smith, 2008).

Other agencies in the Lower Hutt area, such as the Salvation Army, did not report a change in the number of domestic violence cases following the flooding. Again, much of the explanation for this was a lack of ability to produce statistics to track any changes. If changes did occur, they did not create a level of awareness for the agency. 


\section{Chapter 5}

\section{Masterton and the February 2004 Flooding}

In the final case study, another clear increase in domestic violence reporting following a natural hazard event was observed. Wairarapa Women's Refuge went from 23 new women clients in January 2004 to 50 women in February 2004. This is more than double its two-year average of 19 new women a month. These numbers then fell away in March and so it would appear that, in the case of Masterton, the increased reporting of domestic violence was relatively short-lived compared to other case studies.

I specifically asked about other campaigns or events in the community that may have caused the increase in reporting. If the Refuge had undertaken an outreach campaign, or had there been another significant event in the community at this same time, then this could perhaps explain the data. However, no other event was found to have occurred at this time that would contribute to such an increase.

Wairarapa Women's Refuge appeared to have the lowest level of awareness of any increase of all the five Women's Refuges interviewed and yet presented with one of the largest quantitative increases in reporting. At the time of interviewing, staff were not aware of this increase or of what may have caused the increase aside from the event:

Lyn: $\quad$...God I'm really sorry - most of the years all meld together...I just really really cannot remember. Because there are many things that cause this, so far back, it could have been, somebody could have died, like, yeah. I'd even forgotten about the flooding till I got the email, I thought "flooding, what flooding?" Just completely forgot.

(Buckley, 2008)

The representative at the Masterton Police station reported that domestic violence callouts for their area had spiked in the month after the flooding, 


\section{Chapter 5}

March 2004. However, this was prefaced with the fact that domestic violence callouts had spiked in March in years before and after 2004.

Glenn: If we look at '06, '05, '04, you've got peaks in March...you've got peaks in May...the other interesting thing is in '04, there is a huge peak in the August/September...so is that an increase six months on? It's inconclusive really

Ros: Did any of the frontline officers comment on people saying the flooding was affecting the families they were seeing?

Glenn: No. No, so there's nothing that came through. It was something that we looked at. We get told that you've beaten up your intimate partner, we will go and deal with the fact that you've beaten up your intimate partner. Those things aren't in the mix from a policing perspective, we're looking at the now.

(Taplin, 2007)

However, in looking at the breakdown of domestic violence crimes reported, offences that were categorised as assaults (one type of domestic violence offence) had increased in the month of March 2004, up from 15-17 in the months before and after March, to 23 in March. This was an anomaly from other years. This finding is consistent with theory presented by Enarson (1999) and the findings in Fothergill's empirical study (1999) that the nature of the domestic violence within the relationship had changed from abuse that was not physically violent to violent abuse.

The February 2004 event was perceived to be relatively small in scale in Masterton. Agencies noted that much of the flooding occurred either in rural areas or limited to a small geographic area in the south of the town. The event did not cause major disruptions to the everyday lives of the residents in Masterton and no forced evacuations were conducted (Taplin, 2007) and so was the smallest event studied in this research. The Police representative noted that there had been some septic tanks that had flooded in a small part of the town, and families in these houses stayed with families until an alternative 


\section{Chapter 5}

arrangement for a bathroom and repairs got underway (Taplin, 2007). However, whilst there was a low-level of awareness about increased domestic violence work, and the event was relatively small in terms of its impact on Masterton, an increase in reporting still occurred for Women's Refuge and the Police.

\section{Agency Profiles}

Looking at each community as a whole showed any community-specific commonalities or differences. It is also important to understand the increase for each agency, and its length and timing, as this will be essential in formulating policy for that organisation. This chapter will now re-examine the increases through each key agency before moving to a discussion of any differences in increased reporting between agencies or communities.

\section{New Zealand Police}

The New Zealand Police presented varied levels and types of increases across the five case studies. For Whakatane Police, the increase was observed to be immediate. In Timaru there was initially a decrease in caseload, most likely due to the lack of phone reception. In the case of the Timaru Police, the breakdown of communication media may explain the reduced level of reporting of domestic violence (and other events) during the first two weeks of the snowstorm. An increase in reporting in Timaru coincided with the restoration of communication lines. In Palmerston North, no significant change was reported.

The lack of a recognised increase in Palmerston North, given the increase reported by Women's Refuge representative, appears to be an anomaly. The New Zealand Police and Women's Refuges reported good working relationships 


\section{Chapter 5}

and therefore, the lack of data could relate to the statutory nature of the New Zealand Police that involves the criminalisation of perpetrators, which can deter women from reporting. Women's Refuge offers the perceived benefit to women that they are neither a government or statutory agency. Therefore, the option of seeking help from a Refuge, as opposed to the Police or another government agency, is preferred by many women (Felson et al., 2002; Apsler et al., 2003; Felson \& Pare, 2008).

Again, levels of domestic violence reporting to Police did not reduce during the events except when reporting was extremely difficult for the majority of the community who were physically isolated from the Police and lacked access to telephone lines or cellphone coverage. When telephone coverage is maintained or restored, the research suggests that the level of reporting may increase to double that observed prior to the event. Responding to these calls and coping with increased duties during the emergency means an increased workload for the affected stations. Moreover, ensuring that the quality of their service does not drop necessitates advanced planning.

\section{Work and Income New Zealand}

Work and Income discussed differing levels of change in domestic violence reporting. Many of the differences related to whether domestic violence cases were formally recorded at the time of the Civil Defence emergency or not. Whakatane Work and Income was the only agency that felt confident that it could categorically state there was a change in domestic violence cases. This certainty stemmed from an increased awareness through reporting by other agencies. Once the issue of increased domestic violence was raised in the Whakatane Family Violence sector, all the agencies involved became more acutely aware of their own enhanced caseloads. 
Work and Income Whakatane stated that they experienced a tripling in the number of domestic violence cases they were working with, leading to a staff member being assigned full-time to such cases in the weeks following the event. Other Work and Income agencies did not have a formal method for recording domestic violence cases and, therefore, were unsure of whether any changes had occurred. Since the time of the events, Work and Income have initiated a Family Violence programme in their offices and, in the future, this may lead to more significant levels of awareness of the impact of Civil Defence emergencies on staff caseloads.

\section{Women's Refuge}

Clear increases were found either quantitatively, qualitatively or both for Women's Refuges in each of the five case studies. This suggests that in future natural hazard events, it is probable that Women's Refuge will again experience a surge in service demand. It is also likely that it will experience the largest increase across all agencies. The response will be discussed in more detail in the next chapter but one clear issue arising from the interviews was that a lack of planning for such an increase has placed the Refuge itself and, subsequently, the women and children clients wanting access to its services, at an enhanced level of risk following Civil Defence emergencies in New Zealand in the last five years.

The figures included in the research only include clients that initiate contact in the period during and immediately after the event. It does not include the impact on those women that Women's Refuge is already working with. Women's Refuge can work with women consistently for years after they first seek help. Not only is the agency working with an increased number of new 


\section{Chapter 5}

cases, they also have a responsibility to the women clients that they are already working with.

Women's Refuge was consistently the agency most affected by the event, with increased demand for services and a diminished level of staffing (which will be discussed in the next chapter). Women's Refuge has consistently had the most difficult experiences during Civil Defence emergencies. It is clear from these five case studies that Women's Refuge will need to take steps to ensure that their services are still functional during both small-scale and very large-scale events and to ensure that women in the affected communities know how to access services during and after the event.

\section{Other Social Service Agencies}

Each community had a different combination of agencies that played roles in the post-disaster domestic violence response. These agencies consisted of combinations of faith-based, iwi-based, non-governmental, and government agencies. Statistics were not available from all these agencies. However, interviews were conducted with representatives from the majority of agencies involved in each case.

Victim Support's work is tied closely with the New Zealand Police's role. Therefore, it is reasonable to assume that increases in reporting of domestic violence to Police would lead to increased workloads for Victim Support. This correlation was observed in Whakatane where Victim Support's work increased in parallel with the Police in that community. Victim Support Whakatane was the only agency that participated from the Victim Support organisation. Therefore, it is unknown whether this trend was present in other communities. However, this seems likely given the nature of the relationship with the Police. 


\section{Chapter 5}

\section{Why such disparate differences in reporting?}

The agencies reported significant differences in the levels of reporting of domestic violence they experienced after the events in their areas. Understanding the differences between these agencies in terms of their role in domestic violence response, the types of services they provide and the level of awareness displayed by agencies, will explain why some organisations experienced significant increases while other agencies in the same community experienced no change.

\section{Statutory/Non-statutory}

Women's Refuge experienced the greatest increase in caseloads across the board, followed by the New Zealand Police and then other agencies. One of the fundamental differences between Women's Refuge and organisations such as the New Zealand Police and Work and Income is that Women's Refuge is a nonstatutory agency. Victims of domestic violence often report a feeling of powerlessness when dealing with the criminal justice system (Felson et al., 2002; Apsler et al., 2003; Felson \& Pare, 2008). The experience of powerlessness, or fear that this could happen, deters women from reporting domestic violence to statutory or governmental agencies. It was repeatedly noted throughout the interviews that Women's Refuge routinely has more clients than the Police and other agencies throughout the interviews (Peterson, 2005; Thomas, 2005; Kearns, 2008; White, 2008; Byers, 2009). Therefore, the additional caseloads following Civil Defence emergencies came as no surprise to interviewees.

Many of the findings of this study are consistent with Enarson's work, in which domestic violence was observed to increase, not just in women's shelters but in other domestic violence agencies, in the United States and Canada following the 


\section{Chapter 5}

Red River Valley flooding. In Enarson's study (1999), the increases were noted to last between six and twelve months after the event. This research found an even longer impact period of up to 24 months following an event.

Alice Fothergill (1999) studied domestic violence reporting after the 1997 Red River Valley flooding in North Dakota and Minnesota in the United States. As stated previously, Fothergill's work involved interviews with two women who reported domestic violence to her during the course of a wider study on the impacts on women of the flooding and the collection of statistics from the domestic violence agency in the area during the months after the initial event. Fothergill also considered the resources available to the agency in the months after the event to gauge what form of impact the event had on both demand and supply.

Because the agency was not a shelter, the statistics used are that of protection orders sought during the relevant period. Fothergill found a significant increase in the number of protection orders sought. The number almost doubled, from 20 orders in the same period the year before, to 33 in the period following the flooding. At the same time, the agency experienced a drop in the number of volunteer hours.

Both Enarson (1999) and Fothergill (1999) focussed specifically on the impact of events on women's shelters, whereas this study includes other types of agency as well. This was done to build on their work and to gauge how widely the increases were experienced in the domestic violence sector. 


\section{Chapter 5}

\section{Type of Service}

The type of service being offered also influences reporting levels. Agencies such as the James Family Trust and Presbyterian Support Services, both faithbased agencies, do not provide crisis assistance. Both work with women (and in some cases, men) after the violent incident has occurred. This was evident in the timing of increases experienced. James Family Trust's creation of a waiting list for their women's programme three months after the event is congruent with the way in which they work. This demonstrates that potential increases in domestic violence reporting and help-seeking can appear months after the actual Civil Defence event is "over". If agencies are not aware of these powerful yet indirect links, these less direct impacts will go unrecorded and, therefore, undetected.

\section{Awareness Levels}

Wilson, Phillips and Neal (1998) examined domestic violence rates in three American communities after natural hazard events. This research involved newspaper searches, collation of statistics and interviews with representatives of agencies in three communities in the United States. Most significantly, this study concluded that awareness of domestic violence as a social issue within the community impacted significantly on whether an increase in reporting was found after each respective event (Wilson, Phillips and Neal, 1998).

Similarly, this thesis found that the attitudes and awareness of domestic violence agencies impacted on their level of awareness of increased domestic violence after the natural hazard events in their communities. Agencies such as the local Civil Defence and wider social support agencies who do not see domestic violence as a significant social problem in their community, in part due to lack of knowledge rather than denial, were most often the agencies that 


\section{Chapter 5}

did not report any change in the level of domestic violence reporting. Agencies that are in the vanguard of domestic violence intervention and prevention, such as Women's Refuge and the New Zealand Police, were far more likely to be aware of and speak about an increase in domestic violence reporting.

It was also concluded in the Wilson, Phillips \& Neal study that if an increase in demand occurred, and the agency was able to meet this demand, then the agencies were not aware of the increase as an issue (Wilson, Phillips \& Neal, 1998). This study also found that the ability to meet increased demand with existing resources had an impact on the agencies' reporting of domestic violence. The majority of agencies interviewed had a minimal level of awareness that reporting of domestic violence had increased in their area during and after their respective events. These agencies were also the agencies that were able to meet increased demand with very little or no external support. In the case of Women's Refuges, at the time of the events, only one Women's Refuge was aware of an increase in caseloads. This was also the Refuge that experienced the greatest increase in clients in the immediate aftermath of the flooding in their area and sought external support to continue their services. For other Women's Refuges, awareness was only raised through participation in this research and, subsequently, some Refuges reported that an increase had occurred and they had not known. Others were still unaware at the time of interviewing that an increase had occurred. It was only through evaluating their monthly figures that an increase was established and no other factors identified for the spikes. These Refuges did not seek outside help with the increased demand, and because of a coping mentality that is systematic in Women's Refuge (Henare, 2009), the Refuges made do with what they had. This meant the disaster increase was no different to everyday life, where the same coping exists (Henare, 2009). 
Access to other agencies' figures was not possible in this study. Therefore, it is unclear if the lack of awareness played a role in the lack of increases reported in some of these agencies. However, it is unlikely that Women's Refuge alone was influenced by a lack of awareness and, therefore, it may be concluded that the increase in domestic violence was experienced more widely than established in this study. Wilson et al.'s research (1998) has clear implications for explaining why some agencies may not have reported an increase in domestic violence reporting when others in the same community did. However, future measures to address the increase in domestic violence established in this chapter will need to include considerations for future measurement of increases, and for how agencies involved in domestic violence response can capture this data effectively. This type of data will be invaluable for the evaluation and review of future policies.

\section{Conclusions}

This study has established that domestic violence reporting did increase in the months across the five case studies in New Zealand. An increase in reporting was concentrated in the Women's Refuges in Masterton, Lower Hutt, Palmerston North/Feilding, Whakatane and Timaru but was also felt across the domestic violence sector in one community - Whakatane. These rises in domestic violence reporting are congruent with other studies previously conducted on domestic violence reporting during disasters.

The scale of the increase ranged from doubling to tripling in workloads across frontline agencies such as Women's Refuge and the New Zealand Police. For some agencies, the increase was instantaneous, particularly those on the frontline. For others, the caseloads rose three to six months after the event. 


\section{Chapter 5}

The impact of the increased workload had continued for over a year after the event officially began in cases such as the Whakatane 2004 flooding. This period is longer than other research had previously suggested and points to the complexity of the relationship between domestic violence reporting and disasters.

Once an increase is established, it is important to look further into the increase, and examine factors and issues that arise in order to formulate effective policy recommendations. The next chapter will discuss the factors suggested by agencies and any common demographics of the women accessing Women's Refuges' services in the months after the events, while Chapter Seven will discuss the policy and response issues that were mentioned or established during the course of this research. 
Chapter Six: Factors and Demographics 

Chapter Five established that domestic violence reporting increased in 11 of the 17 areas surveyed, and in all five case studies within the 17 Civil Defence emergencies surveyed in the months after each event. This documented rise shows the need for policy and procedures in Civil Defence emergencies that both meet the needs of domestic violence victims, and potentially mitigate some of the stresses created by both the disasters and potential policy shortcomings. Therefore, agency representatives were asked to discuss factors they felt were involved in the increased reporting and a picture of the demographic backgrounds of the women seeking help from Women's Refuge was constructed.

This chapter will first discuss those influences that the agencies suggested as causes for the changes in their workloads. It will then discuss the results of comparisons of the case file summaries from the Women's Refuge national database together with the implications of relevant theory on women's decisionmaking process when deciding to stay or leave an abusive relationship. The chapter will conclude by examining the fit of the demographic data of the case file summaries in the database and consider these in relation to the Pressure and Release model adopted in this research.

\section{Knowledge and Understanding on the Ground}

Agencies considered that the principal contributing factor for the increase in the reported cases of domestic violence was financial strain. The events had impacted on people's financial situation in a variety of ways, including creating unemployment as businesses were closed, the loss of possessions (both material and sentimental) and the destruction of homes in some cases:

Neil: $\quad$ Financially, a lot of people were hit pretty hard. Suddenly they've been displaced, a lot of people had to move to other 
houses and of course just getting day to day stuff, so because of the increased stress, we saw more of family violence cases...

(Peterson, 2005)

Glen: ...Urban people who have no other means but one solitary source of income and their worldly goods, when that's taken away they're just thrown into a topsy turvy and even though, like for beneficiaries and so on, their benefit is carrying on the time that it takes to recover tangibly, for urban poor takes a long, long time.

(Anderson, 2005)

Financial strain is shown in the disaster literature as a factor that increase the likelihood of domestic violence following natural hazard events, though not in isolation (Davis \& Ender, 1999; Ariyabandu, 2000; Rashid, 2000). Compounding the stress of the financial situation were factors such as increased abuse of alcohol and drugs, an absence of childcare, and a lack of accurate information about the hazard event and options available to affected families.

An added complication to the financial strain is that, in some instances, the natural hazard event impacted more severely physically on areas that were home to lower socio-economic groups, because cheaper housing is often developed in low lying areas.

Glenn: Well I think in a community like this [Whakatane], and it's intense, I think it affects the poor - the urban poor. The rural setting's different. In terms of the urban setting, generally it's the poor that get affected because the poor have housing in the most vulnerable parts of the community because of the cost and the entire economic and the societal/sociological causes. And economically it's because the poor can only afford rents or if they have the ability to take a mortgage, generally they're going to buy at the lower end of the housing market because that's where they can get in. Otherwise, the poor have been taken advantage, because you have unscrupulous landlords who want to make the most out of their properties and do the least to them. Also, the poor or the marginalised generally feel disempowered to actually go to bat with their landlord and they feel like the landlord has all the power and if they rock the boat too much, they might get ousted. There's a whole tie up - you know self-worth, self values, and the ability to feel that you are empowered, that you are a person that 
should be treated like anyone else and you shouldn't be treated by a measure of your affluence. But often it is. And in this community, of course Awatapu - a community that was affected greatly by this flood - a strong percentage of the community are Maori, not all Maori but a strong percentage and at the lower end of the socio-economic scale. So there's a lot, in those families, many of those families grapple with dysfunction as a part of everyday life and to have this come against them too is...

(Anderson, 2005)

In Whakatane, the community of Awatapu was completely flooded, an area of state and local council housing. The flooding in Awatapu was so severe and the risk so great that the NZ Police needed to evacuate residents overnight (Peterson, 2005). The flooding in Masterton also created the greatest physical impact on a poorer suburb of the town (Buckley, 2008). This type of unequal financial impact on the poor was observed in international disasters such as Hurricane Katrina, where residents of the Lower Ninth Ward (home to lowersocioeconomic families) had their homes destroyed by the hurricane, and other wealthier parts of the city escaped comparatively unscathed (Colten, 2006: 731). This is another aspect of the Pressure and Release model wherein existing economic, political and social structures within societies result in those who can afford to lose the least, living in areas that will inevitably have the largest losses.

The disproportionately greater impact on lower-socioeconomic groups leads to other factors that both stem from having less disposable income and compound the lesser amounts of resources. Lack of insurance was one of the major factors cited in the increase, as it placed additional financial and emotional stress on individuals. 454 out of the 509 families that responded to a mail survey performed by the Whakatane District Council following the floods did not have flood insurance. During interviews for this thesis, agency representatives in Whakatane and Palmerston North reported that the majority 


\section{Chapter 6}

of women they dealt were without insurance and they felt the pressure this put on families was a contributing factor in these cases. Lower-income groups have less disposable income and, therefore, are less likely to insure their homes and household possessions or more likely to live in State housing, which is insured by the Housing Corporation of New Zealand for damage to the house only, not household possessions.

Existing international literature also pointed to a lack of insurance being a contributor to increases in domestic violence (Ariyabandu, 2000; Rashid, 2000). The financial losses create an immense amount of stress on the family and, in turn, without insurance to replace major material possessions and provide the peace of mind that this can happen, the event is that much more stressful for individuals. Those on lower incomes can least afford to lose their possessions and the impact is, therefore, far greater on lower socio-economic groups.

This situation demonstrates and corroborates the Pressure and Release model, which would suggest that the economic structure of New Zealand, which reinforces a level of poverty and lower socio-economic standards in portions of communities as unsafe conditions, leads to an unequal impact from the disaster on these members of a community. The impact is greater on those with less wealth and a smaller pool of financial resources to draw on day-to-day, let alone in an emergency. They are less able to recover from an event because they are unable to replace items lost in the same way that higher socio-economic groups are able to.

The financial impacts are not limited to the immediate aftermath of the natural hazard event. Financial strain and a lack of resources also led to women returning to unsafe situations, which they might otherwise not have done. 
When asked, few agency representatives knew how many had returned. However, Whanau Awhina Women's Refuge in Whakatane suggested 85\% of those who had come to Women's Refuge returned to their partners and, of that $85 \%, 50 \%$ subsequently returned to Women's Refuge (Te Are, 2005). Representatives of Women's Refuge in Palmerston North, Timaru and Lower Hutt also stated that they noticed women returning to abusive situations postevent due to a lack of financial support to leave:

Ros: Did any women return to the situation because they felt they couldn't leave with the snow situation?

Dawn: I think a couple of women did say when they returned that they felt sorry for him, because the farm was in disarray. Because he'd worked so hard for it and it was all gone. So they put away their own needs and sort of gone back, that emotional sort of, can't do it to him now sort of thing.

(Rangi-Smith, 2008)

Women were returning to dangerous situations solely because their financial situation was one that they were not willing or able to stay in. Victim Support also noted some repeat offenders in the months after the flooding in Whakatane, confirming that women stayed or returned to relationships where continued violence occurred. This is important for policy and planning as women returning to a dangerous situation solely because they cannot afford any alternative does not reflect well on policy or agencies who are charged with administrating domestic violence policy and prevention programmes.

The impact of the events on agencies and victims were both more complex and long-lasting that initially expected. Previous literature pointed to impacts lasting up to a year after the event (Enarson, 1998: 756; Fothergill, 1999: 87-88 \& 93). However, the consequences of many of the events in this study were still being felt by the agencies and those directly affected, one to two years after the event. Women that Women's Refuge had been working with to help leave an 
abusive relationship and start an independent life faced immense difficulty years after the official natural hazard event had finished:

Wini: It's still happening now [in 2005]. And that's the thing that's not widely known either. A case in point is a woman we're working with now - she's got 6 children, she's been a beneficiary since she was probably 17 or 18 , she lives in a house in Awatapu that the landlord still refuses to mend, has made it okay for the power and that to go on but other than that hasn't done any structural thing, it's still damp, it still stinks...Charging rent. And she lost all her stuff...

Only one overseas publication has suggested that the consequential effects would continue for up to a year (Fothergill, 1999). These prolonged impacts were described as being in the form of family separations, domestic violence, children losing interest in school, increases in the price of housing and having to replace lost possessions whilst on a limited income (Anderson, 2005; Te Are, 2005). This has maintained financial and social pressure on families who were already struggling to cope. Civil Defence plans mention that recovery is a medium- to long-term prospect, but discuss only those non-social aspects, such as the return of infrastructure and economy, without providing any recognition of the above social effects (MCDEM, 2008).

Many of the factors described above are linked to lower socio-economic groups and, therefore, not only stem from lower socio-economic status, but feed back to compound fiscal uncertainties and place an enormous amount of pressure on the most vulnerable members of society. In Palmerston North, Whakatane and Timaru, Women's Refuge representatives felt they were working with a majority of lower socio-economic women (Te Are, 2005; Rangi-Smith, 2008; Tukariri, 2008). This confirms the argument of the Pressure and Release model that lower socio- economic groups will experience greater negative consequences from a natural hazard event than those in higher socio-economic groups (Wisner et al., 2004). In at least three of the five case studies, agencies working 
closely with women experiencing domestic violence during disasters noticed that the impact was greater on women with less access to financial resources than those with more:

Wini: The flooding didn't have one specific finance. The only thing I would say about that is probably the lower socio-economic group was the one we had more ongoing work with whereas the support that we gave to the families of Awakere and Edgecumbe was more around not so much resources but information, support, just giving them options of where to go - just that sort of stuff. They were the ones more likely to have insurance cover, they were more likely to be able to have a few days in a hotel for some R \& $R$, whereas our families in Taneatua, especially in Awatapu, Ruatoki, Murupara and down didn't have that same kind of access.

(Te Are, 2005)

As noted above, agencies reported that the increases were across the board in terms of levels of family income and, therefore, it cannot be solely financial pressures driving the increases in domestic violence.

Ros: One thing I wanted to know, in terms of demographics, if there was a specific group in the community that was overrepresented in the family violence statistics...

Neil: $\quad$ Yes

Ros: Was there an age range?

Neil: No, I think the easiest way, is its location really I think. Our lower socio-economic area in Whakatane is called Awatapu and that's surrounded by a stopbank and has got a lagoon running through it and what happened was, the system didn't work and the lagoons flooded and the stopbanks kept the water in. So that lower socio-economic area was hit hard. We're talking two metres of water through that area, and I was there, up to my waist rescuing people. So that was one area. But then it went out to, well we had slips as well as floods, so we've got Ohope, which is quite a wealthy area, had slips and then the farms out in the rural area. They had real problems - the whole plain was under water so again the farming community were hard hit. Out Edgecumbe where Jenny is from, that was another town on the edge of the river that was flooded. So no, every part of the community was affected by the floods, as far as who got involved in domestic violence, that was across the board as well. There were people in the farming community that were under stress, but I think if we look at the figures I still think it would have been perhaps the lower socio-economic areas who 
were hit hardest as far as family violence because they don't have the safety mechanisms in place and I think they react a lot differently...My thoughts are it was well spread across the whole community but worse in the areas like Awatapu.

Ros: So it was across ethnicities?

Neil: $\quad$ Yes

Ros: And age?

Neil: $\quad$ Yes

(Peterson, 2005)

Adding to the stress of material loss, four of the agency representatives pointed out that alcohol and drugs had been a factor in a number of the domestic violence cases they had dealt with (Anderson, 2005; Peterson, 2005; Te Are, 2005; Tukariri, 2008). Whilst alcohol and drugs alone were not the cause, they were contributors or aggravators to the situation.

Neil: Alcohol is the aggravator, obviously there's trigger points but alcohol leads up to the trigger points. The trigger points are stress, lack of money...

(Peterson, 2005)

Wini: I believe what the flooding did was accelerate any of those hyped feelings - in some cases drugs were still present. But the flooding definitely had like a century kind of boom.

(Te Are, 2005)

Interview participants noted that substance abuse was an aggravating factor in domestic violence cases but all those interviewed stressed that, whilst there had been alcohol abuse present in some cases, this was not the principal cause of the violence, confirming a pattern noted in other studies of domestic violence (Kaufman Kantor \& Straus, 1987; Farris \& Fenaughty, 2002, p. 343; Raskin White \& Chen, 2002). Focusing on addiction or misuse of drugs or alcohol sidesteps the question of why abuse, if any, is directed only against intimate partners or children rather than friends or co-workers, and why those who abuse are often able to function well in the public sphere. 
The stress of a natural hazard event not only affects the perpetrators of domestic violence, but also the victims (Enarson, 1998: 755). Both parties are under a lot of pressure and their abuse thresholds may change. Events not only pushed perpetrators of domestic violence beyond their limits but they influenced victims too. The level of violence that was ordinarily tolerable was now excessive, not only because it may well have escalated but also because the bar was lower. . The disaster brought things to a head, and in one case, a woman speaking to Women's Refuge no longer felt able to live in a violent relationship:

Julie: One woman said to me, I wrote it in her file, she said it would have been better for her to perish in the floods than to live one more day with the violence.

Added to everything else that was transpiring, the women would no longer accept the violent behaviour of their partners. An increase in the number of reported cases is indicative of this. With a lowered tolerance level, women are more likely to report domestic violence and, therefore, not only do the number of incidents of domestic violence potentially increase, but the number of reported cases does also:

Wini: I think there was family violence present in those relationships prior to that - I think what was noticeable was a huge percentage of them hadn't asked for assistance before that. It may be like, one of the woman I'm thinking about, you know it only happens a couple of times a year, or he's not so much hitting me but psychologically abusing me and putting me down. And that was more the families on the Awakere plains and families on Brian's beach and from Waiotahi and the farming communities out in Waimana, you know, violence had been present in their relationships however they've never made contact with anybody to actually either find some way through that...

(Te Are, 2005)

Julie: $\quad$ The violence is always there... always there...

Dawn: ...They are already, long before the snow comes, and they are in a situation that is not quite as healthy as they would want it 
to be. So anything like this - be it a major flood or snow, is going to accelerate the feelings this women has got. And make everything seven times worse...no it was definitely underlying and this sort of brought it up to the surface. It was tolerable before but the event kind of pushed it up, yeah, and so it wasn't any more...

(Rangi-Smith, 2008)

On top of the stress of the event itself and the financial impacts, interviewees brought up certain structural factors that added, rather than relieved, the stress individuals were experiencing. Themes such as unclear information, too much bureaucracy and a lack of guidance were evident and need to be explored in depth.

The uncertainty concerning the future that many of those affected by Civil Defence emergencies felt was marked (Te Are, 2005; Millard, 2008; Phiske, 2008; Rangi-Smith, 2008). This was in part because they had no timeframe for when life would return to normal. The downstream impacts of the events continued long after expected recovery times. In Feilding, residents were without water for weeks, in some cases. For rural Timaru residents, electricity that was lost due to the heavy snowfall was not restored for up to two months after the initial snowfall. In Whakatane, it took significantly longer than expected for people to get back into their homes and gaining access to any sort of compensation took months. The agency representatives interviewed noted that many of the women who reported domestic violence to an agency spoke of how frustrating it was to not know accurate timeframes for infrastructural and lifeline repairs to be completed.

There was also problematic communication between Civil Defence and the community, as well as with other agencies. Communication lines were not immediately open, both between, and within, agencies. This meant that there was some contradictory information issued to agencies and the public, and it 
became a time-consuming and frustrating process to gain access to the resources available to cope during and after the event and accurate information on what was transpiring. Getting mixed and inconsistent messages and not knowing how to meet the official requirements for attaining food parcels or bedding or any other basic necessity, adds more stress to the situation rather than mitigating it:

Wini: It would be time-consuming, you had to have the right documentation to get it, the families we were feeding weren't necessarily families that were...not evicted from the flood...there's another word they use...

Ros: $\quad$...Oh right, so they couldn't go home...

Wini: $\quad .$. Yeah, couldn't go home and yet if they didn't have the documentation or the tag that said they were Civil Defence number so and so, they weren't able to access readily the things they needed. Whereas our families were doubling up in different family groups - like we had a grandmother who was struggling to feed her six grandchildren which didn't necessarily mean she fitted under the criteria of Civil Defence, that those grandchildren came from the flooded area - like Awatapu - and they didn't go to the War Memorial meant they weren't eligible for that help. So they didn't get it.

(Te Are, 2005)

The lack of communication also resulted in agencies not knowing what partner agencies were experiencing. In all but one of the case studies, government and non-government agencies were unaware of the increase in workloads for Women's Refuges. Whilst all agencies involved spoke of a strong, open working relationship between themselves and other domestic violence agencies, this appears to have broken down for some period in the time of the Civil Defence emergencies. Four of the five Refuges did not express the doubling of their workloads to other agencies at the time. Instead, the attitude was to "pitch in" and get the work done:

Ros: $\quad$ So you just had to cope?

Dawn: Yeah. We had to cope with what we had. Well I think too Ros, it was a matter of I didn't ask. I think I could have gone to the Mayor or could have asked but I didn't. So we made do with what we had. 


\section{Chapter 6}

(Rangi-Smith, 2008)

This will be discussed further in Chapter Seven in the context of all response issues.

A number of interviewees felt that government agencies they were working with did not have the autonomy needed to get things done and this slowed down the recovery process and led to stress for the agency workers:

Ros: What, if anything created frustration for staff members?

Roberta: Just with regard to, I suppose not having been set up for the rise in domestic violence and having to go through bureaucracy, an incredible amount of bureaucracy, in order to find safe houses for the women affected

(Ripaki, 2005)

The representative went on to discuss the numerous agencies that needed to be consulted and the number of managers that had to concur, which produced a protracted bureaucratic process, without finding extra housing for women and children staying in the Women's Refuge safehouse. As a consequence of this extensive bureaucracy and a lack of trust between agencies, the needs of domestic violence victims were not being met at a time where they were in an exceptionally vulnerable situation.

A further process of the Civil Defence response in all communities that caused difficulties for families was the closure of schools and childcare facilities for varying periods of time. Some were as short as a day while others extended to 10 days. No alternative was given and, therefore, parents were left with children in the home or in temporary accommodation all day whilst trying to sort out the future of their house, possessions, lost income and, for farmers, livestock. Safety of the children is the rationale for this type of decision. However, as in the case of Feilding, whilst there was no water supply at school, 
there was also no water in the homes. Following the snowstorm in Timaru, schools were closed for one week, but many of the rural families were snowedin for weeks after the initial fall. Having children at home in the immediate aftermath of the natural hazard event is problematic. The interviews showed that currently policy neglects parents to have time out and children's needs to have an ordered routine in times of upheaval such as Civil Defence emergencies (Ronan \& Johnston, 2005). Participants stated:

Ros: Did any of the women say that that was a part of it [why they were seeking help] - having the children home while they were trying to deal with it, clean up?

Jenny: My memory is yes it was, it was extra stress put on the families at that time, and it was having children at home.

(Thomas, 2005)

Dawn: $\quad$...it was like a combination of the stress - the stress that the women were on, and general, a lot of children couldn't go to school so children were home, just the whole thing.

(Rangi-Smith, 2008)

Relieving the adults of parental care duties for at least a few hours a day during the first weeks of the state of emergency would have given individuals a chance to regroup and plan without the additional stress and concern of ensuring the safety, and entertainment of, their children. This is also relevant for policies for meeting the needs of children post-disaster, who if given a chance to meet and play with their peers can discuss what has happened, and find adjustment to the losses they experienced less stressful (Ronan \& Johnston, 2005). Other studies have also suggested childcare options during events are a part of the wider network support that would help mitigate domestic violence increases (Davis \& Ender, 1999: 187). 


\section{Chapter 6}

The issue of what tasks are categorised as "recovery work" and how this affected women was raised during interviews. Agencies had differing perspectives of what recovery involved. For some agencies, recovery was simply a matter of offering financial support and aiding in the physical recovery, while other organisations expected recovery to involve a welfarefocussed approach, offering support and counselling as well as advice where appropriate. The Whanau Awhina Women's Refuge representative spoke of cases where people were given money from funds like the Mayoral Relief Fund and then it was assumed that all obligation to those people had ended. These people then used the money unwisely and rather than putting their home back together, they purchased items they had never owned before, or used the cash as down payments for purchases on credit. Some agencies were infuriated by the seemingly senseless purchasing and did not look further to understand that when people go from having little to no purchasing power to sudden access to an extremely large amount of money with no advice on what to do, this situation is almost inevitable. The Women's Refuge representative observed, “That's just charity at its worst isn't it? Their obligation to this family is done because they've issued it (money) and what she does with it is her responsibility," (Te Are, 2005). She argued that entities, such as the Mayoral Fund, have an obligation over and above financial considerations, to help members of the community in the form of guidance and advice.

Financial strain was reportedly at the core of the stress that led to the new domestic violence cases dealt with following the Whakatane floods. The financial uncertainty and loss that accompanies a Civil Defence emergency affected all parts of the community but, in particular, the poorer members of the group who were over-represented in the domestic violence statistics. The disproportionate effect resulted from a lack of work when businesses were 
closed and the overwhelming losses that without insurance were crippling for the lower-socioeconomic groups. Compounding this were aggravators such as alcohol and drugs, having the children at home during the response phase, a lack of accurate information and guidance about how to recover, and the length of the displacement (which was still affecting people more than three years after one event and up to two years after the remaining four case studies). These factors increased the incidence of domestic violence and coupled with different thresholds of abuse on both sides, (i.e., perpetrators' violence being heightened and victims' tolerance levels lowering) led to an increase of abuse reporting of between $100 \%$ and $300 \%$ for agencies in the wake of the five different Civil Defence emergencies.

\section{The Relationship between the Increases and the Events}

The data contained in this research clearly establish a relationship between increases in reported domestic violence and the Civil Defence emergencies occurring in the same community. However, the relationship is complex and multi-faceted. It is not simply that the event causes a man to abuse his domestic partner or turns a healthy relationship abusive. It seems that in most cases, some level or form of abuse was present in the relationship before the event but the event has exacerbated the situation, potentially in multiple ways and, consequently, more women reported domestic violence or seek help. This was discussed by those in frontline agencies:

Diana: ...l would say that in the majority of cases there had been an element of violence or control present in the relationship previous to this. And that it had escalated following the floods.

(Oomen, 2005)

Wini: l've said this before, if there was violence in the relationship beforehand, what the floods did was escalate it.

(Te Are, 2005) 


\section{Chapter 6}

This situation was also highlighted in Fothergill's study (1999), in which one of her interviewed women stated that her husband had not been violent in the relationship in 20 years, but had maintained a pattern of controlling behaviour during that period. Immediately after the flooding struck in their area, the violence returned, and she subsequently left the relationship (Fothergill, 1999).

It is not only perpetrators that are affected by disasters. Enarson (1999) points out disasters often have a multitude of effects on the individuals involved in abusive relationships. The destruction of a house can reduce the level of investment a woman holds in the abusive relationship and provide motivation for reporting of current violence. Aid money can provide the financial means needed for transport out of the area or to a Refuge. This was also seen in Fothergill's work in which one of the women interviewed had experienced an increase in self-esteem and her feeling of self-efficacy as a result of having to respond to the flooding in her area (1999). The woman left the abusive relationship in the period following the flooding, and put much of her decision down to the increased self-esteem and self-efficacy she felt (Fothergill, 1999). In addition, for the perpetrator, the loss of control and increased stress can cause a heightening of the severity and frequency of abuse (1999: 748). This was also exemplified in one of the cases presented by Fothergill discussed in the previous paragraph (1999).

Without interviewing every woman and man involved in the caseloads of domestic violence agencies in the months after each event, the degree to which the event impacted on domestic violence levels cannot be stated irrefutably. What can be shown is that reporting of domestic violence did increase in the months after these events and, other than the event, there is no other changed set of circumstances or explanation offered in each case to explain this. During 
the interview, each agency was asked if there was an outreach campaign, another event, or any other explanation that could account for an increase in domestic violence reporting at that point in time. No other significant explanations were offered to explain this increase. Therefore, it is reasonable to assert that it was the event that acted as a catalyst to varying degrees for different people to report or seek help during the months following each event.

As a measure to probe deeper into the situation of domestic violence during disasters in New Zealand, this study examined 263 case file summaries of women reporting domestic violence to Women's Refuge in all five areas in the months after their respective natural hazard events. The use of the case file summaries from Women's Refuge is a way to examine any commonalities between women seeking help from Women's Refuge in all five case studies and to understand the type of work staff members were undertaking.

Accessing the demographic information will aid in evaluating the Pressure and Release model for its utility in terms of multiple vulnerabilities, as well as giving more insight into factors causing the increase in domestic violence reporting itself. The Pressure and Release model presents intersecting vulnerabilities creating different levels of risk to disaster, stemming from underlying social structures based on factors such as class, race, gender, age, and ability.

The age range of women accessing help from Women's Refuge noted in the case file summaries during the three-month period after each event in the five case study areas was 15 to 81 years of age. However, there were two principal age groups presenting across all seven Refuges. The first is women aged 35-44 years and the second is women aged 15-24 years. Women aged 35-44 years 


\section{Chapter 6}

comprised $30.1 \%$ of the total women seeking assistance, and women aged 15 24 years comprised $29.4 \%$ of all cases.

In terms of ethnicity, the two major groups reporting domestic violence to Women's Refuge were NZ European/Pakeha and NZ Maori. NZ European/Pakeha made up $51.3 \%$ of the total women and NZ Maori made up 43.5\%. Whanau Awhina Women's Refuge in Whakatane was an exception to this trend with 71.7\% Maori clients in the aftermath of the flooding in 2004, an expected result as Whanau Awhina Women's Refuge is a Maori Refuge and the Maori population in Whakatane $42.2 \%$ (Statistics New Zealand, 2008a), three times higher than the national average of $14.6 \%$ (Statistics New Zealand, 2008c). With only $42.2 \%$ of the population listed as Maori, the Maori in Whakatane make up $71.7 \%$ of the domestic violence reports. However, both figures equate to an overrepresentation of Maori reporting domestic violence after disasters. In saying this, ethnicity in isolation does not emerge as a strong predictor of whether domestic violence was reported by women during disasters in New Zealand. The higher percentage or Maori clients was coupled with a majority representation of those in lower socio-economic groups.

Socio-economic status is much harder to measure through the data available in the Women's Refuge national database. However, the employment status of the women was part of the information collected by Women's Refuge workers and can be viewed as a rough proxy for income. A clear majority of the women seeking help from the seven Refuges in the months after each event were not employed in the labour force. Employment status varied from being recorded as a "Stay-at-home mum" to "Unemployed" on a relevant benefit (welfare payment). Grouping these categories together, women not in paid employment represented $76.5 \%$ of the women. Within the $76.5 \%$, the most significant group 
were "Stay-at-home mums" who comprised $45.4 \%$ of the 263 case files analysed. However, what is not clear is whether the women in the "Stay-at-home mum" category are on a welfare benefit also putting them in a lower socio-economic group, or if they are at home and their partner/husband is earning the family income. What this highlights is that the majority of women were either in a low socio-economic group or were solely dependent on their partner/husband for financial support. Both of these positions may leave the women vulnerable during a disaster, as regardless of the family income, their access to finances may be restricted.

This intersection of race/ethnicity and class can be seen in this study in the statistics from Women's Refuge and in the interviews conducted across agencies. Domestic violence research also suggests that race/ethnicity alone is not a significant indicator of domestic violence prevalence although ethnic minority women are more highly represented in reporting statistics (Lockhart, 1987: 609; Fisher, 2006). However, the intersecting variable of social class makes it difficult to separate racial and ethnic over-representation from lowerclass over-representation (Lockhart, 1987: 608).

A lack of access, or strongly restricted access, to financial resources is one of the "unsafe" conditions discussed in the Pressure and Release model. In the context of the Pressure and Release model, domestic violence would be the dynamic pressure that translates an underlying patriarchy in society into unsafe conditions. For many of the women, it is not just a situation of not having financial resources; it is not being able to participate in the decision-making process of how money should be spent. Both of these limit a domestic violence victim's ability to respond to and recover from a disaster. These conditions are 


\section{Chapter 6}

complicated by other factors, as well as intersecting dynamic pressures from other social, political, and cultural structures in the society.

To further understand the relationship between the event and domestic violence reporting, specifically whether there is a strong relationship, the case notes written in each case file summary were examined. Case notes are the part of the case file summary where Women's Refuge workers can enter any extra information that they want recorded that does not fit in the other categories. In reviewing case notes, any references made to the respective events were noted, and this offers the most direct link between the woman seeking help and the event. Interestingly, in one particular case, the worker notes specifically, "the violence has been much worse since the flooding." Given that, at this point in time, there is no formal system for recording that situations such as an emergency are impacting on a case, this type of note is not found extensively throughout the database. However, the existence of such notes further indicates that Civil Defence emergencies impact on levels of reported domestic violence.

The case file summaries provided the opportunity to look at what form of work Women's Refuge was undertaking in the months after the Civil Defence emergencies in their community. Issues such as how long the enhanced workload lasted, how much time was devoted to each case, whether the women were first-time clients or repeat, and whether the women returned again after the initial contact during the post-event period, were examined.

Many of the interviewees reported that they believed the abuse in the relationship had preceded the event (Te Are, 2005; Rangi-Smith, 2008; Tukariri, 2008; Williams, 2008). This is not to say that the violence within the 
relationship had not changed. It may have become more frequent, more severe, or shifted from emotional and financial abuse to more physical abuse. Rather the agency representatives felt that natural hazard events were not turning healthy relationships into abusive ones. To examine this further, two variables that are captured in the national database were considered:

1. Whether the women seeking help in the months after the Civil Defence emergency had sought help from Women's Refuge previously.

2. How long the abuse had been occurring prior to reporting.

The first variable is considered to demonstrate what proportion of the women were first-time reporters. Although this does not create a causal relationship between the event and the reporting, it identifies the number of women who had not previously been motivated to report. The second figure, the duration of abuse prior to reporting, is a much more telling statistic in terms of understanding whether domestic violence had increased, or whether it was the reporting that had increased.

When looking at whether the women had accessed Women's Refuge services before the events, $57.2 \%$ had not been to a Refuge before. This means the majority of clients that Women's Refuge work with during disasters are firsttime reporters. As has previously been observed in this thesis, if a woman seeks help and is met with less than satisfactory service, this will negatively influence the likelihood of her reporting again (Berk \& Newton, 1985; Berk, Newton, \& Berk, 1986; Holiman \& Schilit, 1991; Sullivan, 1991; Davis et al., 1994; Barnett et al., 1996; Sullivan \& Bybee, 1999; Allen et al., 2004; McDermott \& Garofalo, 2004). If these first-time reporters are finally able to make the decision to leave an abusive relationship, but come in contact with an 


\section{Chapter 6}

agency that is unable to manage its caseloads, the opportunity to work with this woman could in all likelihood be lost forever.

In contrast to the first-time reporting majority discussed previously, the most common duration of abuse reported was between five and ten years (23.7\%), followed by between three and five years and between two and three years equally (21.1\%). Combining these three groupings indicates that the majority of the abuses had been occurring for between two and ten years (65.9\%) before the women reported at the time of the emergency. This supports the assertion put forward by numerous agency representatives that the abuse was not new, or caused by the Civil Defence emergency (Te Are, 2005; Rangi-Smith, 2008; Tukariri, 2008).

Wini: It was the biggest part of the group that we worked with, I think there was family violence present in those relationships prior to that - I think what was noticeable was a huge percentage of them hadn't asked for assistance before that. It may be like, one of the woman I'm thinking about, you know it only happens a couple of times a year, or he's not so much hitting me but psychologically abusing me and putting me down.

(Te Are, 2005)

For those interested in a causal analysis of the situation, this moves the focus of research away from looking at factors involved in domestic violence, to looking at factors contributing to domestic violence reporting. An awareness of why a Civil Defence emergency would prompt more women to report domestic violence, if this is the case, is vital in creating effective policy and planning to address increased domestic violence reporting.

Research into a woman's decision to stay or leave an abusive relationship has established six differing theories on the dynamics at play: Learned Helplessness; the Investment Model; Traumatic Bonding; Rational/Planned 
Behaviour Theory; Psychological Entrapment Theory; and the 2-Part Question Model. The theories can be separated into two groups. There are theories based at the individual level which look at the victim's self-esteem and other psychological traits: Learned Helplessness; Traumatic Bonding; and Psychological Entrapment Theory. The second group focuses on both the woman and the society she is based in: Investment Model; Rational/Planned Behaviour; and the 2-Part Question Model.

\section{Learned Helplessness}

Learned helplessness theory was most commonly applied to understanding depression before Walker used its basic principles to examine the case of battered women (1979). Walker (1979: 46) argued that learned helplessness explained why some victims of domestic violence displayed "passivity" and a dependence on their perpetrators. This theory argues that women learn that there is little they can do to reduce the violence in the relationship, as their differing attempts over time to appease the abuser all result in the same response (Launius \& Lindquist, 1988). A hypothetical example would be if a woman constantly tries to perfect her cooking to avoid a confrontation at dinner-time and none of her actions manage to achieve this, her belief in her self-efficacy is diminished. This type of response pattern wears the victim down until she eventually does not believe that the violence will ever stop, regardless of whether she leaves the perpetrator or not (Rhatigan et al., 2006: 332).

Rhatigan et al. (2006: 332-333) point out that this model does explain some women's behaviour in an abusive relationship, but fails to account for why some women do leave, and the motivations behind their decisions. If abused women lose all self-efficacy, then the question of what causes them to try to leave remains unanswered in the Learned Helplessness model. Rhatigan et al. 


\section{Chapter 6}

further posit that this model, although it explains some of the internal barriers to a woman leaving an abusive relationship, does not address the external barriers to leaving (2006: 333). It also does not allow for those women who actively choose to stay in a relationship, instead tacitly assuming all women want to leave but do not have the agency. Finally, it is in conflict with other empirical studies, which find that the level of violence in a relationship makes it more likely for a woman to leave (Rhatigan et al., 2006: 333).

Relating the Learned Helplessness hypothesis to increased reporting of domestic violence in disasters will only explain part of the story. Enarson points out that the disasters may give some women a sense of their own strength and lead them to think that if they can survive such a disaster, then they will be able to survive outside of the relationship (1999: 748). By building their self-esteem through achieving during the disaster, this may break the cycle of learned helplessness and, therefore, is a possible explanation as to why women are more likely to seek help in the months following a disaster. However, it does not go as far as to explain how women can carry out their decision, again because the Learned Helplessness model does not include external factors that may affect the decision to leave or stay.

\section{Traumatic Bonding}

Traumatic Bonding theory is based on the premise that the victim of the abuse develops a bond with her abuser (Dutton \& Painter, 1981). Based in psychology, Traumatic Bonding theory argues that the victim of domestic violence develops a strong emotional link with her abuser through a cycle of alternating negative behaviours (such as the violent outburst) and positive behaviours (such as the "honeymoon period" that follows the outburst) (Rhatigan et al., 2006: 333). The cycle begins when the perpetrator uses 
coercive techniques to make the woman feel as though she cannot look after herself and erodes her self-esteem. This is paired by intermittent violent outbursts followed by periods of remorse on the part of the perpetrator when the perpetrator may try to "make it up" to the woman. This fits with the cycle of violence that other theorists (Walker, 1979; Strube, 1988) and practitioners (National Network of Stopping Violence, 2005; Women's Refuge, 2009) argue exists.

Traumatic bonding theory also submits that if a woman does try to end the abusive relationship, the bonding that has occurred will cause the woman to return to the relationship. Dutton and Painter argue that a period of separation actually increases the bond the woman feels for the man as she minimises the impact of the violent outbursts and focuses on the good aspects of the relationship (1993: 109).

Although this model may explain part of the dynamics involved in an abusive relationship, it also insufficient to explain how women decide to leave the relationship and the external and internal barriers to this. As in the Learned Helplessness model, it only accounts for part of the picture and, therefore, cannot explain, in isolation, the factors involved in a woman's decision to stay or leave an abusive relationship.

Traumatic Bonding theory seems to stand in direct opposition to what has been observed of domestic violence reporting in disasters. Traumatic Bonding theory would argue that if a woman is in an unstable situation then she is more likely to bond with the abuser than if in a stable situation. By extrapolation, this would suggest that the women are less likely to report. Moreover, if agency representatives are correct that, in some cases, the violence in the relationship 


\section{Chapter 6}

became more intense during the disaster, this would suggest that the woman would build a stronger bond with the abuser during the event and would be less likely to report. Therefore, the Traumatic Bonding theory does not explain the situation observed in this research and other similar studies (Enarson, 1999; Fothergill, 1999).

\section{Psychological Entrapment}

Psychological Entrapment focuses wholly on the victim of domestic violence and argues that, as the level of the violence in the relationship escalates, she will increase her efforts to continue the relationship in order to "make good on previous contributions" (Brockner \& Rubin, 1985: 5; Strube, 1988: 241; Ben-Ari, 2003: 540). Strube (1988: 241 ) submits that when the abuse first begins in a relationship, women will put effort in to try and mitigate it. These efforts inevitably fail but rather than accepting their efforts were wasted and the abuse will continue unless she leaves, the women put in even more effort to try and stop the abuse, thus making the previous efforts worthwhile. This cycle continues and is sustained by periods of harmony in the relationship, when the abuse subsides and the perpetrator apologises and attempts to "make it up" to the woman. This act leads the woman to believe she is making progress in her pursuit of a healthy relationship and is one of the reinforcers of the cycle. The good phases of the cycle must be of a sufficient quality that the woman still values her relationship. If the quality decreases, it must do so in a slow fashion such that the accumulated invested effort in the relationship is sufficient to keep the cycle going. If the relationship quickly deteriorates, the invested effort may be insufficient for the woman to continue and, therefore, she will not become entrapped (Strube, 1988). 
Strube (1988) and Rhatigan et al. (2006) discuss the five requisite circumstances needed for a woman to become psychologically entrapped in an abusive relationship. These state that victimised women must:

1. Actively try to maintain their relationships

2. Continue their efforts in spite of violence received

3. Question the benefit of the continued efforts

4. Acknowledge the choice involved in deciding whether or not they should maintain their relationships

5. And the goal of a healthy relationship must be unlikely or hugely costly to be attained.

(Strube, 1988: 241)

This model and others that do not account for external factors acting on the woman and perpetrator, is insufficient to explain a woman's decision to stay or leave. In a similar manner to the Traumatic Bonding theory, this theory would suggest that women are less likely to report during disasters as increased violence leads to women choosing to put more effort in maintaining and "fixing" the relationship. This was clearly not evident in the cases studied in this research.

\section{Investment Model}

The Investment model was initially applied to relationships in general, including friendships and romantic relationships. According to Rusbult and Martz (1995: 559), the model successfully explained why a person would continue in a relationship after a negative experience within it. Proponents of the Investment model argue that victims of domestic violence, as in all relationships, become committed to the relationship through a range of actions, and the level of commitment to a relationship will determine whether a woman chooses to stay or leave. 


\section{Chapter 6}

Commitment is the degree to which the woman wishes to maintain the relationship, feels attached to it, and sustains a long-term mindset about it. Commitment is a complex concept within which, Rusbult and Martz (1995) argue, there are three further factors that affect an individual's commitment to a relationship: satisfaction, alternative quality and investment size. Satisfaction is the degree to which the individual evaluates the relationship positively. Alternative quality refers to the attractiveness of alternatives to the relationship, including other potential relationships, the quality of life when single, housing opportunities, income opportunities, and so on. Investment size refers to the size and number of resources tied to the relationship, such as mutual friends, children and, of course, material possessions (Rusbult \& Martz, 1995: 559-560).

Rusbult and Martz (1995) argue that if there is a high level of commitment, limited or poor-quality alternatives and a large investment of resources, then an individual may stay in a relationship that is otherwise not satisfying. This, the authors submit, is why women may choose to stay in an abusive relationship, even after they realise the abuse will not stop with time (Rusbult \& Martz, 1995).

When this model was applied to a study of 100 women seeking help from a battered women's shelter in the United States between 1978 and 1982, it was found that women had a greater commitment to the relationship if they were satisfied in those non-abusive parts of the relationship. That is, the honeymoon stage of the abuse cycle was good, the quality of alternatives were poor, and the level of investment of resources was high (Rusbult \& Martz, 1995). The research involved interviews with the women consisting of both quantitative questions and qualitative measures. 
This model offers a more thorough explanation of why women leave abusive relationships than the previous models, which were all based on the individual. It is able to include both the dynamics of the individual relationship in looking at the satisfaction the woman feels, as well as external forces through the quality of alternatives and the size of the investment. The size of the investment includes the concept put forward by the Psychological Entrapment theory, in which the woman looks at not only the level of shared resources, but also the effort already put into the relationship when deciding the level of commitment she feels towards the relationship. Rhatigan et al. point out that whilst the model does allow for the dynamic nature of relationships, by acknowledging that commitment changes with time, it does not account for the women who stay in the relationship because of fears for their safety if they leave and not because of a commitment to the relationship (2006: 336).

This model has more success than the previous three in explaining why reporting of domestic violence increases during disasters. During a disaster, all three factors that influence a woman's level of commitment are affected. If the violence becomes heightened (as reported by some of the interviewees) and the good parts of the abuse cycle are reduced during a disaster, owing to the stress of the event and its impact on the home, work and possessions of the couple (also reported by interviewees), then the level of satisfaction a woman derives from the relationship will be reduced. At the same time, the unanticipated access to recovery funds and alternative housing during evacuations may increase the quality of the alternatives a woman sees for herself. Finally, if the household and its possessions are damaged or destroyed (also reported by interviewees) or the social network is broken due to relocation, then the size of a woman's investment in the relationship may be substantially reduced. Any combination of these effects may be enough to reduce a woman's level of 


\section{Chapter 6}

commitment to a level where she will seek help to leave the relationship. Again, the Investment model does not predict the behaviour of those women who stay in a relationship due to fear of the violence that could follow an attempt to leave.

\section{Rational Action/Planned Behaviour}

Rational Action theory was first proposed by Fishbein and Ajzen (Fishbein \& Ajzen, 1975; Ajzen \& Fishbein, 1980) and is based on the premise that all individuals, including domestic violence victims, make rational decisions based on outcome expectancy and the societal norm (Strube, 1988: 247; Choice \& Lamke, 1997: 293; Rhatigan, 2006: 335). In essence, it contends that domestic violence victims make decisions based on a cost-benefit analysis, where potential costs (such as future violent acts or income loss) are weighed against potential benefits (such as being free from the violence, or children not having to witness or be victim to the violence). It argues that the women will make decisions based on all the information available to them at the time, and will base this decision on the expected outcomes of this decision (Strube, 1988: 247; Choice \& Lamke, 1997: 293; Rhatigan, 2006: 335). Factored into this is the societal norm, which is deemed to include the woman's social networks, as well as wider cultural and societal norms, and the influence this has on her decision-making. If the woman has a network or is part of a community that is strongly in favour of reconciliation, this will influence whether she decides to leave an abusive relationship or return in the future (Rhatigan et al., 2006).

Planned Behaviour theory goes one step further, as an extension of Rational Action theory (Ajzen, 1985), and posits that these decisions are then influenced by a range of external forces (such as ease of access to alternative housing or the existence of an independent means of income) which will affect whether or 
not the woman is able to leave the relationship (Rhatigan et al., 2006). This incorporates the concept that the woman is not entirely in control of the decision-making process and that there are external forces acting upon her that will make the decision to leave either more or less easy.

The main criticism of the Rational Action and Planned Behaviour theories are that they are mostly concerned with other decision-making processes, not relationship choices. They assume that the decision to stay or leave a relationship is a rational one. However, when fear is a factor in a decision, the decision cannot be guaranteed to be carried out on a rational basis (Rhatigan, 2006)

\section{Two-Part Question Model}

In response to such varied models as the ones above, Choice and Lamke present a model that amalgamates four of the five models discussed earlier: Learned Helplessness; Reasoned Action/Planned Behaviour; the Investment Model; and Psychological Entrapment (1997). This is the model chosen for use in this research as it offers the greatest understanding of why women may choose to report domestic violence during disasters. Choice and Lamke argue that victims of domestic violence ask themselves two questions with regard to leaving the relationship. The first question is "Will I be better off?" To answer this question, Choice and Lamke suggest that the woman will examine her feelings of satisfaction in the relationship, her perception of the existing levels of investment, the quality of available alternatives and a subjective norm (1997: 294). Many of these concepts are derived from the Investment model, which combined satisfaction, quality of investments and size of investment, to create a level of commitment to the relationship. By not using the term commitment, 


\section{Chapter 6}

Choice and Lamke avoid the difficulty of not accounting for women who are not committed to the relationship but stay out of fear of reprisal if they leave.

If the woman decides that her quality of life would be better without the relationship, then the second question asked is "Can I do it?" To answer this question, Choice and Lamke purport that the woman will look at both personal and structural resources and barriers (1997: 297). Personal resources and barriers consist of self-efficacy and perceived control. Structural resources include money, education, employment and the availability of social service agencies. Structural barriers include ineffective levels of assistance from the said social service agencies, marriage, and having no alternative place to live (Choice \& Lamke, 1997: 297).

In combining aspects of the previous models, Choice and Lamke are able to come up with a theory broad enough to cover many factors suggested by researchers and theorists, but also a theory that can be personalised to individual cases. Applying the two-part question model to the situation of domestic violence reporting in disasters, the impact of natural disasters is indicated by the factors that influence both questions.

As with the Investment model, the disaster can reduce the previous investments in the relationship (by destroying houses and possessions as well as incapacitating social networks through evacuations) and the level of satisfaction with the existing relationship (through stress-induced more frequent or intense violence), whilst also increasing the quality of alternatives. This may cause the woman to answer "yes" to the question, "Will I be better off?" Interviewees reported that some of the factors being recounted to them as causing reporting were a loss of possessions and their home, increased violence due to the stress 
of the event and its subsequent impacts on finances, and a lack of childcare facilities. If having the children in the home for extended periods during the cleanup meant the children were the target of, or perhaps witness to the violence, this may also prompt the woman to feel she will be "better off" out of the relationship.

As predicted by the Learned Helplessness model, the disaster could increase a domestic violence victim's self-efficacy and perceived control over her destiny, as the response and recovery to the disaster provide an opportunity to step out of her normal role. This will render the answer to the question "Can I do it?" more positive. If this is also coupled with available alternative housing or more social support within the community, then increased reporting of domestic violence in disasters would be a potential by-product of these changes. During Civil Defence emergencies, a wealth of social service agency support is made available to the community (Te Are, 2005; Bang, 2008; Rodgers, 2008). Isolation is a significant aspect of domestic violence (Gelles, 1976; Landenburger, 1998; Barnett, 2000; Bornstein, 2006) so it is reasonable to assume that, in their normal lives, some women are unaware of the support available to them when in an abusive relationship. Evacuation, or a home-visit from a social worker or Civil Defence worker, may be the prompt necessary for a woman to feel she is able to leave.

If this is the reality during disasters, then what can policy do to mitigate/enhance any of these factors, and should it do this? Regardless of whether domestic violence is already present in the relationship prior to the disaster or not, if an event causes increased reporting then perhaps policy should try to maximise the positive benefits that could be accrued from the 


\section{Chapter 6}

interaction between disasters and domestic violence and assist agencies to meet the increased demand.

\section{Conclusions}

So far, there is a strong case that a relationship does exist between the Civil Defence emergencies and the increase in reporting experienced by agencies in New Zealand charged with helping domestic violence victims. Whilst the relationship is not causal, that is to say that the events do not directly create an increase in domestic violence, there is a complex relationship that results in more women reporting domestic violence to agencies in the months following the events. These findings for New Zealand align with international studies (Enarson, 1999; Fothergill, 1999) and with theory on the factors behind domestic violence reporting (Walker, 1979; Dutton \& Painter, 1981; Strube, 1988; Rusbult \& Martz, 1995; Rhatigan et al., 2006).

Agencies interviewed for this thesis and prior empirical studies have indicated that the effects of a disaster are demonstrated in both the domestic violence itself and domestic violence reporting. The Pressure and Release model explains why domestic violence may increase in frequency and severity of domestic violence during a disaster, and highlights the greater risk that domestic violence creates for its victims during disasters (Wisner et al., 2004). The increase in severity and frequency was seen in the empirical work undertaken by Fothergill (1999) in the United States and noted by Enarson (1999) in her work examining domestic violence shelters in the United States and Canada. However, these studies also suggest that the disasters can create an increase in reporting also. It is highly probable that both domestic violence itself and domestic violence reporting have increased in New Zealand, and therefore, domestic violence agencies and Civil Defence will need to prepare for 


\section{Chapter 6}

this. If this does not happen, significant issues can arise from a lack of planning and policy. The issues that arose for agencies in the five case studies will be discussed in the next chapter to highlight key lacunae in policy, before moving to policy recommendations in Chapter Eight. 

Chapter Seven: Planning and Response Issues 

In earlier chapters, an increase in domestic violence reporting was established. This chapter discusses any complications brought up in interviews with agency representatives in terms of their response to any increased reporting of domestic violence faced in the weeks and months after the Civil Defence emergency in their area. If an agency representative reported increased domestic violence reporting to their agency, the interviews moved to delve deeper into the capacity of the agency to deal with reporting increases and any potential issues, for both agencies and the women reporting domestic violence during disasters.

This chapter has a different form from Chapter Five. Rather than discussing each event, with a breakdown of each agency in the area followed by a summary of commonalities and differences, this chapter will discuss each agency, with a summary of common issues across agencies at the end. The case-study focussed format of the previous chapter allows examination of the overall increase in reported cases of domestic violence within each area. However, issues of response and planning are better explained by looking at each agency in turn. There were some issues that were specific to an agency, such as safehouse issues for the Women's Refuge. However, other issues crossed agency boundaries, such as a lack of communication, that need to be addressed by all agencies.

As will be discussed in this chapter, the majority of the non-governmental agencies had little or no planning in place that specifically targeted Civil Defence emergencies. When a plan did exist, it was a basic plan that dealt with the evacuation of a single building. In the absence of planning, the focus of specific agencies will be an ad-hoc response to increased workload. The absence of policy and planning speaks volumes for the situation currently in 


\section{Chapter 7}

New Zealand with regard to response to domestic violence during and after Civil Defence emergencies. This chapter will first look at government agencies that have statutory roles during disasters, such as Civil Defence and the New Zealand Police, before moving to non-governmental agencies, such as Women's Refuge and Victim Support.

\section{Agency Issues}

\section{Civil Defence}

Civil Defence planning does not currently include provision for dealing with increased domestic violence reporting during any stage of events. There is a level of anecdotal and informal awareness of increased domestic violence at both a national and local level, but this is not recognised in any formal way and has not resulted in any formal planning and preparation by Civil Defence.

What characterises the Civil Defence response to increased domestic violence most strongly is the complete lack of a formal response. Some Civil Defence representatives had anecdotal information given to them after the event had ended officially (Bang, 2008) while others had no awareness at all (Harrison, 2008; Rodgers, 2008). The Timaru Civil Defence representative stated that he had heard anecdotally after the event that domestic violence had increased, but this was not until Civil Defence had ended the Civil Defence emergency officially. The information was imparted in a casual conversation with an agency and the impact of this information ended there. No changes had been made to Timaru Civil Defence policy since the event and no contact had been made with domestic violence agencies (Bang, 2008).

The Lower Hutt Civil Defence representative was unaware of any increases in domestic violence reporting, either at the time of the event or at the time of 
interviewing. There was no formal relationship between the local Refuges and Civil Defence at the time of interviewing (Rodgers, 2008).

Palmerston North Civil Defence staff interviewed had no awareness of increased domestic violence up until the time of interviewing. It was also evident that this was not perceived to be an issue of concern for Civil Defence. When asked about the relationship between Civil Defence and Women's Refuge, the Civil Defence representative expressed the view that there was no need to establish such a relationship and it was reiterated that this was outside the scope of the work of Civil Defence. When asked if there was any contact between Women's Refuge and Civil Defence during the flooding or the months after, the representative stated that it was not a priority:

Ros: $\quad$ Did anyone at Civil Defence make contact with Refuge at all? To check, for example, if their safehouse got flooded, or anything like that?

Mark: No.

Ros: Would you have thought to have checked?

Mark: No, because where would you draw the line? Would you then call the SPCA and ask them if they're ok...if Palmerston North city had flooded...to be quite frank, ringing people to see if they're alright would be done in a couple months time. It would not happen.

(Harrison, 2008)

Understanding the capacity of non-governmental agencies to respond in Civil Defence emergencies is key to effective disaster response and recovery. This understanding will need to be established by Civil Defence staff, before an event occurs and updated at the time of the event, to ascertain the capacity at the time of the event. When discussing the role of Civil Defence, the local Civil Defence officer felt that it was one of co-ordination rather than operations, and that existing non-government agencies could do the work on the ground with the community under the guidance of Civil Defence: 
Mark: Historically Civil Defence has been like this "Dad's Army," with all sorts of volunteers all trained up for this and trained up for that and the other thing, and what we started to do was say, "Well hold on, there's a bucket of agencies that do this sort of work already, and it's really now just around co-ordinating it." And it's like we used to have plans around feeding animals when there were evacuations going on. You know, one of the questions asked was, "Is there a cat at home," because we needed to get out and feed the cat. Well SPCA do that already, so they do it...and I suppose it would be the same with family violence...so it's very much about just having those building blocks and just bringing it all together.

(Harrison, 2008)

Non-government agencies differ greatly from their government counterparts in terms of the levels of resources available to them for day-to-day work. Agencies such as Women's Refuge are reliant on volunteers to continue their work and are characterised by being significantly under-resourced. The assumption that these organisations can undertake a role in Civil Defence response with Civil Defence only offering co-ordination in return is short-sighted. Agencies such as Women's Refuge will be dealing with their own workloads during an emergency with (as seen above) a likely decreased staff, and it is unreasonable to presume that they will also be available to be co-ordinated into wider work.

At a local level, opinions were varied as to whether domestic violence reporting increases were within the scope of Civil Defence and Emergency Management. One of the Civil Defence representatives stated that domestic violence considerations were outside the scope of their mandate (Harrison, 2008), while other representatives were willing to consider the issues arising from increases in domestic violence reporting, but required more information on how Civil Defence could improve the situation of increased reporting during emergencies (Bang, 2008; Rodgers, 2008). 


\section{New Zealand Police}

The New Zealand Police have a statutory obligation to respond to Civil Defence emergencies. This has led to comprehensive planning with regard to staffing levels and continuity of services during events. Each Police station is required to have staff available for deployment to an affected area with a declared Civil Defence emergency at short notice. In addition, during an emergency, leave is cancelled where possible and staff are required to work longer hours where needed (Harrison, 2008; Peterson, 2008). This ensures that the Police are able to respond to everyday policing, as well as fulfil their statutory obligations to help with evacuation and other Civil Defence response activities.

However, specific planning for increased domestic violence as an issue during Civil Defence emergencies is not in place, locally or nationally, in the New Zealand Police Civil Defence plans. Nothing currently exists to warn and prepare staff that domestic violence callouts are likely to increase at some point during or after the event, or that their partners in domestic violence response (such as Women's Refuge, Victim Support, faith-based support agencies) may be dealing with an increased workloads (Byers, 2009).

Most officers interviewed in the five case studies expressed surprise at the increased domestic violence reporting in their area following an event; both for themselves and for other agencies. Whakatane Police was the only station aware of the increased work at the time of the events and, therefore, this affected the response, if any, to the situation. In all five cases, the increased domestic violence workload was absorbed into existing staff caseloads. No resources were specifically allocated to domestic violence callouts or to dealing with the increased domestic violence. The workload increase was not due to domestic violence alone; the statutory obligations placed on the New Zealand 


\section{Chapter 7}

Police during emergencies meant that there was a large number of extra tasks arising directly from the event, such as evacuations, checks on families in remote areas, and information dissemination, which fell under the purview of the New Zealand Police during emergencies.

Neil: $\quad$ The police, no we just absorbed the increase in work. It's just part of our structure, we just absorb it. We have calamities and floods and problems all the time, so we just absorb it through normal policing. So we didn't get any extra staff, we just absorbed it.

Ros: Were you stretched quite thin then?

Neil: $\quad$ Yip we were, because the first week especially, I was actually out there evacuating people from homes, we had the uni mobs, the army going through there. Probably for a week period, it was just all hands to pump. I suppose we just absorb it by not having days off, by working 12, 15, 16 hour days and so for that week period initially, we all worked very long days with no days off. It gradually eased off, but that's how we absorb it longer days and no days off. No extra resources, I'm just trying to think, we did bring staff from outside. Well, we brought staff from outlying stations like Kawerau and Opotiki, but they were all part of the disaster anyway, so we just absorbed it.

(Peterson, 2005)

These obligations and the resulting increase in overall workloads may explain why an increased domestic violence workload went unnoticed in some situations.

The Whakatane Police displayed the most significant response to the increased domestic violence reporting. The increase was acknowledged, and the Police actively sought to help Women's Refuge and other agencies with their increased demand. Whakatane Police had a Family Violence co-ordinator in place at the time of the flooding, which may, in part, explain why there was such a high degree of awareness and reaction from the Police in this community after the flooding. In two of the case studies, there were not specific Family Violence coordinators in place in the Police station at the time of the event (Lower Hutt and 
Palmerston North/Feilding). This meant no single person had responsibility for monitoring the domestic violence cases occurring in the months following the event. From this stemmed a lack of awareness of the increases in domestic violence reporting. In Whakatane, where there was a designated co-ordinator, the benefits were clear. The increased domestic violence recorded across different agencies, including the Police, was recognized and acknowledged, and a more co-ordinated approach was taken to responding to the increase. This has since changed with the role of Family Violence co-ordinator being more widely instituted across New Zealand. The benefit of Family Violence coordinators may be evident in future events.

Attitudes towards the Police's responsibilities during the events differed from officer to officer. Whilst in the case of Whakatane, it was evident that the officer was concerned not just about the scale of the workload for Women's Refuge but also the impact it was having on the staff personally, this was not universal. In the case of Palmerston North and Feilding, when asked if Women's Refuge had been contacted after the event, the Police representative, like the Civil Defence representative, scoffed:

Dave: We wouldn't ring them, just like we don't ring the Fire Service to see if they're alright...

(White, 2008)

The question asked was, in fact, related to whether Civil Defence had sought to find out if non-government agencies were coping after the event, not emotionally, but in terms of resources and staffing. Although it would also be a productive move to check on the welfare of staff in agencies, the first question related to how agencies coped at a very basic level of physical and human resourcing. 


\section{Chapter 7}

\section{Work and Income}

Work and Income and the New Zealand Police have similar policies in place for working during a Civil Defence emergency. Work and Income also have a statutory obligation during emergencies and, therefore, have more extensive Civil Defence planning than non-government agencies. However, as with the New Zealand Police, domestic violence is not specifically included in the planning. Work and Income also have a requirement that each office has the ability to mobilise a group of staff to go to an area affected by a hazard event (or other significant event such as plant shutdowns or major layoffs). However, there is a delay in this plan being implemented following an event, and in the flooding of Palmerston North/Feilding in February 2004, workers at the Feilding Work and Income office were unable to work for the first couple of days as their premises were flooded:

Penny: In Feilding initially, we said to the whole staff, "Stay home," for their safety on that first day. We thought it was better for them to not be walking round in muddy, sewerage-y water. Then once we set up the emergency centres, we brought staff on slowly. Once the roads were open, we brought staff into Palmerston North so they could do processing work. We did have some staff down, because of care-giving. What we did have the benefit of, was once we saw the scale of what we were dealing with - it really was huge - other parts of the country offered us help, so we brought staff in from other regions. Probably only half a dozen, but good experienced staff who really made a difference.

(Rounthwaite, 2008)

Work and Income displayed a relatively limited response to the increased domestic violence, again tied to a relatively low level of awareness of increases. At the time of each event, there were no protocols in place to record domestic violence cases (this has changed since). Without any way of recording specific cases of domestic violence and with each caseworker handling the domestic violence cases individually, there was no way to tell if the aggregate caseloads had increased for Work and Income in four of the five communities. However, the Whakatane flooding in July 2004 coincided with a new programme within 
Work and Income to assign all domestic violence cases to one staff member nationwide. This assignment of a staff member with responsibility for all domestic violence cases meant that the increased domestic violence reporting during the months after the flooding was more easily noticed in Whakatane.

This chapter will now move to discussing issues reported by non-governmental agency representatives across all five case studies.

\section{Women's Refuge}

Women's Refuge is the organisation that experienced the greatest increase in domestic violence reporting in the five case studies. At the same time, it is one of the organisations that have the least planning in place to ensure continuity of services during a natural disaster. I will begin by first discussing the general planning and policy before moving to the specific details of the responses in the case studies.

As noted earlier, all of the Women's Refuges involved in this study were members of the National Collective of Independent Women's Refuges, a national organisation with 49 refuges across New Zealand. There is no national plan in place for increased domestic violence reporting during disasters. The five Women's Refuges interviewed experienced a doubling or tripling of their caseloads in the months following events, yet there was little prior planning in place at a local level to help them deal with this reality. This lack of planning engendered tension and stress during the emergency and subsequent months:

Wini: We needed to not be worried about could we afford a couple of hundred dollars more of food, could we afford to house another set of families individually. We couldn't afford to put anymore people in the house - the house was just busting at the seams, a lot of children - it would have been good if we could have got some child minders or some advocacy so we 
could take the kids away for the day, you know something like that. But we did not have the resources to be able to pull that in.

(Te Are, 2005)

All of the staff at the five Women's Refuges interviewed had very limited Civil Defence planning in place. No Refuge had a plan in place for monitoring services during an emergency. There was some variability as to whether the Refuge had a supply of food, water and other emergency supplies stored in the safehouse. However, most commonly the Refuges had nothing or a very limited stock of non-perishables. The safehouse accommodation that all five of the Refuges in this research use for both emergency and longer-term housing for women and children were significantly impacted in two of the cases.

South Canterbury Women's Refuge workers in Timaru were physically isolated from the safehouse for a one-week period during and after the snowstorm:

Dawn: Yeah for a whole week...We couldn't get in to the safehouse for a start. I mean the snow blocked all the roads and that. So it was a matter of not getting in to the safehouse at all - we were fortunate enough that the phones were still going, so we had phone contact with those women. We eventually got in, but it wasn't just an easy task just to get in there...

(Rangi-Smith, 2008)

An inadequate supply of food in the house for the women and children to eat, meant that they were left to themselves to manage food rationing whilst completely isolated from the community. A second issue is the immense risk this places the women and children at, should an abuser find the location of the safehouse and attempt to enter the property. The snowstorm and subsequent loss of power, intermittent coverage by cellular telephones and access to food may cause a woman to contact her abuser under the impression that her situation may improve if she is with him and not in the safehouse. Secondly, the perpetrator may know the location of the safehouse and use the storm as an opportunity to gain access to the house in a time when law enforcement may 
be distracted by the snow and cleanup work. Regardless of the reasons, should a perpetrator have attempted access to the house, Refuge workers and the Police would not have been able to get to the location quickly. Staff members were aware of this issue:

Dawn: If there was a dire emergency there, we would never have been able to get in there...

(Rangi-Smith, 2008)

Despite this awareness, no plans were made with other response agencies to either deliver food parcels to the house and check on the women and children there, or to have a vehicle available that would allow access to the safehouse in an emergency. This lack of planning was still evident at the time of interviewing, two years on from the event.

Isolation was not only an issue for women inside the safehouse, as women elsewhere in rural areas were physically unable to access Women's Refuge services in three of the case studies. Te Roopu Whakaruruhau in Palmerston North reported no issues with their safehouse. However, in a similar vein to South Canterbury, Te Roopu Whakaruruhau reported that they were physically cut off from women trying to access their services. The flooding isolated areas covered by Te Roopu Whakaruruhau and, due to a lack of planning for specialist vehicles that could pass through the flooded areas, women calling for help from the cut-off areas were only able to get service over the phone. If a woman wanted to leave the house and utilize the safehouse, this was not an option, as the Refuge did not have the ability to collect the women. Four years on from the event, a plan to make available four-wheel drive or other rough terrain vehicles that are able to get through the flooding is still not in place. This leaves women living in rural and remote areas that are prone to flooding in a position of isolation with the perpetrator. Any opportunity for them to leave 


\section{Chapter 7}

during the crisis has been wasted due to an absence of strategic planning to maintain access to the Refuge facilities.

Te Roopu Whakaruruhau reported that if the flooding was repeated, they would still be unable to help those women living in rural areas as there was no contingency plan in place to get to women in such isolated areas:

Julie: If the flood happened again, we would obviously not be able to help anyone in the rural area.

(Tukariri, 2008)

It is clear that the issue of rural women and how to ensure they are able to access domestic violence services is not currently adequately dealt with. Te Roopu Whakaruruhau were not the only Refuge to discuss the issue of rural isolation. Whanau Awhina Women's Refuge in Whakatane also made mention of the difficulties that rural residents faced in getting access to any services or gaining recognition of their needs:

Wini: I guess I really want to emphasise that being rural has a total disadvantage in terms of people recognising - you know a bit of farmland under water is nothing but of course those families out at Ruatoki were locked out of coming into town. They were people who had less access to money, less access to working transport - they're the most disadvantaged group in our whole area, in terms of financial, ethnicity, low socioeconomic, there was very little said about that.

(Te Are, 2005)

The issue of rural women's access to Women's Refuge services during disasters is another layer that will need to be included in any policy changes.

Whanau Awhina Women's Refuge in Whakatane also reported that the numbers of women seeking shelter in the safehouse had increased so greatly that there were women and children sleeping in the garage, and staff were each housing at least three families in their private homes at any point in time during the disaster.

Wini: I had three families living with me. 


\section{Ros: $\quad$ Three families?}

Wini: Three families, and (worker one) had must have been about two or three families too, because her house was bigger and (worker two) had about two or three families.

(Te Are, 2005)

To respond to this increase in client numbers, the Refuge sought a second safehouse to try and relieve some of the strain on resources. However, the process was complicated by the very specific needs of a safehouse, the amount of bureaucracy involved in obtaining a second house, and the lack of time the staff had to put into the acquisition of a house during the time:

Wini: We just dispersed people between the workers. And because we couldn't get a solid agreement from the funders that we didn't go in to getting another house and find out a month later that we didn't have for the rent, the power, the infrastructure to keep it. Even though we had put the proposals together, the agreements weren't forthcoming so we decided as a group that we couldn't go on panic, we had to have some solid agreements or else we wouldn't do it. So what we did was then dispense the women amongst our houses, it was easier to... Yeah, it was easier to do that, at least then we would have the opportunity to work with them without the headache of worrying about the other bits like if we got another house it would cost us on average $\$ 4500$ a month and we couldn't guarantee, no one could guarantee us that, in terms of rent, in terms of power, and phone.

(Te Are, 2005)

The Women's Refuge representative was not the only interviewee to notice this problem. The Whakatane Victim Support representative and the New Zealand Police representative also spoke about this issue:

Jenny: I am aware that the resources weren't enough for Women's Refuge, that they needed another residence... and to actually do that we came up against brick walls all the time to try and find a suitable place for another refuge to be up and running to cater for the large numbers of women and children who were needing refuge at that time...

Neil: $\quad$ We spent six months on that...I went to repeated meetings with Housing Corp, with WINZ, all these people - we sit there and we just never got anywhere. It's hard to identify a suitable house as well, it was another problem, you've got to have it in certain areas, it's got to... 
Jenny: ...Close to the schools and the shops...because most women would not have vehicles so they've got to have accessibility to medical, shopping, all the things like that...

Neil: I know some of the ladies at the refuge were taking people home with them, the refuge itself was chocka block, the garage was full and there were people sleeping on mattresses and that was just the shocking thing. We tried and tried and tried to get another house for them...

Jenny: ...And one of the clear indications of the level of the high increase in family violence was the stress on the workers...it was very evident to us that the impact for the workers was enormous (Neil - it was, wasn't it) and we had great concerns about the well-being of the workers and we were doing our best to ensure that they...

Neil: $\quad$...Because when you're meeting with the same people every Monday - 1 o'clock in this room - you see them, they were shaking and they were going downhill, they were stressed and they were running around and you just saw the decline in the people, yeah, it took a shocking toll and they were volunteers, the two main ladies were volunteers, they weren't even getting paid to do it.

(Thomas \& Peterson, 2005)

The existing safehouse had also been damaged during the flooding:

Wini: It was flooded, not so much that we couldn't wash out and clean out. Our safe house, the damage was the consistent rain and it came through the roof.

(Te Are, 2005)

Although it was not structurally damaged, the house still needed to be cleaned and washed out, which had to be undertaken whilst the house was overflowing with women and children. Having no alternative location to house the women and children that were in the safehouse during the clean-up meant already cramped quarters were even more constrictive during this time as women and children needed to move from room to room during the cleaning phase.

One action taken by those in Whakatane was the setting up of a transfer arrangement with other Refuges in the Hamilton area during this time to alleviate the housing pressure. This was an ad hoc arrangement and put 
extended pressure on neighbouring Refuges, for which they received little or no extra resources to deal with. Other Refuges did not make this arrangement perhaps, in part, because their safehouses were not as severely affected as Whanau Awhina Women's Refuge's one.

Hutt City Refuge in Lower Hutt and Wairarapa Women's Refuge in Masterton reported that most of their increased workloads were not safehouse clients. However, if they had a need to use the safehouse, the Refuges would not have been prepared.

It was not simply access to the safehouse that presented issues to Women's Refuges. Three of the Refuges reported that their safehouse did not have enough supplies during the emergency to cope with the demand. Whilst Te Roopu Whakaruruhau reported no issues with the safehouse, there was a level of awareness that the safehouse would not have been prepared if there had been a large spike in the number of women wanting safehouse accommodation:

Julie: We didn't have any spare water. We weren't prepared at all, for anything like that.

(Tukariri, 2008)

South Canterbury Women's Refuge stated that there was little food stored in the safehouse. This was due to a lack of funds to buy enough food to stock up:

Dawn: I know we are not very stocked up very well. Like we do not have any, well we might have a bit of bread in the freezer, but we do not have any milk - things like that...For a start, we cannot afford to buy it. We rely on donations, and so it is just whatever comes in. And the problem with donations is that you cannot keep them for that long because they spoil so we end up giving it out to our community women.

(Rangi-Smith, 2008)

Whanau Awhina Women's Refuge in Whakatane also did not have enough food to meet the demands of its clients. They initially tried to access food from the Civil Defence foodbank but fulfilling the criteria for this was difficult as the 
women needed proof they resided in a flooded area, proof that was not always readily available when women fled their homes at short notice. However, in this case, the intervention of the national body was vital and another Women's Refuge, from outside the area, undertook a food drive for them:

Wini: ...We didn't have enough food to cover the families we were working with - the families in our homes, the families in our community. So we contacted our sister refuges in Hamilton, and what they did for us was a food drive in which we were able to feed up to 120 families over a four week period and every week they would come down with that. And that took a huge relief off us. Because the criteria for accessing the emergency food bank was really difficult.

(Te Are, 2005)

Aside from the scarcity of physical resources during emergencies, human resources were also affected. Enarson observed in her work with 77 women's shelters in the United States and Canada that the shelters not only experienced an increase in demand for service, but also a significant drop in the number of workers available to meet the demand (1999: 758). This was also the case for three of the New Zealand Refuges in the five case studies. Women's Refuge's staff are reliant on volunteers with $72 \%$ of their workforce being non-paid staff (National Collective of Independent Women's Refuges, 2005). This has significant implications for the staffing of the Refuges in events that impact directly on the volunteers' homes and families, such as Civil Defence emergencies.

Two issues with regard to staffing arose from the case studies. The first is that staffing was significantly reduced during the events, as staff were cut off from the Timaru township and because volunteers were unable to continue whilst dealing with the response to the event. The second is that the workload for the remaining staff was increased two-fold; first by the lack of other staff and 
second by the increased numbers of women reporting. This took a toll on staff and added to already stressed Refuge workers' worries.

South Canterbury Women's Refuge in Timaru reported that some staff members were unable to get in to the Refuge to work because the roads were blocked. The attitude of all Refuges was also that they could not expect volunteers to work in disaster situations given that they had families to take care of and were not being paid:

Dawn: We couldn't get volunteers into there. It was basically just about three of us who were paid workers, only because we were the only who were directly responsible. You know, you can't expect a volunteer to come in from out of town, and she couldn't get there at any rate.

This is a significant difference between Women's Refuge and government agencies and it is an issue that has been overlooked in much of the Civil Defence planning and policy to date. Organisations such as the New Zealand Police and Work and Income can not only rely on staff to turn up for work during a disaster but also have a backup plan of secondary staff from other areas being made available. Organisations such as Women's Refuge do not have an extended pool of staff to draw from.

Te Roopu Whakaruruhau Women's Refuge in Palmerston North experienced a reduction in staff numbers available to work with the extra cases. In this case, the Refuge did not seek outside help and worked with the other local Refuge (Palmerston North Women's Refuge) to cope with the cases as best they could and as rapidly as they could using their remaining paid and non-paid staff and volunteers. Much of the work being undertaken over this period was conducted over the telephone as the Refuge staff were restricted in their ability to travel outside of Palmerston North due to the flood. This was normal procedure for 


\section{Chapter 7}

busy times so the increased workload was simply absorbed. This is potentially why the increase was not seen as extraordinary by any of the workers:

Julie: We always work longer hours when we're busy

(Tukariri, 2008)

In Whakatane, Whanau Awhina Women's Refuge's staffing levels were maintained through cancelling staff leave:

Wini: ...this is what happened, it was my four weeks holiday because my daughter lives in England and she comes in July. l'd gone up to Auckland to pick her up; I'd already booked out four weeks. All staff had to come back in.

(Te Are, 2005)

This decision was based on a lack of funding for the increased cost of extra staff and the specialised training needed for working in a Women's Refuge. The Refuge did not have the ability to hire extra staff to deal with increased workloads, and did not have a plan in place to access experienced staff if and when this money became available. This highlights the personal impacts that the lack of planning can have on staff.

The impact on staff was not consistent across the Women's Refuges interviewed. Hutt City Women's Refuge did not experience a change in staffing levels. The Refuge was aware of increased reporting following the flooding in Lower Hutt but this was anticipated by their staff who incorporated the increased caseloads into their normal work. The Refuge representative stated that they had experienced an increase in calls for help following major traumatic events both within New Zealand and globally, so was not surprised when they experienced the increase after the local flooding event. Wairarapa Women's Refuge in Masterton did not experience a change in staffing levels either. The Refuge was not aware of the increased workload at the time of the event and the increase, more than a doubling of the number of clients, was absorbed into the everyday work of the staff. 
Another impact on the workers was dealing with their own domestic flooding issues. In Whakatane, two of the staff members who were working full-time during the flooding experienced flooding or near-flooding of their homes:

Wini: $\quad$ My house was always on the verge of flooding because I'm on the creek, and we just built it up and built it up - only surface flooding but not absolute flooding. One of workers who lives out in Purupuru was flooded.

(Te Are, 2005)

Working in the domestic violence field is often very stressful, and this fact, coupled with cleaning up flooding damage in their own homes, created an immensely stressful time for the staff of Whanau Awhina Women's Refuge. Staff members at the Refuge were working unusually long hours and then going home to a clean-up with no support from other agencies:

Wini: I think that that's the only other recognition, that if you're a helping agency and you require help yourself, then there is very little advocacy for that. That you either have to agree to do it or not do it at all.

(Te Are, 2005)

Clearly, being able to take the time to clean up their houses before responding to the increased Refuge workload would have been ideal. However, this was not the case in Whakatane and may not be a realistic option in future hazard events, but it shows an extra area in which there is room for improvement via planning and policy shifts.

Added to the increased workloads that the Women's Refuges faced, two Women's Refuges reported they were working with more children than usual. Both South Canterbury Women's Refuge in Timaru and Whanau Awhina Women's Refuge in Whakatane reported they were working with more children than expected. 
Dawn: Yes we did, we did have a lot of children. Probably a little bit, probably more children than what we'd normally have had...

(Rangi-Smith, 2008)

As all childcare facilities and schools are closed during Civil Defence emergencies, children in the Refuges did not have an alternative location to go to during the day and this created the additional concern of childcare during the cleanup phase. This not only caused stress for Refuge workers but was also mentioned as an added stress felt by the women before contacting and whilst at the Refuges.

Ros: $\quad$ Did any of the women say that that was a part of it (why they were seeking help) - having the children home while they were trying to deal with it, clean up?

Jenny: My memory is yes it was, it was extra stress put on the families at that time, and it was having children at home

(Thomas, 2005)

What this pattern suggests for future events is that, without any intervention, an event that destroys or significantly damages a Refuge safehouse, or reduces the staff numbers available to Women's Refuge will create an increased awareness of the problems. Conversely, in those events that do not impact significantly on the Refuge resources, there may be increases in domestic violence that go unnoticed or unacknowledged.

Women's Refuge was the primary non-government agency experiencing issues. However, there were other non-government agencies that raised issues resulting from the Civil Defence emergencies in their areas.

\section{Victim Support}

Victim Support Whakatane was the only Victim Support agency to participate in this research. At the time of interviewing in 2005, Victim Support Whakatane had no planning in place for increased domestic violence cases in the aftermath 
of Civil Defence emergencies. The increase referred to below came as a surprise to staff. The increased workload was met in the short-term by the current staff working longer hours:

Jenny: We got called in at 10 o'clock at night and I think I left the hall at 1.30-2 the next day and went to a family member in Whakatane because I couldn't travel home and then went back to the hall the next day and everyday

(Thomas, 2005)

In the weeks following the event, Victim Support gained some funding through Child, Youth and Family, for three social workers to work in the community:

Jenny: And we had field workers who were also employed at that time, we had 3 field workers to go and do the personal contact with the families affected by the flood, to help support them. So we had one in Edgecumbe-Rangitikei region, one in Whakatane and one in Opotiki.

(Thomas, 2005)

\section{Presbyterian Support Services}

Presbyterian Support Services and the James Family Trust (in Whakatane) are both faith-based social service agencies. In some cases, such as Whakatane, they run Women's Education programmes for women who have been victim to abuse and, in other cases, they provide one-to-one counselling for domestic violence victims. Presbyterian Support Services do not have any planning in place for increased domestic violence during and after Civil Defence emergencies.

Due to the nature of the work Presbyterian Support Services undertakes with victims of domestic violence, it is likely that any increase in domestic violence cases will occur much later than with other agencies. The James Family Trust responded to an increased demand for their women's education programme by creating a waiting list. This occurred two months after the physical event ended: 
Ros: $\quad$ From your perspective, did you notice an increase in domestic violence?

Diana: Definitely. I don't know that our family workers who went out and did work with the families came back and reported an increase but I do know that after the floods we had a waiting list, which we don't normally have. However, because of the size of our rooms and the number of people wanting to attend, we created it and we've never had that before and that is a direct result of the floods.

Ros: When did that occur?

Diana: Probably a couple of months, about two months. That's when we had our influx, then they stay on the programme and complete it. But it was around about two months that I noticed we had the increase.

(Oomen, 2005)

\section{Common Issues across Agencies}

The most significant issue across all the agencies is a lack of incorporation of increased domestic violence reporting in disasters in their policies and plans. This occurs despite the prior experiences of domestic violence agencies during disasters in New Zealand and the growing international literature that has also established this. The omission has had downstream effects that have varied across the agencies, but the base cause is the same for all, a lack of recognition that domestic violence reporting increases during disasters. Even after it was experienced by agencies, no changes were made at a local or national level to address this issue. This needs to change to ensure that all women and children who seek help because of domestic violence receive the best service possible from these agencies.

A second issue observed was the lack of communication and co-ordination between agencies who respond to disasters and domestic violence. Women's Refuges did not communicate their increased work to any other agencies at the time of the event except in one case study. However, other agencies that work 
closely with Women's Refuge on a daily basis also made no contact with the Refuge (or other agencies involved in domestic violence response) to ascertain if the agency was coping - regardless of the increased workload. Even if reporting levels had maintained a steady level, I would suggest that agencies that work so closely together would benefit from such an interaction. The act of showing concern for staff at other agencies builds rapport and strengthens the relationship. In the future, given that increased domestic violence reporting has been substantiated by this study, agencies should communicate with each other as part of their response to disasters.

Despite a move by many agencies both within New Zealand and internationally to work in a co-ordinated manner to address domestic violence (Kelly, 2004; Robinson, 2006; Hague \& Bridge, 2008), Whanau Awhina Women's Refuge in Whakatane was the only Refuge that discussed its increased workload with other agencies at the time it was happening. Its staff raised the issue of increased caseloads with the local Family Violence co-ordinator at the Whakatane Police and with the Victim Support co-ordinator. This in turn led to the local Work and Income management becoming involved directly and all the agencies then began to discuss increases they were experiencing and, in this manner, the issue of increased levels of domestic violence was recognised across the social service sector. The Police co-ordinator advocated on behalf of the Women's Refuge for a seat on the Welfare Advisory Committee put in place by Civil Defence. Once in place, the Refuge was able to inform the local Civil Defence and other organisations of what was occurring. This was not a formal process and has not been written subsequently into any policy or plan. Therefore, there is no guarantee that, in future events, agencies like Women's Refuge will gain a priori representation on such a committee. 


\section{Chapter 7}

In Lower Hutt, no comment was made to other agencies about the increase and, therefore, there was little awareness among other agencies that the Refuges (both Hutt City and Kokiri Marae Maori Women's Refuge) were experiencing reporting and enhanced workloads. At Hutt City Women's Refuge, the flooding did not significantly affect the safehouse. Therefore, aside from the increased caseload, there was little other impact on the Refuge. This was also the situation in the case of Wairarapa Women's Refuge in Masterton and Te Roopu Whakaruruhau Women's Refuge in Palmerston North. Neither of their safehouses or offices were damaged during the flooding event and, therefore, the increased workload did not create such immediate issues as observed in the cases of South Canterbury Refuge and Whanau Awhina Refuge. This perhaps explains why these Refuges did not mention the increase to other agencies.

Many of the government agencies interviewed stated that they felt their relationships with the local Women's Refuges were such that the staff at the Refuges would tell them if an increase was occurring for them, and they rely on this implicitly (Harrison, 2008; Rounthwaite, 2008; A Wills, 2008; S Wills, 2008). In four of the five case studies (all but Whakatane), the Refuges did not communicate their increased workload to other agencies. This may have been due to a lack of awareness themselves that the increase was happening. However, in some instances, the Refuges were aware of an increased workload but did not attribute it to the Civil Defence emergency. In this case, the increase was noticed but it was not expressed to other agencies.

This may be highlighting a part of Women's Refuges organisational culture of a siege mentality. A siege mentality is a belief that a group are "standing alone in a hostile world" (Bar-Tal \& Antebi, 1992: 251). The group believes that those outside the group want to do harm or wrong to the group and, therefore, they 
are in a constant state of defensiveness (Bar-Tal \& Antebi, 1992). A second aspect to this is the belief that those outside the group do not care about the welfare of the group, and would not help them in the situation of a disaster (Bar-Tal \& Antebi, 1992: 253). This leads the group to turn inwards in times of struggle, rather than out, and may explain why Women's Refuge does not discuss increased workloads with other agencies.

If this is the case, this mentality will need to be overcome within Women's Refuge to ensure that domestic violence reporting increases during disasters do not continue unnoticed:

Ros: $\quad$ So you just had to cope?

Dawn: Yeah. We had to cope with what we had. Well I think too Ros, it was a matter of I didn't ask. I think I could have gone to the Mayor or could have asked but I didn't. So we made do with what we had.

(Rangi-Smith, 2008)

The dissemination of the results of this research to all agencies involved will begin the steps to change this lack of communication between agencies. However, if this mentality is institutionalised and not overcome, Women's Refuge will continue to deal with the increased demands on their services in isolation. This is not a good situation for both the workers at the Women's Refuges, and the women and children accessing these services.

\section{Potential Future Issues}

The events examined in this study varied in effect from causing little physical disruption in a community to causing a moderate impact. However, this study has not examined a large-scale event such as Hurricane Katrina in 2005 or the 2004 Boxing Day tsunami around the Indian Ocean. Events of this scale and magnitude of impact are likely to have more severe outcomes on victims of domestic violence and the agencies that help them. When considering the 


\section{Chapter 7}

issues presented by increased domestic violence reporting in Civil Defence emergencies with little or no policy in place to meet the needs, it would be remiss not to discuss the other feasible issues that could arise from a largescale event. Planning needs to cover not only what has been proven to happen in the past, but also what would happen in the future if an event occurred that lead to wide evacuations and massive destruction of infrastructure and homes in New Zealand.

\section{Conclusions}

Overall, an understanding of domestic violence is needed within Civil Defence and an understanding of disasters' potential impacts on workloads and agency operation is needed by domestic violence agencies. This can only happen if all groups involved convene to discuss their perspectives and contribute their areas of expertise to each others' policies related to disaster response. This may be the necessary first step in addressing a current lacuna in all parties' policies.

Factors listed included the increased stress from dealing with household cleanup, the loss of some or all of a family's possessions, and the uncertainty that accompanies displacement. However, all of this is just an excuse or justification that masks what is actually occurring. Consistently, interviewees reported that the domestic violence women were reporting had been present in the relationship long before the event itself. The event did not create the domestic violence. However, it did change the dynamics within the relationship and led to an increase in reporting.

A significant paradox that became evident during the research is that agencies that experience less of an increase in reported domestic violence are best 
placed for dealing with an increase, and agencies that experienced the greatest levels of increased reporting have little or no planning in place to meet this need. Work and Income and the New Zealand Police have structures in place already to gain access to more human resourcing during any event through other agencies/stations in the country. Women's Refuge, who consistently experienced the greatest increases in each community, currently do not have any plan in place to access any resources, let alone increased human resources, during and after a disaster.

There was clearly no formalised response to any of the increased reporting in any of the five case studies. Even if an increase was acknowledged during the event, an ad hoc arrangement was made to try to meet the needs of clients and lessons learned from this situation have not led to a change in policy or planning to date. Policy is a vital tool in addressing increased domestic violence reporting during disasters. The next chapter will discuss potential policy changes that will lead to an improved response and, hopefully, better outcomes for the women and children affected. 

Chapter Eight: Policy Implications 



\section{Chapter 8}

An element of feminist research is that it aims to use the findings to bring about social change (Ramazanoglu, 1992; Thompson, 1992; Eichler, 1997; Renzetti, 1997: 133; Fonow \& Cook, 2005; Skinner, Hester \& Malos, 2005: 14; Landman, 2006: 431). Thus, though the previous chapters of this thesis have demonstrated the increase in domestic violence reporting observed during three natural disasters and the lacuna that currently exists in the planning for and response to this increase, this thesis does not stop there. The current chapter will discuss the possible implications for policy arising out of the response issues raised in the previous chapter. The chapter commences with the proposition that a shift in policy is needed in order to accommodate the increased domestic violence reporting during disasters. Then, potential policy responses to this issue are examined both in the abstract and in the context of New Zealand policy. Recommendations for changes in policies relating to Civil Defence emergencies in New Zealand, and the internal policies of domestic violence agencies related to preparedness for a natural disaster are presented. Finally, because domestic violence is one of a number of gendered issues during disasters, this chapter will address these further issues and consider the need for greater gendered policy in Civil Defence and Emergency Management.

\section{Why Policy Change?}

Many of the representatives of agencies interviewed referred to personal lessons learned from each event (Anderson, 2005; Te Are, 2005; Bang, 2008; Rangi-Smith, 2008; Rodgers, 2008; Tukariri, 2008). Each event provided the agencies involved with the opportunity to test their current policies and procedures and to isolate and address any lapses or gaps. However, these lessons were not applied during any policy reviews in the aftermath of the events and, therefore, appear destined to be lost as key individuals move on from the agency or on to the next 'crisis' situation. Natural hazard events differ 


\section{Chapter 8}

in their frequency. By way of example, whilst major floods can occur annually or every one hundred years, the return interval for major volcanic eruptions can be thousands of years. The loss of corporate memory of key response issues and best-practice measures is a common feature under these circumstances. Responsive written policies are one of the most effective means of avoiding this problem.

The process of policy development is useful in itself as it provides an opportunity for policy makers to evaluate the variety of scenarios that could occur in the future. New Zealand has not experienced an event on the scale of the 2004 Hurricane Katrina in the United States or the 2004 Boxing Day tsunami across Southeast Asia, since the 1886 AD eruption of Tarawera volcano. The largest event in relatively recent times was the Hawke's Bay earthquake in 1931. However, it is prudent to apply the lessons learned in these significant overseas events in the New Zealand context in order to develop our own best practice for large-scale events. A total reliance on the past experience of individuals working in the field to use their past specific experiences in deciding the form of the response to the next event leaves room for the same mistakes experienced in the United States' response to Hurricane Katrina to be repeated in New Zealand (Batlan, 2008; Jenkins \& Phillips, 2008).

This chapter will cover the existing domestic and international policies that New Zealand is subject to with regard to both domestic violence and Civil Defence emergencies, prior to concluding with suggestions for policy amendments.

\section{Current Policies of Civil Defence and Emergency Management}

The national level policy that New Zealand Civil Defence planners and policy makers currently utilise in addressing disaster risk reduction is the Ministry of 
Civil Defence and Emergency Management (MCDEM) National Strategy (2007).

This strategy is supported by several other policy documents in the form of a national plan, the CDEM Act (2002), Director's guidelines and information pamphlets. However, the strategy is the significant underpinning document on which current practice is based.

The strategy is based on five principles, which are:

1. Individual and community responsibility and self-reliance.

2. A transparent and systematic approach to managing the risk from hazards.

3. Comprehensive and integrated hazard and risk management.

4. Addressing the consequences of hazards.

5. Making best use of information, expertise and structures.

(MCDEM, 2007)

These principles provide the basis for the four goals of the strategy. Each goal is broken down into objectives that aid in achieving each goal. The four goals and their objectives are:

1. Increasing community awareness, understanding, preparedness and participation in civil defence emergency management.

a. Increasing the level of community awareness and understanding of the risks from hazards.

b. Improving individual, community and business preparedness.

c. Improving community participation in CDEM.

d. Encouraging and enabling wider community participation in hazard risk management decisions.

2. Reducing the risk from hazards in New Zealand.

a. Improving the co-ordination, promotion and accessibility of CDEM research.

b. Developing a comprehensive understanding of New Zealand's hazardscape.

c. Encouraging all CDEM stakeholders to reduce the risks from hazards to acceptable levels.

d. Improving the co-ordination of government policy relevant to CDEM.

3. Enhancing New Zealand's capability to manage civil defence emergencies.

a. Promoting continuing and co-ordinated professional development in CDEM.

b. Enhancing the ability of CDEM groups to prepare for and manage civil defence emergencies.

c. Enhancing the ability of emergency services to prepare for and manage civil defence emergencies. 
d. Enhancing the ability of lifeline utilities to prepare for and manage civil defence emergencies.

e. Enhancing the ability of government agencies to prepare for and manage civil defence emergencies.

f. Improving the ability of government to manage and event of national significance.

4. Enhancing New Zealand's capability to recover from civil defence emergencies.

a. Implementing effective recovery planning and activities in communities and across the social, economic, natural and built environments.

b. Enhancing the ability of agencies to manage the recovery process.

(MCDEM, 2007: 10-14)

Across the four goals, there are areas in which policy can be developed to incorporate the response to increased reporting of domestic violence and integrated with disaster planning in domestic violence agencies.

An aspect that became clear during this research is that agencies dealing with domestic violence have little awareness of the potential risks from hazards in their community. The nature of the work of many of these agencies means that they have little time to consider those issues that do not create an immediate problem for them. Therefore, they are an obvious target for Civil Defence education programmes under Objective 1A above.

Increased awareness within domestic violence agencies of the potential impacts a significant disaster could have on their work, may trigger increased preparedness (Objective 1B). This research has already highlighted that participation in flooding responses alone generated attention at a national level for Women's Refuge with regard to including disaster preparedness in policy formulation. The Chief Executive, Heather Henare, stated emphatically that, but for the research, there would have been no awareness and, therefore, no preparation at a national level (Henare, 2009). Currently, non-governmental domestic violence agencies are not participating in any Civil Defence and Emergency Management at a national level (Objective 1C), and local level 


\section{Chapter 8}

participation was not observed in any of the five case studies in this research. However, once the process of engagement between Civil Defence and Emergency Management and these agencies begins, this may lead to key actors in the community continuing to engage more actively with Civil Defence and Emergency Management, at both local and national levels, and participate in decisions with respect to risk management (Objective 1D).

The engagement will benefit both domestic violence agencies and Civil Defence and Emergency Management. For domestic violence agencies, the opportunity to have a voice in decisions that affect them (where they have previously been silent) is vastly positive. What is clear from the five case studies, is that Civil Defence and Emergency Management, at both local and national level, do not have a clear understanding of the needs of a Women's Refuge safehouse or a women's education programme during a disaster. This lack of clarity means that actions taken in the official response and recovery could put these facilities at risk or create unnecessary barriers to effective operation. Understanding the needs of domestic violence victims and their children, and the agencies that support them, during disasters will likely lead to a higher level of goodwill in the community.

The current planning shortfall may, in the future, lead to agencies being unable to provide vital services to victims of domestic violence in disasters. By encouraging agencies to prepare, and setting an example through preparing themselves, Civil Defence and Emergency Management staff will be able to reduce the level of risk to this already vulnerable group (Objective $2 \mathrm{C}$ ).

Domestic violence policy is not currently seen as relevant to Civil Defence and Emergency Management. However, domestic violence policy will have a 


\section{Chapter 8}

significant impact on how well domestic violence agencies respond and recover from disasters. Incorporating domestic violence considerations into planning and policy development within Civil Defence and Emergency Management, and giving input into how domestic violence policies are faring with regard to disasters, will improve the co-ordination of the government policies regarding domestic violence and current Civil Defence and Emergency Management policies (Objective 2D).

At the present time, CDEM groups are unprepared for the consequences of increased domestic violence reporting during disasters/Civil Defence Emergencies. Policy change can be implemented to enhance local CDEM groups' ability to both prepare for and manage this aspect of emergencies (Objective 3B).

Emergency services, such as the New Zealand Police and paramedic organisations, can be called to the scene of a domestic violence incident. However, there is no planning in place for how this will be achieved during a disaster, in circumstances where limited access and resources are likely to be issues (Objective 3C).

Much like emergency services, government agencies, such as Work and Income New Zealand and Child, Youth and Family, have responsibilities relating to domestic violence. Policy changes within Civil Defence and Emergency Management will benefit other government agencies to prepare for and manage this aspect of disaster response and recovery (Objective $3 \mathrm{E}$ ) and improve the ability of government to manage large-scale emergencies (Objective 3F). 


\section{Chapter 8}

Domestic violence is a social issue that creates significant risk for the women and children affected by it. In order to assist these women and children to recover from a disaster (Objective 4A), it is vital that domestic violence agencies are in a position to offer the requisite services needed. Enarson (1999: 748) pointed out that the disaster could be an opportunity for women to leave an abusive relationship, in that the act of surviving of the disaster created enough self-esteem and self-efficacy within the woman that she felt she could leave the relationship for good. If this is so, then agencies need to be at their best in terms of service quality and breadth to ensure that the women receive the support necessary to make this time the final time they need to leave an abusive relationship.

Civil Defence and Emergency Management have the potential to equip domestic violence agencies with the skills necessary for recovery from a disaster as an agency and to help their clients recover (Objective 4B). However, this will only happen if Civil Defence and Emergency Management acknowledge the need for these agencies to learn these skills, and recognise the current problem of increased domestic violence reporting and the lack of planning and policy to address this.

From the discussion above, it is clear that the incorporation of domestic violence increases into Civil Defence and Emergency Management policy, and the inclusion of policies that cover disasters into domestic violence agencies' policies, fit with the National Civil Defence and Emergency Management strategy. All parties will benefit from developing policy to ensure that domestic violence victims are able to gain high quality help during disasters in New Zealand. Maintaining a high quality of assistance during disasters is essential, as this plays a role in whether a woman successfully leaves an abusive 


\section{Chapter 8}

relationship (Berk \& Newton, 1985; Berk, Newton, \& Berk, 1986; Holiman \& Schilit, 1991; Sullivan, 1991; Davis et al., 1994; Barnett et al., 1996; Sullivan \& Bybee, 1999; Allen et al., 2004; McDermott \& Garofalo, 2004). Formal discussions are the first step in the creation of policies and procedures that will execute the necessary steps to achieve this.

\section{Gender and NZ Civil Defence and Emergency Management Policy}

One of the main considerations that must be included when formulating policy to deal with increased reporting of domestic violence during disasters is the gender dynamics underlying social interactions. Since the 1970's, feminists have been raising the issue of gender inequalities and the lack of recognition of this in policy and law (Alston, 2006: 125). If organisations, such as the Ministry of Civil Defence and Emergency Management, are open to changing policy to meet the needs of domestic violence victims, then this could also be the time to consider wider gender issues in parallel.

Within New Zealand, recommendations for government departments to mainstream gender in practice and policies already exist. The Ministry of Women's Affairs in New Zealand is charged with providing the government with advice on "issues relevant to advancing the well-being of women and ensuring they are able to make their full contribution to New Zealand" (Ministry of Women's Affairs, 2006). In 1996, the Ministry released a report titled "The full picture: A framework for gender analysis" (Ministry of Women's Affairs, 1996). This framework was designed for government department to integrate systematic gender analysis into their policy process (Teghtsoonian, 2004: 267). Although this was published more than a decade ago, there is little evidence that the Ministry of Civil Defence and Emergency Management has implemented its recommendations. At the present time, the Civil Defence and Emergency 
Management Strategy, the CDEM Act (2002) and the National Plan do not address gender or gender dynamics (MCDEM, 2007; MCDEM, 2008). This lack of gender awareness is also seen in the practice of those agencies operating at the local level (as seen in Bang, 2008; Harrison, 2008; Rodgers, 2008).

New Zealand also has international obligations with regard to disaster risk reduction. In 2005, the United Nations launched the international decade for disaster risk reduction. The campaign introduced a policy aimed at specifically addressing the need for each nation to employ policies at a national level to address disaster risk reduction. It raised five action areas:

1. Ensure that disaster risk reduction is a national and a local priority with a strong institutional basis for implementation.

2. Identify, assess, and monitor disaster risk and enhance early warning.

3. Use knowledge, innovation and education to build a culture of safety and resilience at all levels.

4. Reduce the underlying risk factors.

5. Strengthen disaster preparedness for effective response at all levels.

(UNISDR, 2005)

Gender is mentioned as one of the five key considerations for the priorities for action. The policy states that:

A gender perspective should be integrated into all disaster risk management policies, plans and decision-making processes, including those related to risk assessment, early warning, information management, and education and training.

(UNISDR, 2005)

There is no evidence that this consideration has been included in the Civil Defence and Emergency Management policies in New Zealand. New Zealand is not currently meeting of its local and international obligations and, in this regard, falling behind other countries in the world who do include a gender perspective in their disaster management policies, such as Pakistan and the Philippines (Gomez, 2008; Ummar, 2008). 
Domestic violence is a form of prohibited discrimination under international law and states are obligated to act with due diligence to prevent, investigate or punish such acts and to provide effective remedies to the victims of domestic violence.

(Fenrich \& Contesse, 2009)

New Zealand also has obligations under the Convention for the Elimination of all forms of Discrimination Against Women (CEDAW). CEDAW requires "a state to act with the existing means at its disposal to address both individual acts of violence against women and the structural causes so as to prevent future violence" (UN, 2006). The lack of planning and policy in place for increased domestic violence reporting during disasters or wider gender issues means New Zealand is not fulfilling its obligations under international law to the international community and perhaps more worryingly, to the women and children who are subject to domestic violence.

\section{Gendering Policy}

The process of gender mainstreaming is not a simple or quick exercise. Prior to the introduction of gender mainstreaming, many policy practitioners opted for a gender-blind approach to policy. This approach involved the removal of any notion of gender in policy (Kenway, 1990: 7; Little, 1994). The rationale for this approach was the belief that it was gender "neutral" and, therefore, a level of equality would be achieved in the policy process. However, gender-blind and gender-neutral are not synonymous. The gender-blind practice introduced to redress some of the inequalities caused by gender, in fact led to further inequality (Alston, 2009: $140 \& 150$ ).

Gendering policy is not a straight-forward concept and, much like the feminist scholarship it was born out of, it faces issues of definition and method of application (Kenway, 1990: 12; Little, 1994: 41; Daly, 2005; Walby, 2005). In some early situations, gendering policy was interpreted as requiring the 


\section{Chapter 8}

inclusion of a reference that men and women have different needs and a strictly sex-based approach was taken. This early approach meant that a focus was put on women's issues. As a result, women's programmes or units in policy teams were created to ensure that women's needs were met (UN, 2001; Alston, 2006: 126; Alston, 2009: 141). Rather than changing the institution to suit those affected by it, policies aimed to change the way individuals fitted within the same institution (Alston, 2009: 141). This approach kept women in the role of the "other" and reinforced the inherently male-privileging systems that were known to disadvantage women (Alston, 2009: 141). At the 1995 Fourth World Conference on Women in Beijing, the idea of gender mainstreaming was recognised as a preferable method of achieving gender equality than the previous women-focussed policies, as gender mainstreaming challenged policies and institutions at their very core (Donaghy, 2004: 393; Moser, 2005: 576; Alston, 2009: 141). The most frequently cited definition of gender mainstreaming is:

Mainstreaming a gender perspective is the process of assessing
the implications for women and men of any planned action,
including legislation, policies or programmes, in all areas and at
all levels. It is a strategy for making women's as well as men's
concerns and experiences an integral dimension of the design,
implementation, monitoring and evaluation of policies and
programmes in all political, economic and societal spheres so that
women and men benefit equally and inequality is not perpetuated.
The ultimate goal is to achieve gender equality. (UN, 1997: 28)

Gender mainstreaming in Civil Defence and Emergency Management is not exclusively related to the inclusion of women in disaster policies. Whilst this may form a part of a gendered response, it does not include consideration of the gendered power dynamics that will affect individuals during a disaster. Gender mainstreaming seeks to address the interests of women and girls but also men and boys. In order to fully mainstream gender into any policy, the structures that enforce the policy will be challenged and transformed (Alston, 
2009: 141). Rather than isolating a separate unit for the consideration of women, the entire team will need to have knowledge of gender and its implications for policy needs and outcomes (Daly, 2005: 442).

A question asked by advocates of gender mainstreaming is, "Is it better to make gender mainstreaming the responsibility of everyone, or to have a person specifically responsible for the gendering role in policy evaluation and creation?" (Donaghy, 2004: 396) The argument for making each individual responsible for gender mainstreaming is that it will ensure that all members of a policy team are aware of the social environment they are working in. However, the argument for a specific role in gendering policy, is that when an issue becomes everyone's responsibility, it can become no one's responsibility.

In order to ensure that Civil Defence and Emergency Management does undertake an effective move towards equity for women and men, a position with gender expertise must be created within Civil Defence and Emergency Management that will support and assist in this change. Civil Defence and Emergency Management policy states that it is everyone's responsibility to be prepared for a disaster (Ministry of Civil Defence and Emergency Management, 2007: 7). However, there is an entire field of planners and policy-makers that must take a lead in increasing the level of preparedness in communities. This is because it has been shown that little will change without some form of leadership and enforcement (Teghtsoonian, 2004; Donaghy, 2005: 405). The role created within Civil Defence and Emergency Management must hold the power to enforce change if policy does not comply with gender mainstreaming as without the support of those in power, those resistant to such change will continue to slow progress (Donaghy, 2005: 400; Veitch, 2005: 605). 


\section{Chapter 8}

For over a quarter of a century, researchers have examined the relationship between gender and disasters (Rivers, 1982; Melick \& Logue, 1985; Jiggins, 1986; Shroeder, 1987; Vaughan, 1987; Fenton, 1989; Begum, 1993; Enarson \& Morrow, 1997; Alway \& Smith, 1998; Enarson, 2000a; Bradshaw, 2002; Ariyabandu \& Wickramasinghe, 2004; Enarson, Fothergill \& Peek, 2006). The literature is broad and covers both gendered vulnerability (Cutter, 1995; Bolin, Jackson \& Crist, 1998; Ahmed, 2004) and gendered resiliency (Neal \& Phillips, 1990; Akhter, 1992; Delica, 1998; Akcar, 2001; Ariyabandu, 2003) in disasters. The main issues highlighted in the literature that affect women during disasters are: violence; housing and evacuation; transportation; income and employment; dependent care; physical and mental health; access to relief resources; and full participation in disaster decision-making. (Pan American Health Organisation, 1991; Agarwal, 1992; Anderson \& Manuel, 1994; Turner, 1997; Wraith, 1997; Wilson, Phillips, \& Neal, 1998; Ollenburger \& Tobin, 1998; Childers, 1999; Clemens et al., 1999; Enarson, 1999; Enarson, 1999b; Ollenburger \& Tobin, 1999; Delica, 2000; Enarson, 2000b; Rashid \& Michaud, 2000; Khogali \& Takhar, 2001; Van Willigen, 2001; Bateman \& Edwards, 2002; Mankuta, 2004; Fisher, 2006; Jenkins \& Phillips, 2008)

These issues have varying degrees of relevance in the New Zealand context. For example, access to relief resources may not be as restricted in New Zealand as it has been seen to be in countries with a strong Muslim influence, where a woman is expected to spend four months isolated from society in mourning if her husband dies. This cultural practice clearly limits women's access to needed resources (Emmanuel, 2005). However, there are other issues, such as violence against women, where this thesis has demonstrated that New Zealand is clearly not up to standard in terms of the level of planning and policy, both within Civil Defence and Emergency Management and across the domestic 


\section{Chapter 8}

violence sector. Whilst this chapter focuses on recommendations to meet the needs of domestic violence victims, who are predominantly women, there is a wealth of literature (mentioned in the previous paragraph) that Civil Defence and Emergency Management can consult to incorporate wider gender issues into policy and practice. This incorporation should mean that New Zealand Civil Defence and Emergency Management are able to comply with their national and international legal obligations, and ensure that the policy is meeting the needs of those affected by it.

\section{Power Dynamics}

It would be remiss to discuss any policy suggestions without addressing the power dynamics that occur between government agencies and non-government agencies. Whilst New Zealand's central government suggests that it wants to take part in an equal relationship with non-government agencies and work in partnership or collaboration with these agencies, this is perhaps idealistic and does not recognise the power imbalance that exists between government and non-government organisations. Government agencies necessarily have greater access to resources, knowledge, capacities, and capabilities through their legal status, size and scope. As a consequence, any relationship with a community agency or a national non-government agency cannot be equal Johnson \& Wilson, 2006).

In democratic societies, governments are seen as the legitimate site of legal and statutory power, which comes with the obligation of not misusing this power (Borowiak, 2007: 998). This power gives agencies of the government a greater level of legitimated power than non-government agencies wield and so the groups are not on an equal footing from the outset of any relationship between the two. The government agencies and structures also possess a greater access 
to resources, particularly financial assets than their non-governmental equivalents. It is also likely that there will be a transfer of money from the government to the non-government agencies during disasters to help with the response and recovery from the disaster. This relationship is inherently an unequal one, in which fiscal and legal power is vested in the central government agencies. This was seen, perhaps most dramatically, in the widely criticized role of the American FEMA in the Hurricane Katrina disaster Jenkins \& Phillips, 2008). Emergency Management texts refer to power dynamics when discussing key stakeholders, such as community agencies (Lindell, Prater \& Perry, 2007). Lindell, Prater \& Perry (2007) discuss the importance for Emergency Managers to understand that there are a variety of power dynamics occurring between national, regional and local governments; government agencies and nongovernment agencies; and agencies and the community. Therefore, future policy amendments must be cognisant of this differential power in the relations between government organisations, such as Civil Defence and Emergency Management, and non-government organisations, such as Women's Refuge and Victim Support.

\section{Suggestions}

Each agency involved in this research plays a different role during disasters. Civil Defence and Emergency Management, the New Zealand Police, and Work and Income New Zealand are central government agencies that have statutory responsibilities during disasters. Their position is different to the roles of nongovernmental agencies, such as Victim Support, Women's Refuge and the faithbased or indigenous-focussed agencies. However, across all agencies there are some general considerations that all should include when evaluating potential policy changes relating to the increase in domestic violence reporting observed 


\section{Chapter 8}

in this research. These general needs are discussed before moving to more specific cases.

A major issue reported or observed across all case studies was a lack of communication between agencies. During the events, agencies appeared to turn inwards and focus on their own roles, which for some was clearly a coping mechanism for the vastly increased workloads. The lack of communication was evident when the New Zealand Police or Work and Income all reported a good working relationship with Women's Refuges, yet showed no awareness of the increased workloads or issues of lack of access to safehouses that local Refuges were dealing with in the months after the events.

A second measure that agencies can take before the event to ensure current relationships either remain as communicative or increase in the level of communication during events is proactive relationship management and building during the months that events are not present. In doing this, actions to meet the needs of agencies during disasters will be undertaken more smoothly as a relationship is in place and trust between parties will exist. This need for relationships was recognised by a number of participants in this research (Peterson, 2005; Bang, 2008; Harrison, 2008; Wills, 2008; MamulaSeadon, 2009). Due to issues such as staff turnover, this relationship building may need to be a formalised part of a role within each organisation to ensure that these relationships do not diminish over time.

Government agencies must be aware of the constraints on non-government agencies from a lack of resources, both financial and human, during a disaster. It was clear during the interviewing that some government agency representatives did not have an understanding of a non-government agency's 


\section{Chapter 8}

inability to respond to a disaster and increased work without external support. Non-government agencies have a wealth of resource in terms of networks and the ability to mobilise staff (Henare, 2009). However, at times, they will require external support, in the form of access to resources that may be held by government agencies. Government agencies may need to provide this support and, therefore, should prepare for this potential actuality.

Finally, in this planning, all organisations must plan for the varying scales of

events. Civil Defence and Emergency Management have the background necessary to educate other organisations on the differing impacts of disaster scenarios. The case studies in this research did not involve events in any way comparable to recent international events. In the New Zealand case studies, whilst safehouses may have been cut off or overflowing, they were not destroyed (and neither were the office premises of the agencies). An escalation of scale of the causal event would significantly alter the requisite response and agencies need to be prepared for such an event.

All domestic violence agencies need to be prepared to maintain their services to current clients, as well as meeting any increase in caseload. Whilst these will be discussed in specific detail in the sections reviewing each agency, an example is how a women's education programme or men's stopping violence programme should continue during a disaster. This may not be a high priority for those most directly affected by the disaster. However, the agencies have a duty to all clients not to cut services without offering an alternative or communicating when these services will resume. A second example is the role of the New Zealand Police in enforcing existing protection orders when officers are preoccupied with disaster response and other law enforcement. It is vital that this 


\section{Chapter 8}

type of enforcement does not halt as the risk to the protection order holder has not decreased and may, in fact, have increased.

\section{Civil Defence and Emergency Management}

New Zealand's Civil Defence and Emergency Management staff at national, regional and local levels now have evidence that they need to be aware of increases in domestic violence reporting and the needs of domestic violence agencies during disasters.

Civil Defence and Emergency Management is based on the principles of the four R's: Reduction, Readiness, Response and Recovery (Ministry of Civil Defence and Emergency Management, 2007). Of all the organisations interviewed, Civil Defence and Emergency Management holds the greatest level of responsibility to ensure that agencies and communities are prepared for disasters and have the capacity to respond and recover from them. It is also considered best practice to involve non-government agencies in the Civil Defence practice, both in planning and policy-making, and in the response and recovery phases (Lindell, Prater, \& Perry, 2007: 29).

Civil Defence and Emergency Management is a de-centralised organisation (Mamula-Seadon, 2009). Aside from the CDEM Act (2002), the Ministry of Civil Defence and Emergency Management's main avenue for communication with the local Civil Defence and Emergency Management (CDEM) groups is through optional guidelines and information (Mamula-Seadon, 2009). The local CDEM groups are relatively autonomous. This has implications for the way in which policy and practice is implemented. The manner in which the following suggestions are incorporated in practice will need to reflect this de- 


\section{Chapter 8}

centralisation, whilst ensuring that the changes are as consistent as possible across New Zealand.

Within Civil Defence and Emergency Management's readiness principle, there is a role for staff involved in Civil Defence and Emergency Management to provide training for organisations and groups to prepare for disasters. Prior to any event, domestic violence agencies are in need of training as to the ways a significant disaster could affect them. At the present time, the Women's Refuges in this research have only basic evacuation plans in place and lack any sort of business continuity planning or provision for what will happen with the women and children once they are evacuated from the safehouse or office. Addressing these inadequacies is an aspect of the readiness principle on which the Civil Defence and Emergency Management work is based.

Planning by Civil Defence and Emergency Management also needs to include consideration of where to evacuate a vulnerable Women's Refuge safehouse to in the event of a disaster. In the Wellington region, there are six Refuges with six separate safehouses, and there are considerably more in the Auckland region. When a disaster affects these areas to the extent that evacuation is necessary, the number of women and children evacuated from safehouses could be in the hundreds. There is currently a director's guideline relating to mass evacuations (MCDEM, 2008), however, this does not mention Women's Refuge safehouses specifically. There are sections that cover vulnerable populations during evacuations, yet, domestic violence victims are not specified in this. The inclusion of safehouses and domestic violence victims into the evacuation planning undertaken by local Civil Defence will prepare Civil Defence for the special needs of domestic violence victims, and ensure that appropriate accommodation is found quickly. 
Finally, Civil Defence and Emergency Management needs to discuss which agency, if any, will be responsible for the additional financial costs incurred by non-government agencies in responding to increased reporting of domestic violence during disasters with other government departments, including, but not limited to, the Ministry of Social Development. Costs would include the rehousing of women and children if a Women's Refuge safehouse is evacuated; the cost of extra staff with the experience necessary to respond to increased demand whilst maintaining a high standard of service; and the use of vehicles needed to gain access to a Women's Refuge safehouse isolated by a disaster. Non-government organisations, such as Women's Refuge, currently lack the capacity to meet these financial demands and this is an issue that will need to be addressed.

\section{New Zealand Police}

The New Zealand Police, also have a statutory responsibility during disasters. This responsibility was observed to increase their workloads more generally, as noted in Chapter Five, and required the cancellation of staff leave and longer work hours for officers. Women's Refuge view the role of the New Zealand Police as key in interfacing between Women's Refuge and Civil Defence. The reason expressed was the fact that the relationships are currently in place:

Heather: Well the confidentiality of the women in the house is an issue. You know, where your local Civil Defence plan might jump in, it might be problematic within a Refuge, because it might be his partner in there. So you've got to consider those, and we can't possibly go around and train every Civil Defence person in the country so you've got to be realistic with what you can work with. Obviously the Police are involved with Civil Defence so they would be your best port of call...

(Henare, 2009) 


\section{Chapter 8}

The New Zealand Police may need to play a role in passing information between Women's Refuge and Civil Defence. The nature of the work of Women's Refuge means that its work requires a high degree of confidentiality. The need for confidentiality can lead to issues with regard to safehouse evacuation or access during the emergency, or the need for the concealment of the names of residents within the safehouse.

The New Zealand Police and Women's Refuges in all five case studies stated that they had good working relationships with each other. However, practical evidence of this during the disasters was scarce in all but Whakatane. In the case of Timaru, the safehouse was isolated from workers for a one-week period after the initial snowfall and the New Zealand Police were not aware of this. In hindsight, the Police could have provided access to all-terrain vehicles, which would have allowed Women's Refuge workers to take food and supplies into the safehouse and evaluate the need to evacuate victims, depending on the level of damage to the house. This co-operation did not happen and women and children were forced to fend for themselves in an under-stocked safehouse during the snowstorm. In the future, it would be beneficial for both Women's Refuge and the New Zealand Police, if policy changes involved formal measures to ascertain whether Women's Refuge needed the assistance of the Police vehicles to access their safehouse during a disaster.

Aside from vehicular access, I submit that it is best practice for the Police force in each community affected by a disaster to check on the non-government agencies they work closely with as soon as practicable. This benefits the nongovernment agencies as any issues raised with the New Zealand Police may obtain an expedited solution through the Police role in the official Civil Defence response. However, it also benefits the Police and the official Civil Defence 


\section{Chapter 8}

structure as community agencies are often involved with the most vulnerable of community members and will be able to inform the responding agencies of gaps in the response. Learning of gaps at a time when these can be addressed rather than retrospectively after the Civil Defence operation is complete will build better relations with those community members and, more importantly, will ensure the Civil Defence response is more effective.

A consideration for the New Zealand Police, with regard to their own work with victims of domestic violence, is how they will continue to enforce protection orders during disasters. It is not unreasonable to consider that in the face of large-scale evacuations, some of the everyday work of the New Zealand Police must be given a lower priority than it would normally receive. However, knowing this, a perpetrator of domestic violence with a protection order against them may choose this time to breach it, assuming enforcement will be given a lower priority.

In addition to the enforcement of existing protection orders, the increased reporting of domestic violence that has been presented in this thesis means that officers and procedures will need to be prepared to meet the needs of new victims of domestic violence in larger numbers than at other times.

Another consideration that should be taken into account when addressing the issue of increased reporting during disasters is the means of contact for the public. In the case of Timaru, it was observed that phone lines were down for varying time periods. This meant that the public were not able to contact the Police (and other agencies) by phone in the aftermath of the event. Being unable to solicit help from the Police in the event of a violent domestic violence incident is a major concern. 


\section{Ministry of Social Development}

The Ministry of Social Development is a government body with, among others, two key social service agencies in New Zealand communities, Work and Income New Zealand (the agency responsible for financial welfare provision), and Child, Youth and Family (the agency responsible for the welfare of children and youth under the age of 18). Both agencies have statutory obligations to respond during disasters. Child, Youth and Family, at a national level, also provide government contracts to non-government agencies, including Women's Refuge. Women's Refuges receive quarterly funding based on the fulfilment of formal contractual obligations. Consequently, both Work and Income New Zealand, and Child, Youth and Family need to be aware of increased domestic violence reporting during disasters.

Work and Income New Zealand provides financial assistance to domestic violence victims upon leaving an abusive relationship. In some of the agencies interviewed, there had been specific liaison with a Work and Income staff member who dealt with all domestic violence victims that request Work and Income support at the time of the disaster. In other communities, the role had been created after the disaster. In future disasters in New Zealand, this role will need to be strengthened to cope with the increased work which is specific to domestic violence and in addition to the increased numbers of people accessing Work and Income for general disaster assistance.

The nature of the work with Women's Refuge clients is likely to change in the aftermath of a disaster. Prior to an event, Women's Refuge may have been able to take the women to Work and Income for their appointments and then return to the safehouse. However, during a disaster, this may not be physically 


\section{Chapter 8}

possible or logistically feasible. This change in the way Women's Refuge and Work and Income will be working together needs to be recognised in Work and Income's emergency response policy. This is to ensure that Work and Income staff are prepared to mobilise during disasters to provide the right level and type of support needed by the local Women's Refuge (and other nongovernment agencies) and their clients.

Documenting increases in domestic violence reporting is also vital to the future understanding and monitoring of this social issue. If Work and Income are willing to include a section in their documentation that allows for the assignment of an external event, such as natural disasters, or a wider category including other "disasters" such as major plant closures, this will allow for the tracking of domestic violence reporting in relation to specific events. Future research will be greatly improved through this measure as it not only collects figures of related cases but also raises awareness within the individuals working at Work and Income about the potential link between the event and their caseloads.

Child, Youth and Family will need to be aware, at a national level, of the impact that a disaster can have on the domestic violence agencies that it funds in areas affected by disasters. The increased workload during disasters may influence an agency's ability to report back to Child, Youth and Family in order to fulfil their contractual obligations. Whilst this reporting is an important part of the contractual process, Child, Youth and Family may need to be more flexible in terms of when these reports need to be submitted.

The question of funding also needs to be discussed when Child, Youth and Family are examining their Civil Defence and Emergency Management policies. 


\section{Chapter 8}

It is unclear who the key funder should be if agencies, such as Women's Refuge require additional funding during a disaster. In the case of Whakatane, an attempt was made to gain funding for a second safehouse in the community to deal with the excess number of women and children staying in the primary safehouse and the houses of the workers (Ripaki, 2005). However, without the authority at local level to do this, delays in getting approval from the national office in Wellington, coupled with the specific needs of a Women's Refuge safehouse, meant that a second house was never found and workers continued to house women and children in their homes throughout the disaster (Te Are, 2005).

At a local level, Child, Youth and Family will also need to consider the downstream effects of increased reporting of domestic violence. Currently, when the New Zealand Police visit a residence for a domestic violence incident, they complete a form called a POL400 (Peterson, 2005). If a family receives three POL400's when children are present, their case is referred to Child, Youth and Family. This means that whilst Child, Youth and Family may not experience an increase in caseloads relating to the floods in the immediate aftermath of an event, it may experience an increase later on, which may be so temporally removed that it is not immediately linked with the disaster. However, the increased reporting may have been related to the event through the necessary extended period of reporting to the Police.

\section{Women's Refuge}

Women's Refuge has different needs from those of other domestic violence response agencies. The provision of Women's Refuge safehouses, which provide accommodation to both women and children, mean that its needs during a disaster are of a different nature to agencies that do not have a 


\section{Chapter 8}

residence. On this basis, they will be treated separately to other domestic violence non-government agencies in this chapter. In addition to the safehouse accommodation, Women's Refuge advocates provide education programmes, support for women who do not want to come into a safehouse, advocacy with other agencies such as medical, legal and government agencies, assistance with formulating safety plans for women who want to stay in their relationships, and work with children who have witnessed the abuse (Te Are, 2005; Buckley, 2008; Rangi-Smith, 2008; Tukariri, 2008; Williams, 2008; Henare, 2009). Women's Refuge services are wide-ranging and complex, which means that a disaster can impact on a local Refuge in a myriad of ways. Policy will need to reflect this complexity.

At a very basic level, Women's Refuge will need to update its policies to incorporate a Civil Defence plan. This plan is not the simple evacuation plan in case of an emergency that can be found in many buildings. It must be a comprehensive and adaptable policy that will meet the needs of the Refuges, and the women and children in the immediate aftermath of a disaster and in the months or years following that are needed to recover. Here, Civil Defence and Emergency Management can provide support and information on potential issues, such as road closure or power outage durations, to ensure the policy is based on the highest level of current knowledge on infrastructure impacts of disasters.

Women's Refuge will also need to address the issue of funding to meet the increased service demands coinciding with potential costs of relocation, cleanup, or replacement of destroyed items. In discussing this issue at a national level, it was clear that Women's Refuge funding is based on grants and contracts that are for specific projects (Henare, 2009). This means that, at 


\section{Chapter 8}

present, there is no reserve left to be pooled for unexpected financial needs, such as disasters. It was also clear that some of the Refuges in the national body do not have the funds to meet daily needs, let alone to insure for disasters or stock up on food and emergency supplies (Henare, 2009). This issue of little financial resourcing is one that will need to be examined by Women's Refuge and a solution agreed upon across the national organisation.

At the present time, the safehouses are particularly vulnerable during disasters, placing the women and children who may be in them at the time of a disaster at great risk. With no pre-existing plans for evacuation of the safehouse or a way to gain access to women in a safehouse who are unable to leave, the safehouses are exposed to dangerous situations. The safehouses are one aspect of planning that are of equal concern for both Women's Refuge and Civil Defence planners. A safehouse can be viewed as a 'special residence'. Therefore, as in the case of retirement homes and hospitals, special plans must be made to ensure that safehouses are able to continue services during a disaster and, if evacuation becomes necessary, that the workers have the resources available to evacuate safely.

Evacuation of a safehouse is not as simple as evacuating to the general site. Domestic violence victims cannot be relocated to where other members of the community are housed for safety reasons (Henare, 2009). It is possible that their abuser, or family and friends of the abuser, will be located at the evacuation site, which puts the victims and their children at a high risk. The point at which a woman leaves an abusive relationship and the weeks following are the most dangerous periods for her (Choice \& Lamke, 1997; Rhatigan, 2006). In addition to the risk to the victims, the staff and other residents at the evacuation centre may be placed at risk because they could be caught in the 


\section{Chapter 8}

incident. A separate evacuation site is the safest option for domestic violence victims and, where possible, it may prove safest to move the victims out of the area entirely. However, if this is not possible, as was the case in Palmerston North and Whakatane, where roads were closed for up to a week after the event, then the bare minimum is a secure, confidential local site. It is in the nature of Women's Refuge's work that confidentiality is required to maintain a secure safehouse.

In the cases where evacuation is not required, but the safehouse is geographically cut off from the workers (as was the case in Timaru). Women's Refuge needs to consider how they will gain access to the premises. Using resources available to other organisations, such as the New Zealand Police, necessitates pre-planning and a specific policy that requires the New Zealand Police to make the vehicles available for such a use as soon as practicable.

Secondly, the issue of food, water and other supplies in the safehouse is one that requires consideration. All five of the Refuges studied reported that there would not be enough food in the house at any one point in time to feed and take care of a full safehouse for an extended period of time. In Timaru, the safehouse was isolated for one week after the initial snowfall and there were insufficient supplies to sustain the families in the safehouse comfortably at the time (Rangi-Smith, 2008). This situation demonstrates to other Women's Refuges the need to stock up on supplies as much as possible. However, it should also indicate to Civil Defence and Emergency Management, that the nature of Women's Refuge's funding structure means that it cannot be assumed that there will be enough food and supplies to meet the needs of those in the residence. 
Finally, the health and safety considerations of those inside the safehouse will need to be included in Women's Refuge disaster policies. The safehouse can accommodate a large number of women and children. Therefore, the use of toilets, showers, and tap water during disasters will need to be examined and addressed in the planning and policy.

A second area of consideration for Women's Refuge is staffing levels. With such a large proportion of its staff being volunteers, it was observed that in the aftermath of events, staffing numbers were reduced not increased (Te Are, 2005; Rangi-Smith, 2008). Women's Refuge needs to consider what it will do in the event that staffing levels are significantly reduced during a disaster. Unlike the government agencies that are under a statutory responsibility and a majority of paid staff, Women's Refuge has no mandate for seconding extra staff outside of the disaster area. This is also, in part, caused by the fact that the Refuges in the National Collective are independently run. However, Women's Refuge can learn from the government agencies in this research. Separately, the New Zealand Police and Work and Income New Zealand representatives discussed a requirement in their organisations to be able to respond to requests from other areas to send staff from their agency to support disaster-affected agencies. This means that if a disaster strikes in one area of New Zealand, such as the Lower North Island flooding, then staff from agencies in other areas, for example the South Island agencies, must be available should a request be made to go to the area and help with the overload of work.

Women's Refuge's work is such that, in a disaster, experienced staff are needed and the people brought in must have domestic violence education and Women's Refuge training. Unfortunately, for this reason, it cannot be volunteers from the community with no experience in domestic violence response. This type of 


\section{Chapter 8}

policy would need to be agreed upon long before an event occurs, as all Refuges are already under-resourced (Henare, 2009) and, therefore, it may not be feasible to send staff to other areas.

The cost of doing this will also need to be discussed by Women's Refuge, and the decision as to who will pay for the relocation, housing, replacement or restoration of computers and other technology and expenses of the staff coming into the area must be made before an event. There are a number of options for the financing of this type of initiative and it is important to have clarity as to who will meet the costs before an event so that this is not an added stress for the Women's Refuge staff during a disaster.

Women's Refuge needs to plan for the contingency of power and phone outages, as observed in Timaru in the Canterbury snowstorm. During the first week, when snow was still blocking roads and phones and power were out, women were not able to reach the services of Women's Refuge. This was reflected in the Timaru figures, which showed only four new women requesting Women's Refuge services during the month of June and then 25 in July. Other parts of South Canterbury were without power and phone access for up to six weeks in this event. It is less clear whether there were women from outer areas unable to get help during this period as nothing was recorded in the case file summaries. However, it is plausible to consider this was present in other areas also. In the case of a larger-scale disaster, Women's Refuge needs to consider how they will ensure their services are still accessible in some form when phones are not working for extended periods. This is perhaps one of the most difficult situations to deal with and will require some specific technical advice given to Women's Refuge policy-makers to help with effective decision-making. 
Another technical consideration that Women's Refuges will need to incorporate into their planning is how they will continue to record details of cases they are working with during a disaster. If their computers and database are destroyed during the disaster, a backup exists at the national office. However, this file does not have the names of the women and children the staff are working with, as these are deleted in the process of sending them to the national office for security and confidentiality processes. It is important to continue to keep a record of the women and children the staff are working with and the specifics of each case.

Finally, clients can require years of counselling with Women's Refuge and, it is likely that during a disaster, the Refuge will have existing clients as well as the new ones that are increased in number. A plan to maintain the relationships and work with their current clients needs to be in place before the disaster. This needs to be communicated to the current clients at the time of the disaster so that they are not left unaware of what to do and when the work can continue if stopped. Similarly with current clients accessing the women's and children's education programmes that are run by the Refuges. A disaster could strike at any point in the programme and the consequences of a cancelled or interrupted programme could create an unsafe situation for the women or children involved. It will be integral for the Refuge to communicate clearly what is happening to the programmes during the disaster and what services women can access.

\section{Other domestic violence non-governmental agencies}

These other non-governmental agencies do not have the same safehouse considerations. However, demand for their services may also increase, and they will have the task of supporting existing clients during a time when offices may 


\section{Chapter 8}

be destroyed or unusable. As with Women's Refuge, some of the other nongovernmental agencies offer education programmes for women and children, and stopping violence programmes for men. If a disaster occurs in the middle of a programme, plans will need to be made to convey this to participants and an alternative set up for those participants who need it.

An increased workload during a disaster will mean that an agency, particularly a non-governmental agency, will need to be doing more with less. Scarce financial resources in non-governmental agencies means a strong dependence on human resources becomes part of the organisation's culture (Henare, 2009). If a disaster causes a reduction in the number of staff available to help or offices are destroyed, non-governmental agencies may lack the resources to address the replacement of such resources whilst managing an increased workload. Civil Defence should also include other domestic violence, nongovernment agencies in business continuity training that will aid each organisation in making decisions about policies addressing disaster events. The policies will also need to consider where extra funding can be found during a disaster should they require more resources - physical, financial or human.

\section{Conclusions}

This chapter has discussed the current policies, both local and international, in place that provide the basis for New Zealand's current Civil Defence and Emergency Management approach. It has also covered the policy for gender mainstreaming analysis in New Zealand that all government departments are expected to apply to their policy analysis. I then presented the process of gendering policy as one of the considerations necessary for the creation of effective policy to address increased domestic violence reporting during 


\section{Chapter 8}

disasters. Finally, I have offered suggestions for the key agencies involved in Civil Defence and Emergency Management and domestic violence response.

The process of changing or creating policy to address increased domestic violence will only be successful if the agencies join together to share their knowledge and come to an understanding on each agency's role. The policy changes will not be immediate as there are a large number of considerations. Initiation of the process would benefit from a meeting between the key agencies at a national level and a clear agreement on the steps to follow.

The policy suggestions set out above have been formulated through discussions with agency representatives, at the local and national levels, and an examination of practices suggested by the international literature. Specific planning for increased reporting of domestic violence in disasters is a womenspecific initiative, which is the first step towards gender mainstreaming. However, domestic violence is a manifestation of the gendered nature of social life. It is one way in which an underlying patriarchy in New Zealand society creates an unsafe condition for a specific group of diverse women. In addressing this issue, policy makers are taking a step towards dealing with gender inequality, which is a goal of gender mainstreaming. This step is a good start to the overall gender mainstreaming process as the agency representatives that will be involved in making policy changes are currently open to making these changes (Byers, 2009; Henare, 2009; Mamula-Seadon, 2009).

Women-focussed initiatives are used in the early stages of gender mainstreaming. However, the approach has yet to be widely applied to policy (UN, 2004). Civil Defence and Emergency Management policy makers and 


\section{Chapter 8}

planners will need to consider other gender-based inequalities, such as those discussed above, that create differing levels of risk for men and women in the future to ensure that the policies used are not gender-blind, and enforce rather than mitigate gender inequality. However, a top priority for both Civil Defence and Emergency Management and domestic violence agencies is to put in place policies and plans that address increased domestic violence reporting during Civil Defence emergencies, as the current lack of either heightens the risk already vulnerable women and children during disasters. 
Chapter Nine: Conclusions 

Violence against women is perhaps the most shameful human rights violation, and it is perhaps the most pervasive. It knows no boundaries of geography, culture or wealth. As long as it continues, we cannot claim to be making real progress towards equality, development and peace.

(Kofi Annan, 1999)

A decade after Kofi Annan's statement, it still holds true. Domestic violence continues to be a pervasive issue that affects women across the demographic spectra. This thesis has addressed one aspect of domestic violence in one country, New Zealand, that of increased domestic violence reporting during disasters. Overall, the research has presented evidence for increased domestic violence reporting in 11 of the 17 events that were part of the survey and, in all five detailed case studies. Moreover, it has examined the multifaceted nature of the relationship between domestic violence and disasters.

\section{Understanding Domestic Violence and Disasters}

The relationship between domestic violence, domestic violence reporting and disasters is complex and reciprocal. Both disasters and domestic violence are social phenomena. Where these two phenomena intersect, outcomes of each are intensified by the other. Disasters have been reported to influence the incidence of both domestic violence and domestic violence reporting. Conversely, domestic violence creates a higher level of risk to those subjected to it prior to, and during disasters, which impacts upon the magnitude of the disasters.

As this thesis studies an intersection between two social issues, the sociology of disasters was the most appropriate discipline to use within this project. Out of the sociology of disasters came the Pressure and Release model, which provides a framework to explain why domestic violence reporting may increase 


\section{Chapter 9}

during disasters. Disasters expose social structures within a society that remain somewhat obscured during times of environmental normalcy. The Pressure and Release model uses three levels to explain the risk created by social, cultural, political and economic structures (Wisner et al., 2004). These are "root causes," "dynamic pressures," and "unsafe conditions" (Wisner et al., 2004). Domestic violence is one of the dynamic pressures that the root cause patriarchy creates. During disasters, domestic violence becomes more visible placing violence in the view of those it is normally hidden from.

The model also explains the way in which domestic violence places its victims at a level of higher risk from natural disasters than those who are not subjected to it. Domestic violence is a dynamic pressure that creates a number of unsafe conditions. These conditions include isolation, a heightened level of fatalism in both victims and perpetrators, and lack of access to resources, to social support networks and to communication media. All of these conditions are very common in cases of domestic violence, and all put the women (and children) that are subjected to domestic violence at a greater level of risk during disasters.

However, both the pre-existing body of work on domestic violence and disasters, and this research have demonstrated that it is not just domestic violence that may increase, it is also reporting of domestic violence (Enarson, 1999; Fothergill, 1999; Jenkins \& Phillips, 2008). Literature regarding women's stay/leave decision-making in violent relationships aids in understanding why domestic violence reporting increases during disasters. Six models have been proposed to explain a women's decision to stay or leave an abusive relationship: Learned Helplessness, Traumatic Bonding, Psychological Entrapment, Investment, Rational Action/Planned Behaviour and Two-Part 
Question model (Fishbein \& Ajzen, 1975; Walker, 1979; Dutton \& Painter, 1981; Brockner \& Rubin, 1985; Launius \& Lindquist, 1988; Strube, 1988; Rusbult \& Martz, 1995; Choice \& Lamke, 1997; Rhatigan et al., 2006).

The model favoured in this work is the two-part question model. This model proposes that women base a decision on whether to stay or leave on their answers to two self-imposed questions. These questions are "Will I be better off?" and "Can I do it?" (Choice \& Lamke, 1997: 297). A disaster can be seen to affect the responses to both questions. For the first question, a woman will look at her previous investment in the relationship, the level of satisfaction she feels in the relationship and the quality of alternatives (Choice \& Lamke, 1997: 297). The disaster can reduce the previous investments in the relationship (by destroying houses and possessions and/or incapacitating social networks through evacuations) and the level of satisfaction with the existing relationship (through stress-induced, more frequent or more intense violence), whilst also increasing the quality of alternatives, via disaster-relief.

Choice and Lamke propose that if a woman decides she would be better off by leaving the relationship, the subsequent question she asks herself is, "Can I do it?" (Choice \& Lamke, 1997: 297). During Civil Defence emergencies, a wealth of social service agency support is made available to the community (Te Are, 2005; Bang, 2008; Rodgers, 2008). Evacuation, or a home-visit from a social worker or Civil Defence worker, may be the prompt necessary for a woman to feel she is able to leave. If this is coupled with increased availability of alternative housing or more social support within the community, then increased reporting of domestic violence in disasters may be a by-product of improved self-efficacy as a result of these changes. 


\section{Chapter 9}

The existing literature provides background regarding why domestic violence and domestic violence reporting may increase during disasters. To establish support for these hypotheses, interviewees in this research were asked their impressions of factors influencing women's decisions to report during that period. In speaking to agency representatives, a number of factors were reported as significant. Financial stress was one of the most frequently cited factors involved in the increased domestic violence reporting (Peterson, 2005; Te Are, 2005). This occurred due to a loss of house and/or possessions, and reduced work hours due to businesses closing for cleanup. Structural factors were also raised (Anderson, 2005; Hetet, 2005; Ripaki, 2005; Te Are, 2005). These include a lack of communication, between agencies, and between agencies and the community (Anderson, 2005; Hetet, 2005; Ripaki, 2005; Te Are, 2005). This created increased stress for victims of the emergency as they were sometimes unclear how to fulfil the requirements to qualify for support (Te Are, 2005).

However, these factors are not causes. Domestic violence is not created by a lack of money, disasters or stress. What is not explained by these factors is why the perpetrators of domestic violence are abusive with their partners and not with colleagues, friends, or other members of the community. Domestic violence is fundamentally about control and, in particular, the control of women by their intimate partners (Umberson et al., 2004). It is a clear indicator of how fundamentally gendered society is.

Although reporting of domestic violence increases during disasters, there is, currently, a lack of any significant planning or policy in place that addresses this phenomenon during Civil Defence emergencies in New Zealand. This research has created a greater awareness among the agency representatives 
involved but has, as yet, not led to changes in policy or practice. This lacuna means that women and children who are subjected to domestic violence will still be placed at heightened risk during disasters. For example, domestic violence victims may not have access to traditional communications media, such as television or radio and, therefore, may not be aware of evacuation orders or other emergency information. Policy and practice for Civil Defence and Emergency Management must adapt to fill this short-coming which is currently creating unequal outcomes for victims of natural disasters in New Zealand.

Just as Civil Defence and Emergency Management is unprepared for increases in domestic violence reporting, domestic violence organisations are also underprepared and, in some instances, ill-equipped to deal with a significant Civil Defence emergency and the subsequent increase in domestic violence reporting. At the present time, there are no specific policies in place, in domestic violence agencies including the New Zealand Police, Women's Refuge and secondary agencies such as Victim Support, to respond to increased domestic violence reporting during a disaster. Organisations such as Women's Refuge and other non-government organisations also lack any continuity planning to maintain, let alone increase, levels of their services during a Civil Defence emergency. In the past, this lack of planning has led to the overflowing of a safehouse in Whakatane, to the degree that workers housed families in their own homes, a safehouse being physically cut off for a week from workers and food or water in Timaru, and women being unable to access services of Women's Refuge due to road closures in Palmerston North.

At the present time, both domestic violence organisations and Civil Defence and Emergency Management are not providing best practice for women and children 


\section{Chapter 9}

who are subjected to domestic violence. Given that the quality of service a woman receives when seeking help significantly influences her decision as to whether she will leave an abusive relationship (Berk \& Newton, 1985; Berk, Newton, \& Berk, 1986; Holiman \& Schilit, 1991; Sullivan, 1991; Davis et al., 1994; Barnett et al., 1996; Sullivan \& Bybee, 1999; Allen et al., 2004; McDermott \& Garofalo, 2004), this is unacceptable.

Domestic violence and disasters do not have a causal relationship. Domestic violence was reportedly already present in the relationships of the women seeking assistance in the months following significant Civil Defence emergencies in New Zealand, before the events. However, a link does exist and has been demonstrated, in this research, to lead to increased domestic violence reporting in New Zealand.

\section{Where to from Here?}

I hope that the next step arising from this research is for domestic violence organisations and Civil Defence and Emergency Management to apply the findings of this thesis to address shortfalls in policy and practice. The policy suggestions offered are agency-specific and are realistic given the constraints each organisation faces. The process may involve a significant undertaking from organisations, and require time to fully address the needs of each institution and their clients. However, the outcomes for domestic violence victims (both women and children) will be significantly improved if policy and planning changes are implemented effectively.

Further research into the topic of domestic violence and disasters should include the interviewing of women who experienced a change in their abusive relationship following a significant Civil Defence emergency in New Zealand. 
This change could consist of either a change in the nature of the abuse, or a change in the woman's acceptance of the abuse leading her to leave the relationship, with or without the assistance of a domestic violence agency. It is only through speaking to the victims and assessing any changes in their attitude towards the violence that the theories presented in this thesis can be confirmed or amended.

This research provides baseline data on domestic violence reporting and disasters in New Zealand. Research participants noted that in contributing to this research, their awareness of the issues had been raised (Rangi-Smith, 2008; Rounthwaite, 2008; Tukariri, 2008; Byers, 2009; Henare, 2009). Future research that compares the level of increased reporting, and the agencies' abilities to respond to this, will be useful in gauging if this research has created positive change. Conversely, if no changes are made to policy or practice, future research can examine the impact a lack of change has had on domestic violence and the reporting of it.

\section{Conclusions}

An excuse that there is no evidence of increased domestic violence reporting during disasters in New Zealand is no longer plausible. As a result, agencies in the field of domestic violence response and agencies in the field of Civil Defence and Emergency Management now need to address the effects on their work during disasters. Policy and planning present the most durable methods for improvements, as they withstand changes in staff over time. Policy-making and planning are iterative processes that allow for the re-evaluation and amendment of practice. 


\section{Chapter 9}

The policy changes should be the first step towards gender mainstreaming within New Zealand Civil Defence and Emergency Management. New Zealand has formal obligations to ensure that policy does not create inequitable results between different groups. These policy suggestions are women-focussed initiatives that fit into the early stages of gender mainstreaming. As gender mainstreaming progresses, policy will need to incorporate wider considerations of the role gender plays in the lives of victims of a disaster, and how gender impacts on their experiences. If this is not undertaken, Civil Defence and Emergency Management will fail in its legal and social obligations to those affected by disasters in New Zealand. However, if New Zealand can successfully introduce gender into its Civil Defence and Emergency Management practice, it will lead the developed world in this area and create policy and practice that is truly reflective of the reality of disasters. This is surely something to be strived for. 


\section{Appendices}





\section{Reported Domestic Violence following Disasters}

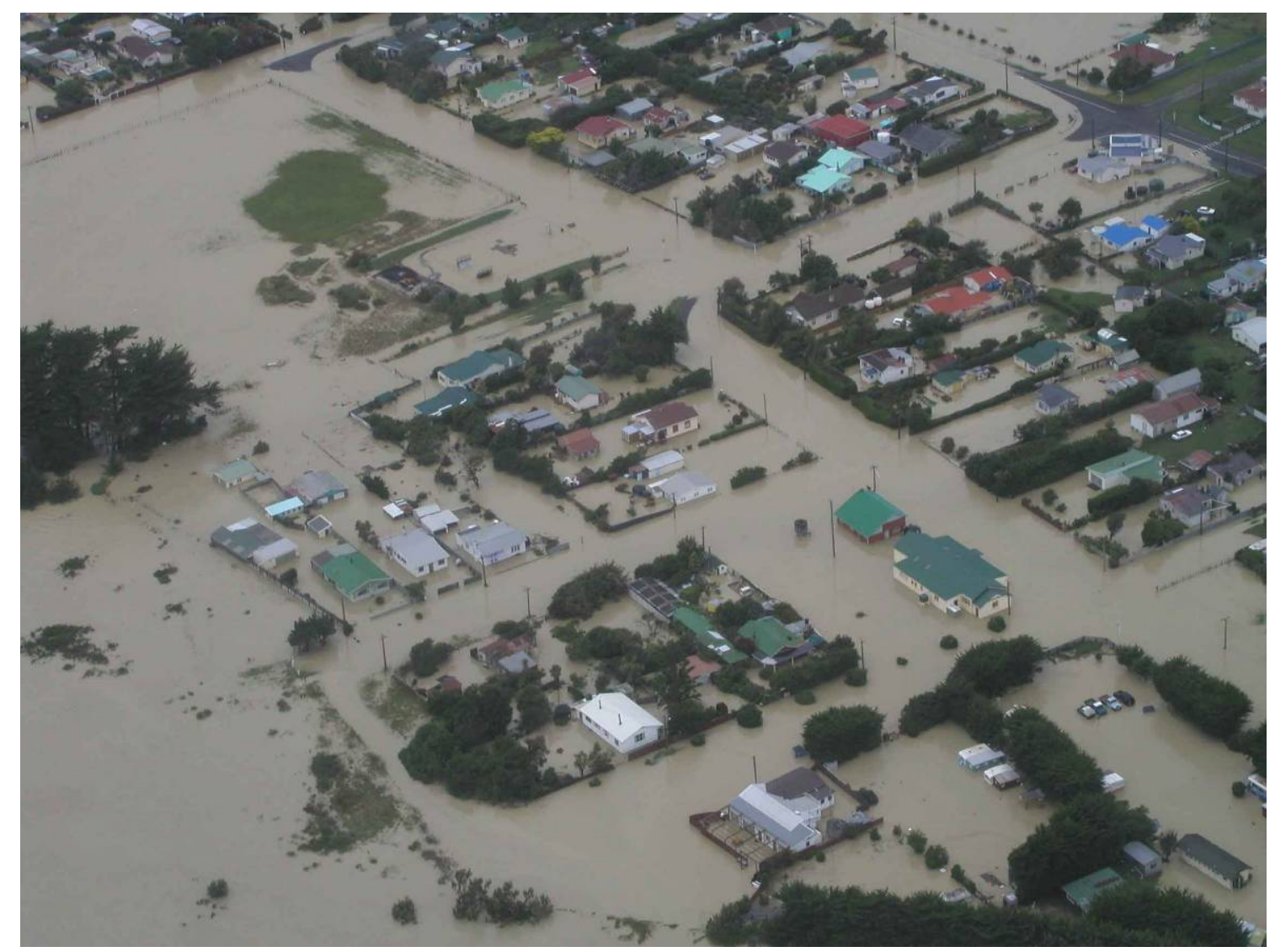

(Photo: Tangimoana, Ministry of Civil Defence and Emergency Management)

A survey of social service agencies following disasters in their communities

\section{Victoria \\ UNIVERSITY OF WELLINGTON \\ Te Whare Wānanga \\ o te Upoko o te Ika a Mäui \\ 年圈果}


1. What does your agency do in relation to domestic violence?

2. Do you deal with: (Tick all that apply)

Victims/Survivors

Perpetrators

Family and Whanau

Other

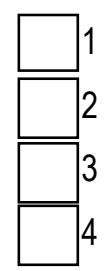

(Please Specify)

3. Following the event, did your agency experience a change in the number of clients reporting or referred to you for domestic violence-related help?

(Please provide your best estimate of the \% increase/decrease that followed the event)

Immediately after the event (first 2 weeks):

Yes, an increase

Yes, a decrease

No, numbers remained static
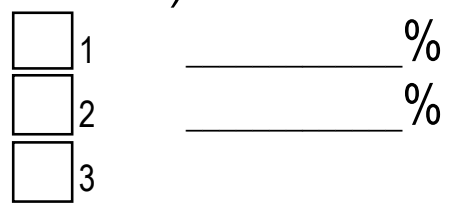

Between 2 weeks and 6 months following the event:

Yes, an increase

Yes, a decrease

No, numbers remained static
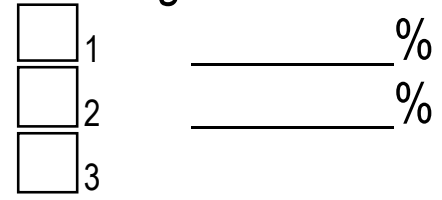

Between 6 months and months following the event:

Yes, an increase

Yes, a decrease

No, numbers remained static

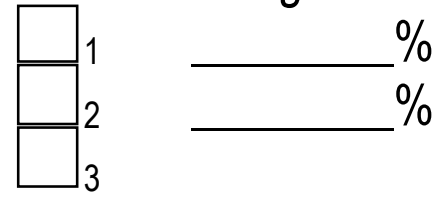


4. If the number of clients you were dealing with changed following the event, was this expected or planned for? (Tick one)

Both expected and planned for

Expected but not planned for

Not expected or planned for

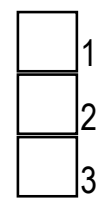

5. Were your clients: (Tick all that apply)

Male

Female

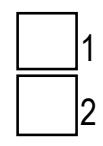

6. What gender were the majority of your clients? (Tick one)

Male

Female

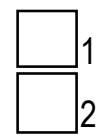

7. What age groups did you work with? (Tick all that apply)

Children: $0-17$ years

Youths: $18-24$ years

Adults: $\quad 25-34$ years

35-44 years

45-54 years

55-64 years

$65+$ years

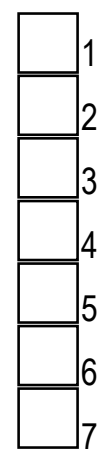

8. What age group were the majority of your clients? (Tick one)

Children: $0-17$ years Youths: $18-24$ years

Adults: $\quad 25-34$ years

35-44 years

45-54 years

55-64 years $65+$ years

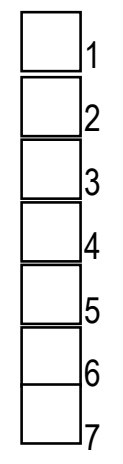


9. Which ethnic groups did you work with? (Tick all that apply)

NZ European

Maori

Pacific Peoples

Asian

Other

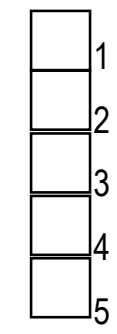

(Please specify)

10. What ethnic group were the majority of your clients? (Tick one)

NZ European

Maori

Pacific Peoples

Asian

Other

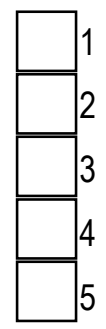

(Please specify)

11. What suburb/town were the majority of your clients from?

12. Was this the area most affected by the event?

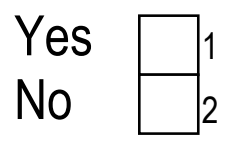

13. What types of violence did you deal with?

(Please rank them with 1 being the most common and 5 being the least common)

Physical

Psychological/Emotional

Sexual

Economic

Other

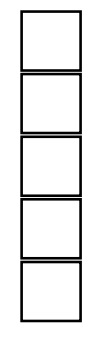

(Please Specify) 
14. What was the most common relationship between perpetrator and victim/survivor?

15. Were the majority of your clients:

New clients

Existing clients

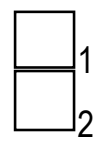

16. Why do you think the number of clients changed?

(Please rank them with 1 being the most likely reason and 5 being the least likely reason)

Increased/Decreased Violence Increased/Decreased Reporting Increased/Decreased Policing

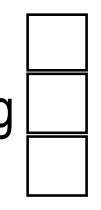

(Fill in if there is another reason for the change)

(Fill in if there is another reason for the change)

17. Please explain why you chose the ranking you did above: 
18. Following the event, did your agency experience a change in the number of paid staff able to work?

Yes, an increase

Yes, a decrease

No, numbers remained static $\mathrm{N} / \mathrm{A}$

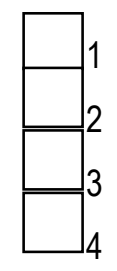

19. Following the event, did your agency experience a change in the number of unpaid staff/volunteers able to work?

Yes, an increase

Yes, a decrease

No, numbers remained static $\mathrm{N} / \mathrm{A}$

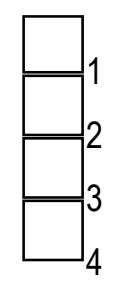

20. Was your agency able to keep normal services running following the event?

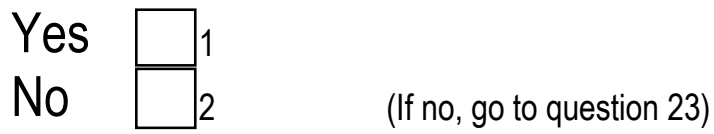

21. What services were you unable to provide? 
22. What were the main reasons for this?

(E.g. funding shortage, staff shortage, premises unavailable)

23. Did the event impact upon the operations of your agency in any other way?

24. What other agencies did you work with following the event? 
25. Does your agency have an internal civil defence plan or set of procedures to follow in a civil defence emergency? (Tick one)

Yes $\square_{1}$
No $\square_{2} \quad$ (Go to question 27)

26. What does the plan or set of procedures cover?

27. Is your agency involved with any national or regional civil defence planning? E.g. A regional CDEM group member or a taskforce committee member (Tick one)

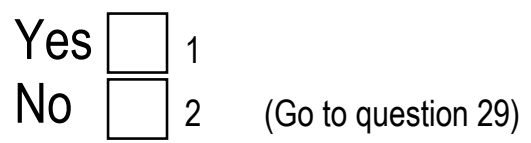

28. In what way are you involved? 
29. What role did your agency play in the response and recovery phases following the emergency?

\section{Response}

(The response phase is the period immediately after the event has occurred, it can vary in length, most commonly it can last from 2 days to 2 weeks.)

E.g. counselling, accommodation, financial support 


\section{Recovery}

(Recovery is focused on the long-term rehabilitation of the community. It is the period after the response phase, and can last for many months following a specific event.)

E.g. financial advice, support, planning 
30. Please add any comments that you feel are relevant but have not been included: 
I consent to this information being used in a PhD, published articles and media interviews. (Please note, your name will not be published in any of the reporting, only agency names will be used).

Signed:

Date:

Print name:

\section{THANK YOU FOR COMPLETING THIS SURVEY}

If you would like a summary of the findings please enter your contact details below:

Name:

Postal or email address:

Phone Number:

FINALLY, would you be willing to be interviewed at a later stage on this topic?

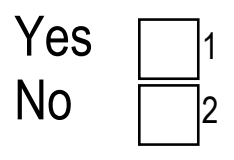




\section{Victoria

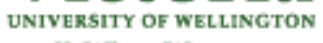 \\ Te Whare Wānanga \\ o te Upoko o te lka a Mäui

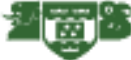

\section{Participant Information Sheet}

Researcher: Rosalind Houghton: School of Social and Cultural Studies, Victoria University of Wellington

I am a PhD student in Social Policy at Victoria University of Wellington. As part of this degree I am undertaking a research project investigating social impacts of natural hazard events in New Zealand.

To collect data on this topic, I am interviewing people working in agencies that deal with the women affected by domestic violence. It is estimated the interview will take at most one hour and questions will be based around the incidence of domestic violence after the natural hazard event. No specifics will be asked about individual cases but rather trends and commonalities over all the cases, such as demographics and the number of cases dealt with over the months following the floods.

The interview will be recorded with your consent and I would like to quote you if necessary. The transcript will be made available to you so that you are able to make any additions or factual corrections before publication and use. A summary of the findings will also be made available to you at the conclusion of the research if you are interested.

This research has been approved by the Victoria University of Wellington Human Ethics Committee. The PhD will be submitted for marking to the School of Social and Cultural Studies and deposited in the Victoria University of Wellington library. It is intended that one or more articles will be submitted for publication in scholarly journals and also that media interviews may be done during and after research. Transcripts and tapes of the interviews will be destroyed 5 years after the end of the project so as to allow some time following the $\mathrm{PhD}$ for the writing and submission of articles.

If you have any questions or would like to receive further information about the project, please contact me by email at Ros.Houghton@vuw.ac.nz, phone 0274636 415; or my supervisor, Dr Sandra Grey, at the School of Social and Cultural Studies at Victoria University, PO Box 600, Wellington, phone (04) 463 5361, email Sandra.Grey@vuw.ac.nz.

Rosalind Houghton 


\section{CONSENT TO PARTICIPATION IN RESEARCH}

\section{Social Impacts of Natural Hazard Events in New Zealand}

I have been given and have understood an explanation of this research project. I have had an opportunity to ask questions and have them answered to my satisfaction. I understand that I may withdraw myself (or any information I have provided) from this project (before data collection and analysis is complete) without having to give reasons. (Please tick the following boxes once you have read and agreed to them).

I consent to information or opinions which I have given being attributed to me in publication of this research which will be available to the public, such as the $\mathrm{PhD}$, journal articles, and conference papers.

I agree to the interview being recorded and then transcribed.

I consent to information or opinions which I have given being attributed to me in potential media interviews after I have checked the transcript for factual accuracy.

I understand that the data I provide will not be used for any other purpose or released to others without my written consent.

I would like to access a summary of the results of this research when it is completed.

I consent to the tapes and transcripts being kept for up to 5 years.

I agree to take part in this research

Name of participant

(Please print clearly)

Signed Date. 


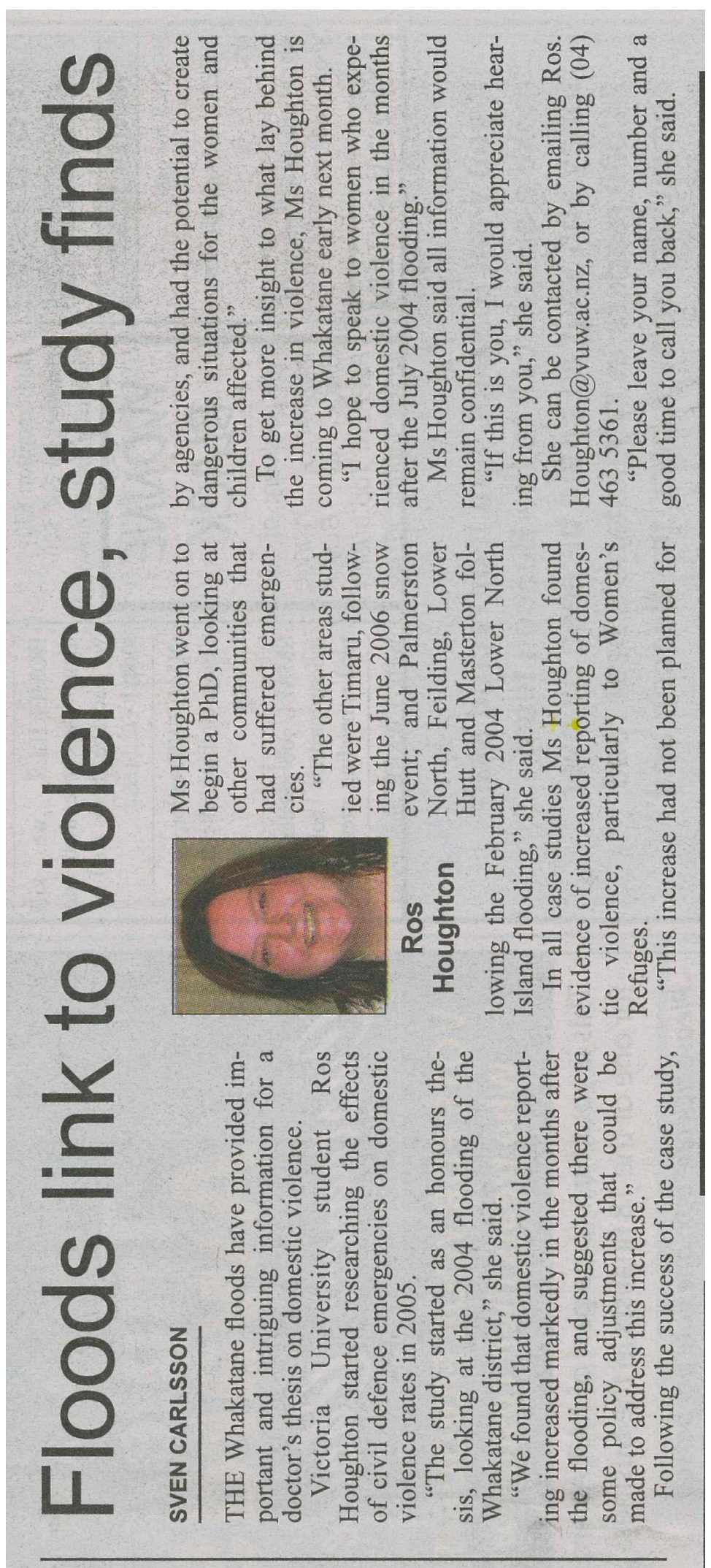




\section{MEMORANDUM}

Phone 0-4-4635676

Fax 0-4-463 5209

Email_Allison.kirkman@vuw.ac.nz

\begin{tabular}{l|l}
\hline TO & Rosalind Houghton \\
\hline $\begin{array}{l}\text { COPY } \\
\text { TO }\end{array}$ & Dr Sandra Grey Janeen Batchelor \\
\hline FROM & $\begin{array}{l}\text { Associate Professor Jenny Neale, Acting Convener, Human } \\
\text { Ethics Committee }\end{array}$ \\
\hline DATE & 23 August 2006 \\
\hline PAGES & 1 \\
\hline
\end{tabular}

SUBJEC

$\mathrm{T}$

Ethics Approval: No 25/2006 SACS, Domestic Violence following natural hazard events in New Zealand

Thank you for your application for ethical approval, and the amendments made which have now been considered by the Standing Committee of the Human Ethics Committee.

Your application has been approved and this approval continues until March 2009 If your data collection is not completed by this date you should apply to the Human Ethics Committee for an extension to this approval.

Best wishes with the research.

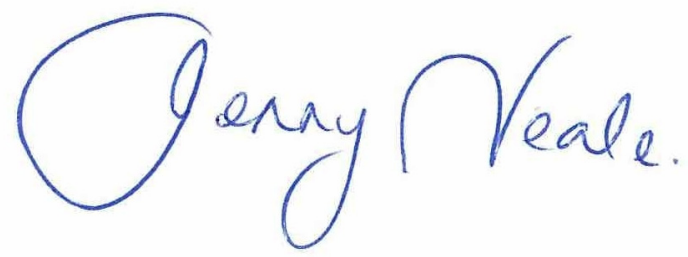

Jenny Neale

Acting Convenor

pp Allison Kirkman

Convener 
References 



\section{References}

Interviews

Anderson, Glenn. (2005) Personal Interview, Whakatane, 2 August 2005

Bang, Mark. (2008) Personal Interview, Timaru, 18 February 2008

Buckley, Lyn. (2007) Personal Interview, Masterton, 27 August 2007

Byers, Ged. (2009) Personal Interview, Wellington, 28 May 2009

Harrison, Mark. (2008) Personal Interview, Palmerston North, 26 March 2008

Henare, Heather. (2009) Personal Interview, Wellington, 12 February 2009

Hetet, Pania. (2005) Personal Interview, Whakatane, 3 August 2005

Kearns, Zane. (2008) Personal Interview, Palmerston North, 26 March 2008

Lander, Evelyn. (2005) Personal Interview, Whakatane, 3 August 2005

Mamula-Seadon, Ljubica. (2009) Personal Interview, Wellington

Millard, Margaret. (2008) Personal Interview, Palmerston North, 26 March 2008

Oomen, Diana. (2005) Personal Interview, Whakatane, 3 August 2005

Peterson, Neil. (2005) Personal Interview, Whakatane, 2 August 2005

Phiske, Rob. (2008) Personal Interview, Timaru, 21 February 2008

Rangi-Smith, Dawn. (2008) Personal Interview, Timaru, 20 February 2008

Ripaki, Roberta. (2005) Personal Interview, Whakatane, 3 August 2005

Rodgers, Angie. (2008) Personal Interview, Lower Hutt,

Rounthwaite, Penny. (2008) Personal Interview, Palmerston North, 27 March 2008

Taplin, Glenn. (2007) Personal Interview, Masterton, 2007

Te Are, Wini. (2005) Personal Interview, Whakatane, 2 August 2005

Thomas, Jenny. (2005) Personal Interview, Whakatane, 2 August 2005

Thompson, Sue. (2008) Personal Interview, Timaru, 19 February 2008

Tukariri, Julie. (2008) Personal Interview, Wellington, 27 March 2008 
References

White, Dave. (2008) Personal Interview, Palmerston North, 26 March 2008

Williams, Lorraine. (2008) Personal Interview, Lower Hutt,

Wills, Amanda. (2008) Personal Interview, Timaru, 18 February 2008

Wills, Stephen. (2008) Personal Interview, Timaru, 21 February 2008 


\section{References}

Secondary Sources

Abeyesekera, S. (2006) Tsunami aftermath: Violation of women's human rights in Sri Lanka, Thailand: APWLD, 30p

Agarwal, B. (1992) 'Environmental action, gender equity and women's participation,' Feminist Studies, 18(1): 1-43

Ahmed, S. (2004) The gendered context of vulnerability: Coping/adapting to floods in Eastern India, 26p

Ajzen, I. (1985) 'From intentions to actions: A theory of planned behavior' in Kuhl, J., \& Beckman, J. (eds.) Action control: From cognition to behavior, Heidelberg: Springer

Ajzen, I., \& Fishbein, M. (1980) Understanding attitudes and predicting social behavior, Englewood Cliffs, NJ: Prentice-Hall

Akçar, S. (2001) 'Grassroots women's collectives roles in post - disaster effort: potential for sustainable partnership and good governance: Lessons learned from the Marmara earthquake in Turkey,' Paper prepared for the Expert Working Group meeting, Ankara, Turkey [Online] Available: www.un.org/womenwatch/daw/csw/ env_manage/documents.html.

Akhter, F. (1992) 'Women are not only victims,' in Hossain, H. et al. (eds) (1992) From Crisis to Development: Coping With Disasters in Bangladesh: 59-65, Dhaka: University Press Limited

Alcock, P. (1998) 'What is social policy?' in Alcock, P., Erskine, A., \& May, M. (1998) Student's companion to social policy, Malden, MA: Blackwell

Alexander, D. (1991) 'Natural disasters: A framework for research and teaching,' Disasters, 15(3): 209-226

Alexander, D. (1997) 'The study of natural disaster, 1977-1997: Some reflections on a changing field of knowledge,' Disasters, 21(4): 284-304

Allen, N. E., Bybee, D. I., \& Sullivan, C. M. (2004) 'Battered women's multitude of needs: Evidence supporting the need for comprehensive advocacy,' Violence against Women, 10(9): 1015-1035

Alston, M. (2006) 'Gender mainstreaming in practice: A view from rural Australia,' NWSA Journal, 18(2): 123-147

Alston, M. (2009) 'Drought policy in Australia: Gender mainstreaming or gender blindness,' Gender, Place \& Culture, 16(2): 139-154

Alway, J., \& Smith, K. J. (1998) 'Back to normal: gender and disaster,' Symbolic Interaction 21(2): 175-195

Amarasiri de Silva, M. W. (2008) 'Ethnicity, politics and inequality: post-tsunami humanitarian aid delivery in Ampara District, Sri Lanka,'

Disasters, 33: 253 - 273 
Anderson, K. L. (1997) 'Gender, status, and domestic violence: An integration of feminist and family violence approaches,' Journal of Marriage and the Family, 59(3): 655-669

Anderson, K., \& Manuel, G. (1994) 'Gender differences in reported stress response to the Loma Prieta earthquake,' Sex Roles 30: 9-10

Anderson, K., \& Jack, D. C. (1991) 'Learning to listen: Interview techniques and analyses' in Berger Gluck, S., \& Patai, D. (1991) Women's words: The feminist practice of oral history, London: Routledge, pp 1126

AP. (2004) 'New Zealand on edge after quakes and floods' In The Age [Online] Available: http://www.theage.com.au/articles/2004/07/19/1090 089093893.html [Accessed: 28 January 2009]

Apsler, R., Cummins, M. R., \& Carl, S. (2003) 'Perceptions of the police by female victims of domestic partner violence,' Violence Against Women, 9: 1318-1335

Ariyabandu, M. M. (2000) 'Impact of hazards on women and children situation in South Asia.'

Ariyabandu, M. M. (2003) 'Women: the risk managers in natural disasters,' Voice of Women: Sri Lankan Journal for Women's Liberation, 6(1)

Ariyabandu, M. M., \& Wickramasinghe, M. (2004) Gender Dimensions in Disaster Management; A Guide for South Asia. ITDG South Asia, Colombo, Sri Lanka.

Baehler, K. (2003) 'Evaluation and the policy cycle' (pp. 27-39) in Lunt, N., Davidson, C., \& McKegg, K. Evaluating policy and practice: A New Zealand Reader, Auckland: Pearson Education Limited

Bar-Tal, D., \& Antebi, D. (1992) 'Siege mentality in Israel,' International Journal of Intercultural Relations, 16(3): 251-275

Barnett, O. W. (2000) 'Why battered women do not leave, part 1: External inhibiting factors within society,' Trauma, Violence, \& Abuse, 1(4): 343-372

Barnett, O. W., Martinez, T. E., \& Keyson, M. (1996) 'The relationship between violence, social support, and self-blame in battered women,' Journal of Interpersonal Violence, 11(2): 221-233

Barrows, H. H. (1923) 'Geography as human ecology,' Annals of the Association of American Geographers, 13: 1-14

Bartlett, E. (2006) Family Court Report 2004, Wellington: Ministry of Justice

Barton, A. H. (1970) Communities in disaster, New York: Anchor

Bateman, J., \& Edwards, R. (2002) 'Gender and evacuation: a closer look at why women are more likely to evacuate for hurricanes,' Natural Hazards Review, 3(3) 


\section{References}

Batlan, F. (2008) 'Weathering the storm together (Torn apart by race, gender, and class),' NWSA Journal, 20(3): 163-184

Begum, R. (1993) 'Women in environmental disasters: The 1991 cyclone in Bangladesh,' Focus on Gender, 1(1): 34-39.

Beinin, L. (1985) Medical Consequences of Natural Disasters, New York: Springer-Verlag

Bell, H. (2003) 'Cycles within cycles: Domestic violence, welfare and low-wage work,' Violence against Women, 9(10): 1245-1262

Ben-Ari, A., Winstok, Z., \& Eisikovits, Z. (2003) 'Choice within entrapment and entrapment within choice: The challenge facing battered women who stay,' Families in Society, 84(4): 539-546

Benson, M., Fox, G. L., DeMaris, A., \& Van Wyk, J. (2003) 'Neighbourhood disadvantage, individual economic distress and violence against women in intimate relationships,' Journal of Quantitative Criminology, 19: 207-234

Berg, B. L. (1998) Qualitative research methods for the social sciences, Boston: Pearson/Allyn \& Bacon

Berger Gluck, S., \& Patai, D. (1991) Women's words: The feminist practice of oral history, London: Routledge

Berk, R. A., \& Newton, P. J. (1985) 'Does arrest really deter wife battery? An effort to replicate the findings of the Minneapolis spouse abuse experiment,' American Sociological Review, 50: 253-262

Berk, R. A., \& Newton, P. J., \& Berk. S. F. (1986) 'What a difference a day makes: An empirical study of the impact of shelters for battered women,' Journal of Marriage and the Family, 48: 481-490

Berke, P. R., Kartez, J., \& Wenger, D. (1993) 'Recovery after disaster: Achieving sustainable development,' Disasters, 17(2): 93-108

Bernard E. N. (2005) 'Developing tsunami-resilient communities: The National Tsunami Hazard Mitigation Program,' Natural Hazards, 35: 1

Blaikie, P. T., Cannon, T., Davis, I., \& Wisner, B. (1994) At risk: Natural hazards, people's vulnerability and disasters, London: Routledge

Block, R. (1974) 'Why notify the Police: The victim's decision to notify the Police of an assault,' Criminology, 11 (4): 555-569

Bogat, G. A., Levendosky, A. A., \& von Eye, A. (2005) 'The future of research on intimate partner violence: Person-oriented and variable-oriented perspectives,' American Journal of Community Psychology, 36(1/2): 49-70

Bograd, (1988) 'Feminist perspectives on wife abuse,' in Yllo, K., \& Bograd, M. (eds) (1988) Feminist perspectives on wife abuse, Thousand Oaks, London \& Delhi: Sage Publications 
Bolin, R., Jackson, M., \& Crist, A. (1998) 'Gender inequality, vulnerability, and disaster: Issues in theory and research,' in Enarson, E., \& Morrow, B. H. (eds) (1998) The Gendered Terrain of Disaster, Florida: International Hurricane Center, 27-44

Bolin, B. (2007) 'Race, class, ethnicity and disaster vulnerability,' in Rodriguez, H., Quarantelli, E. L., \& Dynes, R. R. (eds) (2007) Handbook of Disaster Research, New York: Springer, 113-129

Bornat, J., \& Diamond, H. (2007) 'Women's History and Oral History: developments and debates', Women's History Review, 16(1): 1939

Bornstein, R. (2006) 'The complex relationship between dependency and domestic violence: Converging psychological factors and social forces,' American Psychologist, 61 (6): 595-606

Borowiak, C. T. (2007) 'Accountability debates: The federalists, the antifederalists, and democratic deficits,' The Journal of Politics, 69(4): 998-1014

Bouma, G. D. (2000) The research process, Melbourne \& Oxford: Oxford University Press

Bradshaw, S. (2002) 'Exploring the gender dimensions of reconstruction processes post-hurricane Mitch,' Journal of International Development, 14: $871-879$

Bradshaw, S. (2004) 'Socio-economic impacts of natural disasters: A gender analysis,' Serie Manuales, 32, Santiago: United Nations, 60p

Brand, P. A., \& Kidd, A. H. (1986) 'Frequency of physical aggression in heterosexual and female homosexual dyads,' Psychological Reports, 59: 1307-1313

Briggs, S. M., \& Brinsfield, K. H. (2003) Advanced Disaster Medical Response Manual for Providers, Boston, MA: Harvard Medical International, inc., $199 p$

Brockner, J., \& Rubin, J. Z. (1985) Entrapment in escalating conflicts: A social psychological analysis, New York: Springer-Verlag

Brownridge, D. A., \& Halli, S. S. (1999) 'Measuring family violence: The conceptualization and utilization of prevalence and incidence rates,' Journal of Family Violence, 14(4): 333-350

Buckle, R., Mars, G., \& Smale, S. (2000) 'New approaches to assessing vulnerability and resilience.' Australian Journal of Emergency Management, 15(2): 8-14

Burnad, F. \& SRED Team. (2006) Tsunami aftermath: Violations of human rights of Dalit women, Tamil Nadu, India, India: APWLD, 34p

Burton, I., Kates, R. W., \& White, G. F. (1978) The environment as hazard, New York: Oxford University Press 


\section{References}

Butler, J. (1997) 'Performative acts and gender constitution: An essay in phenomenology and feminist theory,' in Conboy, K., Medina, N., \& Stanbury, S. (eds) (1997) Writing on the body: Female embodiment and feminist theory, New York: Columbia University Press

Buzawa, E. S., \& Buzawa, C. G. (1996) Domestic Violence: The Criminal Justice Response. $2^{\text {nd }}$ edition. Thousand Oaks, London \& New Delhi: Sage Publications

Campbell, J. C., Webster, D., Koziol-McLain, J., Block, C., Campbell, D., Curry, M. A., Gary, F., Glass, N., McFarlane, J., Sachs, C., Sharps, P., Ulrich, Y., Wilt, S. A., Manganello, J., Xu, X., Schollenberger, J., Frye, V., \& Laughon, K. (2003) 'Risk factors for femicide in abusive relationships: Results from a multisite case control study,' American Journal of Public Health, 93(7): 1089-1097

Cancian, F. M. (1992) 'Feminist science: Methodologies that challenge inequality.' Gender \& Society, 6(4): 623-642

Cannon, T. (2002) 'Gender and climate hazards in Bangladesh,' Gender and Development, 10(2): 45-49

Cernea, M. (1990) 'Internal refugee flows and development induced population displacement,' Journal of Refugee Studies, 3:320-29

Child, Youth and Family (2009) 'About us' [Online] Available: http://www.cyf. govt.nz/AboutUs.htm [Accessed: 20 March 2009]

Childers, C. (1999) 'Elderly female-headed households in the disaster loan process,' International Journal of Mass Emergencies and Disasters, 17(1): 99-110

Choice, P., \& Lamke, L. K. (1997) 'A conceptual approach to understanding abused women's stay/leave decisions,' Journal of Family Issues, 18: $290-314$

Ciottone, G. (2003) Disaster Medicine, St. Louis, Mo: Mosby, 984p

Clay, J. (1988) Indigenous Peoples and Tropical Forests: Models of Land Use and Management from Latin America, Cambridge, MA: Culture Survey, $116 \mathrm{p}$

Clemens, P., Hietala, J., Rytter, M., Schmidt, R., \& Reese, D. (1999) 'Risk of domestic violence after flood impact: Effects of social support, age, and history of domestic violence,' Applied Behavioral Science Review, 7(2): 199-206

Coburn, A., \& Spence, R. (1992) Earthquake protection, New York: Wiley and Sons

Collins, R., Saltzman Chafetz, J., Lesser Blumberg, R., Coltrane, S., \& Turner, J. H. (1993) 'Towards an integrated theory of gender stratification,' Sociological Perspectives, 36(3): 185-216 
Colten, C. E. (2006) 'Vulnerability and place: Flat land and uneven risk in New Orleans,' American Anthropologist, 108(4): 731-734

Cook, J. A., \& Fonow, M. M. (1986) 'Knowledge and women's interests: Issues of epistemology and methodology in feminist sociological research.' Sociological Inquiry, 56:2-29.

Cox, H. (1998) 'Women in bushfire territory,' in Enarson, E., \& Morrow, B. H. (1998) (eds) The Gendered Terrain of Disaster, 133-142

Craig, H. (1953) 'The geochemistry of the stable carbon isotopes,' Geochemica et Cosmochimica Acta, 3(2-3): 53-92

Cranny-Francis, A., Waring, W., Stavropoulos, P, \& Kirby, J. (2003) 'Ways of talking,' in Gender Studies: Terms and Debates, Basingstoke, $\mathrm{NH}$ : Palgrave McMillan

Cuny, F. C. (1983) Disasters and Development, New York: Oxford University Press

Cuny, F. C. (1994) Disasters and Development, Dallas TX: Oxfam

Cutter, S. (1995) 'The forgotten casualties: Women, children, and environmental change,' Global Environmental Change, 5(3): 181194

Daly, M. (2005) 'Gender mainstreaming in theory and practice,' Social Politics, 12(3): 433-450

Daniels, R. J., Kettl, D. E., \& Kunreuther, H. (2006) On risk and disaster: Lessons from Hurricane Katrina, Philadelphia: University of Pennsylvania Press

Davis, E. G. (1971) The First Sex, New York: Putnam

Davis, I. (1978) Shelter after disaster, Oxford: Oxford Polytechnic Press

Davis, K. M., \& Ender, M. G. (1999) 'The 1997 Red River Valley flood: Impact on marital relationships,' Applied Behavioral Science Review, 7(2): $181-188$

Davis, L. V., Hagen, J. L., \& Early, T. J. (1994) 'Social services for battered women: Are they adequate, accessible, and appropriate?' Social Work, 39(6): 695-704

DeKeseredy, W. J., Alvi, S., Schwartz, M. D., \& Perry, B. (1999) 'Violence against and the harassment of women in Canadian public housing: An exploratory study,' Canadian Review of Sociology and Anthropology, 36: 499-516

Delica, Z. (1998) 'Balancing vulnerability and capacity: women and children in the Philippines,' in Enarson, E., \& Morrow, B. H. (1998) (eds) The Gendered Terrain of Disaster, 109-114

Delica, Z. (2000) 'Enhancing women's capacity to manage and recover from disasters,' Paper prepared for the ILO InFocus Programme on 
Crisis Response and Reconstruction, in High-Level Research Consultation on Crisis. Geneva: ILO Recovery and Reconstruction Department, 71-73

DeVault, M. L. (1996) 'Talking back to sociology: Distinctive contributions to feminist methodology,' Annual Review of Sociology, 22: 29-50

Delpit, L., \& Payne, C. (2007) 'Katrina's last victims?' In The Nation, January 1 2007, [Online]. Available: http://www.thenation.com/doc/ 20070101/delpit [Accessed: 20 March 2009]

Dobash, R. E., \& Dobash, R. P. (1998) 'Violent men and violent contexts.' In Dobash, R. E., \& Dobash, R. P. (eds) Rethinking violence against women. Thousand Oaks, London \& New Delhi: Sage Publications

Dobson, N. (1994) 'From under the mud-pack: Women and the Charleville floods,' Australian Journal of Emergency Management, 9: 11-13

Dombrowsky, W. R. (1995) 'Again and again: Is a disaster what we call "disaster"? Some conceptual notes on conceptualizing the object of disaster sociology,' International Journal of Mass Emergencies and Disasters, 13(3): 241-254

Donaghy, T. B. (2004) 'Applications of mainstreaming of Australia and Northern Ireland,' International Political Science Review, 25(4): 393-410

Drabek, T. E. (1989) 'Disasters as non-routine social problems,' International Journal of Mass Emergencies and Disasters, 7(3): 253-264

Dutton, D. G., \& Painter, S. L. (1981) 'Traumatic bonding: The development of emotional attachments in battered women and other relationships of intermittent abuse.' Victimology, 6: 139-155

Dynes, R. R. (1970) Organized Behavior in Disaster, Lexington, Mass: Heath Lexington Books

Eastern Bay of Plenty Recovery (2005) 'July 2004 Information' [Online]. Available: http://www.easternboprecovery.org.nz/july2004 info. html

Ehrensaft, M. K., Cohen, P., Brown, J., Smailes, E., Chen, H., \& Johnson, J. G. (2003) 'Intergenerational transmission of partner violence: A 20year prospective study,' Journal of Consulting and Clinical Psychology, 71(4): 741-753

Eichler, M. (1997) 'Feminist methodology,' Current Sociology, 45(2): 9-36

Ellsberg, M., Heise, L., Pena, R., Agurto, S., \& Winkvist, A. (2001) 'Researching domestic violence against women: Methodological and ethical considerations.' Studies in Family Planning, 32: 1-16

Emery, R., E., \& Laumann-Billings, L. (1998) 'An overview of the nature, causes, and consequences of abusive family relationships: Towards differentiating maltreatment and violence,' American Psychologist, 53(2): 121-135 
Emmanuel, S. (2005) 'Relief for women affected by tsunami: Experiences of NGOs - A case study from a district level network of women's organisations - Batticaloa,' Disaster Watch, [Online] Available: http://www.disasterwatch.net/READINGS/Relief\%20for\%20Women \%20Affected\%20by\%20Tsunami_srla.pdf [Accessed 20 January 2009]

Enarson, E. (1998a) 'Through women's eyes: A gendered research agenda for disaster social science,' Disasters, 22(2): 157-173

Enarson, E. (1998b) Surviving domestic violence and disasters, Vancouver, BC: The FREDA Centre for Research on Violence against Women and Children, $8 p$

Enarson, E. (1999) 'Violence against women in disasters: A study of domestic violence programs in the United States and Canada.' Violence against Women, 5(7): 742-768

Enarson, E. (1999b) 'Women and housing issues in two US disasters,' International Journal of Mass Emergencies and Disasters, 17(1): 39-63

Enarson, E. (2000) "We will make meaning out of this": Women's cultural responses to the Red River Valley flood,' International Journal of Mass Emergencies and Disasters, 18(1): 39-62

Enarson, E. (2000a) A gender analysis of work and employment issues in natural disasters, Final report prepared for the International Labour Organization's InFocus Programme on Crisis and Reconstruction. [Online] Available: http://www.ilo.org/public/ english/employment/recon/crisis/gender.htm

Enarson, E. (2001a) "We want work": Rural women in the Gujarat drought and earthquake,' Natural Hazards Center Quick Response Report 135, $28 p$

Enarson, E. (2001b) 'Gender equality, environmental management, and natural disaster mitigation,' Paper presented at the Online Conference conducted by the Division for the Advancement of Women, 6-9 November 2001 in Ankara, Turkey

Enarson, E., Fothergill, A., \& Peek, L. (2006) 'Gender and Disaster: Foundations and Possibilities,' Rodriguez, H., Quarantelli, E. L., \& Dynes, R. R. (2006) (eds) Handbook of Disaster Research, New York: Springer

Enarson, E., Meyreles, L., Gonzalez, M., Morrow, B. H., Mullings, A., \& Soares, J. (2003) Working with women at risk: Practical guidelines for assessing local disaster risk, Florida: International Hurricane Center, 94p

Enarson, E., \& Morrow, B. H. (1997) 'A gendered perspective: The voices of women,' in Peacock, W. G., Morrow, B. H., \& Gladwin, H. (1997) (eds) Hurricane Andrew: Race, Gender and the Sociology of Disaster, London: Routledge, 116-140 


\section{References}

Enarson, E., \& Morrow, B. H. (1998) The gendered terrain of disaster: Through women's eyes, Florida: International Hurricane Center

Enarson, E., \& Scanlon, J. (1999) 'Gender patterns in flood evacuation: A case study in Canada's Red River valley.' Applied Behavioural Science Review, 7(2): 103-124

Environment Bay of Plenty (2004a) 'July 2004' In Flood Updates [Online]. Available: http://www.envbop.govt.nz/CD/Flood-Updates.asp [Accessed 28 January 2009]

Environment Bay of Plenty (2004b) 'August 2004' In Flood Updates [Online]. Available: http://www.envbop.govt.nz/CD/Flood-Updates.asp [Accessed 28 January 2009]

Environment Bay of Plenty (2004c) 'September-December 2004' In Flood Updates [Online]. Available: http://www.envbop.govt.nz/CD/ Flood-Updates.asp [Accessed 28 January 2009]

Erskine, A. (1998) 'The approaches and methods of social policy' In Alcock, P., Erskine, A., \& May, M. (1998) Student's companion to social policy, Malden, MA: Blackwell

Family Works. (2009) 'Family Works Northern in the Eastern Bay of Plenty' [Online] Available: http://www.familyworks.org.nz/Site/Regions /Northern/Service_Centres/Service_Centre_8.aspx [Accessed: 20 March 2009]

Fanslow, J. \& Robinson, E. (2004). 'Violence against women in New Zealand: Prevalence and health consequences.' The New Zealand Medical Journal, 117: 1-12

Farris, C. A., \& Fenaughty, A. M. (2002) 'Social isolation and domestic violence among female drug users.' American Journal of Drug and Alcohol Abuse, 28(2): 339-352

Felson, R. B., \& Messner, S. F. (2000) 'The control motive in intimate partner violence,' Social Psychology Quarterly, 63(1): 86-94

Felson, R. B., Messner, S. F., Hoskin, A. W., \& Deane, G. (2002) 'Reasons for reporting and not reporting domestic violence to the Police,' Criminology, 40(3): 617-647

Felson, R. B., \& Pare, P. P. (2008) 'Gender and the victim's experience with the criminal justice system,' Social Science Research, 37: 202-219

Fenrich, J., \& Contesse, J. (2009) "It's not OK": New Zealand's Efforts to Eliminate Violence against Women, New York: Leitner Center for International Law and Justice, $55 \mathrm{p}$

Fenton, H. (1989) Impact of hurricane Gilbert on Jamaican women, Paper presented at Meeting on the Role of Women in Disaster Management, Port of Spain, November 13-15, 1989 
Fergusson, D. M., Horwood, L. J., \& Ridder, E. M. (2005) 'Partner violence and mental heath outcomes in a New Zealand birth cohort.' Journal of Marriage and Family, 67: 1103-1119

Fishbein, M., \& Ajzen, I. (1975) Belief, attitude, intention and behaviour: An introduction to theory and research, Boston: Addison-Wesley

Fisher, J. W. (2004) 'Survivors of domestic violence: Demographics and disparities in visitors to an interdisciplinary specialty clinic,' Family Community Health, 29(2): $118-130$

Fisher, S. (2005) Gender-based violence in Sri Lanka in the aftermath of the 2004 tsunami crisis: The role of international organisations and international NGOs in prevention and response to gender-based violence, Master of Arts in International Studies, University of Leeds.

Foley, S. (1985) The abuse of New Zealand army wives. Taihape: S. Foley

Fonow, M. M., \& Cook, J. A. (2005) 'Feminist methodology: New approaches in the academy and public policy,' Signs: Journal of Women and Culture, 30(4): 2211-2236

Fordham, M. H. (1998) 'Making women visible in disasters: Problematising the private domain,' Disasters, 22(2): 126-143

Fordham, M. (1999) 'The intersection of gender and social class in disaster: Balancing resilience and vulnerability,' International Journal of Mass Emergencies and Disasters, 17(1): 15-36

Fordham, M., \& Ketteridge, A. (1998) 'Men must work and women must weep: Examining gender stereotypes in disasters,' in Enarson, E., \& Morrow, B. H. (eds) (1998) The Gendered Terrain of Disaster, Florida: International Hurricane Center, 81-94

Foster, H. D. (1976) 'Assessing disaster magnitude: A social science approach,' Professional Geographer, 28(3): 241-247

Fothergill, A. (1996) 'Cender, risk, and disaster,' International Journal of Mass Emergencies and Disasters, 14(1): 33-56

Fothergill, A. (1998) 'The neglect of gender in disaster work: An overview of the literature,' in Enarson, E., \& Morrow, B. H. (eds) (1998) The Gendered Terrain of Disaster, Florida: International Hurricane Center, 11-25

Fothergill, A. (1999) 'An exploratory study of woman battering in the Grand Forks flood disaster: Implications for community responses and policies,' International Journal of Mass Emergencies and Disasters, 17(1): 79-98

Fothergill, A. (2003) 'The stigma of charity: Gender, class, and disaster assistance,' Sociological Quarterly, 44(4): 659-680 


\section{References}

Fothergill, A. (2004) Heads above water: Gender, class and family in the Grand Forks flood, New York: State University of New York Press

Fothergill, A., \& Peek, L. (2004) 'Poverty and disasters in the United States: A review of recent sociological findings,' Natural Hazards, 32: 89110

Fowler, F. J. (2002) Survey research methods, Thousand Oaks: Sage Publications

Gardner, R. (1989) 'Method of conflict resolution and characteristics of abuse and victimization in heterosexual, lesbian, and gay male couples,' (Doctoral dissertation, University of Georgia, 1988) Dissertation Abstracts International, 50, 746B

Geiger, S. N. G. (1986) 'Women's life histories: Method and content,' Signs, $11(2): 334-351$

Geis, D. (2000) 'By design: The disaster resistant and quality-of-life community.' Natural Hazards Review, 1(3): 151-160

Gelles, R. J. (1976) 'Abused wives: Why do they stay,' Journal of Marriage and the Family, 38(4): 659-668

Gelles, R. J. (1974) The violent home: A study of physical aggression between husbands and wives, Beverly Hills: Sage Publications

Gelles, R. J. (1985) 'Family violence,' Annual Review of Sociology, 11: 347-367

Gerring, J. (2004) 'What is a case study and what is it good for?' American Political Science Review, 98(2): 341-354

Giles, J., Curreen, H., \& Adamson, C. (2005) 'The social sanctioning of partner abuse: Perpetuating the message that partner abuse is acceptable in New Zealand.' Social Policy Journal of New Zealand, 26: 97116

Gomez, Y. (2008) Making a difference in disaster management through gender sensitive information campaigns, Gender and Disasters Workshop 2008 in Wellington, New Zealand, July $31^{\text {st }} 2008$

Goode, W. J. (1971) 'Force and violence in the family,' Journal of Marriage and the Family, (November): 624-636

Griffiths, S., \& Hanmer, J. (2005) 'Feminist quantitative methodology: Evaluating policing of domestic violence' in Skinner, T., Hester, M., \& Malos, E. Researching gender violence: Feminist methodology in action, Devon \& Oregon: Willan Publishing

Guha-Sapir, D., Hargitt, D., \& Hoyois, P. (2004) 'Thirty years of natural disasters, 1974-2003: The numbers,' Centre for Research on the Epidemiology of Disasters, 188p, Belgium: Presses universitaires de Louvain 
Hague, G., \& Bridge, S. (2008) 'Inching forward on domestic violence: The 'coordinated community response' and putting it in practice in Cheshire,' Journal of Gender Studies, 17(3): 185-199

Hague, G., \& Wilson, C. (2000) 'The silenced pain: Domestic violence 19451970,' Journal of Gender Studies, 9(2): 157-169

Halpern, C. T., Oslak, S. G., Young, M. L., Martin, S. L., \& Kupper, L. L. (2001) 'Partner violence among adolescents in opposite-sex romantic relationships: Findings from the national longitudinal study of adolescent health,' American Journal of Public Health, 91(10): 1679

Hanmer, J. (2000) 'Domestic violence and gender relations: Contexts and connections,' in Hanmer, J., \& Itzin, C. (eds) (2000) Home Truths about Domestic Violence, London: Routledge

Hegarty, K., \& Roberts, G. (2008) 'How common is domestic violence against women? The definition of partner abuse in prevalence studies,' Australian and New Zealand Journal of Public Health, 22(1): 4954

Hegarty, K., Sheehan, M., \& Schonfeld, C. (1999) 'A multidimensional definition of partner abuse: Development and preliminary validation of the composite abuse scale,' Journal of Family Violence, 14(4): 399415

Hendrikx, J. (2006) 'Preliminary analysis of the 12 June 2006 Canterbury snow storm,' NIWA Client Report, 2006-088, 18p.

Hewitt, K. (1983) Interpretations of calamit: From the viewpoint of human ecology, Boston: Allen \& Unwin

Hewitt, K. (1994) '"When the great planes came and made ashes of our city": Towards an oral geography of the disasters of war,' Antipode, 26(1): 1-34

Hewitt, K. (1995) 'Excluded perspectives in the social construction of disaster,' International Journal of Mass Emergencies and Disasters, 13(3): 317-339

Hoffman, S. M, \& Oliver-Smith, A. (2002) Catastrophe \& Culture: The Anthropology of Disaster, Santa Fe: School of American Research Press

Hogan, D. E., \& Burstein, J. L. (2007) Disaster Medicine, $2^{\text {nd }}$ edition, Philadelphia, PA: Lippincott Williams \& Wilkins, 512p

Holiman, M., \& Schilit, R. (1991) 'Aftercare for battered women: How to encourage the maintenance of change,' Psychotherapy, 28(2): 345-353

Holtzworth-Monroe, A., Smutzler, N., \& Bates, L. (1997) 'A brief review of the research on husband violence: Part III: Sociodemographic factors, relationship factors and differing consequences of husband and wife violence,' Aggression and Violent Behavior, 2(3): 285-307 
Honeycombe, B. (1994) 'Special Needs of Women in Emergency Situations,' Australian Journal of Emergency Management, 8(4): 28-31

hooks, b. (1984) Feminist theory: From margin to center, Cambridge, MA: South End Press

Horizons District Council. (2004) Storm: Civil Emergency - Storm and flood report, Palmerston North: Brebner Print

Hornung, C. A., McCullough, B. C., \& Sugimoto, T. (1981) 'Status relationships in marriage: Risk factors in spouse abuse,' Journal of Marriage and the Family, 43(3): 675-692

Hotaling, G. T., \& Sugarman, D. B. (1986) 'An analysis of risk markers in husband to wife violence: The current state of knowledge,' Violence and Victims, 1: 101-124

Houghton, B. F., \& Wilson, C. J. N. (1989) 'A vesicularity index for pyroclastic deposits,' Bulletin of Volcanology, 51(6): 451-463

Howlett, M., \& Ramesh, M. (1995) Studying public policy: Policy cycles and policy subsystems, Oxford: Oxford University Press

Hutton, D., \& Haque, C. E. (2004) 'Human vulnerability, dislocation and resettlement: Adaptation processes of river-bank erosion-induced displaces in Bangladesh,' Disasters, 28(1): 41-62

Hyndman D., \& Hyndman D. (2009) Natural Hazards \& Disasters, Belmont: Brooks/Cole

Insurance Council of New Zealand (2008) 'The cost of disaster events,' in Weather [Online]. Available: http://www.icnz.org.nz/current/ weather/ [Accessed: 1 March 2009]

Inter-Agency Secretariat of the International Strategy for Disaster Reduction. (2006) Living with risk: A global review of disaster reduction initiatives, Geneva: United Nations Publications

Isaacs, B., Oliver, J., \& Sykes, L. R. (1968) 'Seismology and new global tectonics,' Journal of Geophysical Research, 73(18): 5855-

Island, D. \& Letellier, P. (1991) Men who beat the men who love them: Battered gay men and domestic violence, Binghamton, NY: Haworth Press

Jackson, N. A., \& Oates, G. C. (1998) Violence in intimate relationships: Examining sociological and psychological issues, Boston: Butterworth-Heinemann

James, S. E., Johnson, J., \& Raghavan, C. (2004) “I couldn't go anywhere," Contextualising violence and drug abuse: A social network study,' Violence against Women, 10(9): 991-1014

Jasinski, J. L. (2001) 'Theoretical explanations for violence against women.' (pp. 5-22) in Renzetti, C. M., Edleson, J. L., \& Kennedy Bergen, R. 
Sourcebook on violence against women, Thousand Oaks, London $\&$ New Delhi: Sage Publications

Jenkins, P., \& Phillips, B. (2008) 'Battered women, catastrophe, and the context of safety after Hurricane Katrina,' NWSA Journal, 20(3): 49-68

Jensen, J., Krishnan, V., Hodgson, R., Sathiyandra, S. G., Templeton, R., Jones, D., Goldstein-Hawes, R., \& Beynon, P. (2006) New Zealand Living Standards 2004, Wellington: Ministry of Social Development, $210 p$

Jewkes, R., Levin, J., \& Penn-Kekana, L. (2002) 'Risk factors for domestic violence: Findings from a South African cross-sectional study,' Social Science \& Medicine, 55: 1603-1617

Jiggins, J. (1986) 'Women and seasonality: coping with crisis and calamity,' IDS Bulletin, 17(3), Sussex: Institute of Development Studies

Johnson, M. P. (1995) 'Patriarchal terrorism and common couple violence: Two forms of violence against women,' Journal of Marriage and the Family, 57: 283-294

Johnston, D. M., Paton, D., Crawford, G. L., Ronan, K., Houghton, B. F., \& Burgelt, P. (2005) 'Measuring tsunami preparedness in coastal Washington, United States,' Natural Hazards, 35: 173-184

Jukes, A. E. (1999) Men who batter women. London \& New York: Routledge

Kanamori, H., \& Anderson, D. L. (1975) 'Theoretical basis of some empirical relations in seismology,' Bulletin of the Seismological Society of America, 65(5): 1073-1095

Kantor, G. K., \& Jansinski, J. (1998) 'Dynamics and risk factors in partner violence,' pp. 1-43 in Jansinski, J. L., \& Williams, L. M. (1998) Partner violence: A comprehensive review of 20 years of research, Thousand Oaks, London \& New Delhi: Sage Publications

Kaufman Kantor, G., \& Straus, M. A. (1987) 'The "drunken bum" theory of wife beating.' Social Problems, 34(3): 213-230

Keller E. A., \& Blodgett R. A. (2008) Natural Hazards, Upper Saddle River: Pearson, Prentice Hall

Kelly, K. A. (2004) 'Working together to stop domestic violence: Statecommunity partnerships and the changing meaning of public and private,' Journal of Sociology \& Social Work, 31(1): 27-48

Kennett, B. L. N., \& Engdahl, E. R. (1991) 'Travel times for global earthquake location and phase identification,' Geophysical Journal International, 105(2): 429-465

Kenway, J. (1990) Gender and education policy: A call for new directions, Geelong, Victoria: Deakin University Press

Khogali, H., \& Takhar, P. (2001) 'Empowering women through cash relief in humanitarian contexts,' Gender and Development, 9(3): 40-49 


\section{References}

Kimmel, M. S. (2002) '"Gender Symmetry" in domestic violence,' Violence against Women, 8(11): 1332-1363

Kirby, R. K. (2008) 'Phenomenology and the problems of oral history,' The Oral History Review, 35(1): 22-38

Klug, C., \& Cashman, K. V. (1996) 'Permeability development in vesiculating magmas: Implications for fragmentation,' Bulletin of Volcanology, 58(2-3): $87-100$

Kottegoda, S. (1997) 'Gender and disasters: Key issues,' in Fernando, P., \& Fernando, V. (1997) South Asian women: Facing disasters, securing life, Colombo, Sri Lanka: Duryog Nivaran Publication

Landenburger, K. M. (1998) 'The dynamics of leaving and recovering from an abusive relationship,' JOGNN, 27: 700-706

Landman, M. (2006) 'Getting quality in qualitative research: A short introduction to feminist methodology and methods,' Proceedings of the Nutrition Society, 65: 429-433

Launius, M. H., \& Lindquist, C. U. (1988) 'Learned helplessness, external locus of control, and passivity in battered women,' Journal of Interpersonal Violence, 3(3): 307-318

Levendosky, A. A., Bogat, G. A., Theran, S. A., Trotter, J. S., von Eye, A., Davidson II, W. S. (2004) 'The social networks of women experiencing domestic violence,' American Journal of Community Psychology, 34(1/2): 95-109

Lindell, M. K., Prater, C., \& Perry, R. W. (2007) Introduction to Emergency Management, Hoboken, NJ: John Wiley \& Sons, inc

Litton Fox, G., \& McBride Murry, V. (2000) 'Gender and families: Feminist perspectives and family research,' Journal of Marriage and the Family, 62(4): 1160-1172

Lockhart, L. L. (1987) 'A re-examination of the effects of race and social class on the incidence of marital violence: A search for reliable differences,' Journal of Marriage and the Family, 49: 603-610

Logan, T. K., Walker, R., Cole, J., Ratliff, S., \& Leukefeld, C. (2003) 'Qualitative differences among rural and urban intimate violence victimization experiences and consequences: A pilot study,' Journal of Family Violence, 18(2): 83-92

MacKinnon, C. A. (1983) 'Feminism, marxism, method and the state: Toward feminist jurisprudence,' Signs: Journal of Women in Culture and Society, 8: 635-658

Major, A. M. (1999) 'Gender differences in risk and communication behaviour: Responses to the New Madrid earthquake prediction,' International Journal of Mass Emergencies and Disasters, 17(3): 313-338 
Mankuta, D (2004) 'Anxiety and fears of pregnant women: Evaluation of incidence during the earthquake in Turkey, 1999,' International Journal of Disaster Medicine, 2: 38-40

Manni, C., \& Magalini, S. I. (eds) (1985) Emergency and Disaster Medicine, New York: Springer-Verlag

Margolin, G. (1993) 'Wife abuse versus marital violence: Different terminologies, explanations, and solutions,' Clinical Psychology Review, 13: 59-73

Mari, L. (2009) Online Posting, The Last Straw [Online] Available: http://thelaststraw.wordpress.com/2007/08/15/quotes-aboutdomestic-violence/ [Accessed: 19 July 2009]

Marks, E., \& Fritz, C. (1954) Human reactions in disaster situations, Chicago: National Opinion Research Center, University of Chicago

Mattingly, D. J., \& Falconer-al-Hindi, K. (1995) 'Should women count? A context for the debate,' Professional Geographer, 47(4): 427-435

Maynard, M. (1994) 'Doing feminist research,' in Maynard, M. \& Purvis, J. (1994) Researching women's lives from a feminist perspective, London: Taylor and Francis

McAllister, I. (1993) Sustaining relief with development: Strategic issues for the Red Cross and Red Crescent, Boston: Marinus Nijhoff Publishers

McDermott, M. J., \& Garofalo, J. (2004) 'When advocacy for domestic violence victims backfires,' Violence against Women, 10(11): 1245-1266

McDonough, W. F., \& Sun, S. S. (1995) 'The composition of the Earth,' Chemical Geology, 120(3-4): 223-253

McEntire, D. A. (2004) 'Development, disasters and vulnerability: A discussion of divergent theories and the need for their integration,' Disaster Prevention and Management, 13(3): 193-198

McEntire, D. A., Fuller, C., Johnston, C. W., \& Weber, R. (2002) 'A comparison of disaster paradigms: The search for a holistic policy guide.' Public Administration Review, 62(3): 267-281

McLafferty, S. L. (1995) 'Counting for women,' Professional Geographer, 47(4): 436-442

McRobbie, A. (1982) 'The politics of feminist research: Between talk, text and action,' Feminist Review, 12: 46-57

Mears, D. P., \& Visher, C. A. (2005) 'Trends in understanding and addressing domestic violence,' Journal of Interpersonal Violence, 20(2): 204211

Melick, M. E., \& Logue, J. (1985) 'The effect of disaster on the health and wellbeing of older women,' International Journal on Aging and Human Development, $21(1):$ 27-38 


\section{References}

Merton, (1970) 'Foreword,' in Barton, A. H. (ed) (1970) Communities in disaster, Garden City, NY: Doubleday

Messerschmidt, J. W. (2009) "Doing gender": The impact and future of a salient sociological concept,' Gender \& Society, 23(1): 85-88

MetService. (2009) 'July 2004 Flooding in Whakatane' In Learning Centre, [Online]. Available: www.metservice.co.nz/default/index.php? alias=2004winter0227395 [Accessed 28 January 2009]

Michalski, J. H. (2004) 'Making sociological sense out of trends in intimate partner violence,' Violence against Women, 10(6): 652-675

Miles-Doan, R. (1998) 'Violence between spouses and intimates: Does neighbourhood context matter?' Social Forces, 77: 623-645

Mileti, D. S. (1999) Disasters by design: A reassessment of natural hazards in the United States. Washington DC: Joseph Henry Press

Mileti, D. S., Darlington, J. D., Passarini, E., Forest, B. C., \& Myers, M. F. (1995) 'Toward an integration of natural hazards and sustainability,' Environmental Professional, 17(2): 117-126

Millman, M., \& Kanter, R. M. (eds) (1975) Another voice, Garden City, NY: Anchor

Mills, C. W. (1959) The Sociological Imagination, New York: Oxford University Press

Minister, K. (1991) 'A feminist frame for the oral history interview,' in Berger Gluck, S., \& Patai, D. (1991) Women's words: The feminist practice of oral history, London: Routledge pp 27-42

Ministry of Civil Defence and Emergency Management (2007) National Civil Defence Emergency Management Strategy, Wellington: Ministry of Civil Defence and Emergency Management, 16p

Ministry of Civil Defence and Emergency Management. (2008) Mass Evacuation Planning, Director's Guidelines for Civil Defence Emergency Management Groups [DGL 07/08], Wellington: Ministry of Civil Defence and Emergency Management, 86p

Ministry of Justice (2005) Family Violence Death Review, 24p, Wellington: Ministry of Justice

Ministry of Social Development (2002) Te Rito Family Violence Strategy, Wellington: Ministry of Social Development

Ministry of Women's Affairs. (1996) The full picture: Guidelines for gender analysis, Wellington: Ministry of Women's Affairs

Ministry of Women's Affairs. (2004) Statement of intent: 2006-2009, Wellington: Ministry of Women's Affairs, $47 p$ 
Moore, D. M. (1979) 'Editor's introduction: An overview of the problem.' In Moore, D. M. (ed). Battered women. Beverly Hills \& London: Sage Publications

Morrow, B. H. (1994) 'A grass-roots feminist response to domestic violence in the Caribbean,' Women's Studies International Forum, 17(6): 579592

Morrow, B. H. (1999) 'Identifying and mapping community vulnerability,' Disasters, 23(1): 1-18

Morrow, B. H., \& Enarson, E. (1996) 'Hurricane Andrew through women's eyes: Issue and recommendations,' International Journal of Mass Emergencies and Disasters, 14(1): 5-22

Moser, C. (2005) 'Has gender mainstreaming failed?' International Feminist Journal of Politics, 7(4): 576-590

NASH. (2009) 'Social services from NASH' [Online] Available: http://www.nash.org.nz/ [Accessed: 20 March 2009]

National Collective of Independent Women's Refuges. (2005) Annual Report 2004-2005, Wellington: National Collective of Independent Women's Refuges, $32 \mathrm{p}$

National Network of Stopping Violence. (2005) 'The cycle of violence' [Online] Available: http://www.nnsvs.org.nz/whoaffected/ women.aspx \#thecycle [Accessed 1 July 2009]

Neal, D. M. (1997) 'Reconsidering the phases of disaster,' International Journal of Mass Emergencies and Disasters, 15(2): 239-264

Neal, D. M \& Phillips, B. (1990) 'Female-dominated local social movement organizations in disaster-threat situations,' in G. West and R. Blumberg (1990) (eds) Women and Social Protest, New York: Oxford, 243-255

Norris, F. H., Friedman, M. J., Watson, P. J., Byrne, C. M., Diaz, E., \& Kaniasty, K. (2002) '60,000 disaster victims speak: Part I. An empirical review of the empirical literature, 1981-2001,' Psychiatry, 65(3): 207239

NZ Police (2009) 'Overview' [Online] In About Us, Available: http://www.police.govt.nz/about/ [Accessed: 20 March 2009]

NZPA. (2004) 'Floods leave wake of family violence.' The New Zealand Herald. 20 August 2004 [Online]. Available from http://www.nzherald.co.nz/index.cfm?ObjectID=3585755 [Accessed 18 April, 2005]

Oakley, A. (1998) 'Gender, methodology and people's ways of knowing: Some problems with feminism and the paradigm debate in social science,' Sociology, 32(4): 707-731

Ollenburger, J. \& Tobin, G. (1998) 'Women and post-disaster stress,' in Enarson, E., \& Morrow, B. H. (1998) (eds) The Gendered Terrain of Disaster, 95-108 


\section{References}

Ollenburger, J., \& Tobin, G. (1999) 'Women, aging, and post-disaster stress: Risk factors,' International Journal of Mass Emergencies and Disasters, 17(1): 65-78

Oliver-Smith, A. (1990) 'Post-disaster housing reconstruction and social inequality: A challenge to policy and practice,' Disasters, 14(1): 719

Oliver-Smith, A. (1996) 'Anthropological research on hazards and disasters,' Annual Review of Anthropology, 25: 303-328

Packwood, A. (2002) 'Evidence-based policy: Rhetoric and reality,' Social Policy \& Society, 1(3): 267-272

Palinkas, L. A., Downs, M. A., Petterson, J. S., \& Russell, J. (1993) 'Social, cultural and psychological impacts of the Exxon Valdez oil spill,' Human Organization, 52(1): 1-13

Pan American Health Organization. (1991) Guidelines on the Role of Women in Disaster Management: Caribbean Region, [Online] Available: http://www.crid.desastres.net/crid/indexen.htm

Parfitt, E. A. (2004) 'A discussion of the mechanism of explosive basaltic eruptions,' Journal of Volcanology and Geothermal Research, 134(1-2): 77-107

Paton, D., Houghton, B. F., Gregg, C. E., Gill, D. A., Ritchie, L. A., Mclvor, D., Larin, P., Meinhold, S., Horan, J., \& Johnston, D. M. (2008) 'Managing tsunami risk in coastal communities: Identifying predictors of preparedness,' The Australian Journal of Emergency Management, 23(1): 4-9

Pelling, M. (2001) 'Natural disasters?' in Castree, N., \& Braun, B. (eds) Social nature: theory, practice and politics, Oxford: Blackwell: 170-188

Perry, R. W. (2007) 'What is a disaster?' in Rodriguez, H., Quarantelli, E. L., \& Dynes, R. R. (eds) Handbook of Disaster Research, New York: Springer

Phillips, B., \& Morrow, B. H. (2008) Women and disasters: From theory to practice, USA: Xlibris Corporation

Picou, J. S., Marshall, B. K., \& Gill, D. A. (2004) 'Disaster, litigation, and the corrosive community,' Social Forces, 82(4): 1493-1522

Pielke Jr., R. A., Gratz, J., Landsea, C. W., Collins, D., Saunders, M. A., \& Musulin, R. (2008) 'Normalized hurricane damage in the United States: 1900-2005,' Natural Hazards Review, 9(1): 30-42

Ploughman, P. (1997) 'Disasters, the media and social structures: A typology of credibility hierarchy persistence based on newspaper coverage of the love canal and six other disasters,' Disasters, 21 (2): 118-137 
Pope, M. T., \& Muller, A. (1991) 'Polyoxometalate chemistry - An old field with new dimensions in several disciplines,' Angewandte ChemieInternational Edition with English, 30(1): 34-48

Prasertcharoensuk, R., \& Sirisook, D. (2006) Tsunami aftermath: Violations of women's human rights in Thailand, Thailand: APWLD, $53 \mathrm{p}$

Presbyterian Support. (2009) 'James Family service for children and families' [Online] Available: http://www.ps.org.nz/Site/Northern/Family_ Works/default.aspx [Accessed: 20 March 2009]

Press, F. (1975) ‘Earthquake prediction,' Scientific American, 232: 14-23

Prince, S. (1920) Catastrophe and social change, London: Kind \& Son, 155p

Quarantelli, E. L. (1954) 'The nature of conditions of panic,' American Journal of Sociology, 60: 267-275

Quarantelli, E. L. (1978) Disasters: Theory and research. Beverly Hills, CA: Sage Publications

Quarantelli, E. L. (1987) 'Disaster studies: An analysus of the social historical factors affecting the development of research in the area,' International Journal of Mass Emergencies and Disasters, 5: 285310

Quarantelli, E. L. (1994) 'Disaster studies: The consequences of the historical use of a sociological approach in the development of research,' International Journal of Mass Emergencies and Disasters, 12(1): 25-49

Quarantelli, E. L. (1995) 'What is a disaster?' International Journal of Mass Emergencies and Disasters, 13(3): 221-229

Quarantelli, E. L. (1998) What is a disaster? New York: Routledge

Quarantelli, E. L. (2001) 'Statistical and conceptual problems in the study of disasters.' Disaster Prevention and Management, 10(5): 325-338

Quarantelli, E. L., \& Dynes, R. R. (1977) 'Response to social crisis and disaster.' Annual Review of Sociology, 3: 23-49

Raghavan, C., Mennerich, A., Sexton, E., \& James, S. E. (2006) 'Community violence and its direct, indirect and mediating effects on intimate partner violence,' Violence against Women, 12(12): 1132-1149

Ramazanoglu, C. (1992) 'On feminist methodology: Male reason versus female empowerment,' Sociology, 26(2): 207-212

Rashid, S. F. (2000) 'The urban poor in Dhaka city: Their struggles and coping strategies during the floods of 1998,' Disasters, 24(3): 240-253

Rashid, S., \& Michaud, S. (2000) 'Female adolescents and their sexuality: notions of honour, shame, purity and pollution during the floods,' Disasters, 24(1): 54-70 


\section{References}

Raskin White, H., \& Chen, P-H. (2002) 'Problem drinking and intimate partner violence.' Journal of Studies on Alcohol, 63(2): 205-214

Reid, P., Brunsdon, D., Fitzharris, P., \& Oughton, D. (2004) 'Review of the February 2004 flood event - Review team report,' Wellington: Ministry of Civil Defence and Emergency Management, 94p.

Reinharz, S. (1992) Feminist methods is social research, New York: Oxford University Press

Renzetti, C. M. (1997) 'Confessions of a reformed positivist: Feminist participatory research as good social science' in Schwartz, M. D. (ed) Researching sexual violence against women: Methodological and personal perspectives, Thousand Oaks, London \& New Delhi: Sage Publications

Renzetti, C. M., \& Curran, D. J. (1999) 'Studying Gender: An Overview.' In Women, Men and Society. $4^{\text {th }}$ ed. Boston: Allyn \& Bacon

Renzetti, C. M., \& Maier, S. L. (2002) 'Private crime in public housing: Violent victimisation, fear of crime and social isolation among women public housing residents,' Women's Health and Urban Life, 1: 4665

Rhatigan, D. L., Moore, T. M., \& Street, A. E. (2005) 'Reflections on partner violence: 20 years of research and beyond,' Journal of Interpersonal Violence, 20(1): 82-88

Rhatigan, D. L., Street, A. E., \& Axsom, D. K. (2006) 'A critical review of theories to explain violent relationship termination: Implications for research and intervention,' Clinical Psychology Review, 26(3): $321-345$

Ridgeway, C. L., \& Correll, S. J. (2004) 'Unpacking the gender system: A theoretical perspective on gender relations,' Gender \& Society, 18(4): 510-531

Ridgeway, C. L., \& Smith-Lovin, L. (1999) 'The gender system and interaction,' Annual Review of Sociology, 25: 191-216

Risman, B. J. (2004) 'Gender as a social structure: Theory wrestling with activism,' Gender \& Society, 18(4): 429-450

Ritchie, J., \& Ritchie, J. (1993) Violence in New Zealand. Wellington: Huia Publishers

Rivers, J. P. W. (1982) 'Women and children last: an essay on sex discrimination in disasters,' Disasters, 6(4): 256-267

Roberts, R. D., Burgess, D., \& Meister, M. (2006) 'Developing tools for nowcasting storm severity,' Natural Hazards Review, 1: 107-118

Robinson, A. L. (2006) 'Reducing repeat victimization among high-risk victims of domestic violence: The benefits of a coordinated community response in Cardiff, Wales,' Violence against Women, 12(8): 761788 
Rodriguez, H., \& Russell, C. N. (2006) 'Understanding disasters: Vulnerability and resiliency,' in Blau, J., \& lyall Smith, K. E. (eds) (2006) Public Sociologies Reader, Lanham: Rowman \& Littlefield Pulishers, inc.

Rodriguez, J., Vos, F., Below, R., \& Guha-Sapir, D. (2009) Annual disaster statistical review 2008, Melin: Jacoffset Printers

Ronan, K. R., \& Johnston, D. M. (2005) Promoting Community Resilience in Disasters: The Role for Schools, Youth, and Families, New York: Springer

Rosenthal, U. (1998) 'Future disasters, future definitions,' in Quarantelli, E. L. (1998) What is a disaster? Perspectives on the Question, London: Routledge

Rusbult, C. E., \& Martz, J. M. (1995) 'Remaining in an abusive relationship: An investment model analysis of nonvoluntary dependence,' Personality and Social Psychology Bulletin, 21 (6): 558-571

Sangster, J. (1994) 'Telling our stories: Feminist debates and the use of oral history', Women's History Review, 3(1): 5-28

Sayeed, A. T. (2006) Earthquake aftermath: Violations of women's human rights in Pakistan, Pakistan: APWLD, 45p

Scanlon, J. (1996) 'Human behaviour in disaster: The relevance of gender,' Australian Journal of Emergency Management, 10(1): 2-7

Schechter, S. (1982) Women and male violence: The visions and struggles of the battered women's movement, Boston: South End.

Scheuren, J-M., Le Polain de Waroux, O., Below, R., Guha-Sapir, D., \& Ponserre, S. (2008) 'Annual disasters statistical review: The numbers and trends,' Centre for Research on the Epidemiology of Disasters, 47p, Belgium: Jacoffset Printers

Shroeder, R. (1987) 'Gender vulnerability to drought: a case study of the Hausa social environment,' Natural Hazards Center, Working Paper, 58, [Online] Available: www.colorado.edu/hazards/ publist.html\# 1

Semple, R. J. (2001) 'Psychological abuse in intimate relationships: A New Zealand perspective.' New Zealand Journal of Psychology, 30(2): 60-71

Sen, A. (1990) 'Gender and cooperative conflict.' In Tinker, I. (ed) Persistent inequalities: Women and world development. Oxford: Oxford University Press

Sharp, J. (2005) 'Geography and gender: Feminist methodologies in collaboration and in the field,' Progress in Human Geography, 29(3): 204-209

Sjoberg, G. (1962) 'Disaster and social change,' in Baker, G., \& Chapman, D. (eds) Man and Society in Disaster: 356-384, New York: Basic Books 
Skinner, T., Hester, M., \& Malos, E. (2005) 'Methodology, feminism and gender violence' in Skinner, T., Hester, M., \& Malos, E. Researching gender violence: Feminist methodology in action, Devon \& Oregon: Willan Publishing

Smith, D. E. (1979) 'A sociology for women.' In Sherman, J., \& Beck, E. (eds) The prism of sex: Essays on the sociology of knowledge, Madison: University of Wisconsin Press.

Smith, M. D. (1990) 'Patriarchal ideology and wife beating: A test of a feminist hypothesis,' Violence and Victims, 5(4): 257-273

Sokoloff, N. J., \& Dupont, I. (2005) 'Domestic violence at the intersections of race, class, and gender,' Violence against Women, 11(1): 38-64

Spiegel, J. P. (1957) 'The English flood of 1953,' Human Organization, 16: 3-5

Stallings, R. A. (2005) 'Disaster, crisis, collective stress and mass deprivation,' in Perry, R. W., \& Quarantelli, E. L. (eds) What is a Disaster: New Answers to Old Questions: 237-274, Philadelphia, PA: Xlibris

Stanko, E. (1997) '"I second that emotion": Reflections on feminism, emotionality, and resarech on sexual violence' in Schwartz, M. D. (ed) Researching sexual violence against women: Methodological and personal perspectives, Thousand Oaks, London \& New Delhi: Sage Publications

Statistics New Zealand. (2001) Around the clock: Findings from the New Zealand time use survey 1998-99, Wellington: Statistics New Zealand, $91 \mathrm{p}$

Statistics New Zealand. (2006a) QuickStats about Incomes, Wellington: New Zealand, $17 p$

Statistics New Zealand. (2009) Living Density Table, [Online] Available: http://www.stats.govt.nz/NR/rdonlyres/E96FCEAC-7DEB-42F088B6-548450E1 A241/0/LivingDensityTable1.xls [Accessed July 1, 2009]

Stehlik, D., Lawrence, G., \& Gray, I. (2000) 'Gender and drought: Experiences of Australian women in the drought of the 1990s,' Disasters, 24(1): 38-53

Stets, J. E. (1991) 'Cohabiting and marital aggression: The role of social isolation,' Journal of Marriage and the Family, 53(3): 669-680

Stets, J. E., \& Burke, P. J. (1996) 'Gender, control, and interaction,' Social Psychology Quarterly, 59(3): 193-220

Straus, M. A. (1980) 'Victims and aggressors in marital violence.' American Behavioral Scientist, 23: 681-704

Straus, M. A. (1990) 'Measuring intrafamily conflict and violence: The Conflict Tactic (CTS),' In Straus, M. A., \& Gelles, R. J. (eds), Physical 
violence in American families (pp. 29-47) New Brunswick, NJ: Transaction Books.

Straus, M. A., \& Gelles, R. J. (1986) 'Societal change and change in family violence from 1975 to 1985 as revealed by two national surveys,' Journal of Marriage and the Family, 48: 465-479

Straus, M. A., Gelles, R. J., \& Steinmetz, S. (1980) Behind closed doors: Violence in the American family, New York: Anchor

Strube, M. J. (1988) 'The decision to leave an abusive relationship: Empirical evidence and theoretical issues,' Psychological Bulletin, 104(2): $236-250$

Sullivan, C. M. (1991) 'The provision of advocacy services to women leaving abusive partners: An exploratory study,' Journal of Interpersonal Violence, 6(1): 41-54

Sullivan, C. M., \& Bybee, D. I. (1999) 'Reducing violence using communitybased advocacy for women with abusive partners,' Journal of Consulting and Clinical Psychology, 67(1): 43-53

Sullivan, C. M., \& Cain, D. (2004) 'Ethical and safety considerations when obtaining information from or about battered women for research purpose,' Journal of Interpersonal Violence, 19:603-61 8

Taylor, D. (2005) 'Governing through evidence: Participation and power in policy evaluation,' Journal of Social Policy, 34(4): 601-618

Taylor, M. J., \& Smith Barusch, A. (2004) 'Personal, family, and multiple barriers of long-term welfare recipients,' Social Work, 49(2): 175-183

Teghtsoonian, K. (2004) 'Neoliberalism and gender analysis mainstreaming in Aotearoa/New Zealand,' Australian Journal of Political Science, 39(2): $267-284$

Thomson, A. (1998) 'Fifty years on: An international perspective on oral history,' Journal of American History, 85(2): 581-595

Thomson, A. (2006) 'Four paradigm transformations in oral history,' The Oral History Review, 34(1): 49-70

Thompson, L. (1992) 'Feminist methodology for family studies,' Journal of Marriage and the Family, 54(1): 3-18

Tierney, K. (2006) 'Social inequality, hazards and disasters,' in Daniels, R. J., Kettl, D. E., \& Kunreuther, H. (eds) On risk and disaster: Lessons from Hurricane Katrina, Philadelphia: University of Pennsylvania Press: 109-128

Tolman, R. M., \& Raphael, J. (2000) 'A review of research on welfare and domestic violence,' Journal of Social Issues, 5: 655-682

Torry, W. I. (1979) 'Anthropological studies in hazardous environments: Past trends and new horizons,' Current Anthropology, 20(3): 517-540 


\section{References}

Turner, D. (2006) 'Recovery from Bay of Plenty flooding and landslides: Social issues in Community Recovery' Natural Hazards Management Conference, August 22-25 2006, in Christchurch, New Zealand

Turner, E. H. (1997) 'After the storm: Women, public policy, and power,' in Women, Culture, and Community: Religion and Reform in Galveston, 1880-1920, New York: Oxford University Press, 187227

Umar, R., Ismail, S., Djalil, H., \& Dewy, P. (2006) Tsunami aftermath: Violations of women's human rights in Nanggroe Aceh Darussalam, Indonesia, Indonesia: APWLD, 58p

Umberson, D., Anderson, K., Glick, J., \& Shapiro, A. (1998) 'Domestic violence, personal control, and gender,' Journal of Marriage and the Family, 60(2): 442-452

Ummar, F. (2008) Promoting gender mainstreaming from the centre earthquake 2005, Pakistan, Gender and Disasters Workshop 2008 in Wellington, New Zealand, July $31^{\text {st }} 2008$

UN. (1997) 'Report of the Fourth World Conference on Women, Beijing, 4-15 September 1997' (United Nations publication, Sales No. E.96.IV.13), Chap. I, Resolution 1, Annex II. [Online] Available: http://www.un.org/womenwatch/daw/followup/main.htm

UN. (2001) Important concepts underlying gender mainstreaming, [Online]. Available: http://www.un.org/womenwatch/osagi/pdf/factsheet 2.pdf [Accessed 19 March 2009]

UN. (2006) In-depth study on all forms of violence against women, Report of the Secretary General, U.N. Doc. A/61/122/Add.1

UNISDR, (2005) Hyogo framework for action 2005-2015: Building the resilience of nations and communities to disasters, [Online] Available: http://www.unisdr.org/eng/hfa/docs/Hyogo-frame work-foraction-english.pdf, $22 p$

Van Willigen, M. (2001) 'Do disasters affect individuals' psychological wellbeing? An over-time analysis of the effect of Hurricane Floyd on men and women in Eastern North Carolina,' International Journal of Mass Emergencies and Disasters 19(1): 59-83

Vaughan, M. (1987) The Story of an African Famine: Gender and Famine in Twentieth Century Malawi, UK: Cambridge University Press

Veitch, J. (2005) 'Looking at gender mainstreaming in the UK Government,' International Feminist Journal of Politics, 7(4): 600-606

Vest, J. R., Catlin, T. K., Chen, J. J., Brownson, R. C. (2002) 'Multistate analysis of factors associated with intimate partner violence,' American Journal of Preventative Medicine, 22(3): 156-164 
Victim Support. (2009) 'Home’ [Online] Available: http://www.victimsupport .org.nz/ [Accessed: 20 March 2009]

Vision Manawatu, Bevan, S., \& Hughes, W. (2004) 'Economic impact analysis of the major Manawatu-Wanganui flooding 2004,' Report for the Ministry of Economic Development, Palmerston North, 17p.

Vivian, D. \& Langhinrichsen-Rohling, J. (1996) 'Are bi-directionally violent couples mutually victimised? A gender-sensitive comparison,' pp. 23-52 in Hamberger, L. K., \& Renzetti, C. (1996) Domestic partner abuse, New York: Springer Publishing Company, Inc.

Walby, S. (2005) 'Gender mainstreaming: Productive tensions in theory and practice,' Social Politics, 12(3): 321-343

Walker, L. E. (1984) The Battered Woman Syndrome, New York: Springer Publishing Company

Weisman, S. (1958) Case-study of a flood-stricken city, New York: Graduate School of Public Administration and Social Service, New York University

West, C., \& Zimmerman, D. H. (1987) 'Doing gender,' Gender \& Society, 1(2): 125-151

White, G. E., \& Haas, J. E. (1975) Assessment of research on natural hazards, Cambridge: MIT Press

White, G. F. (1945) 'Human adjustment to floods: A geographical approach to the flood problem in the United States,' Research Paper no. 29, Department of Geography, University of Chicago: 225p

Wiest, R., Mocellin, J., \& Motsisi, T. (1994) The needs of women in disasters and emergencies, Technical report for the United Nations Disaster Management Training Programme, Manitoba: University of Manitboa

Williams, K. R. (1992) 'Social sources of marital violence and deterrence: Testing an integrated theory of assaults between partners,' Journal of Marriage and the Family, 54: 620-629

Wilson, J. (1999) 'Professionalization and gender in local emergency management,' International Journal of Mass Emergencies and Disasters, 17(1): 111-122

Wilson, J., Phillips, B. D., \& Neal, D. M. (1998) 'Domestic violence after disaster,' in Enarson, E., \& Morrow, B. H. (eds) (1998) The Gendered Terrain of Disaster, Florida: International Hurricane Center, 115-122

Wilson, T. M., Johnston, D. M., \& Paton, D. (2008) 'Impacts and emergency response to the 12 June 2006 South Island snowstorm: Tabulated results of a survey of responding organisations in the Canterbury region,' GNS Science Report, 2008/, 49p. 
Wisner, B., Blaikie, P., Cannon, T., \& Davis, I. (2004) At Risk: Natural hazards, people's vulnerability and disasters. $2^{\text {nd }}$ edition. London \& New York: Routledge

Women's Refuge. (2009) Herstory, [Online] Available: http://womensrefuge .org.nz/index.cfm?objectid=0CFAF56E-1321-AE99696CF0C9BA02CC49 [Accessed 1 July 2009]

Wood, W., \& Eagly, A. H. (2002) 'A cross-cultural analysis of the behaviour of women and men: Implications for the origins of sex differences,' Psychological Bulletin, 128(5): 699-727

Work and Income. (2009) 'About us' [Online] Available: http://www.work andincome.govt.nz/about-work-and-income/ [Accessed: 20 March 2009]

World Bank. (2006) 'Hazards of nature, risks of development: An IEG evaluation of World Bank assistance for natural disasters,' Independent Evaluation Group Report, Washington D. C.: World Bank, $181 \mathrm{p}$

Wraith, R. (1999) 'Women in disaster management: where are they?' Australian Journal of Emergency Management, Jan: 9-11

Wright, T. L., \& Pierson, T. C. (1992) 'Living with volcanoes,' U.S. Geological Survey Circular, 1073

Yin, R.K. (ed) (2003) Case study research: Design and methods, $3^{\text {rd }}$ edition, Thousand Oaks, CA: Sage

Yllo, K. (1988) 'Political and methodological debates in wife abuse research,' pp. 28-50, in Yllo, K., \& Bograd, M. (eds) (1988) Feminist perspectives on wife abuse, Thousand Oaks, London \& Delhi: Sage Publications 